\title{
Avaliação de Desempenho de Políticas de Escalonamento de Processos
}

\author{
Jorge Antonio Moraes de Souza
}

Orientador: Prof. Dr. Marcos José Santana

Dissertação apresentada ao Instituto de Ciências Matemáticas e de Computação - ICMC-USP, como parte dos requisitos para obtenção do título de Mestre em Ciências de Computação e Matemática Computacional.

USP - São Carlos

Dezembro de 2000 
"Ali, lembranças contentes Na alma se representaram; E minhas cousas ausentes Se fizeram tão presentes Como se nunca passaram."

Camões 


\section{Agradecimentos}

Agradeço à Deus por ter me concedido saúde, paz e tranquilidade para conduzir o meu trabalho.

Aos meus pais, Maria e Milton, por terem dado o suporte necessários para que tivesse todas as condições de atingir o meu objetivo.

Às minhas tias Célia, Lea e Lúcia, por todo apoio e torcida para o meu êxito.

À minha esposa Laura, por ter tido paciência e por estar sempre presente (mesmo que distante) nos momentos de alegria e de dificuldades, me apoiando em minhas decisões e aconselhando nas minhas dúvidas.

Ao professor Santana, meu orientador, e à professora Regina por terem me dado a oportunidade de cursar o mestrado e pela paciência e pela filosofia de nos dar os ensinamentos para que possamos construir o nosso próprio caminho.

Às minhas amigas de república Andrezza, Flávia, Maju e Selma, foi muito bom morar com vocês, compartilhar tantas alegrias e algumas tristezas e fazer parte, mesmo que um pouco, da vida de vocês.

À Andrezza por todas as nossas longas conversas, as vezes um tanto filosóficas, e pela sua amizade de longa data.

À Mayb e ao Camillo, pela amizade, pelas idas aos videokes e pelos churrascos, vocês são demais, vocês vão estar sempre no meu coração.

Ao Renato, companheiro de república, por ter ajudado bastante no meu trabalho e pela amizade iniciada e consolidada durante o mestrado.

Ao Márcio que teve uma participação extremamente importante neste trabalho, muito obrigado.

Aos Alquimistas MC Souza e Francês, com quem tive a oportunidade de enveredar por caminhos que nem imaginava, o de compor letras e músicas, valeu. Alquimia sempre!

Ao Paulo e a Renata por contribuírem com sugestões para este trabalho. 
Aos amigos de laboratório Tatiana (por ter ajudado na validação do meu modelo), Sarita, Kalinka, Célia, Mara, Renata, Roberta, Aletéia (grande amiga), Márcio, Arion, Renato, Tomas, Omar, João Carlos, Ricardo, Mário, Álvaro, Daniel (companheiro de república), Fernando e Luciano.

Aos amigos Rudinei e Sílvio, pelo futebol e pelas idas aos barzinhos da vida.

Às meninas da secretaria, Beth, Marilia e Laura, sem vocês, este mestrado teria menos alegrias.

À CAPES por ter financiado a minha pesquisa. 


\section{Sumário}

CAPÍTULO 1 - INTRODUÇÃO............................................................................................................

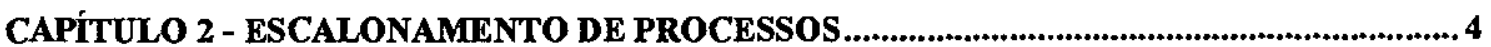

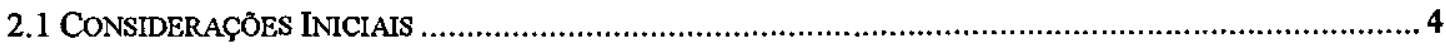

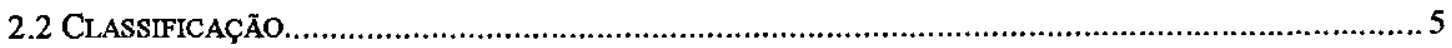

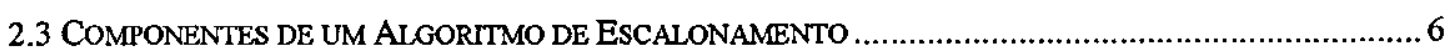

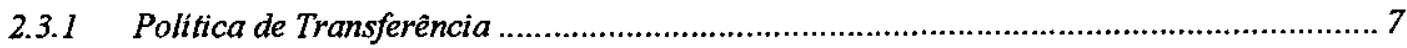

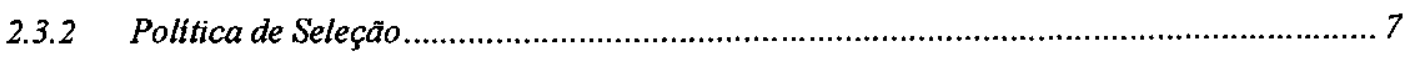

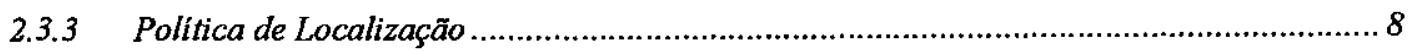

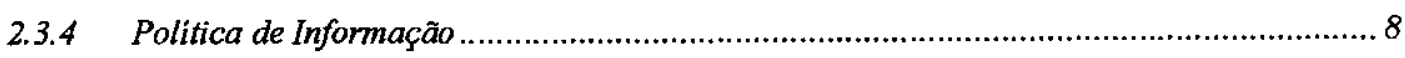

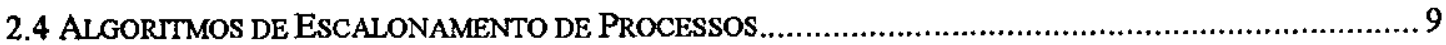

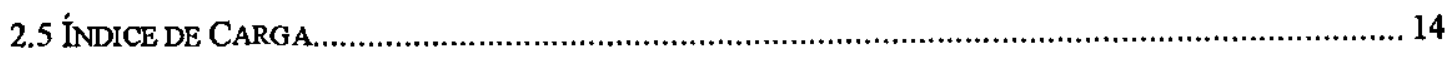

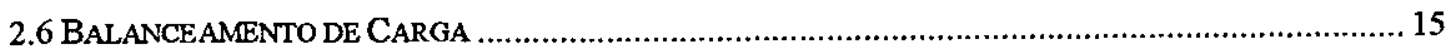

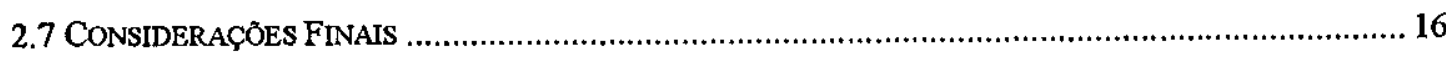

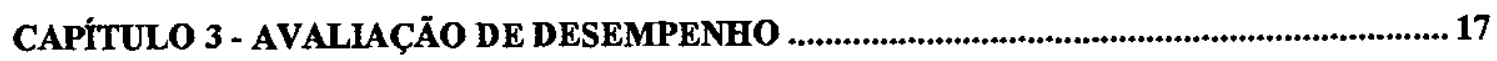

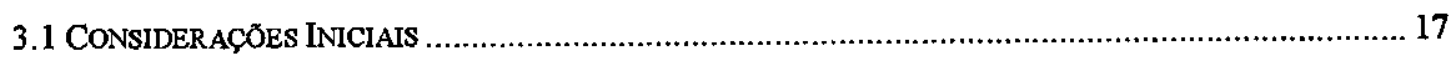

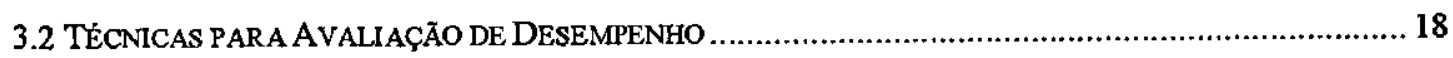

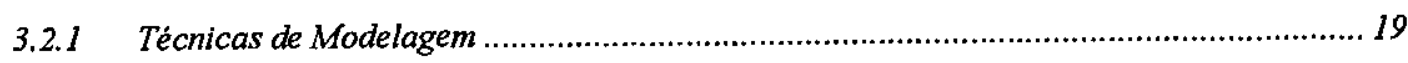

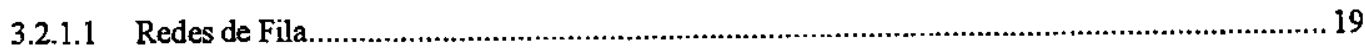

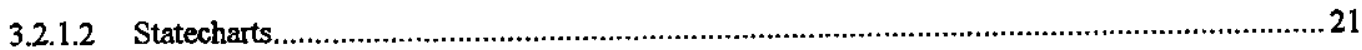

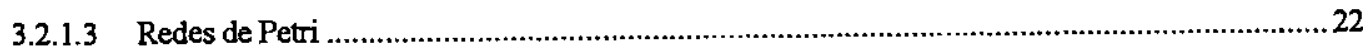

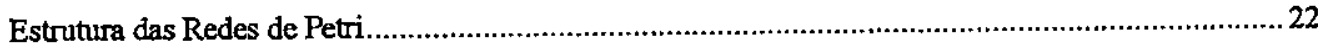

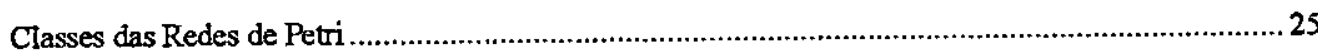




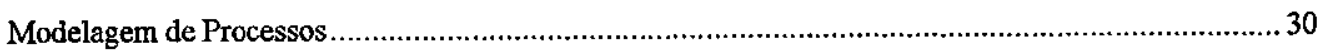

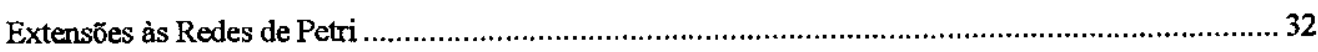

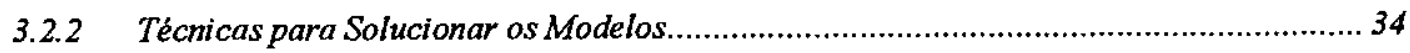

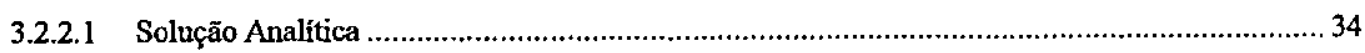

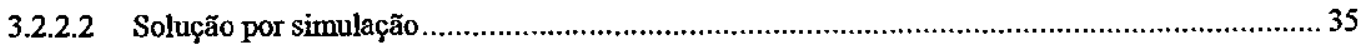

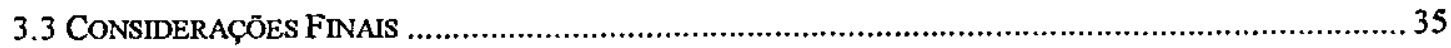

\section{CAPÍTULO 4 - METOdOLOGIA PARA AVALIAÇ̃̃O DE POLÍTICAS dE}

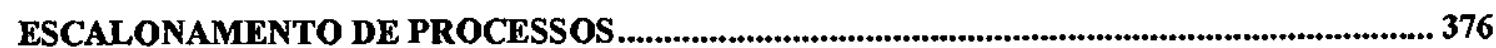

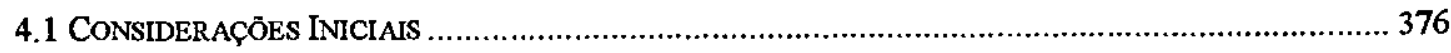

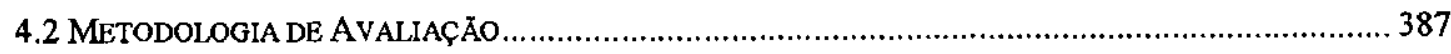

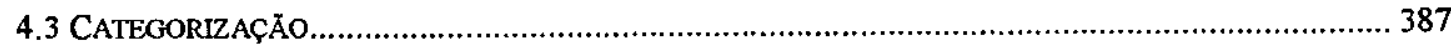

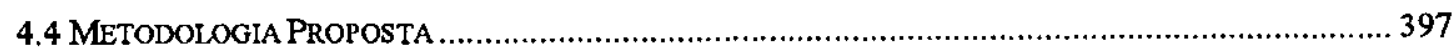

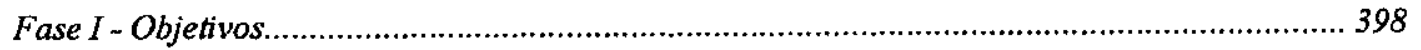

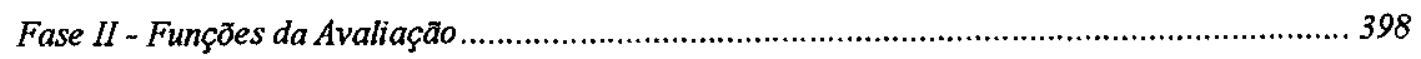

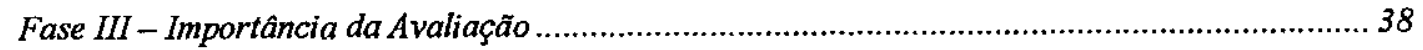

Fase IV - Conhecimento da Politica a ser Avaliada ........................................................ 39

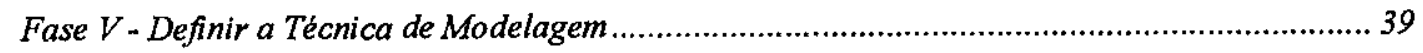

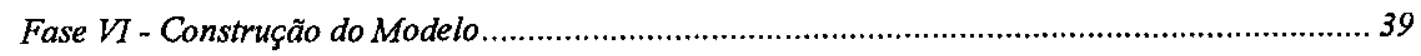

Fase VII - Escolha das Medidas de Desempenho ...................................................... 40

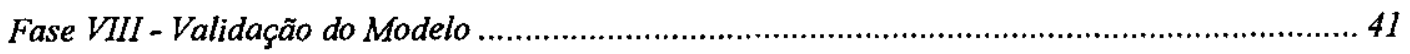

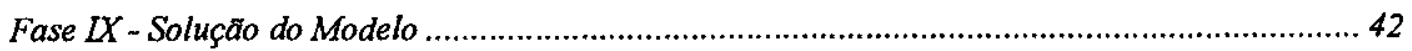

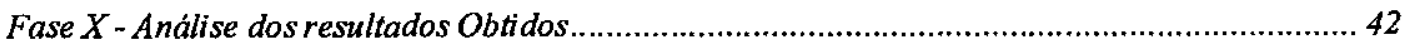

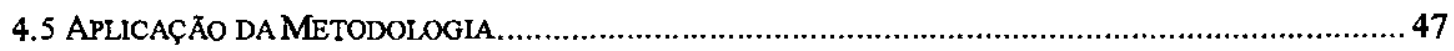

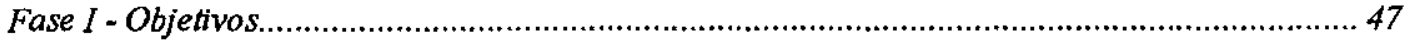

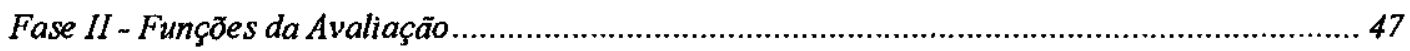


Fase III - Importância da Avaliação.................................................................................... 47

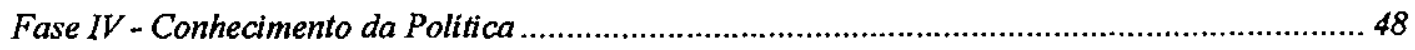

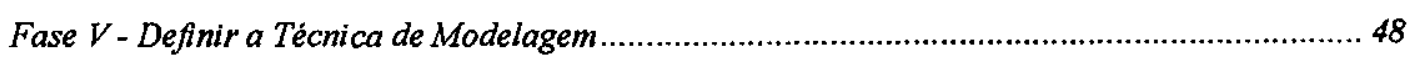

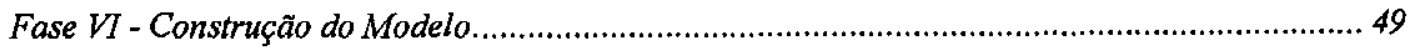

Fase VII - Escolha das Medidas e/ou Métrica de Desempenho...................................................5

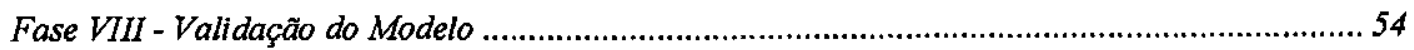

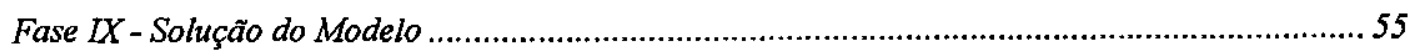

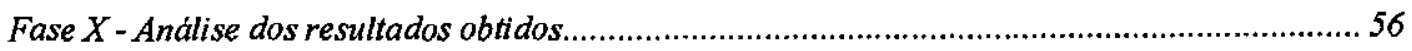

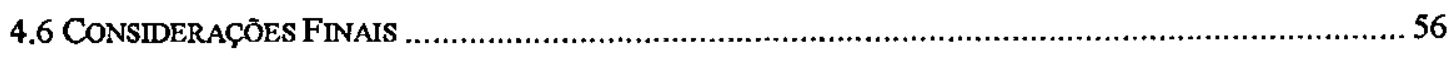

\section{CAṔ́TULO 5 - RESULTADOS OBTDOOS NA APLICAÇÃO DA METODOLOGIA À DPWP... 57}

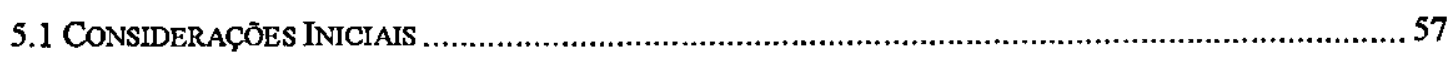

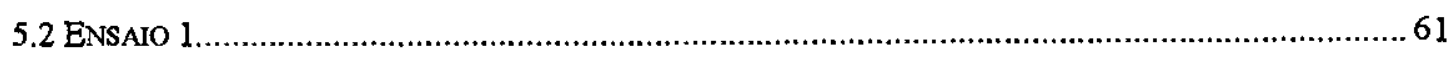

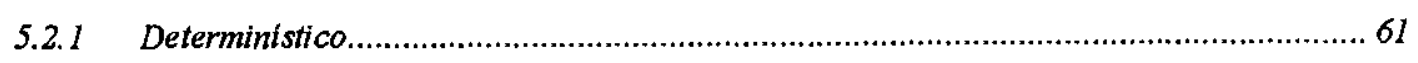

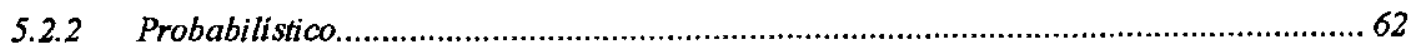

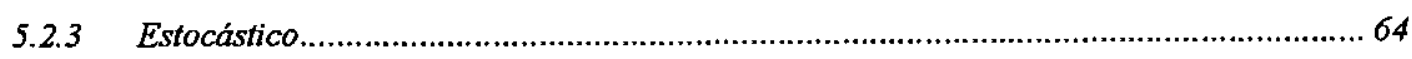

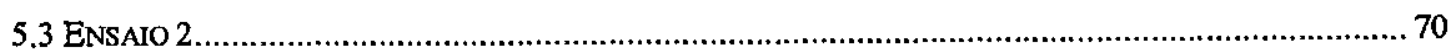

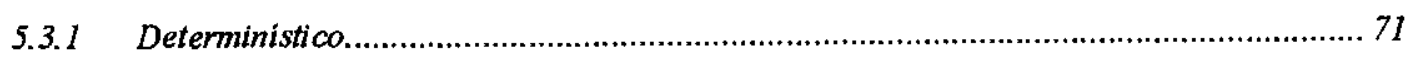

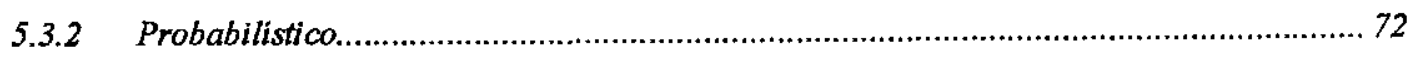

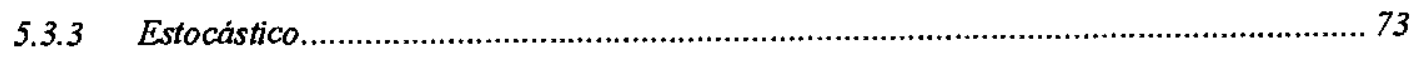

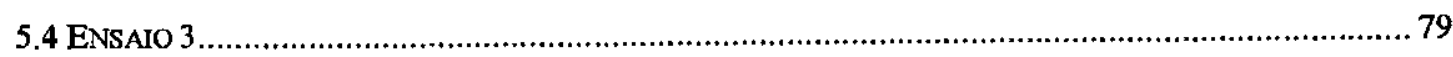

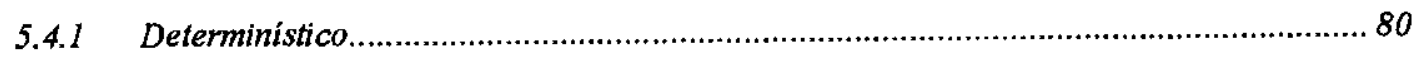

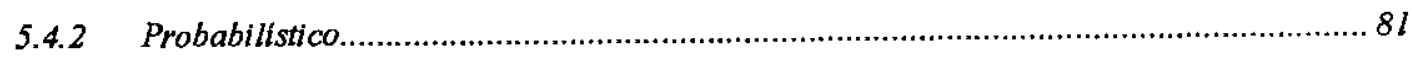

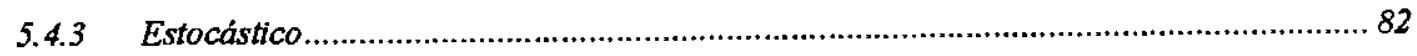

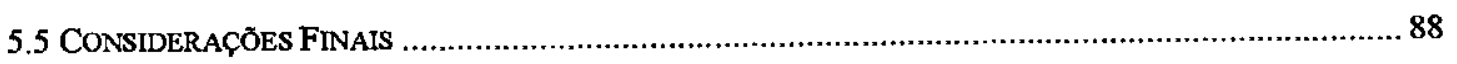


CAPÍTULO 6 - CONCLUSÃO

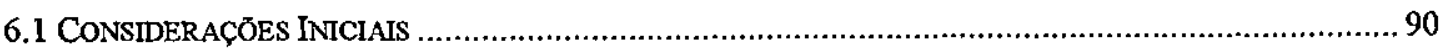

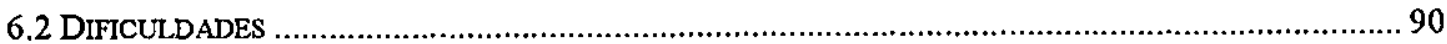

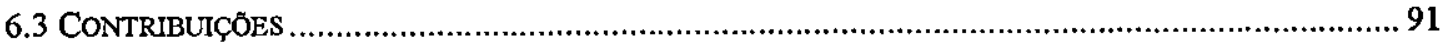

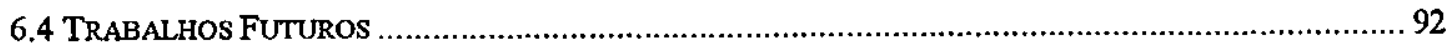

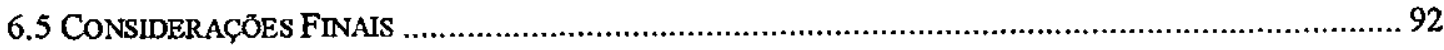

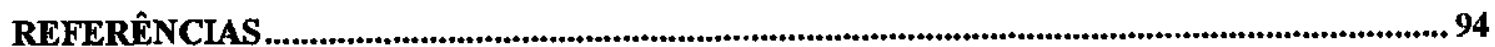

APÊNDICE A. 


\section{Índice de Figuras}

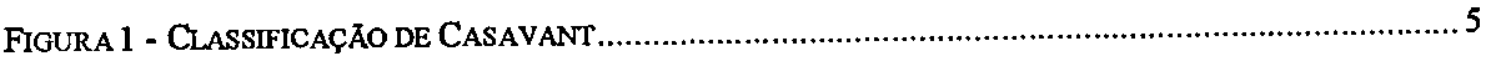

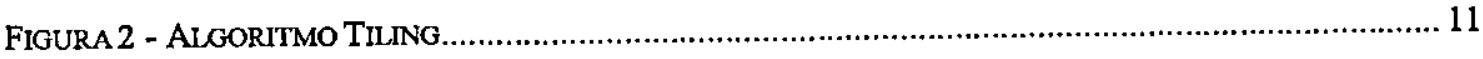

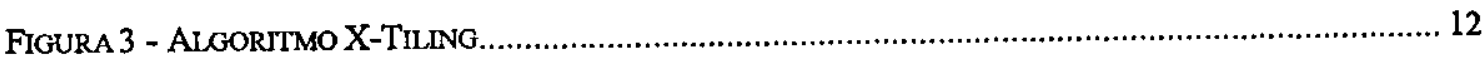

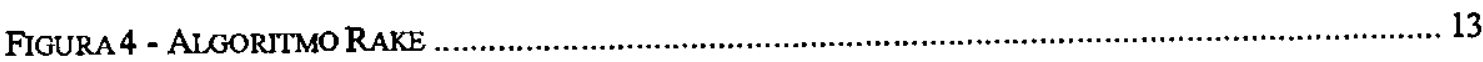

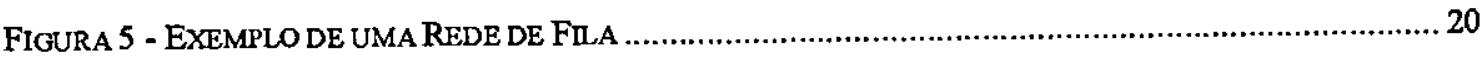

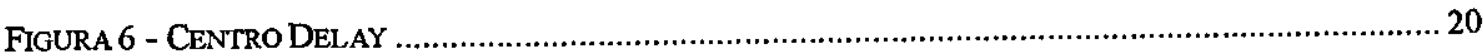

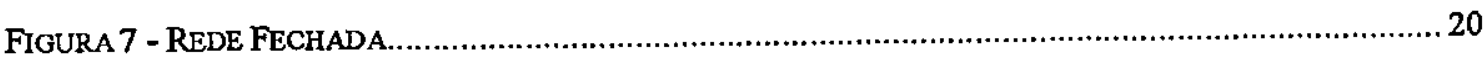

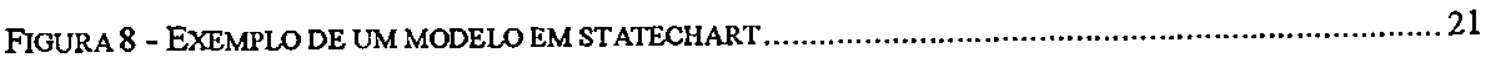

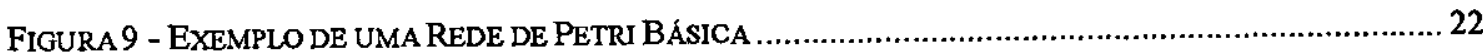

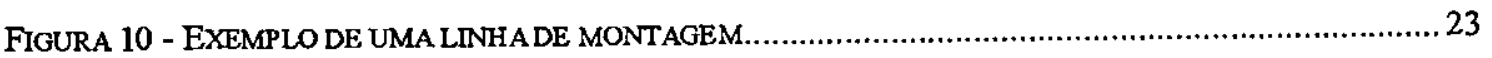

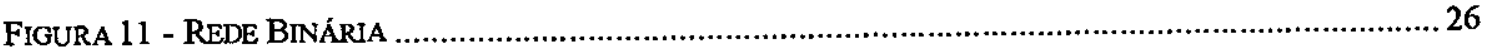

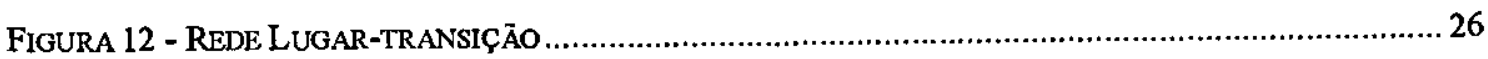

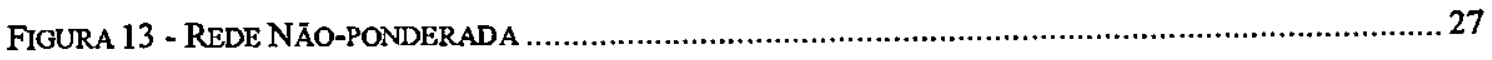

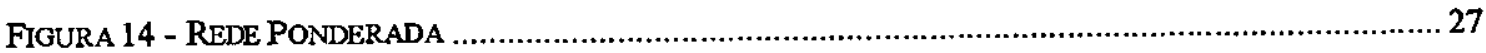

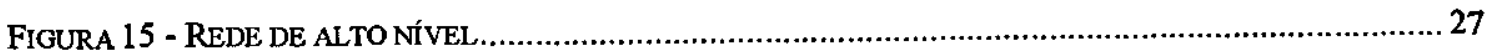

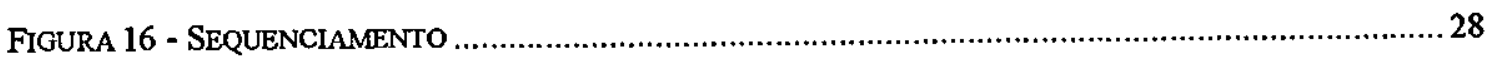

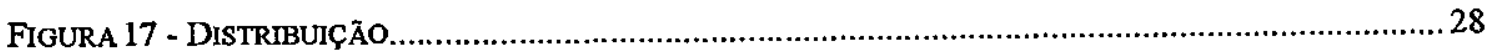

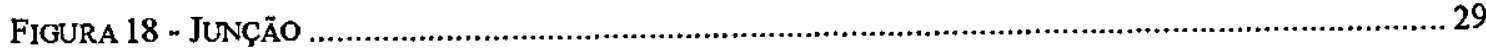

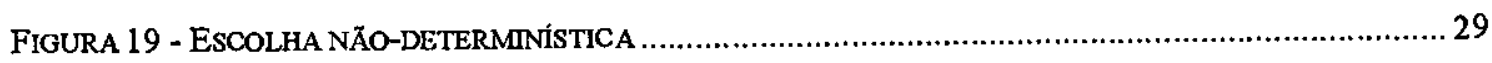

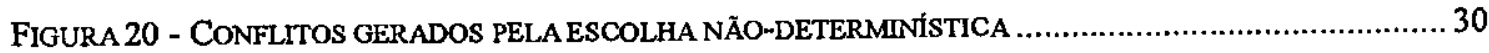

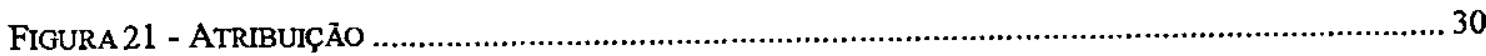

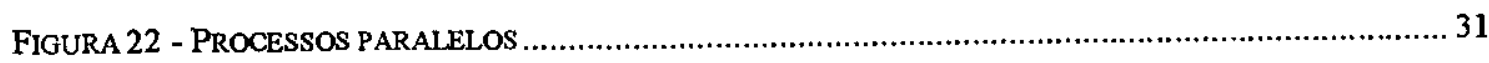

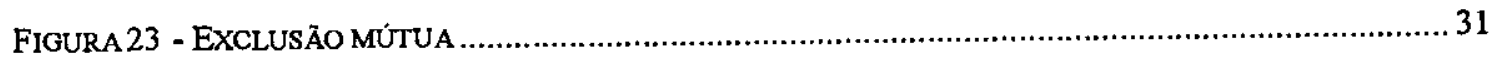

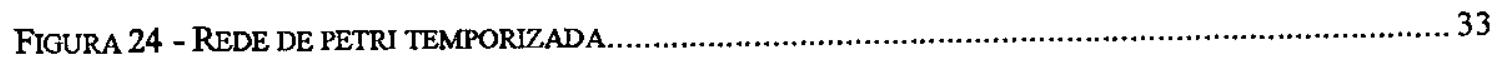

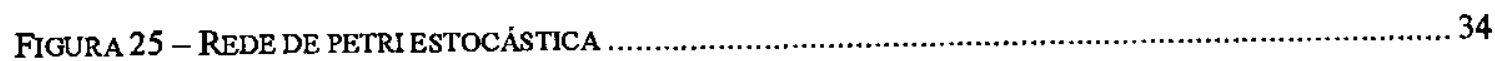




\section{Resumo}

Este trabalho propõe uma metodologia para avaliação de desempenho de políticas de escalonamento de processos. Essa metodologia, projetada para ser simples e flexível, é composta de dez passos, cada um definindo características da política ou abordagem da avaliação.

A modelagem e simulação da DPWP - Dynamical Politics Without Preempition, uma política de escalonamento "CPU-Bound", são usadas como um exemplo do uso da metodologia proposta. Essa política é modelada usando Redes de Petri Estocásticas Generalizadas, e simulada usando o ALPHA/Sim, um ambiente para simulação de Redes de Petri. Os resultados obtidos mostram que a metodologia atinge plenamente seus objetivos, permitindo uma avaliação simples e útil de políticas de escalonamento de processos. 


\begin{abstract}
This work proposes a methodology for performance evaluation of process scheduling policies using modeling techniques and simulation. This methodology, designed to be simple and flexible, is composed of ten steps each one defining features either from the policy or for the evaluation approach. Thus, the methodology proposed allows the evaluation of both policies already implemented and those still under development.

The modelling and simulation of DPWP - Dynamical Politics Without Preempition, a CPU-bound scheduling policy, are used as an example of the use the proposed methodology. This policy is modelled using Generalised Stochastic Petri Nets and simulated using the ALPHA/Sim, an environment for Petri Net simulation. The results obtained show that the methodology reaches its objectives, allowing a simple and usefull evaluation of process scheduling policies.
\end{abstract}




\section{Capítulo 1}

\section{Introdução}

Avaliar o desempenho de sistemas computacionais tem sido uma atividade largamente difundida ao longo de décadas. Várias técnicas têm sido desenvolvidas e utilizadas visando a avaliação dos sistemas computacionais em todas as suas fases, do projeto ao uso diário e extrapolando resultados para o que se espera no futuro (Francês, 1998).

Modelagem e simulação são duas técnicas que têm sido aplicadas com sucesso na avaliação de desempenho de sistemas computacionais, especialmente nos sistemas atuais onde a complexidade dos modelos arquiteturais, aliada à diversidade de elementos, são ingredientes primários para que se obtenham vantagens do uso conjunto da modelagem e simulação (Soares, 1992).

Nessa associação, a simulação é utilizada como uma técnica alternativa para a solução dos modelos definidos para o sistema em estudo. Também é possível solucionar modelos analiticamente, utilizando métodos matemáticos para tal.

Quando a área de interesse abrange sistemas computacionais distribuídos (Coulouris et al., 1994) e computação paralela, surgem inúmeros pontos de interesse onde a avaliação de desempenho é necessária.

Nesse contexto, o escalonamento de processos constitui uma área de interesse e a adoção de diferentes políticas de escalonamento, pode produzir sistemas com diferentes níveis de desempenho (Souza et al., 2000).

Definir uma política de escalonamento, implementá-la e testá-la no sistema real não constituem tarefas triviais. Um estudo prévio sobre as políticas e seu potencial em termos dos objetivos estipulados é altamente atrativo, podendo reduzir muitos dos problemas envolvidos na sua implementação e teste no sistema real. 
Modelagem e simulação podem então ser utilizadas no estudo das políticas de escalonamento, produzindo um ambiente de teste para o desempenho obtido a partir de uma dada política. Isso constitui o assunto abordado nesta dissertação de mestrado, com ênfase especial dada às políticas de escalonamento utilizadas em ambientes paralelos virtuais, tais como PVM (Beguelin et al., 1994)) e o MPI (Snir et al., 1996), onde sistemas computacionais distribuídos heterogêneos são utilizados como plataforma básica para a construção de máquinas paralelas virtuais, através do uso de bibliotecas de passagem de mensagens (Souza, 1996).

O objetivo desta dissertação é apresentar uma metodologia para a avaliação de desempenho de políticas de escalonamento. As políticas serão estudadas através da construção de modelos (no caso deste trabalho redes de Petri são adotadas), de sua parametrização e solução através de simulação.

A metodologia proposta compreende uma seqüência de passos bem definidos, de simples aplicação e que conduzem à geração de resultados obtidos através de métricas de desempenho definidas pelo usuário e, portanto bem sintonizados com as características de interesse.

Foram utilizadas Redes de Petri Estocásticas Generalizadas(Chiola et al., 1993) e o ambiente de simulação ALPHA/Sim (ALPHA/Sim, 1995) para o desenvolvimento do modelo e sua solução por simulação.

Uma política de escalonamento de processos, "CPU-Bound", denominada DPWP Dynamic Potitics Without Preemption (Araújo, 1999) foi escolhida para a aplicação da metodologia proposta. Essa política foi desenvolvida por Araújo (Araújo, 1999), tendo sido implementada e testada fisicamente juntamente com o AMIGO - dynAMical flexIble schedulinG envirOnment (Souza, 2000) em três trabalhos anteriores (Araújo, 1999) (Souza, 2000) (Figueiredo, 2000), e podendo atuar, através do AMIGO, tanto com aplicações PVM como MPI.

Com isso, o modelo elaborado para a política, DPWP, em sua forma original, pode ser validado a partir de dados reais, coletados no sistema.

A avaliação da metodologia mostra como falhas podem ser identificadas e corrigidas no modelo, levando a um aprimoramento das políticas.

Assim, este trabalho está organizado em 6 Capítulos incluindo esta Introdução (Capítulo 1), que apresenta a motivação e os objetivos desse trabalho. Nos Capítulos 2 e 3 têm-se uma revisão bibliográfica sobre Escalonamento de Processos e Avaliação de Desempenho. O 
Capítulo 4 descreve a metodologia proposta, apresentando os passos para a avaliação de desempnho de uma política de escalonamento e o detalhamento de cada passo. Esse Capítulo apresenta ainda a aplicação da metodologia à DPWP. O Capítulo 5 apresenta os resultados obtidos com a aplicação da metodologia, discutindo o tipo de avaliação que pode ser realizada. As Conclusões finais são apresentadas no Capítulo 6 juntamente com as dificuldades encontradas para a realização deste trabalho. A seguir são apresentadas as referências bibliográficas, além de um apêndice contendo os dados gerados pela simulação dos modelos. 


\section{Capítulo 2}

\section{Escalonamento de Processos}

\subsection{Considerações Iniciais}

O escalonamento de processos está presente em várias áreas do conhecimento que necessitam que processos sejam divididos entre recursos, como por exemplo engenharia de produção e computação.

O escalonamento pode ser local ou global (Casavant \& Kuhl, 1988). O escalonamento local é realizado em máquinas com apenas um processador, e é feito pelo sistema operacional, através de um algoritmo de escalonamento de processos. O escalonamento global é realizado em vários processadores. Neste caso, o escalonamento deve-se preocupar com as características do escalonamento local e ainda determinar quais os melhores processadores para executar os processos. (Souza et al., 2000)

Em sistemas distribuídos, que são sistemas constituídos por diversos computadores autônomos interligados por uma rede de computadores, as tarefas são distribuídas entre os diferentes elementos de processamento integrantes do sistema, através de um processo de escalonamento. Esse escalonamento pode ser balanceado ou não, pois pode ocorrer de algumas máquinas ficarem sobrecarregadas enquanto outras estão ociosas. Isso ocorre, na maioria das vezes, devido à heterogeneidade do sistema. Algumas máquinas possuem capacidade de processamento maior, além de outras diferenças como quantidade de memória, arquitetura e sistema operacional. A não observância dessas diferenças de hardware e software pode fazer com que o escalonamento seja deficiente, já que uma máquina com menos potência computacional pode receber tarefas grandes enquanto que as com mais potência recebem tarefas menores.

O escalonamento realizado de forma incorreta pode fazer com que o desempenho global do sistema deprecie, gerando conseqüências indesejáveis. 


\subsection{Classificação}

Devido à grande quantidade de estudos na área de escalonamento de processos, muitas técnicas e metodologias foram criadas. Juntamente com o aumento das pesquisas nessa área, cresceu também a quantidade de terminologias, que muitas vezes eram inconsistentes e contraditórias. Para minimizar esse problema, Casavant criou a classificação mostrada na figura $1:$

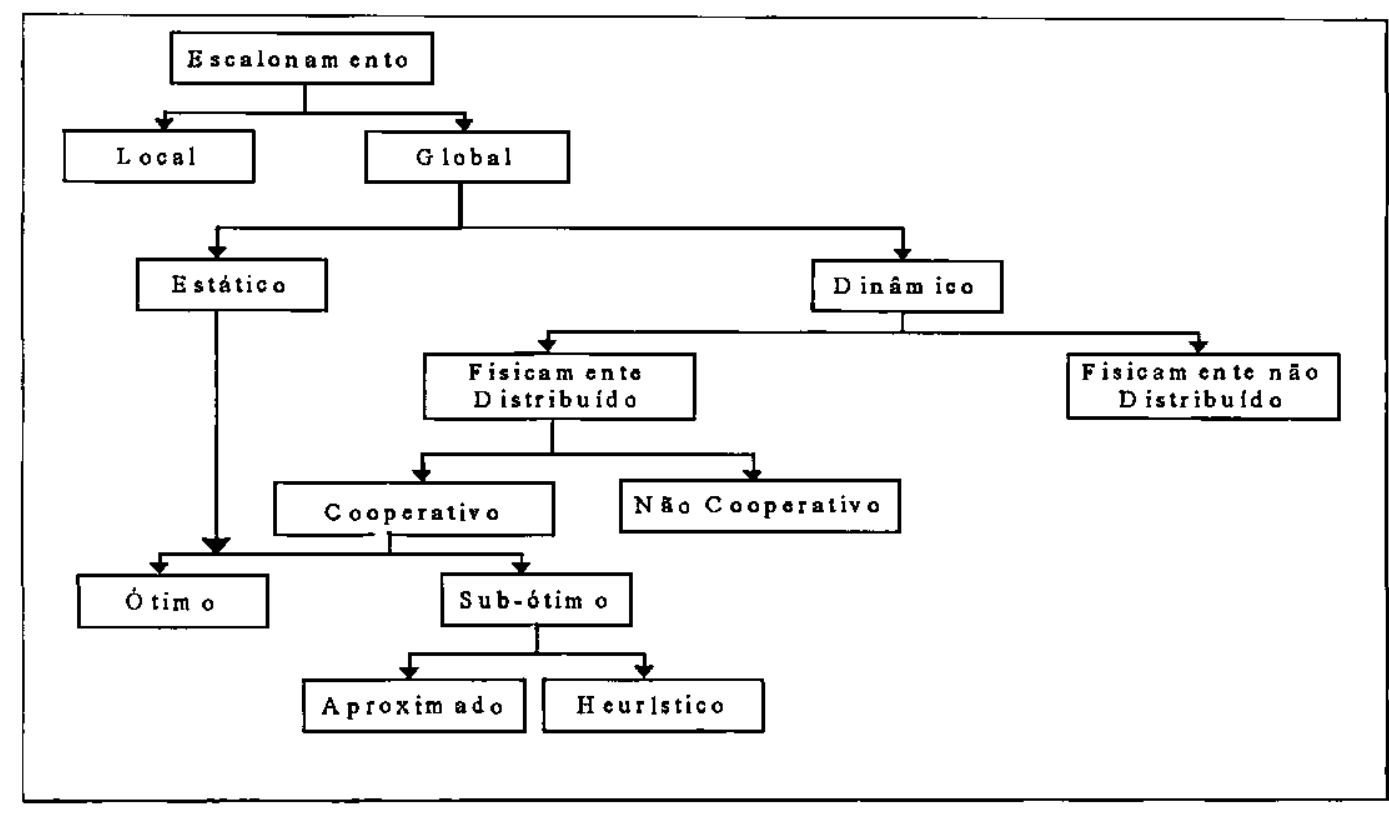

Figura 1- Classificação de Casavant

O escalonamento local ocorre quando existe apenas um processador. Nesse caso é utilizada a técnica de escalonamento de processos através de time-slices. No escalonamento global, o objetivo é a escolha de qual processador receberá o processo.

No caso do escalonamento global, tem-se o caso estático e o dinâmico. A diferença entre um e outro está no tempo em que o escalonamento e as decisões são tomadas. Se dados como tempo que os processos irão gastar para serem completados e o número de processos são conhecidas previamente, em tempo de compilação, tem-se o escalonamento global estático. Esse tipo de escalonamento não é flexível e levando-se em conta que, em programas paralelos, podem ser criados novos processos durante a execução, esse método pode tornar-se pouco eficiente. Se as informações são coletadas em tempo de execução, e baseado nelas é feito o escalonamento, tem-se o escalonamento global dinâmico. A grande vantagem desse método é que não é necessário nenhum conhecimento prévio sobre o comportamento da aplicação, o que o torna 
capaz de se adaptar mais facilmente às mudanças que ocorrem durante a execução (Jackson \& Humphres, 1997)(Shirazi et al., 1995).

O escalonamento dinâmico pode ser dividido em distribuído e não-distribuído. A diferença entre os dois é que no distribuído o trabalho de tomar as decisões pode estar fisicamente distribuído, enquanto que no não-distribuído esse trabalho fica a cargo de um único processador. Esse tipo de escalonamento ainda pode ser com preempção, quando ocorre migração de processos e sem preempção, em caso contrário.

O escalonamento dinâmico distribuído ainda pode ser subdividido em cooperativo e nãocooperativo. No primeiro caso, as decisões são tomadas em conjunto pelos processadores. Já no segundo, os processadores tomam suas decisões individualmente, independentemente das ações dos demais elementos de processamento.

Neste trabalho, o termo balanceamento de carga será utilizado como sinônimo de escalonamento dinâmico de processos.

\subsection{Componentes de um Algoritmo de Escalonamento}

Os algoritmos de escalonamento de processos podem ser divididos basicamente em dois, três ou quatro componentes. $O$ número de componentes e sua natureza não modificam o objetivo do algoritmo, que é o de escalonar processos.

Autores como (Henderson, 1995) (Mehra \& Wah, 1993) consideram dois componentes, já (Shirazi et al. 1995) (Muniz, 1994) utilizam uma divisão com três componentes, enquanto que (Shivaratri et al., 1992) utiliza quatro componentes. Uma abordagem bastante abrangente sobre essas divisões pode ser encontrada em (Souza et al., 2000).

Neste trabalho, será considerada a divisão de Shivaratri (Shivaratri et al., 1992), por ser de fácil entendimento. Shivaratri divide um algoritmo de escalonamento nas seguintes partes:

- Política de transferência, política de seleção, política de localização e política de informação.

Cada uma dessas políticas será abordada a seguir. 


\subsubsection{Política de Transferência}

A política de transferência decide se um nó ${ }^{1}$ é emissor ou receptor. Para ser emissor, pode-se considerar, por exemplo, que a carga da máquina seja igual ou maior que um valor máximo pré-determinado, e para ser receptora, que a carga seja menor que esse valor. Logo, todas as vezes que uma nova tarefa é criada em um computador, a política de transferência se encarrega de verificar se ele é um emissor. Em caso positivo, essa tarefa é enviada para um processador receptor; caso contrário, o processador estará apto a receber tarefas remotas.

O estado de emissor ou receptor também pode ser decidido levando-se em consideração a carga individual de cada nó do sistema, ou seja, um processador será emissor se sua carga for maior do que a carga de alguns processadores do sistema e será receptor em caso contrário.

\subsubsection{Política de Seleção}

Essa política é responsável por selecionar qual tarefa será transferida de um nó emissor para um nó receptor. Devem-se considerar três pontos para tornar essa seleção mais eficiente.

- deve-se procurar o mínimo de sobrecarga na transferência;

- o número de chamadas de sistema com dependência de localização feitas pela tarefa selecionada deve ser mínima;

- o tempo de processamento que resta para que o processo termine deve ser grande o suficiente para compensar o overhead causado pela comunicação.

\subsubsection{Política de Localização}

Após a política de transferência ter decidido se o nó é um emissor ou um receptor, caberá à política de localização encontrar o nó mais propício a receber a tarefa. Essa escolha é feita após ter sido questionado aos outros nós qual o seu estado atual. Isso pode ser feito serialmente ou em paralelo, através de uma comunicação do tipo multicast.

\footnotetext{
${ }^{2}$ O termo nó será utilizado para designar uma máquina pertencente ao sistema.
} 
Pode ser usada uma política centralizada onde existe um nó chamado de coordenador, que é responsável por manter a informação sobre o estado de todos os outros nós. Nesse caso, para que um nó saiba qual o melhor parceiro para sua transação, basta perguntar ao coordenador que estará apto a informar.

\subsubsection{Política de Informação}

Nessa política serão decididas quais informações sobre o estado de um nó serão necessárias, quando serão requisitadas e de qual nó serão coletadas, podendo ser:

\section{(a) Sob Demanda}

Nessa política, um nó só coletará informações sobre o estado de outros nós, 'se este se tornar um emissor ou um receptor. Essa política é dinâmica já que suas ações dependem do estado do sistema.

Existem três estados possiveis de serem assumidos por um nó:

- iniciado pelo emissor, que procura por receptores para os quais ele possa transferir sua carga;

- iniciado pelo receptor, onde os receptores ficam solicitando carga;

- iniciado simetricamente, é um misto dos anteriores, onde o balanceamento de carga é acionado pela necessidade de um poder de processamento extra ou trabalho extra.

\section{(b) Periódica}

Essas políticas podem ser centralizadas ou não, e coletam informações periodicamente, podendo transferir ou não as tarefas. Essas políticas normalmente não adaptam suas atividades de acordo com o estado do sistema. Isto quer dizer que, com o sistema muito carregado e máquinas ocupadas, o balanceamento de carga obterá um ganho muito pequeno no desempenho global. 


\section{(c) Por Mudança de Estado}

Nessas políticas, a informação sobre o estado de um nó é difundida toda vez que este muda o seu estado. Ela pode ser centralizada, quando existe a figura de um nó que concentra toda essa informação, ou descentralizada, onde as informações são mandadas ao par.

\section{(d) Política de Aprovação}

Nessa política, é verificado se um determinado processador deve receber a transferência de um processo e também controla o número de processadores que um processo deve percorrer até que seja "obrigado" a ser processado.

\subsection{Algoritmos de Escalonamento de Processos}

A seguir serão mostrados alguns algoritmos de escalonamento de processos, que possuem como componentes as políticas vistas no item 2.3 .

\section{Algoritmo Central}

Nesse algoritmo, baseado nos estudos de Powley (Powley et al., 1993) e Hillis (Hillis, 1988), é feito o cálculo da média da carga no sistema e, então, essa informação é difundida entre os processadores (política de informação). Os processadores podem ser classificados como: ociosos, quando não possuem dados para computar; sobrecarregados, quando a sua carga está acima da média; e os demais(política de transferência).

O objetivo desse algoritmo é formar pares de processadores sobrecarregados com outros menos carregados ou ociosos (políticas de localização e seleção).

\section{Algoritmo Rendez-Vous}

Esse algoritmo é tido como mais eficiente que o central, já que ele também cria pares, mas com a diferença de que os pares são compostos por processadores extremos, ou seja, o mais carregado com o menos carregado e assim sucessivamente até que o pouco acima da média forme par com o pouco abaixo da média.

O objetivo principal desse algoritmo é realizar a distribuição regular da carga total. 


\section{Algoritmo Aleatório}

A idéia desse algoritmo é simples, considerando que toda vez que um elemento é criado em um processador, este é enviado a um nó do sistema que foi selecionado aleatoriamente. Isso faz com que seja mantido um estado de balanceamento, já que a probabilidade de um determinado nó ser selecionado é a mesma para todos, não importando sua localização no sistema (políticas de transferência, seleção e localização).

Em contra partida, quando um elemento é retirado do sistema, o mesmo passa a ter um estado de desbalanceamento que o algoritmo é incapaz de reverter.

Teoricamente, esse algoritmo deveria funcionar bem, mas experimentos mostram um desempenho muito fraco devido à grande quantidade de comunicação que demanda.

\section{Algoritmo Disted}

Nesse algoritmo, as políticas de informação e localização são descentralizadas, e em períodos de $T$ segundos cada processador envia o seu índice de carga para todos os demais. Caso no próximo período o índice de carga de um processador não tenha mudado, este não precisa enviá-lo novamente.

Conforme os índices vão chegando, os processadores constróem um vetor chamado vetor de carga. Cada processo que chega ao processador, faz uma cópia do vetor de carga desse processador. A política de localização verificará quais os processadores mais descarregados e dentre eles um é escolhido arbitrariamente. A carga deste é comparada à do processador local (política de transferência), se ela for menor, o processo será executado remotamente, caso contrário, localmente (Vaughan \& O'Donovan, 1998).

\section{Algoritmo Tiling}

Nesse algoritmo, um novo conceito é introduzido, constituindo as janelas. Uma janela é um sub-domínio disjunto de processadores. O próprio algoritmo é responsável por dividir o sistema nesses sub-domínios.

Um balanceamento "perfeito" é conseguido através de comunicações regulares nas janelas. $O$ balanceamento é propagado através do chaveamento entre as janelas. 


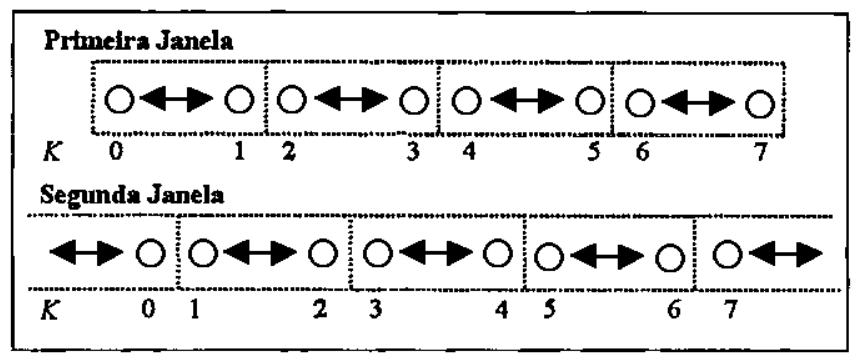

Figura 2 - Algoritmo Tiling

Para uma malha de dimensão $n$, têm-se $2^{n}$ processadores por janela e $2 n$ comunicações, o que garante o balanceamento perfeito em cada janela. Terminada essa fase, é feito um chaveamento em cada uma das $n$ dimensões da malha.

\section{Algoritmo X-Tiling}

Segundo Lüling et al (Lüling et al., 1991), os algoritmos que utilizam comunicação entre vizinhos, tornam-se pouco eficientes quando o número de processadores é muito grande, principalmente se as partições forem feitas baseadas na carga dos processadores (sobrecarregados ou pouco carregados), isso porque o algoritmo Tiling levaria bastante tempo para propagar o trabalho dos processadores sobrecarregados para os pouco carregados.

Uma solução proposta por (Fonlupt et al., 1998) é a adição de mais canais de comunicação, com o intuito de aumentar o número de processadores vizinhos.

Com a adição dos canais, a topologia passa a ser um hipercubo, sendo essa a melhor topologia para esse propósito.

O algoritmo X-Tiling é semelhante ao Tiling e a comunicação regular é garantida pela extensão da topologia e porque as comunicações são feitas na mesma direção, na mesma distância. 


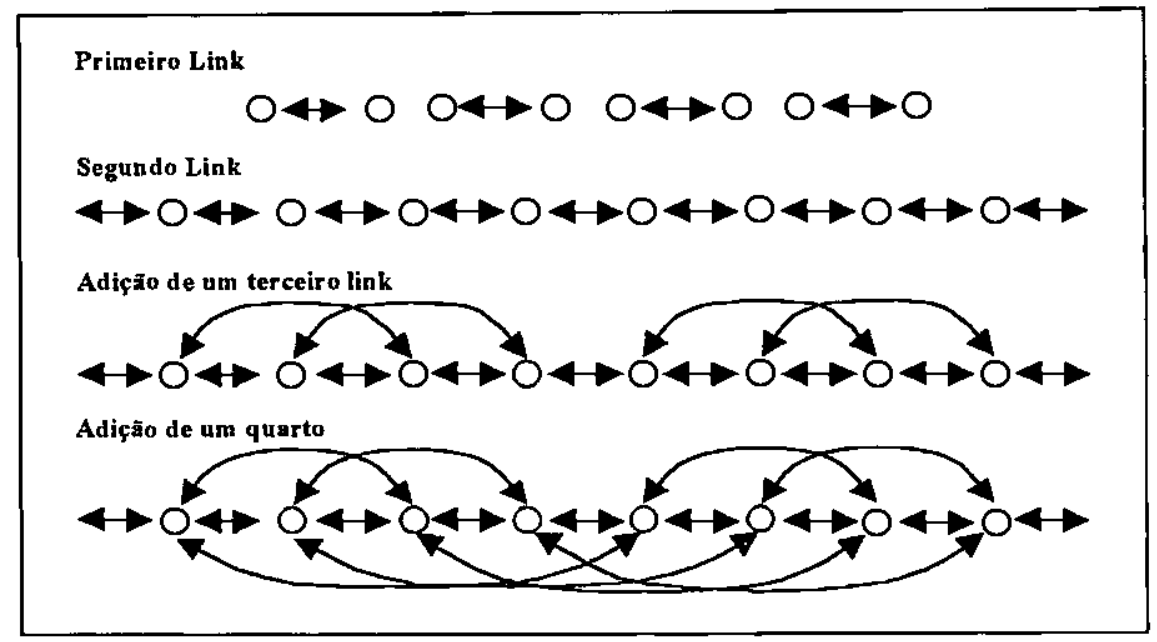

Figura 3 - Algoritmo X-Tiling

\section{Algoritmo Rake}

Os dois algoritmos vistos anteriormente utilizam uma troca elementar de carga entre os processadores, mas múltiplas comunicações são possíveis. Para esse caso o algoritmo Rake pode ser utilizado. Nesse algoritmo, a carga é dividida uniformemente entre os processadores. Ele é bastante adequado para o uso em malhas multi-dimensionais.

A carga do sistema é dada através da seguinte fórmula:

$$
W=\bar{w} P+r
$$

onde $\bar{w}$ é a média de carga, $P$ é o número de processadores e $r$ é o resto da divisão de $W$ por $P$, $0 \leq r<P$.

Na primeira fase de execução do algoritmo é calculada a média de carga do sistema e após $P$ iterações, os processadores que possuíam carga acima de $\bar{w}$ deverão ter mandado essa diferença para o seu vizinho da direita. Ao final dessa fase, $P-r$ processadores deverão estar com carga igual a $\bar{w}$. (políticas de transferência, seleção e localização)

Para a segunda fase, serão feitas $r$ iterações e todos os processadores que possuírem carga maior que $\bar{w}+I$ enviarão a diferença ao seu vizinho da direita. Terminada essa fase, o sistema deverá estar com a carga balanceada. Deve-se notar que esse é o caso de uma malha de uma dimensão, para malhas multi-dimensionais, o primeiro passo é feito para todas as dimensões. 


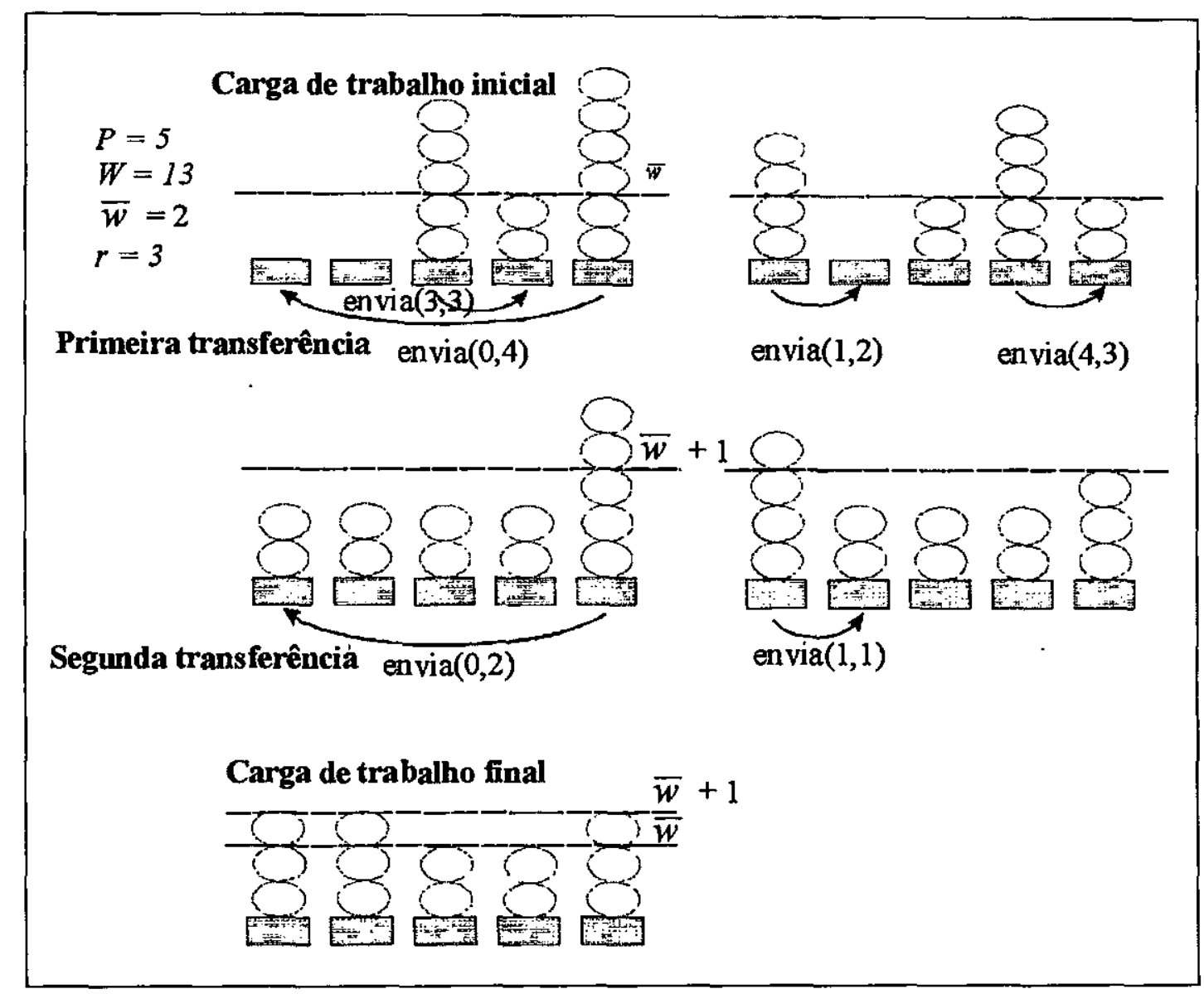

Figura 4 - Algoritmo Rake

\section{Algoritmo Pre-computing Sliding}

Esse algoritmo é uma melhora do algoritmo Rake, com a diferença que ao invés de transferir os dados que estão acima da média da carga, ele calcula o número mínimo de transferências necessárias para se balancear a carga.

Antes de ser utilizado o algoritmo pela primeira vez, existem $r$ processadores com $\bar{w}+1$ de carga e $P$ - $r$ processadores com $\bar{w}$ de carga.

$\mathrm{Na}$ primeira fase, são calculadas as cargas que serão enviadas aos processadores da esquerda, e então são feitas todas as transferências da esquerda para a direita. Na segunda fase, as da direita para esquerda. 


\section{5 Índice de Carga}

Para a realização de um escalonamento são necessárias algumas informações que serão obtidas pela política de informação implementada. Uma das informações é a carga de trabalho da plataforma computacional. Para obter o valor desta carga, é utilizada uma métrica chamada de índice de carga. Segundo (Ferrari \& Zhou, 1987), índice de carga é um valor não negativo iniciado em zero (ocioso) e cresce positivamente conforme aumenta a carga.

A obtenção do índice de carga, além de ser eficiente na representação da carga de trabalho, deve gerar o mínimo de sobrecarga possível. A forma como o índice é constituído influencia diretamente na sobrecarga gerada.

Índices de carga específicos geram pouca sobrecarga e, dependendo da aplicação, são bastante eficientes. Índices especificos são aqueles formados por um único valor obtido em cada processador, tais como tamanho da fila de execução e tamanho da fila de acesso à memória.

Existem, ainda, os chamados índices de carga genéricos, que são utilizados quando se tem pouco conhecimento sobre a aplicação a ser executada e sobre os objetivos do escalonamento. Os índices genéricos são formados pela junção de dois ou mais índices específicos. Uma desvantagem da sua utilização é a tendência de gerar uma maior sobrecarga.

Outro ponto importante em relação ao índices de carga é no caso em que a plataforma utilizada é heterogênea e distribuída. Para essa situação, os índices de carga devem ser capazes de normalizar as carga em relação às potências computacionais. Dependendo da aplicação, essa normalização pode ter uma maior ou menor eficiência. Supondo que um índice normalize a carga considerando apenas uma característica específica do processador, pode ocorrer que em aplicações CPU-bound o seu impacto seja maior do que em aplicações I/O-bound que necessita de um menor processamento.

\subsection{Balanceamento de Carga}

Em sistemas computacionais distribuídos, deseja-se sempre que seja atingida uma distribuição uniforme de carga de trabalho entre as máquinas, de tal forma que não existam máquinas ociosas enquanto outras estiverem sobrecarregadas. 
O problema da distribuição de carga envolve, principalmente, a realocação da carga de trabalho entre os nós do sistema, obtendo assim, tempos de resposta melhores, um aumento na utilização dos recursos computacionais e um ganho no desempenho do sistema.

O balanceamento de carga pode ser feito com o uso de algoritmos sem preempção ou com preempção. Na primeira, um processo é designado para uma máquina antes de ser executado, e permanecerá nela até que esteja completado (Eskicioglu, 1989). Na Segunda, que também é conhecida como migração de processo, a execução de um processo pode ser movida, em qualquer momento, da máquina onde está sendo processado para uma outra (Chen, 1996). Pode existir uma sobrecarga significativa associada à migração, mas apesar disso, ela tem-se mostrado capaz de aumentar o desempenho do sistema (Hjálmtýsson \& Whitt, 1998).

Existem dois objetivos principais na migração de processos: o primeiro refere-se à escolha de máquinas com um bom tempo de resposta, quando o sistema está pouco carregado; o segundo é melhorar o throughput total do sistema através da redução da sobrecarga de comunicação causada pela troca de mensagens, quando o sistema está sobrecarregado.

O ganho de desempenho com o uso da migração pode ser muito bom, considerando-se que em um sistema computacional distribuído, muitas máquinas podem ficar ociosas, desperdiçando parte do potencial computacional.

Litzkow (Litzkow et al.,1997), propôs uma classificação dos usuários de sistemas distribuidos em três grupos que mostram bem a afirmação anterior:

- usuários casuais, aqueles que raramente utilizam a capacidade total de suas máquinas;

- usuários esporádicos, aqueles que utilizam por pequenos períodos de tempo a capacidade máxima das máquinas;

- usuários frustrados, aqueles que por longos períodos de tempo possuem uma grande demanda computacional, que não consegue ser atendida pelo sistema.

Pode-se perceber que dos três grupos, dois deles não utilizam ou utilizam pouco o sistema, favorecendo, assim, a migração de processos. 


\subsection{Considerações Finais}

Neste capítulo foram abordados alguns conceitos de escalonamento de processos, considerando pontos como componentes do algoritmo, políticas, mostrando a importância do índice de carga neste processo, os tipos de índice e algumas vantagens e desvantagens de cada um deles. Neste contexto, foi apresentado o balanceamento de carga com e sem migração de processos, suas caracteristicas e alguns de seus objetivos.

O capítulo 3 enfocará a avaliação de desempenho, com particular interesse para o escalonamento de processos, principalmente as políticas responsáveis pelo mesmo. 


\section{Capítulo 3}

\section{Avaliação de Desempenho}

\subsection{Considerações Iniciais}

O desempenho de um sistema computacional, na visão dos usuários, diz respeito, principalmente, ao tempo de resposta do mesmo (Santana, 1990). Esse não é o parâmetro mais adequado a ser utilizado, mas se os usuários estão descontentes com o sistema, é sinal que algo de errado pode estar ocorrendo, e uma análise minuciosa faz-se necessária, para que sejam identificados possíveis gargalos no sistema (Orlandi, 1995).

Analisar o desempenho de um sistema é uma tarefa que pode envolver sistemas em vários estágios de desenvolvimento: sistemas existentes, em construção ou em fase de projeto.

Para analisar o desempenho de um sistema computacional, deve-se verificar qual a metodologia mais adequada para cada caso. A escolha da metodologia é um fator fundamental para o sucesso ou fracasso da análise. O conhecimento profundo do sistema a ser avaliado é um dos grandes desafios da análise (Soares, 1992).

A motivação para realizar-se uma avaliação de desempenho depende do tipo do sistema em consideração e do estágio de seu desenvolvimento. Para sistemas em fase de projeto ou em desenvolvimento, a análise de desempenho servirá para prever o possível comportamento do sistema, permitindo ajustes no projeto, caso os resultados não sejam os desejados, gerando, potencialmente, uma redução nos custos de implementação.

Se o sistema já existe, a análise de desempenho pode servir para otimizar operações (como o processamento de uma carga de trabalho), melhorar o tempo de resposta, maximizar a utilização de recursos e aumentar, de modo geral, a sua eficiência.

Adicionalmente, para sistemas existentes, uma aplicação importante da avaliação de desempenho é a seleção de sistemas, o que é feito através da comparação do desempenho dos 
diversos sistemas considerados, sendo escolhido aquele que melhor se adeqüe às necessidades do usuário.

Mesmo sabendo da importância da avaliação de desempenho, muitas vezes a mesma não é realizada, porque os usuários desconhecem as técnicas de avaliação ou, mesmo conhecendo-as, não o fazem por tornar-se um tarefa muito dificil (Orlandi, 1995).

\subsection{Técnicas para Avaliação de Dese mpenho}

Para estudar-se o desempenho de sistemas existentes, ou em fase final de desenvolvimento, podem ser feitas experimentações nos mesmos, podendo ser realizadas por hardware ou software.

As técnicas indicadas para esse fim são as técnicas de aferição. Assim como todas as técnicas de avaliação de desempenho, as técnicas de aferição não são completamente exatas, elas possuem vantagens e desvantagens que devem ser analisadas por ocasião de sua escolha.

As técnicas de aferição fornecem, potencialmente, resultados bastante precisos, embora seja necessário que se evite que as experimentações interfiram no resultado final.

Dentre as técnicas de aferição existentes, as principais são: os protótipos, os benchmarks e a coleta de dados (Orlandi, 1995). Neste trabalho essas técnicas não serão abordadas.

Por outro lado, pode-se utilizar uma técnica conhecida como modelagem. Modelar um sistemas é abstrair as principais características do mesmo e através dessa abstração construir o modelo. Os modelos podem ser construídos de forma gráfica ou através de fórmulas matemáticas, apenas a primeira será abordada neste capítulo.

Para construir-se um modelo graficamente, podem-se utilizar técnicas como Redes de Fila, Statecharts e Redes de Petri.

Com o modelo construído, é necessário que este seja solucionado para que sejam retiradas as medidas de desempenho desejadas. Para solucionar um modelo, podem ser usadas soluções analíticas ou por simulação.

$\mathrm{Na}$ solução analítica, são utilizados métodos matemáticos, tais como Redes de Jackson, cadeias de Markov entre outros, que fornecem resultados bastante precisos (Silva, 2000). 
Na solução por simulação, o modelo que descreve o sistema é analisado através de um processo computacional . (Prado, 1999)

\subsubsection{Técnicas de Modelagem}

Com o envolvimento da sociedade moderna com os computadores, tornou-se fundamental que as empresas dos diversos setores da economia passassem a se preocupar com questões até então não tão valorizadas, como por exemplo formas mais eficientes de responder perguntas tais como, custo e desempenho de seus sistemas.

Segundo (Lazowska et al., 1984), a modelagem de sistemas permite que sejam abstraídas aquelas informações mais importantes sobre o sistema e a partir delas construir o modelo, que ao ser parametrizado, poderá fornecer respostas mais acertadas para perguntas como as vistas anteriormente.

Entre as técnicas de modelagem mais utilizadas estão as Redes de Petri, as Redes de Fila e os Statecharts, que serão vistas a seguir com um enfoque maior para as Redes de Petri.

\subsubsection{Redes de Fila}

Existem sistemas que naturalmente geram filas, ou seja, clientes esperando para serem atendidos por um determinado recurso. As redes de filas compreendem uma técnica de modelagem, cuja finalidade é representar sistemas onde há disputa por recursos e, consequentemente, geração de filas.

Redes de fila é uma coleção de centros de serviço, que representam os recursos do sistema, clientes que representam os usuários e as transições. (Lazowska et al., 1984) (Soares, 1992). Um centro de serviço é constituído por um ou mais servidores, que representam os recursos e uma ou mais áreas de espera, chamadas filas (Francês, 1998). A Figura 5 mostra um exemplo de rede de fila composta por um centro de serviço com um servidor e uma fila. 


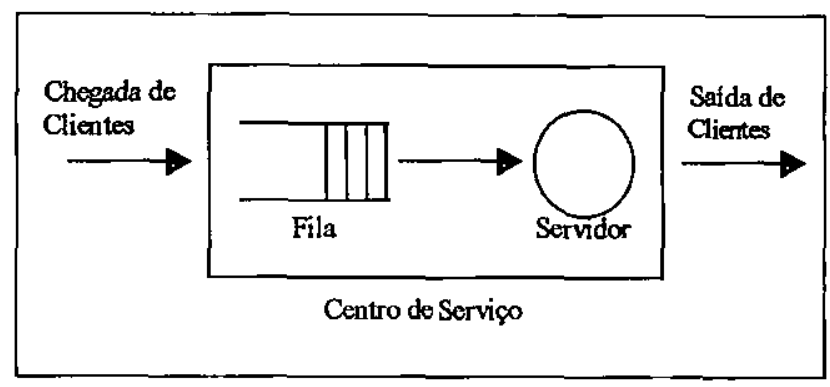

Figura 5 - Exemplo de uma Rede de Fila

Existem, também, centros de serviço que não possuem filas, estes centros são chamados de centros delay. Isto ocorre porque o centro possui um número muito grande de servidores, o que não permite a formação de fila.

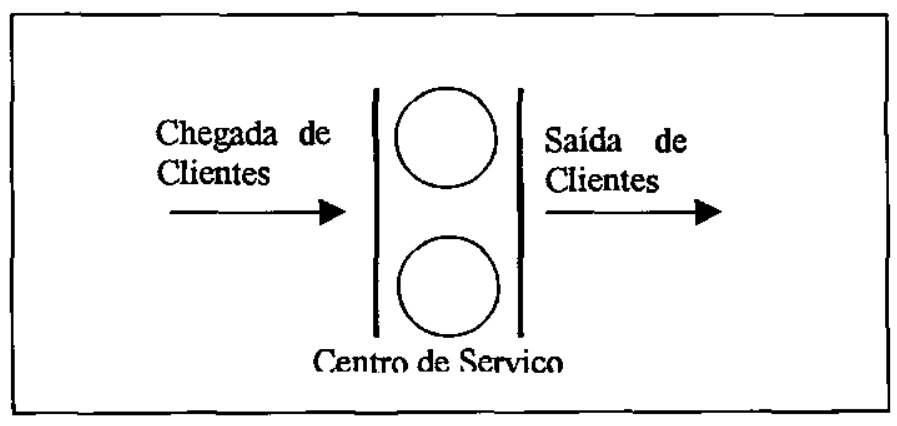

Figura 6 - Centro Delay

Existem dois tipos de redes de fila, as abertas e as fechadas. No caso de redes abertas, existe um fluxo de chegada e de saída dos clientes no sistema. Já as redes fechadas, o número de clientes é constante, ou seja, não há entrada ou saída de clientes do sistema. A Figura 5 representa uma rede aberta e a Figura 7, uma rede fechada.

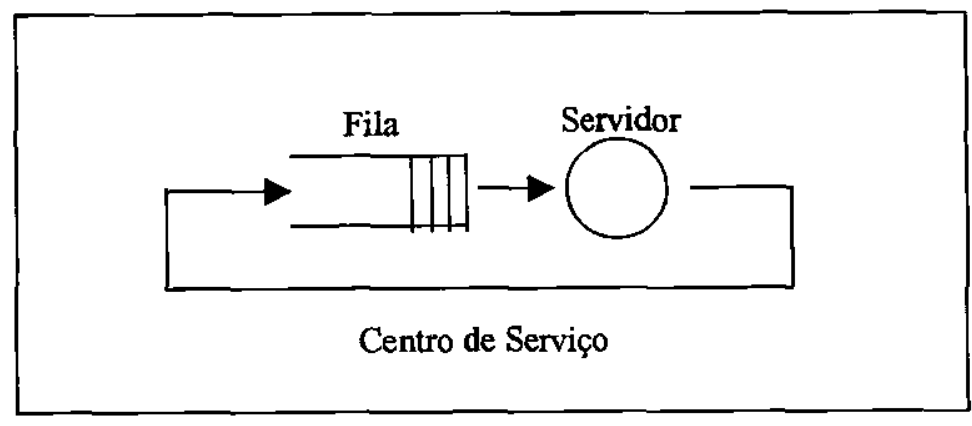

Figura 7 - Rede Fechada

Uma outra forma de representar uma rede de fila é através de uma notação bastante utilizada por vários autores como (Jain, 1991) e (MacDougall, 1989), chamada notação de Kendall. Segundo Kendall, um sistema de filas pode ser especificado por um descritor da forma 
$\mathrm{A} / \mathrm{B} / \mathrm{c} / \mathrm{K} / \mathrm{Z}$, onde $\mathrm{A}$ representa a distribuição do tempo entre chegadas dos clientes, $\mathrm{B}$, a distribuição do tempo de serviço, c, o número de servidores, $\mathrm{k}$, o máximo número de clientes permitido pelo sistema, $m$, o número de clientes disponíveis na fonte e $Z$, a disciplina de fila. (Prado, 1999)

Outras formas de escrever esta notação podem ser encontradas na literatura como por exemplo, A/S/m/B/k/SD em (Jain, 1991) ou A/S/c/k/m (MacDougall, 1989).

\subsubsection{Statecharts}

Statecharts é uma técnica de modelagem onde os estados que o sistema pode assumir e os eventos responsáveis pela transição de um estado para o outro são modelados. Essa técnica é derivada das máquinas de estado finito.

Os statecharts possuem uma visualização bastante clara, fornecendo uma idéia geral do sistema de uma forma direta. Com statecharts é possível representar o paralelismo e a hierarquia de componentes, entrada por condição, além de poder acrescentar delays e timeouts entre outras coisas.

Os statecharts são baseados em um conjunto de estados, transições, eventos e condições. O estados são representados por retângulos com bordas arredondadas, as transições, por arcos orientados, os eventos, por letras minúsculas nos arcos e as condições, por letras minúsculas entre parênteses.

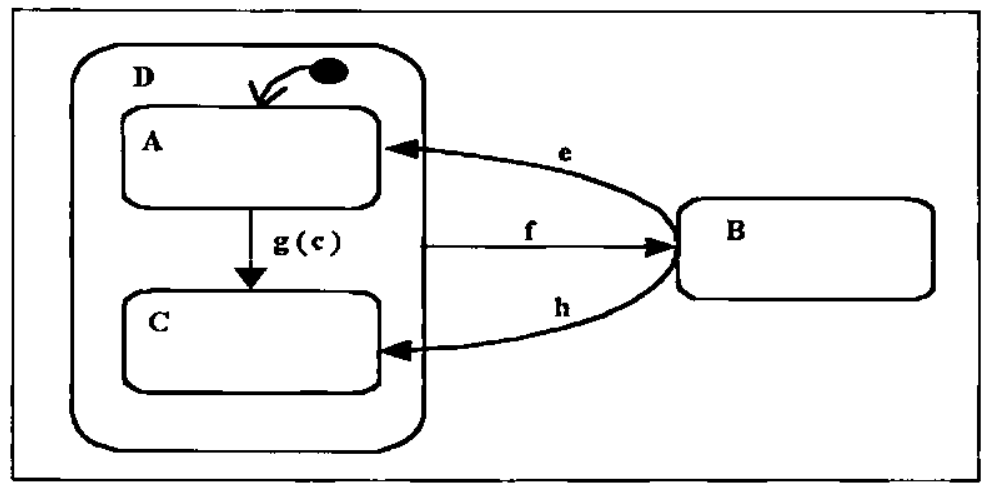

Figura 8 - Exemplo de um modelo em statechart

A Figura 8 possui quatro estados $\mathrm{A}, \mathrm{B}, \mathrm{C}$ e D. Ocorrem três eventos $e, f$ e $h$, que disparam as transições associadas, e um quarto evento $g$, pode ocorrer caso seja satisfeita uma condição $c$. D é o superestado e A e C são seus subestados. O subestado A é o chamado estado default 
(representado por uma seta característica de D), significando que o estado D sempre começa por A.

\subsubsection{Redes de Petri}

Essa técnica modela sistemas através da representação de seus estados e das transições de um estado para o outro. Ela pode ser aplicada a uma gama variada de sistemas, sendo adequada à modelagem de sistemas paralelos, concorrentes, assíncronos e não determinísticos.

Uma Rede de Petri básica é representada graficamente por dois componentes: a transição (barra), componente ativo que corresponde às ações realizadas pelo sistema, e o lugar (circulo), componente passivo que corresponde às variáveis de estado (Maciel et al., 1996). As ligações entre um lugar e uma transição são feitas por intermédio de arcos dirigidos que podem ser únicos ou múltiplos.

A Figura 9 mostra uma Rede de Petri básica, onde $P_{i}$ representa os lugares e $T_{i}$ as transições.

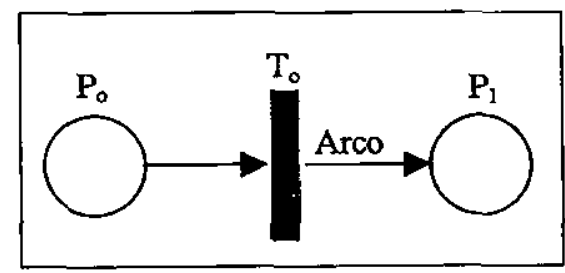

Figura 9 - Exemplo de uma Rede de Petri Básica

\section{Estrutura das Redes de Petri}

A seguir serão apresentadas algumas definições formais de redes de petri. A primeira delas diz respeito a estrutura definida em Bags, a segunda define de forma matricial e a última em forma de relação. 


\section{Estrutura definida em Bag}

Uma rede de Petri $\mathbf{R}$ pode ser definida como uma quíntupla $R=(P, T, I, O, K)$, onde $P=$ $\left\{\mathrm{p}_{1}, \mathrm{p}_{2}, \ldots, \mathrm{p}_{\mathrm{n}}\right\}$ é um conjunto finito não-vazio de lugares, $\mathrm{T}=\left\{\mathrm{t}_{1}, \mathrm{t}_{2}, \ldots, \mathrm{t}_{\mathrm{m}}\right\}$ é um conjunto finito não-vazio de transições. I : $\mathrm{T} \rightarrow \mathrm{P}$ é um conjunto de bags ${ }^{1}$ que representa o mapeamento de transições para lugares de entrada. $\mathrm{O}: \mathrm{T} \rightarrow \mathrm{P}$ é um conjunto de bags que representa o mapeamento de transições para lugares de saída. $\mathrm{K}: \mathrm{P} \rightarrow \mathrm{N}$ é o conjunto da capacidades associadas a cada lugar, podendo assumir um valor infinito (Peterson, 1981) (Francês, 1998).

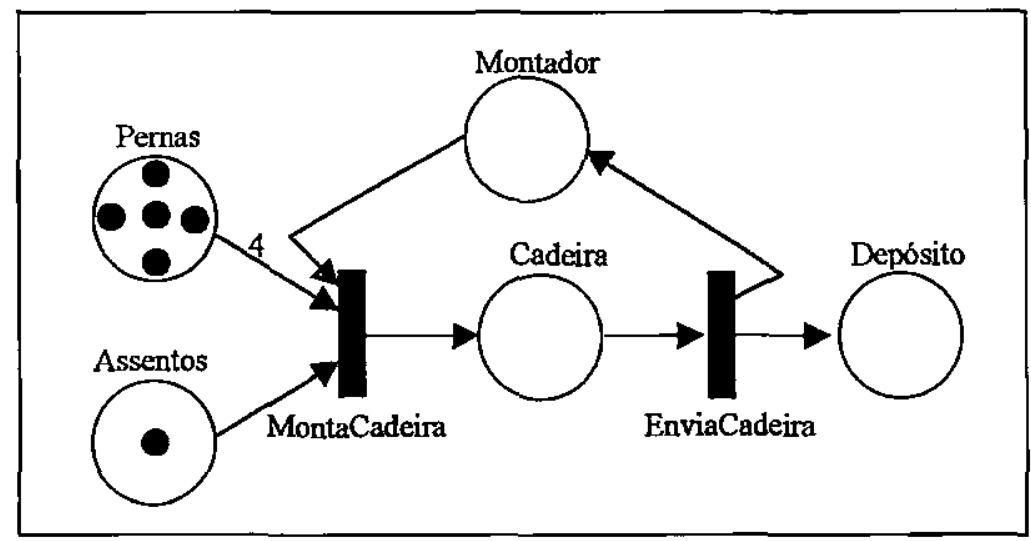

Figura 10 - Exemplo de uma linha de montagem

A Figura 10 mostra um exemplo de uma linha de montagem de cadeiras, onde para uma cadeira ser montada, são necessários um assento, quatro pernas e um montador. Após a montagem da cadeira, ela será enviada para o depósito. Utilizando a definição de bags, a representação deste modelo seria feita da seguinte forma:

$R_{\text {Linha_de_montagem }}=(P, T, I, O, K)$, onde

$\mathbf{P}=\{$ Pernas, Assentos, Cadeira, Montador, Depósito $\}$,

$T=\{$ MontaCadeira, EnviaCadeira $\}$,

$\mathrm{I}=\{\mathrm{I}($ MontaCadeira $), \mathrm{I}($ EnviaCadeira $)\}$,

$\mathrm{I}($ MontaCadeira $)=[$ Pernas, Pernas, Pernas, Pernas, Assento, Montador $]$

$\mathrm{I}($ EnviaCadeira $)=[$ Cadeira $]$

${ }^{1}$ Bag é uma generalização do conceito de conjunto que admite a repetição de elementos. Na notação de bags, utiliza-se [ ], enquanto que para denotar conjuntos, utiliza-se \{ \} (Maciel et. al., 96). 
$\mathrm{O}=\{\mathrm{O}($ MontaCadeira $), \mathrm{O}($ EnviaCadeira $)\}$

$\mathrm{O}($ MontaCadeira $)=[$ Cadeira $]$

$\mathrm{O}($ EnviaCadeira $)=[$ Montador, Depósito $]$

$\mathrm{K}=\left\{\mathrm{K}_{\text {Pernas }}=\mathrm{w}, \mathrm{K}_{\text {Assentos }}=\mathrm{w}, \mathrm{K}_{\text {Cadeira }}=1, \mathrm{~K}_{\text {Montador }}=1, \mathrm{~K}_{\text {Depósito }}=\mathrm{w}\right\}$

\section{Estrutura definida em Matriz}

A estrutura de uma rede de Petri, segundo o ponto de vista matricial, é uma quíntupla $\mathrm{R}=$ $(\mathrm{P}, \mathrm{T}, \mathrm{I}, \mathrm{O}, \mathrm{K})$, onde $\mathrm{P}$ é um conjunto finito de lugares. $\mathrm{T}$ é um conjunto finito de transições, $\mathrm{I}: \mathrm{P}$ $\mathrm{x} T \rightarrow \mathrm{N}$ é a matriz de pré-condições. $\mathrm{O}: \mathrm{P} \times \mathrm{T} \rightarrow \mathrm{N}$ é a matriz de pós-condições. $\mathrm{K}$ é o vetor das capacidades associados aos lugares $(\mathrm{K}: \mathrm{P} \rightarrow \mathrm{N})$ (Peterson, 1981).

Utilizando o mesmo exemplo do item anterior, na forma de matriz seria representado da seguinte forma:

MontaCadeira EnviaCadeira

$$
I=\left[\begin{array}{lll}
4 & 0 \\
1 & 0 \\
0 & 1 \\
1 & 0 \\
0 & 0
\end{array}\right] \begin{aligned}
& \text { Pemas } \\
& \text { Assentos } \\
& \text { Cadeira } \\
& \text { Montador } \\
& \text { Deposito }
\end{aligned}
$$

$$
\mathrm{O}=\left[\begin{array}{cc}
\text { MontaCadeira EnviaCadeira } \\
0 & 0 \\
0 & 0 \\
1 & 0 \\
0 & 1 \\
0 & 1
\end{array}\right] \text { Deposito }
$$




\section{Estrutura definida por Relações}

A estrutura de redes de Petri, utilizando-se relações, é formada por uma quíntupla $\mathrm{R}=(\mathrm{P}$, $\mathrm{T}, \mathrm{A}, \mathrm{V}, \mathrm{K}$ ), onde $\mathrm{P}$ é o conjunto de lugares, $\mathrm{T}$ o de transições, $\mathrm{A}$ o conjunto dos arcos e V corresponde ao conjunto de valorações desses arcos. Os elementos de A são arcos que conectam transições a lugares ou lugares a transições $(A \subseteq(P \times T) \cup(T \times P))$. Assim, os elementos de $A$ podem ser agrupados em dois subconjuntos - o conjunto das entradas às transições e o de saída às transições, $I=\left\{\left(\mathrm{p}_{\mathrm{i}}, \mathrm{t}_{\mathrm{j}}\right)\right\}$ e $\mathrm{O}=\left\{\left(\mathrm{t}_{\mathrm{j}}, \mathrm{p}_{\mathrm{i}}\right)\right\}$, respectivamente (Murata, 1989).

Utilizando o mesmo exemplo da Figura 10, a sua representação na forma de relação é a seguinte:

$R_{\text {Linha_de_montagem }}=(P, T, I, O, K)$, onde

$\mathbf{P}=\{$ Pernas, Assentos, Cadeira, Montador, Depósito $\}$, $\mathrm{T}=\{$ MontaCadeira, EnviaCadeira $\}$,

$\mathrm{A}=\{($ Pernas, MontaCadeira), (Assentos, MontaCadeira), (Montador, MontaCadeira), (MontaCadeira, Cadeira), (Cadeira, EnviaCadeira), (EnviaCadeira, Montador), (EnviaCadeira, Depósito)\}

$\mathrm{V}=\{4,1,1,1,1,1,1\}$

$\mathrm{K}=\left\{\mathrm{K}_{\text {Permas }}=\mathrm{w}, \mathrm{K}_{\text {Assentos }}=\mathrm{w}, \mathrm{K}_{\text {Cadeira }}=1, \mathrm{~K}_{\text {Montador }}=1, \mathrm{~K}_{\text {Deposito }}=\mathrm{w}\right\}$

\section{Classes das Redes de Petri}

Durante a construção de um modelo, pode ocorrer a necessidade de representar o sistema estudado com um maior ou menor detalhamento, mas de uma forma compacta, isto porque, dependendo do tamanho do sistema, o modelo pode tomar dimensões não práticas e pouco esclarecedoras.

Para tentar contemplar estes aspectos, a literatura sugere classificações para as redes de petri:

- Redes Ordinárias

- Binária (condição/evento)

- Lugar-transição (place-transition) 
- Não-ponderadas

- Ponderadas

- Redes de Alto Nível

- Predicado-evento

- Coloridas

- Hierárquica

- Estocásticas

\section{Redes de Petri Ordinárias}

As redes ordinárias diferenciam-se, principalmente, das redes de alto nível, pelos valores assumidos pelos tokens. Nas redes ordinárias, os tokens só podem assumir valores inteiros não negativos, já as de alto nível, os tokens podem assumir valores particulares.

A classe binária possui a característica de só possuir valores unitários para os arcos e cada lugar só pode possuir um token.

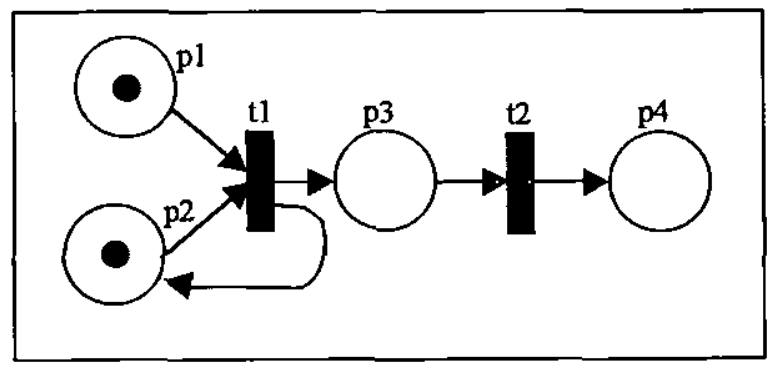

Figura 11 - Rede Binária

Na classe lugar-transição, os lugares podem acumular tokens, e os arcos podem ter valor maior que um.

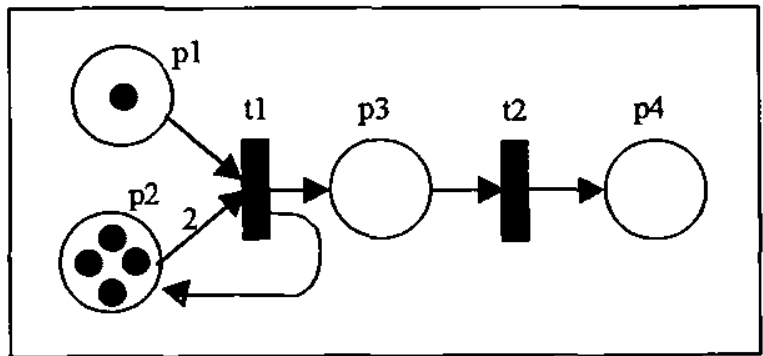

Figura 12 - Rede Lugar-transiçāo

Nas redes não-ponderadas permitem que os lugares acumulem tokens, mas a valoração dos arcos é igual a um. Neste caso, um lugar pode representar os recursos do sistemas, disco e impressora por exemplo, e o número de tokens neste local indica quantos recursos estão 
disponíveis no momento. A Figura 13, mostra uma rede com dois tokens no lugar recurso, indicando que existem dois recursos disponiveis.

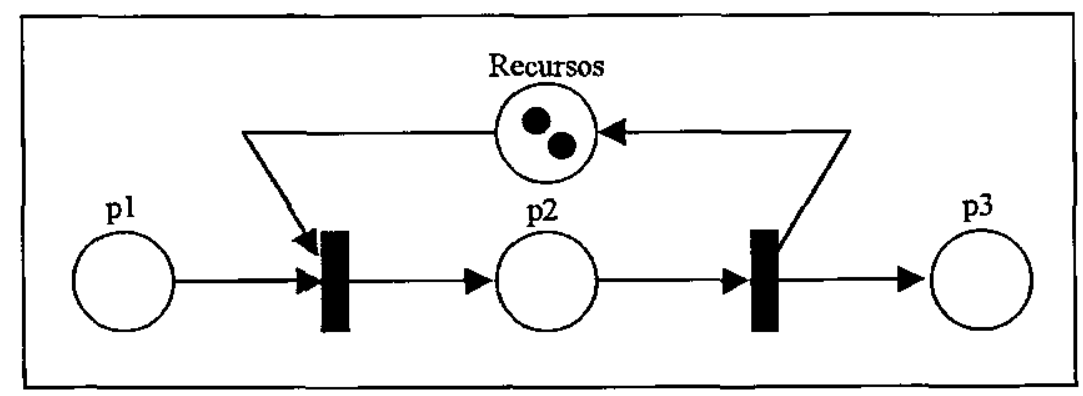

Figura 13 - Rede Não-ponderada

Nas redes ponderadas, a valoração dos arcos pode ser diferente de um, além de arcos múltiplos poderem ser representados por um único arco valorado.

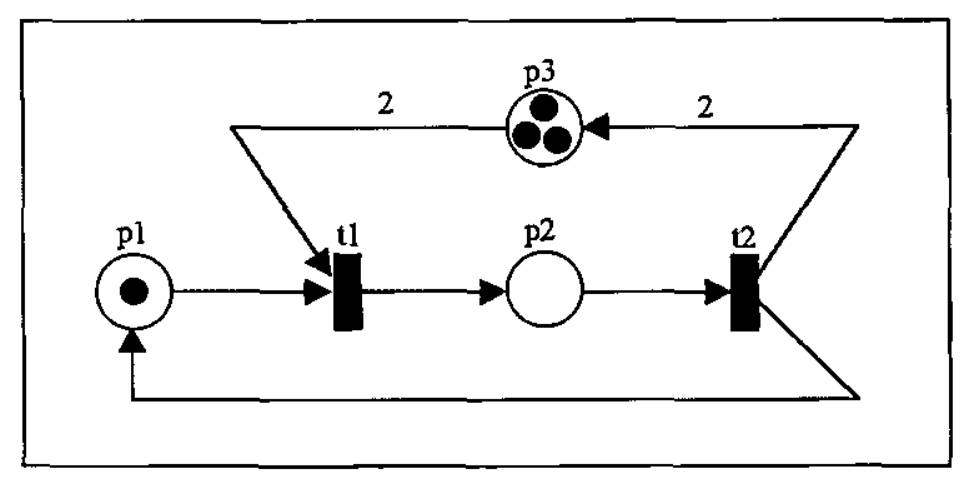

Figura 14 - Rede Ponderada

\section{Redes de Alto Nível}

Nas redes de alto nível, os tokens assumem valores complexos como cores ou estruturas de dados, tais valores permitem a diferenciação dos tokens que percorrem a rede.

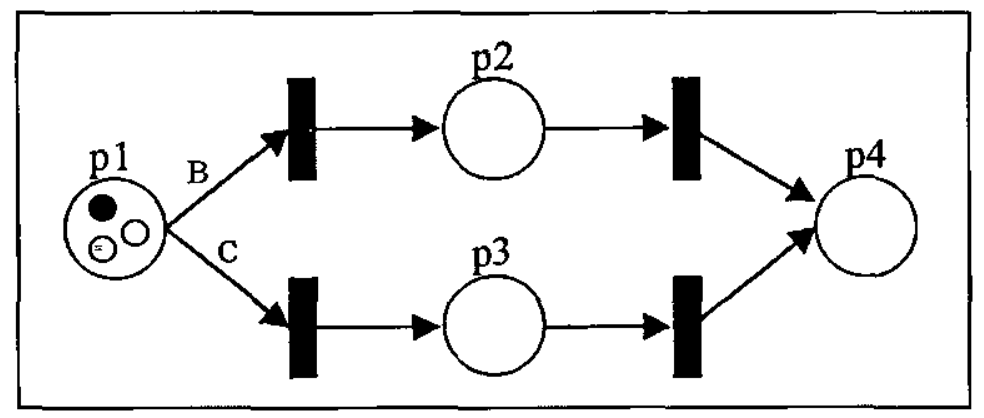

Figura 15 - Rede de alto nível 
As redes de alto nível são extensões às redes de petri tais como redes de petri coloridas, temporizadas e redes de petri estocásticas. Dependendo do nível de abstração desejado, do tipo de aplicação, entre outras, é interessante que se escolha uma determinada classe de rede para a modelagem do problema.

\section{Redes Elementares}

Redes elementares são blocos básicos que permitem a construção de modelos mais complexos. Alguns desses blocos são os de sequenciamento, distribuição, junção, escolha nãodeterministica e atribuição.

\section{Sequenciamento}

O sequenciamento ocorre quando a execução de uma ação, resultante de uma condição verdadeira, gera uma nova condição que pode habilitar uma nova ação.

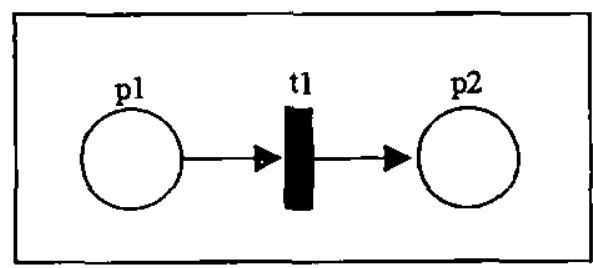

Figura 16 - Sequenciamento

Com um token em p1, a transição tl é habilitada, com o seu disparo, uma nova condição é criada em p2. Essa condição pode habilitar uma outra transição que esteja associada a ele.

\section{Distribuição}

A distribuição é utilizada para representar a criação de processos paralelos a partir de um pai.

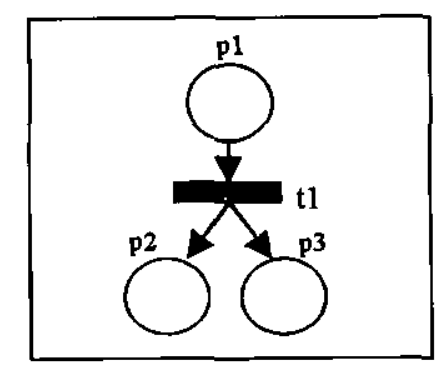

Figura 17 - Distribuição

Um token em p1 habilita a transição $t 1$, que gera um token para cada um dos lugares associados a ela (p2 e p3). 


\section{Junção}

A junção é utilizada para sincronizar processos. Neste caso, a transição t1 só estará habilitada se p1 e p2 possuírem tokens.

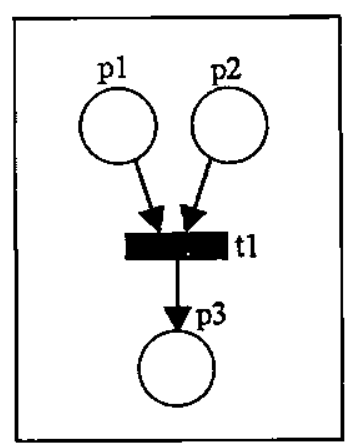

Figura 18 - Junção

\section{Escolha não-determinística}

Esta rede elementar pode ser chamada, dependendo da aplicação, de conflito, escolha ou decisão. A Figura 19 representa uma escolha não-determinística, onde o disparo de uma transição desabilita a outra.

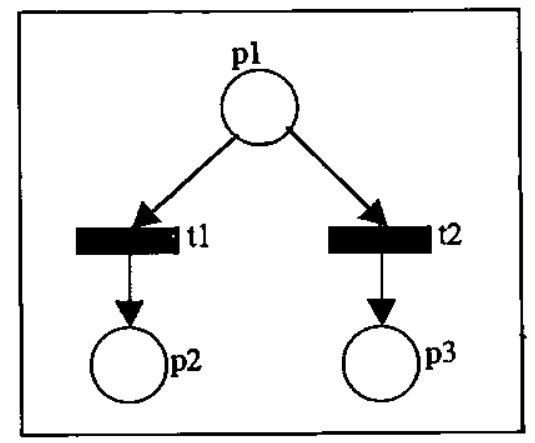

Figura 19 - Escolha não-determinística

Esta rede pode gerar dois tipos de conflito, o estrutural e o efetivo. Um conflito estrutural existe, se e somente se, duas transições $t 1$ e $t 2$ possuírem um lugar de entrada comum p1. Para tornar-se um conflito efetivo, o lugar $\mathrm{p} 3$, comum para $\mathrm{t} 1 \mathrm{e} \mathrm{t} 2$, deve possuir um token que habilitará uma das transições e desabilitará a outra. 


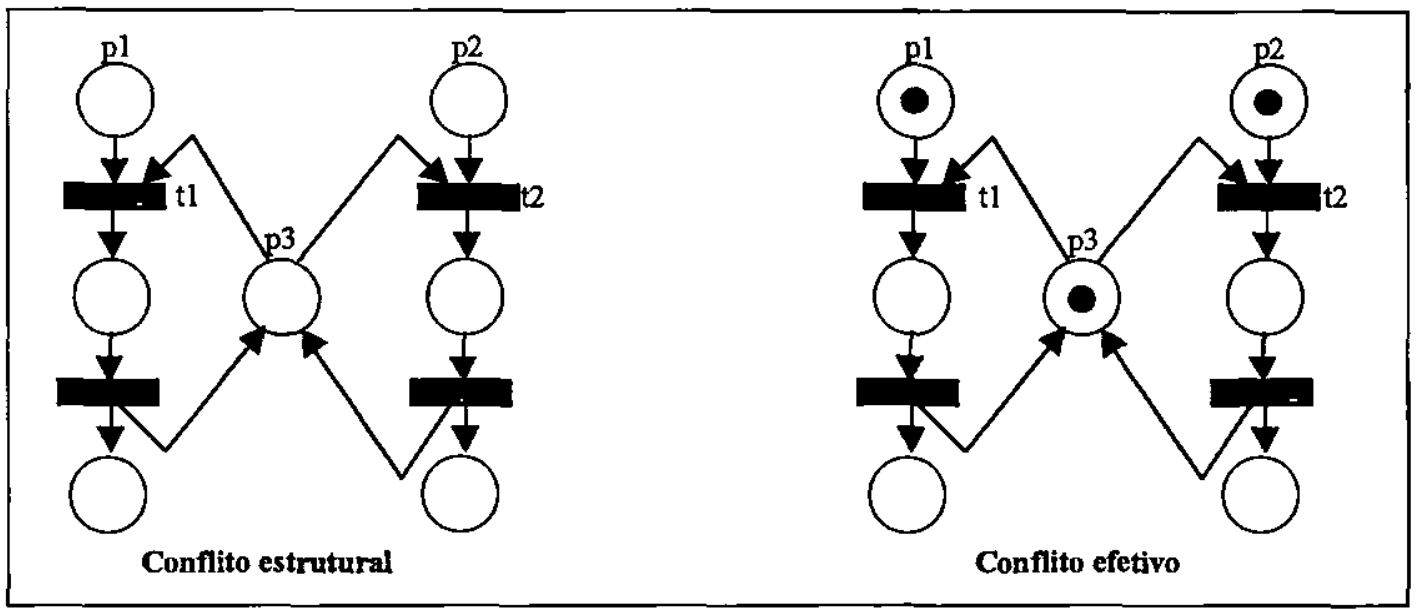

Figura 20 - Conflitos gerados pela escolha não-deterministica

\section{Atribuição}

Nesta rede elementar, dois ou mais processos possibilitam o disparo de uma mesma transição. A Figura 21 mostra o modelo da atribuição, onde os lugares pl e p2 são independentes entre si, mas ao serem marcados, geram uma condição em p3 que pode habilitar uma transição associada à rede.

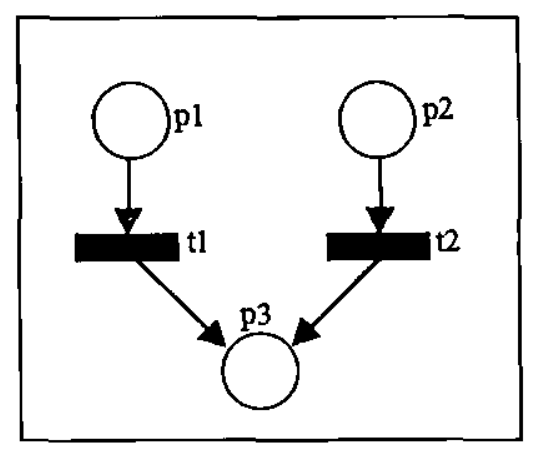

Figura 21 - Atribuição

\section{Modelagem de Processos}

A seguir serão mostrados dois problemas que podem ser modelados utilizando redes elementares, são eles os processos paralelos e a exclusão mútua.

\section{Processos Paralelos}

O modelo global é formado pelos modelos da distribuição, sequenciamento e sincronização dos mesmos. 


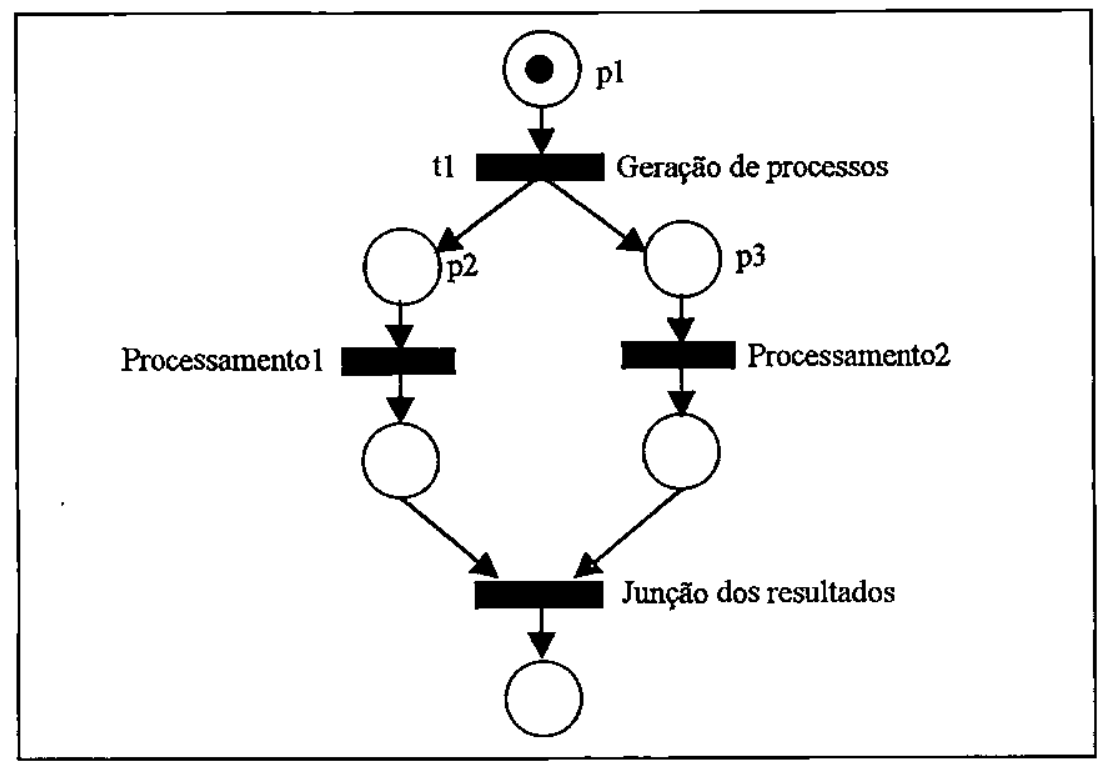

Figura 22 - Processos paralelos

Na Figura 22, o lugar p1 ao ser marcado habilita a transição tl que gera um token para cada lugar associado a ela, modelando assim, a criação de dois processos paralelos.

\section{Exclusão Mútua}

A exclusão mútua é utilizada para modelar situações em que os processos são paralelos, mas devem compartilhar o mesmo recurso.

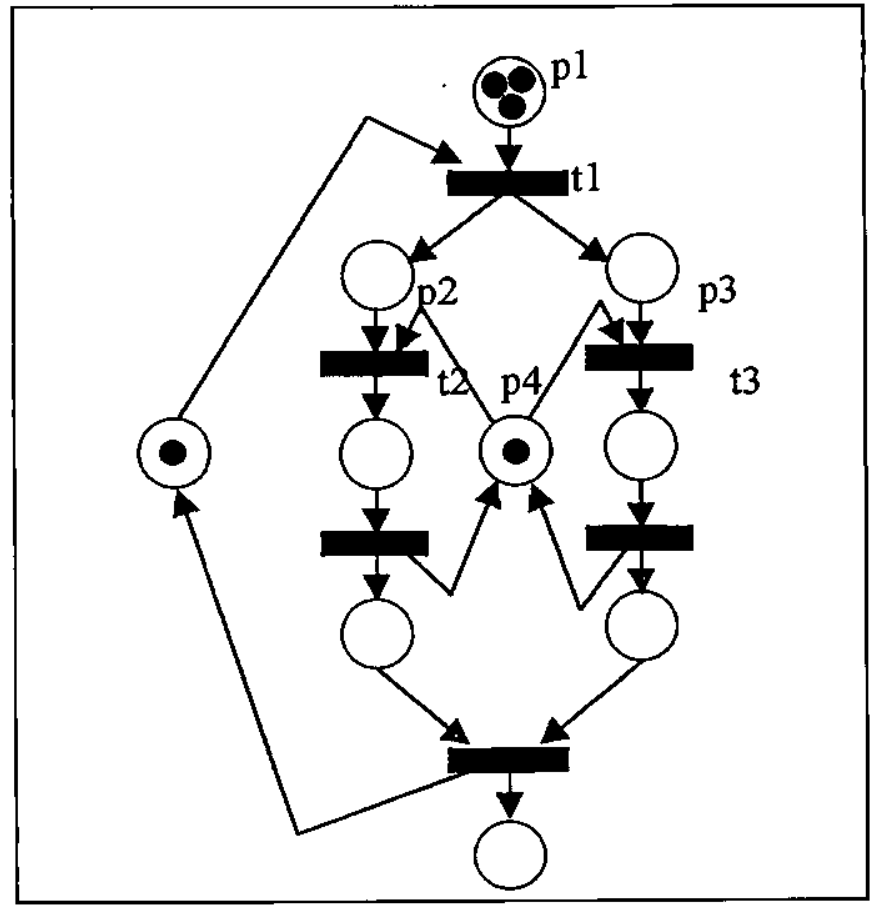

Figura 23 - Exclusão mútua 
A Figura 23 mostra um caso de exclusão mútua. Supondo que o lugar p4 é um recurso necessário para a execução de dois processos iniciados em p2 e p3. Uma marca em p4 habilitará o disparo de apenas uma das transições associadas a ele de cada vez. Caso $\mathbf{t} 2$ seja habilitada, t3 não dispara ou vice-versa.

\section{Extensões às Redes de Petri}

Com o propósito de tornar as redes de petri capazes de modelar sistemas mais complexos, realizar avaliações de desempenho, entre outras, foram propostas extensões à especificação original. Algumas dessas extensões serão vistas a seguir, são elas as Redes de Petri Coloridas, Redes de Petri Temporizadas Determinísticas e as Redes de Petri Estocásticas.

\section{Redes de Petri Coloridas}

Rede de petri colorida é um tipo de rede de alto nível que ao contrário das redes ordinárias, que possuem apenas um tipo de token, permite o uso de tokens diferentes. Segundo (Maciel et al., 1996), o principal objetivo das redes de petri coloridas é a redução de tamanho do modelo, permitindo que os tokens individualizados (coloridos) possam representar processos e recursos diferentes na mesma sub-rede.

Os tokens, que apesar do termo colorido, não necessariamente são diferenciados pela cor, podem ser representados por estruturas de dados complexas que os diferencie entre si.

\section{Rede de Petri Temporizada Determinística}

A definição original das redes de petri não contemplava o conceito de tempo. Para possibilitar a modelagem de sistemas de tempo real, avaliação de desempenho e problemas de escalonamento, foi necessário a inclusão de retardos de tempo.

Algumas formas de especificar o tempo encontradas nas várias abordagens de redes de petri são vistas a seguir (Maciel et al., 1996):

- O tempo pode estar associado aos lugares, desta forma, os tokens nos lugares de saída só estarão disponíveis para disparar uma nova transição, após decorrido um determinado tempo associado ao lugar.

- O tempo pode estar associado às marcas. Nesse caso o token só estará disponível para disparar uma transição quando o tempo associado a ele houver decorrido. 
- O tempo pode estar associado às transições. Nesse caso após a transição ter sido sensibilizada, ela disparará após decorrido o tempo associado.

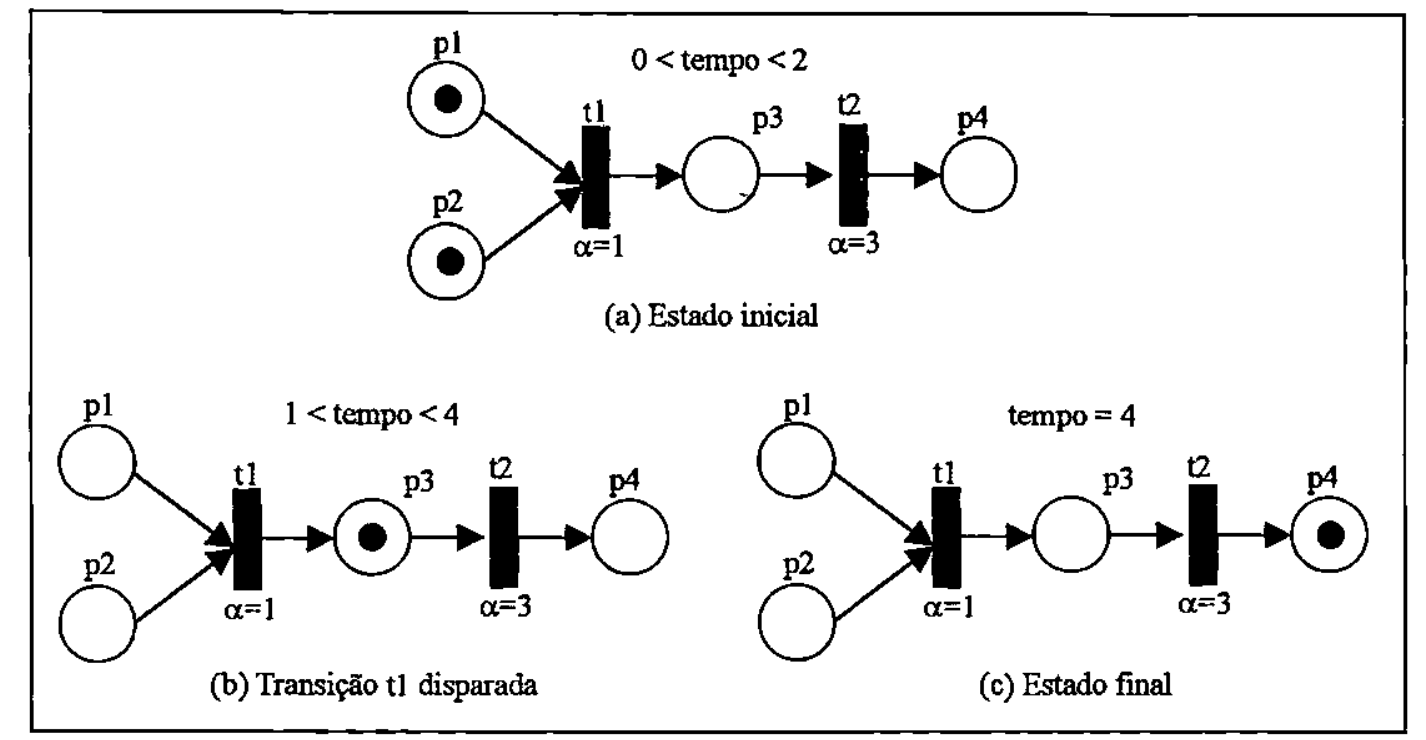

Figura 24 - Rede de petri temporizada

\section{Redes de Petri Estocásticas}

As redes de Petri, originalmente, não proviam avaliação de desempenho, mesmo sendo capazes de modelar sistemas complexos. Em 1982, surgiram as redes de petri estocásticas (Stochastic Petri Nets - SPN), propostas por Molloy (Molloy, 1982), como uma técnica que além de especificar sistemas, poderia realizar análises probabilísticas dos mesmos.

Segundo Molloy, todas as transições em uma SPN seriam temporizadas e este tempo obedeceria uma distribuição exponencial. Desta forma, a teoria de Markov poderia ser utilizada para o cálculo das medidas de desempenho.

Em 1993, Chiola (Chiola et al., 1993) propôs uma melhoria às SPN chamada de Redes de Petri Estocásticas Generalizadas (Generalized Stochastic Petri Nets - GSPN). Nas GSPN, as transições podem ser imediatas, isto é, não-estocásticas. Para as transições imediatas Chiola definiu que o retardo de disparo seria igual a zero, e que apenas as que forem estocásticas teriam retardos diferentes de zero. 


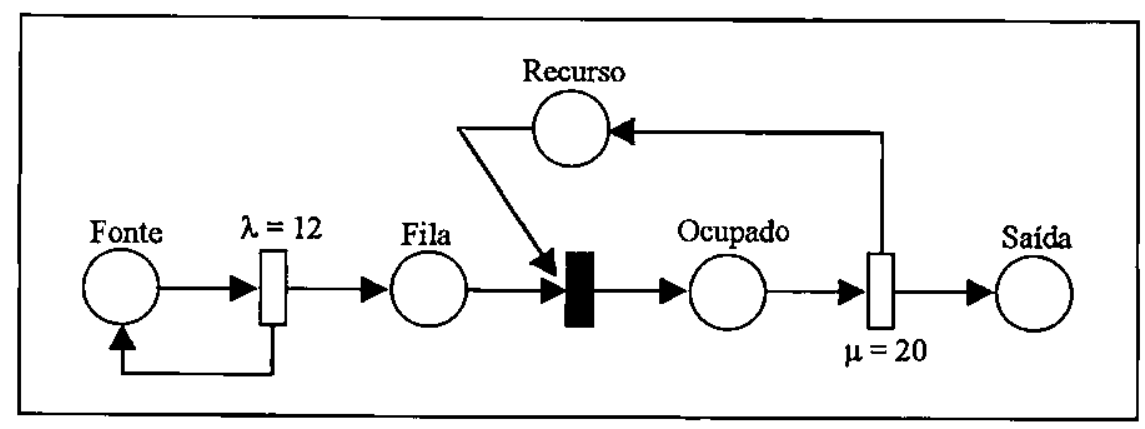

Figura 25 - Rede de petri estocástica

Na Figura 25, é mostrado o modelo de um sistema $M / M / 1$, onde a taxa de entrada $\lambda$ é igual a 12 e a taxa de serviço $\mu$ é igual a 20 . De acordo com a especificação das GSPN, as transições estocásticas são representadas por barras brancas enquanto que as imediatas, por barras pretas. Com o auxílio de um simulador (DNANet), obtêm-se medidas de desempenho como utilização do processador e tamanho médio da fila. Para este exemplo, a utilização do processador $U=60 \%$ e o tamanho média da fila é igual a 0,9 , para um tempo de observação igual a 100000 .

\subsubsection{Técnicas para Solucionar os Modelos}

Um modelo pode ser solucionado através de técnicas analíticas e/ou por simulação. O uso de uma ou de outra técnica depende dos requisitos propostos, dos resultados desejados, entre outros.

\subsubsection{Solução Analítica}

A solução analítica é uma resolução que utiliza métodos matemáticos (como álgebra e cálculo) para solucionar os modelos (Hoover, 1990). Segundo Kleinrock (Kleinrock, 1976), os métodos analíticos são geralmente mais rápidos e em conseqüência disso, em muitos casos, mais adequados. O problema é que nem sempre são aplicáveis, isso porque, normalmente, são necessárias algumas simplificações (restrições) para que se possa solucionar o modelo. A questão é que essas simplificações podem fazer com que os resultados obtidos se tornem imprecisos, já que o modelo pode deixar de ser representativo para o sistema.

Um modelo pode ser solucionado analiticamente, por exemplo, através da aplicação das propriedades de processo nascimento e morte (Jain, 1991), cálculo de limites de desempenho (Lazowska et al., 1984) e cálculo do valor médio (Santana, 1990) (Jain, 1991). 


\subsubsection{Solução por simulação}

A possibilidade de antever-se o comportamento de um sistema, sem a necessidade de sua existência, traz muitos benefícios ao projetista do sistema (Francês, 1998).

Sistemas muito complexos e sistemas que permitem poucas simplificações são melhor solucionados através de simulação. A simulação é o emprego de um programa computacional, que implementa um modelo de um fenômeno ou sistema dinâmico (Orlandi, 1995).

Em relação à computação, a simulação é bastante empregada na análise de desempenho de sistemas computacionais (Francês, 1998). A simulação não fornece um resultado exato como a solução analítica, mas sim uma aproximação do comportamento do sistema.

Para simular um modelo, podem ser utilizados ambientes de simulação ou simuladores. A estrutura e a complexidade de um simulador depende do escopo da simulação (Kobayashi, 1978).

Como exemplo de um ambiente de simulação, podem ser citados o Ambiente para Simulação Automática - ASiA, desenvolvido e aprimorado pelo Grupo de Sistemas Distribuídos e Programação Concorrente do ICMC/USP e o Alpha/Sim da Alphatec Inc, para modelos em rede de petri.

\subsection{Considerações Finais}

Neste capítulo foram apresentadas algumas técnicas comumente adotadas na avaliação de desempenho de sistemas computacionais. Verificou-se que a escolha de uma técnica depende do tipo de sistema que está sendo estudado, do nível de detalhes desejado e da precisão dos resultados obtidos, podendo ser de aferição ou de modelagem. Nas técnicas de modelagem foi dado um enfoque maior para as Redes de Petri, mostrando características, elementos básicos e algumas de suas extensões. Para a resolução dos modelos, foram apresentadas duas soluções possíveis, a analítica e a por simulação.

o Capitulo 4 trará a proposta de uma metodologia para avaliação de políticas de escalonamento de processos. 


\section{Capítulo 4}

\section{Metodologia para Avaliação de Políticas de Escalonamento de Processos}

\subsection{Considerações Iniciais}

Avaliar sistemas, sejam eles computacionais ou não, é uma tarefa muito difundida nas diversas áreas do conhecimento humano mas, apesar disso, não é uma atividade trivial. Quando se deseja avaliar um sistema alguns fatores devem ser considerados a priori, incluindo quais os objetivos da avaliação, se os resultados serão relevantes e se compensarão os custos.

Esses fatores implicam em algumas das questões que devem ser respondidas previamente, a fim de que possam ser definidos todos os pontos que conduzirão à avaliação e também verificar sua viabilidade e necessidade.

Para auxiliar nessa tomada de decisão, metodologias de avaliação podem ser empregadas de acordo com a natureza do objeto de estudo.

A área de educação é um bom exemplo para ilustrar o uso de metodologias de avaliação, onde as mesmas são utilizadas para avaliações curriculares, de políticas educacionais, de desempenho de alunos, de sistemas de avaliação adotado por professores, entre outros.

Na computação, podem ser utilizadas em qualquer área de concentração, com a finalidade de avaliar softwares, hardwares, protocolos de comunicação de redes de computadores, servidores de arquivos, webcaches, enfim, tudo aquilo que se deseja conhecer o comportamento para ser corrigido e/ou otimizado.

Em relação às políticas de escalonamento de processos, as aplicações são as mais variadas, podendo-se verificar, por exemplo, qual o desempenho global da política, levando-se em conta ou não a aplicação; pode-se ainda avaliar se a política de informação adotada é valida 
ou se alterando-a, o desempenho aumentará; é possível também verificar se o índice de carga utilizado representa claramente o estado das máquinas, entre outros. Isso tudo pode ser realizado tanto em políticas já existentes como naquelas em fase de projeto.

A seguir, são apresentados alguns conceitos sobre metodologia de avaliação e em seguida é apresentada a proposta de uma metodologia para avaliar o desempenho de políticas de escalonamento de processos. Essa metodologia tem como objetivo auxiliar na avaliação de políticas de escalonamento de processos, o que envolve usuários que normalmente conhecem a área, mas que poderão otimizar essa tarefa ao adotar a metodologia proposta neste trabalho.

\subsection{Metodologia de Avaliação}

O termo metodologia é derivado de duas palavras gregas méthodos e logos, o que a caracteriza como aquela que estuda as técnicas, métodos, ferramentas e suas aplicações seqüenciadas ou sistemáticas, na definição, organização e solução de problemas teóricos e práticos. (Lawrence et al., 1997)

\subsection{Categorização}

A metodologia de avaliação pode ser classificada em diferentes perspectivas segundo a abordagem de avaliação, suas finalidades, objeto, grau de envolvimento entre o avaliador e o objeto avaliado, entre outros. Um exemplo de classificação é quanto à abordagem, podendo ser quantitativa e qualitativa.

No caso da quantitativa, o objetivo é realizar mensurações no sistema, podendo utilizar métodos de delineamentos experimentais, por exemplo.

A abordagem qualitativa, objetiva descrever e interpretar um fenômeno. Podendo utilizar métodos e técnicas como estudo de caso e observação participante.

\subsection{Metodologia Proposta}

A seguir será apresentada a metodologia proposta para a avaliação de desempenho de políticas de escalonamento de processos. Essa metodologia tem como objetivo identificar as etapas necessárias à avaliação das políticas, com o intuito de facilitar e racionalizar este estudo. 
A metodologia em discussão procura servir como uma contribuição para aqueles que possuem conhecimento sobre esse objeto de estudo, mas necessitam realizá-la de uma forma mais rápida.

A metodologia possui dez fases que serão apresentadas a seguir:

\section{Fase I - Objetivos}

Nesta fase, o usuário deverá definir o que será avaliado na política.

Tanto para o caso da política já estar implementada ou estar em fase de projeto, o objetivo da avaliação poderá ser o de avaliar a política como um todo ou parte dela. Pode-se, por exemplo, querer avaliar o índice de carga adotado, a política de informação implementada e assim por diante.

O importante é que o usuário seja o mais específico possível em sua resposta para evitar possíveis interpretações equivocadas.

\section{Fase II - Funções da Avaliação}

Nesta fase, a pergunta a ser respondida é: "para que avaliar".

O usuário após ter escolhido o que será avaliado, deverá definir qual a finalidade de sua avaliação, a qual pode ser a verificação de possiveis falhas de projeto, formas de otimizar a política, entre outros.

Para políticas existentes normalmente a avaliação está centrada na verificação de efeitos gerados por modificações na política original, para políticas ainda em projeto, as avaliações podem ser úteis para estimar o desempenho da mesma ou possíveis alterações no projeto original.

Essas duas primeiras fases são particularmente importantes, pois com elas em mente, o usuário tem menos possibilidade de perder a direção a ser seguida durante a sua pesquisa.

\section{Fase III - Importância da Avaliação}

Nesta fase, o usuário irá determinar a viabilidade de sua avaliação, qual a importância dos resultados obtidos, quais consequências podem advir das conclusões e dos resultados da avaliação e qual a relevância de sua contribuição. 


\section{Fase IV - Conhecimento da Política a ser Avaliada}

A importância do conhecimento da política a ser avaliada, por parte do usuário, origina da necessidade de abstração das características que serão utilizadas por ocasião da construção do modelo. Isto é, caso o usuário esteja avaliando o impacto da comunicação no desempenho da política, será necessário que o mesmo conheça bem as características relativas à comunicação, para que sejam modeladas o mais fielmente possível.

Para políticas já implementadas, esta tarefa poderá tornar-se mais fácil, já que o usuário, na maioria das vezes, terá acesso à documentação explicativa e à própria política. Para as políticas que ainda estão em projeto, o projetista terá uma participação fundamental, visto que poderá auxiliar o usuário a obter as informações que necessitar.

Além da política, o usuário precisa conhecer o ambiente (plataforma e SO) em que a política é ou será executada. Isso porque precisará acrescentar ao modelo características do ambiente que porventura influenciem no comportamento da política em questão.

Enfim, o bom conhecimento da política faz com que diminua a possibilidade de um detalhe importante deixar de ser contemplado pela avaliação, além de facilitar a sua modelagem.

\section{Fase V - Definir a Técnica de Modelagem}

Por ocasião da escolha da técnica de modelagem, que será empregada, o usuário deverá identificar aquela que mais se adequa ao seu problema. Dentre as mais usadas estão as Redes de Fila, Redes de Petri e Statecharts, abordadas no capítulo 3. Outros pontos devem ser considerados como a disponibilidade de bibliografia sobre a técnica, a experiência do usuário, ou seja, se o usuário possuir algum domínio sobre uma técnica, caso seja possível, o mesmo deverá utilizá-la em detrimento de outra.

Deve-se ter bastante cuidado nesta escolha para que, após o início da avaliação, não seja concluído que outra técnica poderia ser mais adequada. Isto pode causar um grande atraso na avaliação, além de ser bastante desanimador.

\section{Fase VI - Construção do Modelo}

Segundo (Prado, 1999), modelo é a representação de um sistema e pode ser, dentre outros tipos, matemático, quando puder ser analisado por equações matemáticas, e diagramáticos, 
quando as características são representadas por um diagrama. MacDougall (MacDougall, 1989) refere-se ao modelo como sendo uma abstração de um sistema, representando uma visão particular desse sistema.

Um modelo, normalmente, tem a forma de um diagrama que mostra os recursos do sistema e suas interconexões, que mostram o fluxo do trabalho através do sistema e as operações envolvidas. Caso o sistema seja muito complexo, o diagrama pode ter múltiplos níveis (MacDougall, 1989).

O usuário poderá utilizar-se basicamente de dois tipos de abordagem para construir um modelo, são elas a sintese e a decomposição. Na síntese, o sistema é visto de uma forma bastante detalhada, e a partir dela, vão sendo feitas simplificações sucessivas até que seja atingido o nível de detalhamento desejado. Já na decomposição, o sistema é uma única entidade que a partir dela, os niveis de detalhamento vão aumentado até que seja atingido o nível previsto.

Outra coisa importante é a forma como a carga será representada no modelo. $\mathrm{O}$ usuário poderá utilizar, por exemplo, um arquivo que conterá valores hipotéticos de carga, que serão lidos no decorrer da simulação, ou acrescentar diretamente ao modelo valores fixos ou ainda, que estas cargas sejam obtidas dinamicamente pelo modelo, através de uma operação, entre outras. Os valores que serão utilizados pelo modelo, podem ser obtidos com base na literatura, caso a política não esteja implementada, ou colhidas através da execução da política, quando esta existir. Neste último caso, o usuário deverá ter bastante cuidado para que a instrumentação da política não influencie no seu desempenho.

A complexidade na construção de um modelo está relacionada com o grau conhecimento, por parte do usuário, da técnica utilizada, da política, de sua experiência e do nível de detalhamento desejado.

\section{Fase VII - Escolha das Medidas de Desempenho}

Durante a construção do modelo, é necessário que seja adicionada alguma instrumentação ao mesmo, para que seja capaz de colher dados que serão utilizados na obtenção das medidas de desempenho.

Através dessas medidas é que muitas das conclusões, em relação à política serão observadas. O usuário deverá definir quais medidas são adequadas para exprimir 0 
comportamento da política, de acordo com os objetivos da avaliação. Algumas das medidas utilizadas são o tamanho médio de fila, o tempo médio de fila, a utilização, troughput do sistema entre outras.

Dependendo do simulador adotado, o mesmo poderá fornecer recursos para o cálculo automático dessas medidas, bastando que sejam fornecidos parâmetros como tempo entre chegada dos clientes e tempo de serviço dos recursos. $O$ usuário deverá verificar se o seu modelo pode fornecer as medidas desejadas, em caso negativo, deverá alterá-lo.

\section{Fase VIII - Validação do Modelo}

Segundo (MacDougall, 1989), validação é a tarefa de demonstrar que um modelo é uma boa representação de um sistema, neste caso uma política. $O$ modelo deve reproduzir $o$ comportamento da política de uma forma tão fiel quanto for necessária para satisfazer os objetivos da análise. $O$ modelo não precisa ser válido para todas as partes da política e sim apenas para aquelas que estão envolvidas na avaliação.

A forma como a validação será realizada difere de acordo com o estado de desenvolvimento da política, isto é, uma política existente ou em fase de projeto.

Para políticas existentes, a validação pode ser feita através da comparação de valores medidos na política, com os resultados obtidos com o modelo. Caso sejam correspondentes, pode-se assumir que a simulação do modelo gerará estimativas válidas para a mudança proposta. Usualmente, são coletados os valores de carga de trabalho e algumas medidas de desempenho durante um determinado período. Os valores de carga de trabalho são colocados no modelo e após a sua simulação, são comparados os valores obtidos com o modelo com os medidos na política.

Em relação às políticas em projeto, o usuário possui pouco ou nenhum dado para comparar, neste caso a comparação pode ser feita tendo como base modelos implementados de sistemas similares. Os valores para carga de trabalho podem ser obtidos tendo por base outras políticas.

Por fim, após as mudanças ou o projeto terem sido implementados, as predições ou os valores obtidos para o desempenho poderão ser comparados. Segundo MacDougall, 
normalmente isso não acontece na prática, pois a implementação pode diferir do projeto original devido a mudanças não relacionadas ao desempenho.

Após todas essas verificações, se o modelo não for considerado válido, o mesmo deve ser corrigido, caso contrário está pronto para ser utilizado.

\section{Fase IX - Solução do Modelo}

Um modelo pode ser solucionado basicamente de duas formas, por simulação ou analiticamente. Neste trabalho, a solução adotada será por simulação, por ser simples de ser utilizada e fornecer resultados bem próximos dos obtidos com a solução analítica, quando devidamente utilizada.

Para que o modelo seja simulado, são utilizados programas de simulação, que podem ser implementados a partir de linguagens de programação convencionais (por exemplo, C e Fortran), linguagens de simulação (por exemplo, SLAM II), extensões funcionais (por exemplo, SMPL) e ambientes de simulação. Os ambientes de simulação são bastante difundidos, existindo versões para plataformas UNIX, Windows, Macintosh, entre outros. Como exemplos podem ser citados o Ambiente de Simulação Automática - ASiA, para redes de fila, o Statsim para statecharts e o ALPHA/Sim (ALPHA/Sim, 1995) para redes de Petri.

Muitos dos ambientes de simulação possuem uma interface gráfica, que permite que o usuário desenhe o modelo, parametrize-o e simule-o, além de fornecer medidas de desempenho diretamente, observados através de relatórios ou no próprio modelo.

De posse do modelo, o usuário deve parametrizá-lo, fornecendo os parâmetros de entrada que podem ser o tempo de serviço dos recursos, a carga de trabalho, tempo entre chegada de clientes, etc. Com o modelo devidamente parametrizado, o usuário poderá então o simulá-lo. A simulação fornece os resultados que deverão ser analisados estatisticamente.

\section{Fase $X$ - Análise dos resultados Obtidos}

Como a simulação é um experimento aleatório, os resultados obtidos são amostras observadas de variáveis aleatórias logo, para que esses resultados possam ser utilizados, deve-se levar em consideração a sua variabilidade, construindo-se, por exemplo, intervalos de confiança (Soares, 1992). Sem esses cuidados, os resultados obtidos podem não ser válidos. 
O exemplo a seguir ilustra a utilização de intervalos de confiança.

Será considerado a simulação de um sistema $\mathrm{M} / \mathrm{M} / \mathrm{l}$, onde se deseja estimar o valor da utilização do servidor. Supõem-se que foram obtidos 5 valores médios, Tabela 1 , para a característica de interesse, após 5 execuções do modelo e que $\bar{Y}$ é a média desses valores. Deseja-se, então, saber o quão próximo de um valor $\mu$ está $\bar{Y}$.

Tabela 1 - Valores obtidos para a utilização do servidor

\begin{tabular}{|c|c|}
\hline Execuçöes & Valores \\
\hline 1 & 0,49 \\
\hline 2 & 0,66 \\
\hline 3 & 0,7809 \\
\hline 4 & 0,9855 \\
\hline 5 & 0,5971 \\
\hline
\end{tabular}

Observam-se que os valores variam de 0,49 até 0,9855 , o que mostra que não se pode tomar o valor de uma única execução isoladamente, considerando-o verdadeiro.

Para calcular o intervalo de confiança, são necessários os seguintes passos:

1. Determinar o nível de confiança $1-\alpha$, que é a probabilidade do valor absoluto da diferença entre $\bar{Y}$ e $\mu$, ser menor ou igual a $\mathrm{H}$.

$$
\begin{gathered}
\mathrm{P}[|\bar{Y}-\mu| \leq \mathrm{H}]=1-\alpha \\
\mathrm{P}[\bar{Y}-\mathrm{H} \leq \mu \leq \bar{Y}+\mathrm{H}]=1-\alpha \text { (Intervalo de confiança) }
\end{gathered}
$$

Normalmente 1- $\alpha$ é tomado como 0,90 ou 0,95 . Neste caso $1-\alpha=0,95$, ou seja, $\alpha=0,05$ ( $95 \%$ de confiança).

$$
\bar{Y}=0,7027
$$

2. Calcular a média $\bar{Y}$ dos valores obtidos.

$$
\bar{Y}=\sum_{i=1}^{N} Y_{i} / N
$$


3. Calcular a variância $s^{2}$.

$$
\begin{gathered}
\overline{s^{2}=0,036077} \\
s^{2}=\sum_{i=1}^{N}\left(Y_{i}-\bar{Y}\right)^{2} /(N-1)
\end{gathered}
$$

4. Calcular o desvio padrão.

$$
\begin{gathered}
\text { Desv.Pad. }=0,1899 \\
\text { Desv.Pad. }=\sqrt{s^{2}}
\end{gathered}
$$

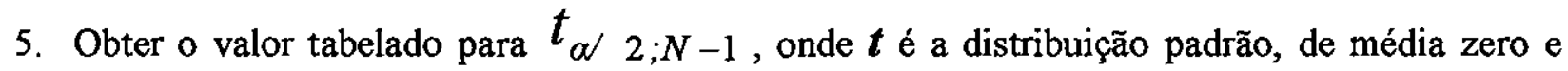
desvio padrão igual a 1 (MacDougall, 1989)

$$
\begin{gathered}
\alpha=0,05 \text { logo, } \alpha / 2=0,025 \\
t_{0,025 ; 4=2,78} \\
\text { N-1 }=4
\end{gathered}
$$

6. Calcular o valor de $H$

$$
\begin{gathered}
H=t_{\alpha 2, N-1} \text { X Desv.Pad. } \\
H=0,5279 \\
H=2,78 \times 0,1899
\end{gathered}
$$

7. Calcular o intervalo de confiança.

$$
\begin{gathered}
\text { Int.Conf. }=0,7027 \pm 0,5279 \\
\text { Int.Conf. }=\bar{Y} \pm H
\end{gathered}
$$

Pode-se notar que os valores obtidos com a simulação não são bons, em que para ter-se um nível de confiança de $95 \%$, o intervalo encontrado foi de 0,1748 até 1,2306 , ou seja, muito 
grande. Para que os valores que estão sendo analisados sejam considerados bons, o intervalo de confiança deve ser pequeno.

Este valor para o intervalo de confiança mostra que pode haver algum erro no modelo ou na sua implementação, ou ainda, o tamanho da simulação (em termos de tempo e execução) pode não ter sido suficiente, entre outras coisas.

Para corrigir os resultados, o usuário poderá aumentar o tamanho da simulação ou o número de replicações, verificar o algoritmo de geração de números aleatórios ou se as sementes usadas são adequadas, verificar a implementação do modelo e assim por diante. É interessante ressaltar que a verificação dos resultados é realizada durante todo o processos de avaliação, é através dela que os modelos vão sendo refinados até que forneçam valores satisfatórios. 
A Figura 26 mostra todos as fases da metodologia proposta, através de um esquema resumido, o que permite sua visualização de forma global, facilitando seu entendimento.

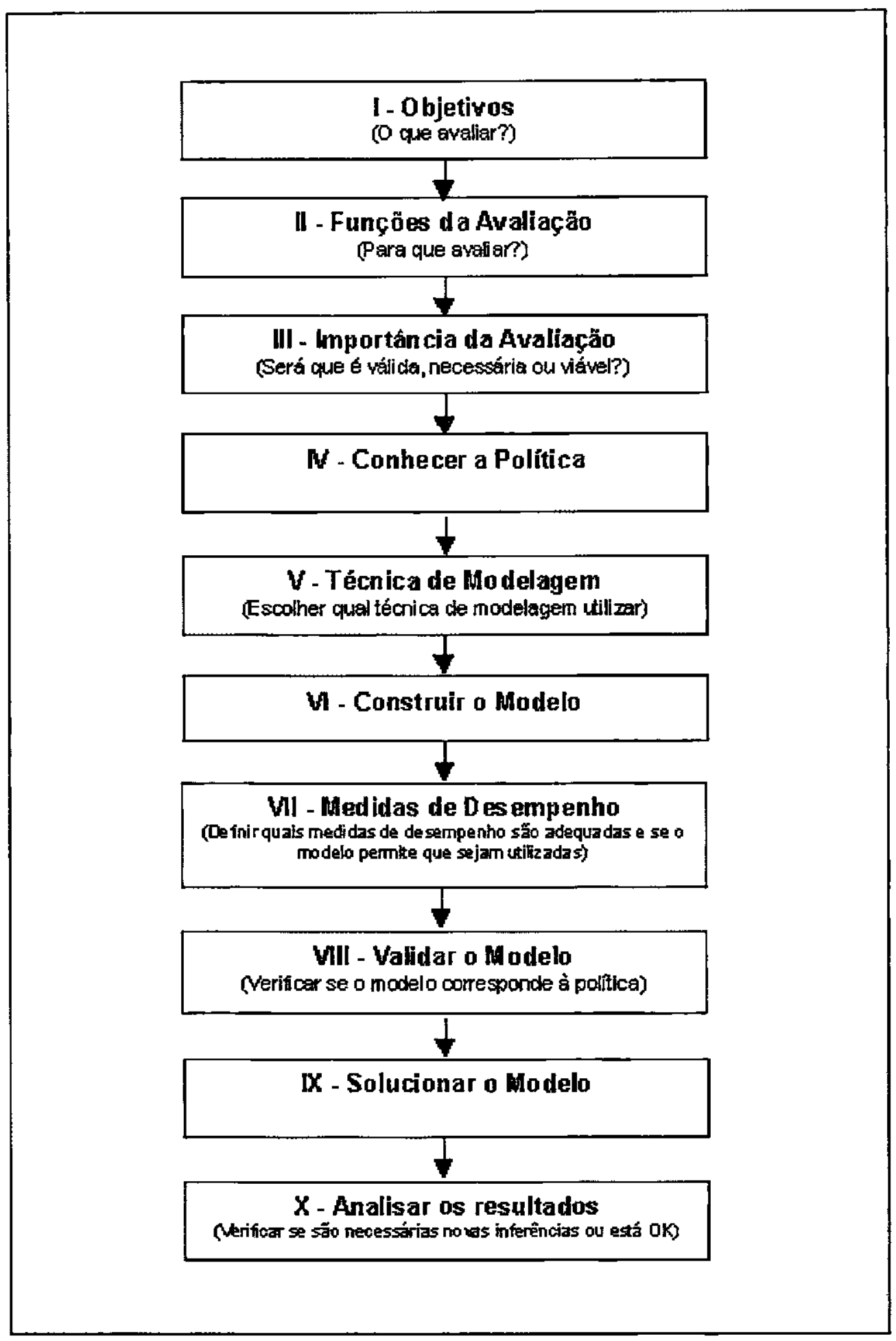

Figura 26 - Metodologia para Avaliação de Políticas de Escalonamento de Processos 


\subsection{Aplicação da Metodologia}

Para ilustrar o uso da metodologia proposta, será apresentado um exemplo, considerandose a DPWP que é uma política de escalonamento de processos voltada para aplicações do tipo CPU/Bound, desenvolvida no ICMC/USP, grupo de Sistemas Distribuídos e Programação Concorrente. (Araújo, 1999).

A DPWP é responsável por verificar dentre as máquinas pertencentes ao sistema, aquelas que melhor se apresentam, num dado momento, para receber os processos. $O$ número de processos é informado pelo ambiente de passagem de mensagem e chega até a DPWP por intermédio do AMIGO, que é um ambiente de escalonamento de processos que tem por objetivo viabilizar, de modo coerente, fácil e organizado, a utilização das melhores políticas e mecanismos, em uma única ferramenta de escalonamento de processos para aplicações paralelas (Souza, 2000).

A determinação dessas máquinas é feita baseada no número de processos e no estado das máquinas envolvidas, que pode ser ocioso, moderado ou carregado, preferencialmente utilizando-se as máquinas ociosas, depois as máquinas moderadas e apenas no caso de o sistema estar saturado, as máquinas carregadas.

\section{Fase I - Objetivos}

O objetivo desta avaliação é observar o comportamento da política DPWP, identificando possiveis falhas no seu projeto, com base na analise do balanceamento de carga obtido com o seu uso.

\section{Fase II - Funções da Avaliação}

Caso sejam constatadas falhas ou comportamento inadequado na DPWP, serão propostas alterações a fim de corrigir essa falha e melhorar o balanceamento de carga obtido.

\section{Fase IIl - Importância da Avaliação}

A possibilidade de analisar a DPWP, verificando suas características, seus prós e contras e de propor modificações, é de grande interesse para melhorar o desempenho do sistema, além de aćumular conhecimentos para futuras avaliações ou implementações de novas politicas. 


\section{Fase IV - Conhecimento da Política}

A DPWP constitui uma política de escalonamento de processos, sem preempção, voltada para aplicações CPU/Bound (isto é, onde as atividades como entrada e saída são raras quando comparadas ao volume de processamento), que tem como objetivo identificar as melhores máquinas para receberem os processos gerados pela aplicação.

A política DPWP verifica a carga local das máquinas pertencentes ao ambiente paralelo virtual periodicamente. Essa carga é normalizada com a potência computacional da máquina, depois é armazenada em um vetor com quatro posições para que seja calculada a carga média. Esse valor médio será usado como a carga da máquina. Foi optado por usar um valor médio, para evitar possiveis flutuações de carga, o que poderia não retratar o estado real da máquina.

Após o cálculo da carga, é verificado o estado da máquina. Caso o estado tenha mudado, o novo estado é divulgado para as demais máquinas pertencentes ao sistema. Isso é feito através do AMIGO, que serve como intermediário entre todas as comunicações entre as instâncias da DPWP. A política de informação adotada é por demanda.

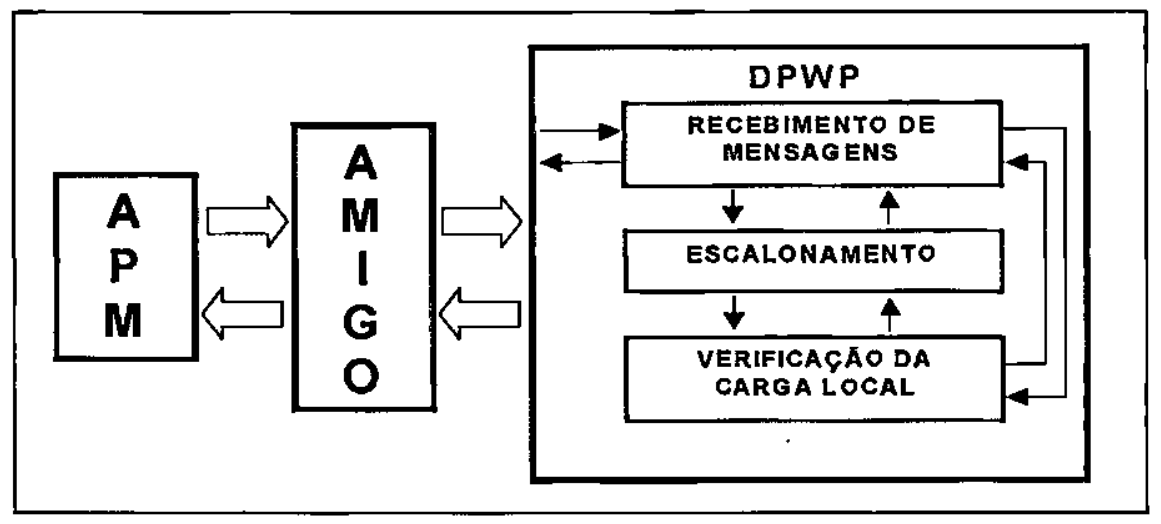

Figura 27 - Esquema da DPWP

\section{Fase V - Definir a Técnica de Modelagem}

A técnica escolhida foi a de Redes de Petri, por ser baseada em estados, permitir a utilização de tokens multivalorados, posse simultânea, além de possuir uma vasta bibliografia.

O simulador utilizado foi o ALPHA/Sim da Alphatec Inc (ALPHA/Sim, 1995). O ALPHA/Sim é um simulador para redes de Petri estocásticas generalizadas, que permite a utilização de tokens complexos, possibilita a construção de estruturas de decisão nos lugares, 
permite a utilização de vários tipos de distribuições de probabilidade nas transições, além de ter a possibilidade do usuário construir a sua própria regra para o disparo das transições.

\section{Fase VI - Construção do Modelo}

Na construção do modelo, foram considerados a verificação periódica da carga local, a escolha das melhores máquinas, comunicação entre as políticas, entre o AMIGO e o ambiente de passagem de mensagem, entre o AMIGO e a DPWP e etc.

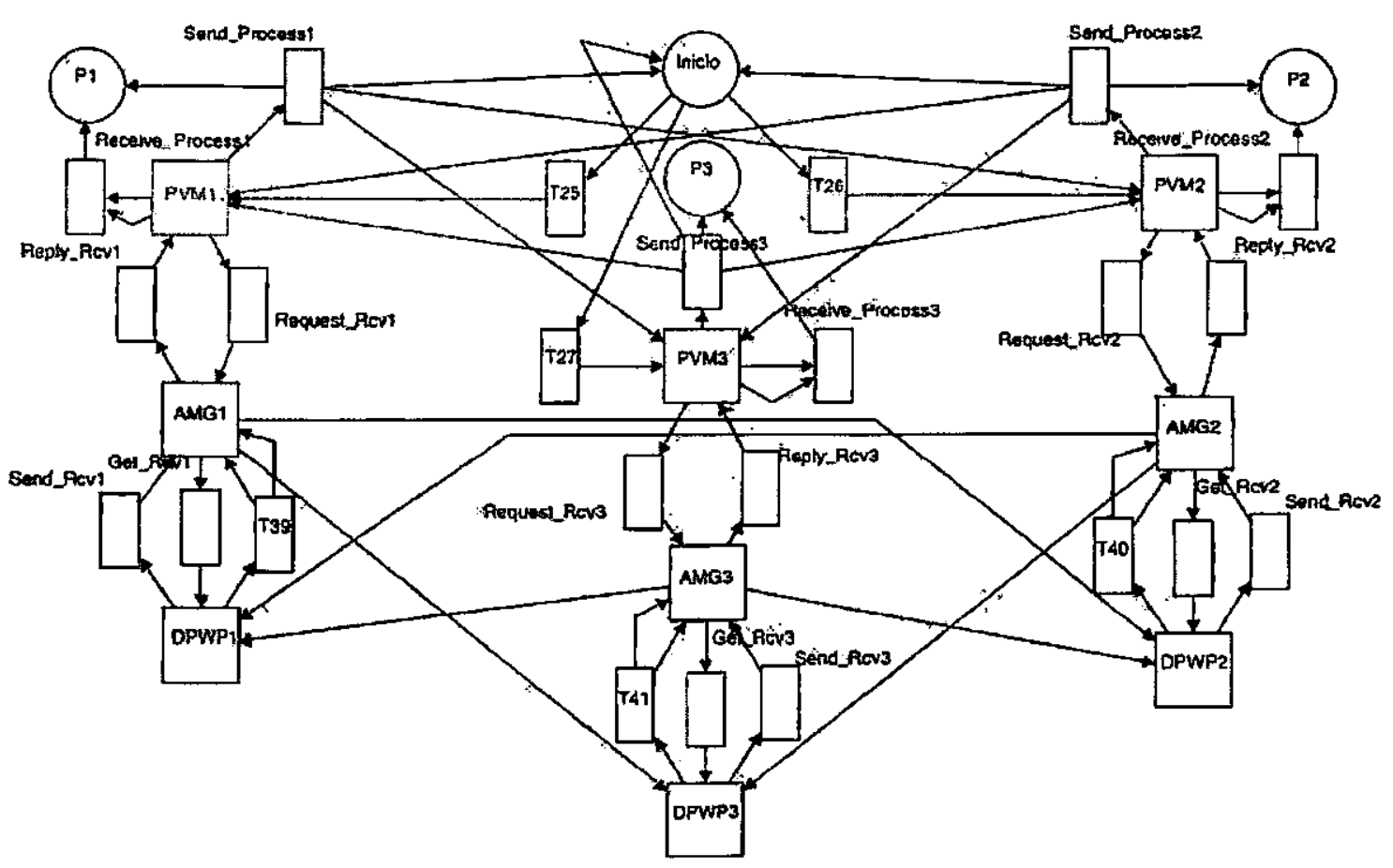

Figura 28 - Visão Macro do Modelo

A Figura 28 mostra o modelo em uma visão macro, com três máquinas, onde a DPWP, o AMIGO e o ambiente de passagem de mensagens (PVM) são visualizados na forma de caixas, que contêm o modelo de cada um deles. Isso é usado para melhorar a visualização do modelo.

O modelo funciona da seguinte forma:

- O lugar INICIO é o responsável por gerar tokens com a informação do número de processos a serem escalonados, de forma aleatória, obedecendo uma distribuição exponencial. Probabilisticamente é decidido qual das máquinas irá responder a essa requisição. 
- Após a decisão, o ambiente de passagem de mensagem, neste caso o PVM, envia ao AMIGO a informação do número de processos através da transição Request_Rcv, o AMIGO repassa essa informação para a instância da DPWP associada a ele pela transição Get_Rcv.

- A DPWP irá escolher as máquinas mais adequadas para receber os processos. A resposta passa pelo AMIGO, transição Send_Rcv, e chega até o lugar PVM através da transição Reply_Rcv, de lá são enviados os processos que foram designados para as outras máquinas. Os tokens que contêm a informação do escalonamento ficam armazenados nos lugares P1, P2 e P3.

O modelo da DPWP é composto por duas partes distintas como visto a seguir:

- A primeira é responsável por verificar a carga da máquina periodicamente. Essa verificação é feita da seguinte forma:

(a) primeiro é capturado o número de processos prontos na fila do processador, esse valor é normalizado com a potência da máquina;

(b) os valores normalizados são colocados em um vetor para que seja calculada a carga que será utilizada, através da média desses valores;

(c) é calculado o estado da máquina; caso o estado tenha mudado, a DPWP avisa ao AMIGO, que informa esta mudança às demais máquinas.

A Figura 29 mostra o modelo da DPWP, com a parte responsável por todo procedimento visto acima em destaque. 


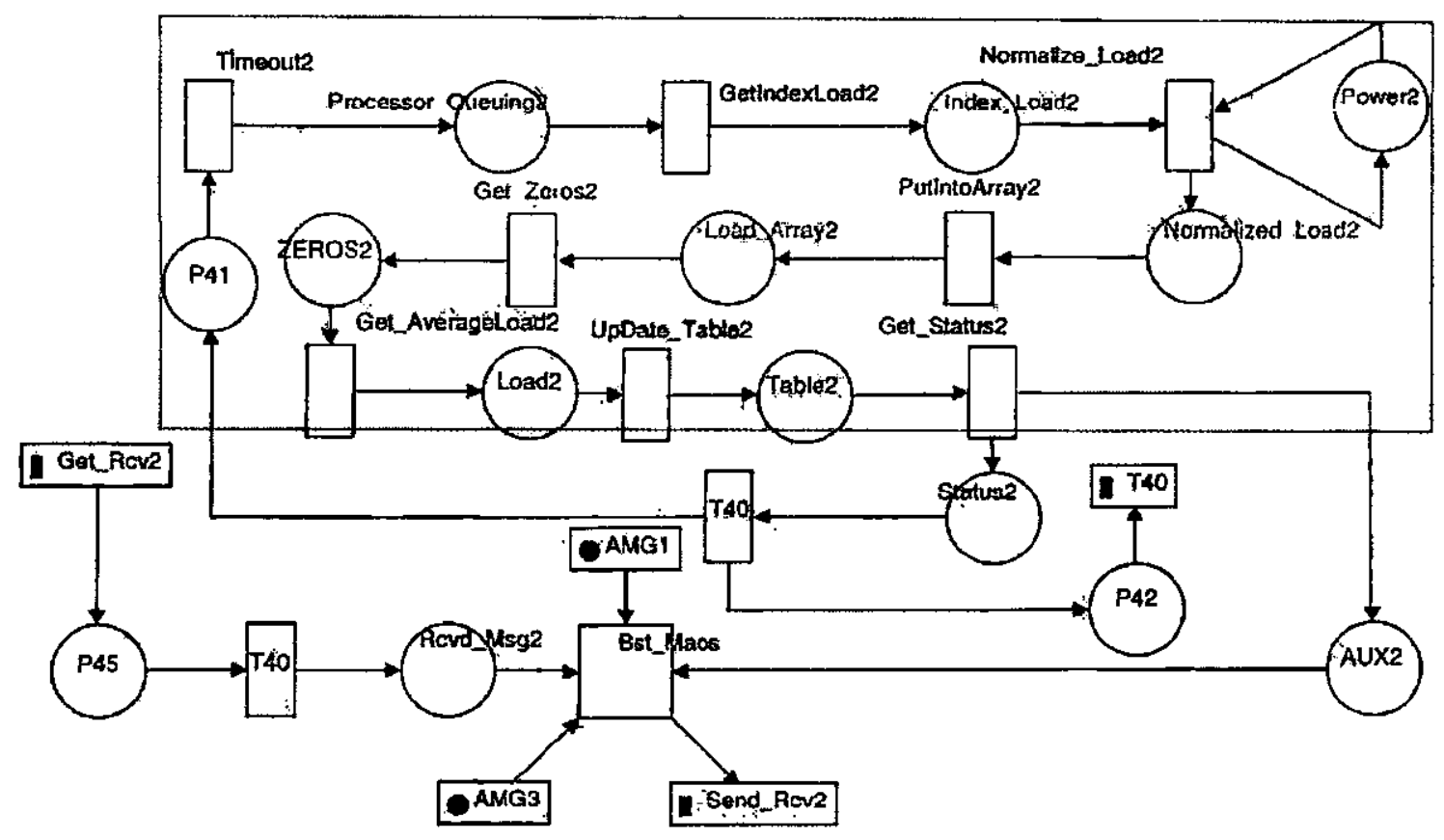

Figura 29 - Modelo da DPWP com destaque para o cálculo da carga

Periodicamente, a DPWP verifica a carga local da máquina, isto é feito de 5 em 5 unidades de tempo; a transição Timeout é responsável por gerar este tempo entre as verificações. $O$ índice de carga é obtido na transição GetlndexLoad; esse valor pode ser fornecido como parâmetro de entrada, pelo usuário, ou como um valor aleatório obtido por uma distribuição exponencial ou outra qualquer (no caso desse experimento, forma utilizadas as duas primeiras formas). De posse desse valor, o mesmo é multiplicado pela potência da máquina, contida no lugar Power. Essa multiplicação é feita com o intuito de diminuir a influência da heterogeneidade das máquinas. $\mathrm{O}$ valor resultante, chamado de valor normalizado, é colocado num vetor de cargas para calcular a média das cargas (isto é utilizado para evitar possíveis picos). Este processo é feito nas transições PutIntoArray, Get_Zeros e Get_AverageLoad. Após o calculo da carga, é verificado o estado da máquina (ociosa, moderada, carrega); a transição Get_Status é responsável por fazer essa verificação. $O$ estado da máquina é utilizado no escalonamento.

- A segunda é responsável por definir quais máquinas serão utilizadas. Cada uma das instâncias da DPWP, no modelo, recebe os estados da sua máquina e das outras. Esses dados, juntamente com o número de processos, são suficientes para que seja feita a alocação dos processos. 
A Figura 30 mostra em destaque, a parte responsável em realizar o que foi visto acima.

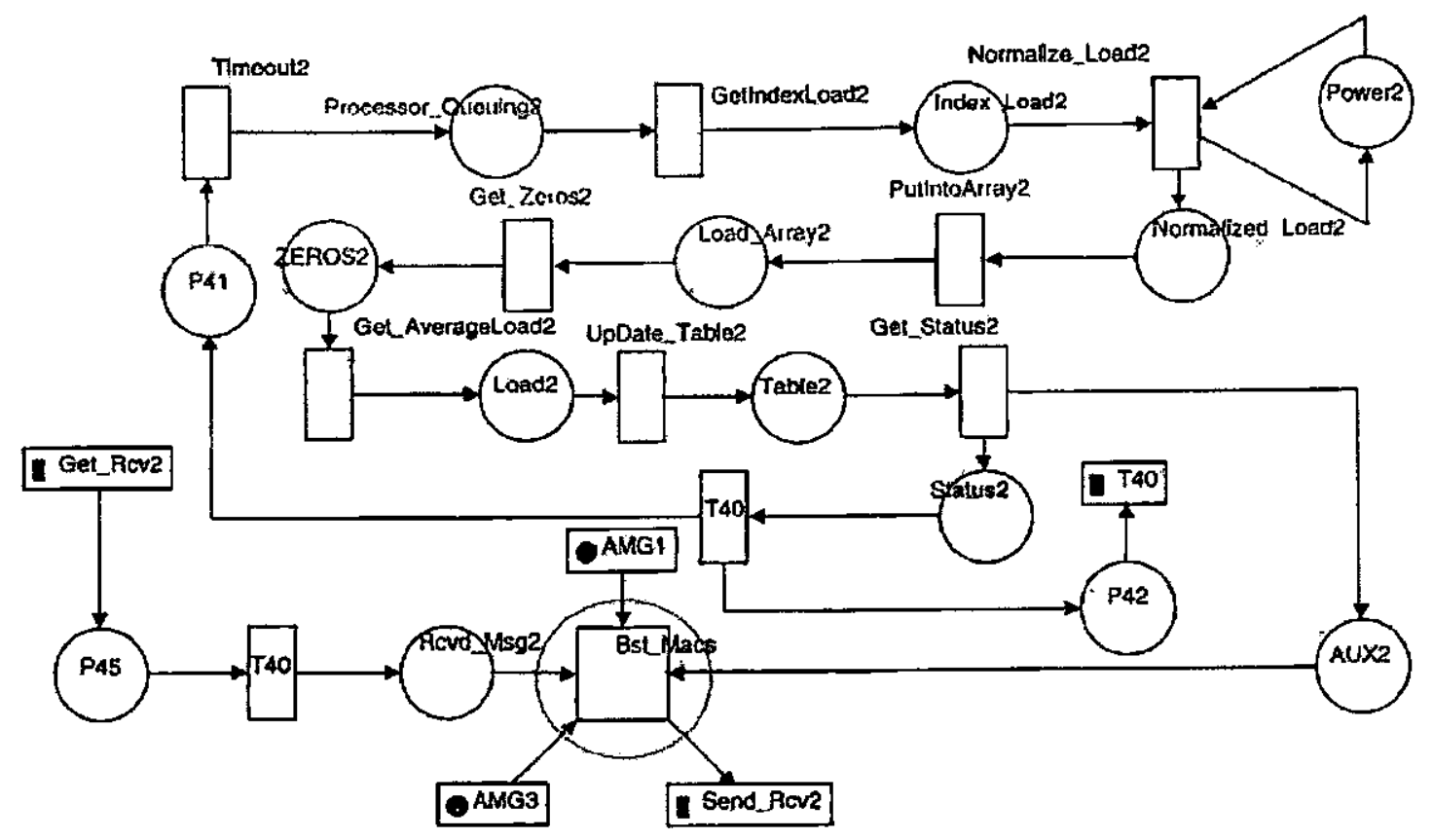

Figura 30 - Modelo da DPWP com destaque para a escolha das máquinas

A informação com o número de processos a serem escalonados chega até a caixa Bst_Macs através do lugar Rcvd_Msg. O estado das outra máquinas chegam pelos lugares $A M G 1$ e $A M G 2$, neste caso. A resposta com as melhores máquinas é enviada através da transição Send Rcv.

A Figura 31 mostra o modelo contido na caixa Bst_Macs, que é responsável por escalonar os processos. 


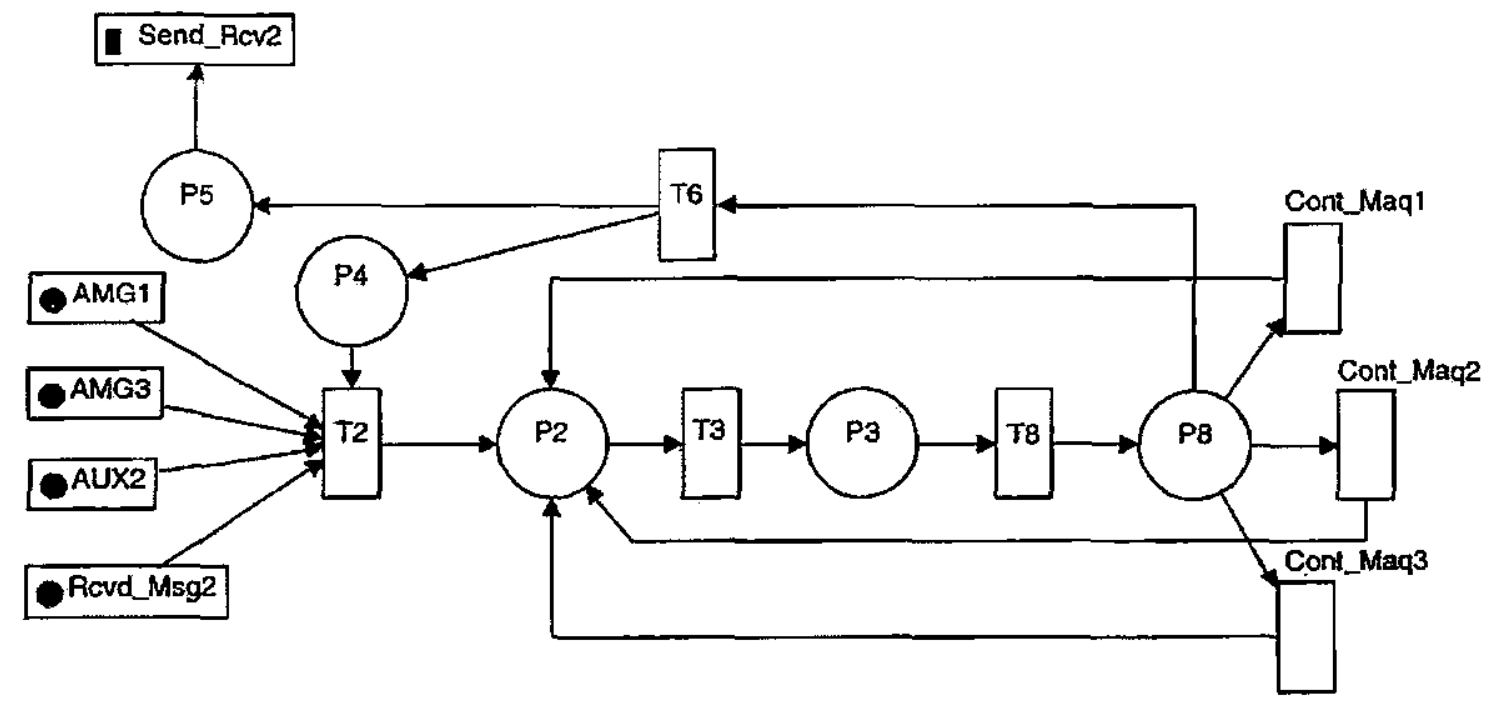

Figura 31 - Modelo contido na caixa Bst_Macs

Com a informação dos estados das máquinas e do número de processos a serem escalonados, é iniciado um laço que irá escolher as máquinas mais adequadas para receberem os processos. As transições Cont_Maq1, Cont_Maq2 e Cont_Maq3 contabilizam o número de processos que cada máquina irá receber, respectivamente máquina1, máquina2 e máquina3.

Na DPWP original, essa informação é colocada em um vetor de $\mathrm{N}$ posições, onde $\mathrm{N}$ é o número de processos totais. Como o que interessa na verificação do balanceamento obtido é apenas o número de processos que foram enviados para cada máquina, pode-se utilizar esses contadores, o que simplifica a tarefa.

Para os lugares Power1, Power2 e Power3, localizados no modelo de cada instância da DPWP, são atribuídos valores de potência das máquinas. No caso do experimento apresentado nesta dissertação, os valores adotados foram obtidos por (Figueiredo, 2000). Os valores são os apresentados na Tabela 2.

Tabela 2 - Tabela de Potência Computacional das Máquinas Utilizadas

\begin{tabular}{|c|c|c|}
\hline 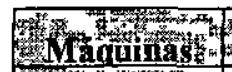 & Potencia & Nelocidade \\
\hline TEASNIX & 1 & + LENTA \\
\hline LASDECO34 & 0,9998 & \\
\hline LASDPCI & 0,91563 & \\
\hline ASDPEOS & 0,79206 & 7 \\
\hline ASDPEDT & 0,52758 & \\
\hline ASDPCO8: & & \\
\hline
\end{tabular}


Esses valores foram obtidos da seguinte forma:

(a) foi executada uma aplicação (resolução de integrais) em cada uma das máquinas;

(b) foi calculado, para cada máquina, o tempo médio de 100 execuções;

(c) a máquina com o valor médio maior, foi considerada como referência, sendo atribuídos à ela a menor potência e um índice igual a 1 ;

(d) os valores médios das demais máquinas foram divididos pelo da máquina mais lenta. O resultado dessas operações foram os índices para cada uma das máquinas.

\section{Fase VII - Escolha das Medidas e/ou Métrica de Desempenho}

Como o objetivo da avaliação é verificar o balanceamento de carga gerado pela DPWP, optou-se por adotar uma variação da métrica proposta em (Santana \& Zaluska, 1988), para medir esse balanceamento. A métrica adotada consiste em calcular a média dos valores obtidos com a multiplicação do número de processos, em cada máquina após o escalonamento, pela sua potência. É usado, também, o desvio padrão dos valores para considerados para levar em conta a dispersão dos dados. Assim, o balanceamento é dado por:

$$
\text { Balanceamento }=\left[1-\left(\frac{\text { Desv.Pad. }}{\text { Média }}\right)\right] \times 100 \%
$$

O melhor valor para o balanceamento é o de $100 \%$, ocorrendo quando todos os valores são iguais à média (desvio padrão $=0$ ). $\mathrm{O}$ menor valor é o zero, indicando que não existe balanceamento no sistema.

\section{Fase VIII - Validação do Modelo}

Como a DPWP é uma política já implementada, a validação do modelo foi realizada através da comparação dos resultados obtidos em testes reais feitos com a DPWP com os valores obtidos na simulação do modelo, utilizando-se parâmetros tais como, carga local inicial de cada máquina e o número de processos a serem escalonados, todos retirados a partir da execução da política.

A comparação dos resultados considerou o escalonamento realizado pela política e pela simulação do modelo, constatando que o modelo gerava os mesmo resultados que a política. 
O testes com a DPWP foram controlados, isto é, a carga de cada máquina, suas potências e o número de processos a serem escalonados eram conhecidos. Os valores referentes a um dos vários testes realizados, estão apresentados na Tabela 3 .

Tabela 3 - Teste de validação

\begin{tabular}{|c|c|c|c|c|c|}
\hline \multicolumn{7}{|c|}{ TESTE1 } \\
\hline Máquinas & Carga Inicial & Potência & Estado & $\begin{array}{c}\text { Processos Recebidos } \\
\text { (DPWP) }\end{array}$ & $\begin{array}{c}\text { Processos Recebidos } \\
\text { (Modelo) }\end{array}$ \\
\hline LASDPC08 & 5 & 0,52758 & Carregado & 3 & 3 \\
\hline LASDIX & 4 & 1 & Carregado & 4 & 4 \\
\hline
\end{tabular}

Os demais testes seguiram o mesmo raciocínio, apenas variando o estado das máquinas e o número de máquinas, observando o resultado do escalonamento ealizado pela DPWP. Para todos os testes, os resultados do modelo são idênticos aos observados no sistema real.

Assim, o modelo proposto foi considerado adequado e a fase de validação concluída.

\section{Fase IX - Solução do Modelo}

O modelo foi simulado utilizando-se o ambiente de simulação ALPHA/Sim da Alphatec Inc. O ALPHA/Sim é uma ferramenta de propósito geral para simulação de eventos discretos, que permite a construção de modelos de forma gráfica, utilizando a técnica de redes de Petri. $\mathrm{O}$ simulador permite que sejam usadas regras de tempo, decisões lógicas baseadas em probabilidade, prioridade ou através da avaliação de expressões, disciplinas de fila FIFO, LIFO ou ordenada através de um atributo definido pelo usuário.

O ALPHA/Sim fomece relatórios estatísticos para recursos, filas ou para atributos especificados pelo usuário, além disso, o simulador permite que sejam adicionados a ele, códigos extemos de funções criadas pelo usuário.

Algumas das possíveis aplicações desse simulador abrangem: projeto e análise de sistemas de manufatura, avaliação de políticas de gerenciamento de estoque, projeto e avaliação de sistemas de armamento e táticas militares, projeto e avaliação de hardwares e softwares de computadores, entre outros. (ALPHA/Sim, 1995) 
Com a simulação, foi possivel identificar falhas do modelo, por ocasião de sua construção e validação, e obter os dados para a análise do comportamento da DPWP.

\section{Fase $\mathrm{X}$ - Análise dos resultados obtidos}

A partir dos valores obtidos nas simulações, foram construídos os gráficos do balanceamento, comparando-os entre si, a fim de serem tiradas as conclusões sobre o modelo e suas variações. Para os testes estocásticos, foram utilizados intervalos de confiança para os dados obtidos.

Essa análise e mostrada em detalhes no Capítulo 5.

\subsection{Considerações Finais}

A avaliação de políticas de escalonamento de processos, assim como qualquer avaliação de um sistema, não é uma atividade trivial, sendo necessário que os responsáveis pela avaliação possuam conhecimentos suficientes na área de estudo para que a realizem da melhor forma possível. Como muitas vezes essas pessoas possuem pouco tempo para realizar a avaliação, a metodologia apresentada poderá servir como uma ferramenta de apoio à avaliação de políticas de escalonamento de processos, a fim de otimizar essa tarefa.

Como visto no exemplo apresentado, a metodologia é de fácil utilização, além de possibilitar ao usuário a geração de uma documentação detalhada sobre todas as etapas da avaliação, o que pode ajudar significativamente em exemplos futuros.

No Capítulo 5, são apresentados e comentados os resultados obtidos com à simulações dos modelos. 


\section{Capítulo 5}

\section{Resultados Obtidos na Aplicação da Metodologia à DPWP}

\subsection{Considerações Iniciais}

Para a avaliação da DPWP, foram construídos 3 modelos básicos, onde o primeiro representa a DPWP original e o restante são modelos da DPWP modificada, segundo observações realizadas ao longo dos experimentos.

Com a avaliação, foram identificadas pelo menos duas falhas básicas na DPWP:

- Ao realizar o escalonamento, a política DPWP utiliza as informações dos estados de cada máquina no momento do escalonamento. Ocorre que para um número grande de processos a serem escalonados, o balanceamento final obtido pode ser ruim em razão da nova carga representada pelos processos escalonados. Para corrigir essa falha, é proposta uma alteração na política onde a cada $\mathbf{N}$ processos escalonados, o estado das máquinas é novamente verificado. Isso faz com que a divisão dos processos seja mais equilibrada procurando um melhor balanceamento. $\mathbf{O}$ valor $\mathbf{N}$ utilizado é igual ao número de máquinas envolvidas no processo de escalonamento.

- A política DPWP considera que todos os processos são idênticos, o que, na realidade, dificilmente ocorre. Para verificar qual o impacto no balanceamento, quando são submetidos processos diferentes à DPWP, é realizada uma pequena alteração no modelo para que ao final de cada escalonamento seja possível saber quantos processos leves, médios e pesados são alocados, sem que para isso, a DPWP seja alterada. A denominação de processos leves, processos médios e processos pesados, é usada para diferenciar os tipos de processos considerados. Para efeito de testes é considerado: 
(a) os processos são classificados em leves, médios e pesados;

(b) a geração desses processos é probabilística sendo gerados $\mathbf{T}(\mathbf{T}=$ no. de processos) números aleatórios entre 0 e 1 e se o número for $\leq 0,4$ é considerado um processo leve, se estiver entre 0,4 e 0,7 o processo é considerado moderado e se for $\geq 0,7$ o processo é considerado pesado, com isso têm-se uma distribuição de $40 \%$ de processos leves, $30 \%$ de processos moderados e $30 \%$ de processos pesados.

(c) Após a DPWP ter realizado o escalonamento, a informação da quantidade de processos leves, médios e pesados alocados para cada máquina, é utilizada para calcular o balanceamento de carga.

As simulações para a DPWP original e suas alterações são realizadas de três formas distintas:

- A primeira é determinística, isto é, os valores para a carga inicial das máquina e para o número de processos a serem escalonados são conhecidos previamente. Esse teste é bastante básico, servindo como reforço à validação do modelo mas, mesmo sendo básico pode, potencialmente, identificar detalhes relevantes do comportamento da politica. Em termos práticos, o mesmo teste poderia ser realizado sem o uso do modelo definido neste trabalho, bastando a implementação de um algoritmo simples que descreva a política. Entretanto, nesta dissertação o teste é conduzido a partir do modelo elaborado.

Desta forma, na abordagem determinística tem-se que:

Objetivos: reforçar a validação do modelo e evidenciar o comportamento da política em situações previamente definidas, dando uma visão focada em uma situação provocada de forma precisa.

Plataforma: consideram-se três máquinas seguindo duas combinações de potências para as máquinas sendo uma com um ambiente homogêneo onde as potências computacionais são iguais (potências igual a 1) e outra com um ambiente heterogêneo onde as potências das máquinas são diferentes (no caso, potência igual a 1 - menos potente; igual a 0,79206 e igual a 0,52758 - mais potente).

Cargas: conforme definido por Araújo em Araújo 1999 as máquinas podem estar em três estados: ocioso (O), moderado (M) ou carregado (C). As combinações de 
estados usados para os testes cobre todos os casos principais, isto é: ocioso/ocioso/ocioso (OOO), moderado/moderado/moderado (MMM), carregado/carregado/carregado (CCC), ocioso/moderado/carregado (OMC) e carregado/carregado/ocioso (CCO).

- A segunda é probabilística, onde os valores para a quantidade de processos e para a carga inicial, são obtidos durante a simulação, obedecendo a uma distribuição exponencial. Novamente, esse teste é ainda bastante básico, servindo para reforçar a validação do modelo e para evidenciar um pouco mais as características do comportamento da política em estudo. $\mathrm{O}$ modelo proposto nesta dissertação é utilizado e os resultados obtidos complementam as observações levantadas no caso determinístico. Não há uma razão especial para a distribuição exponencial ter sido adotada, simplesmente procurou-se uma forma de gerar os dados através de uma distribuição que permitisse observar o comportamento da política de forma não determinística.

Para a abordagem probabilística tem-se que:

Objetivos: reforçar ainda mais a validação do modelo e complementar o que foi estudado no caso determinístico, não controlando a quantidade de processos gerados por cada aplicação e nem a carga inicial de cada máquina.

Plataforma: da mesma forma que no caso determinístico, consideram-se duas combinações de potências para as três máquinas sendo uma com um ambiente homogêneo (potências computacionais iguais) e outra com um ambiente heterogêneo onde as potências são diferentes (no caso $1,0,79206$ e 0,52758).

Cargas: a carga inicial de cada máquina é gerada aleatoriamente durante a simulação, obedecendo uma distribuição exponencial de média 2. A quantidade de processos a serem escalonados são obtidos através de uma distribuição exponencial de média 10 . Os valores adotados são meramente ilustrativos e se baseiam nas seguintes considerações:

- Média de 10 processos por aplicação: em geral as aplicações paralelas implementadas em PVM, manipulam um número variado de processos. Uma média de 10 processos privilegia aplicações de porte médio, o que é um fato realista nos ambientes de desenvolvimento. 
- Carga inicial média de 2 processos: indica um ambiente levemente carregado, em média.

- A terceira é estocástica e o valor para o número de processos é obtido durante a simulação, partindo-se de uma carga inicial do sistema igual a zero. Cada processo escalonado possui um tempo de permanência no sistema, simulando sua carga, o que influencia o comportamento das máquinas para os próximos escalonamentos.

Desta forma, na abordagem estocástica tem-se que:

Objetivos: procurar retratar uma situação mais realística, onde cada escalonamento influencia os próximos, permitindo uma análise do comportamento da política como um todo. Para os valores obtidos, foi calculado o intervalo de confiança de $95 \%$.

Plataforma: da mesma forma que os demais casos (determinístico e probabilístico), consideram-se duas combinações de potências para as máquinas sendo uma com um ambiente homogêneo (potências computacionais iguais) e outra com um ambiente heterogêneo onde as potências são diferentes (no caso 1, $0,79206$ e 0,52758$)$.

Cargas: a carga inicial de cada máquina é igual a zero, mas conforme são realizados os escalonamentos, os processos alocados em cada máquina passam a ser considerados. Cada processo possui um tempo de permanência no sistema, simulando a sua carga.

Os valores de potências utilizados consideram os dados obtidos a partir da plataforma real utilizada no Laboratório de Sistemas Distribuídos e Programação Concorrente e indicam que a máquina com potência 1 é a de menor potência, tomada como padrão. Assim o menor valor indica a maior potência.

Os resultados obtidos são mostrados e analisados detalhadamente no próximos itens.

Nas próxima seções são apresentados os resultados obtidos com a aplicação da metodologia definida no Capítulo 4 à DPWP. O balanceamento alcançado é determinado utilizando-se a métrica definida na seção 4.5 deste trabalho. 


\subsection{Ensaio 1}

Para o primeiro ensaio, é utilizado o modelo da DPWP original, e os resultados apresentados dizem respeito ao balanceamento obtido considerando 5 combinações de estados para a abordagem determinística e 100 aplicações (por aplicação entende-se cada geração nova de um número de processos para ser escalonado) para os demais casos.

\section{Determinístico}

Os resultados obtidos para o caso determinístico são vistos nos Gráficos 1 (para plataformas homogêneas)e 2 (para plataformas heterogêneas):

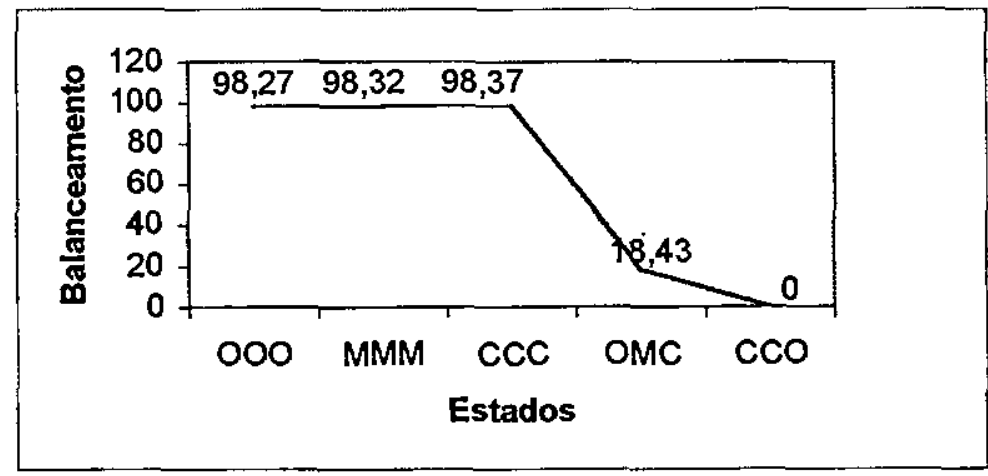

\section{Gráfico 1 - DPWP Original Determinística c/ Plataforma Homogênea}

Pode-se perceber pelo Gráfico 1 que para os casos em que os estados da máquina são iguais, o balanceamento obtido é muito bom, mas quando os estados variaram, ele sofre uma queda até atingir o valor zero. Esse valor zero, indicando desbalanceamento total, ocorre porque a DPWP atribui toda a carga à maquina ociosa, ignorando as maquinas carregadas, caso "CCO". No caso "OMC" fato semelhante ocorre, porém considerando as máquinas ociosas e moderadas.

Este ensaio é bastante simples, mas já mostra uma falha na política, devido à amostragem da carga ser unicamente efetuada no início do escalonamento, não considerando a dinâmica do processo como um todo. 


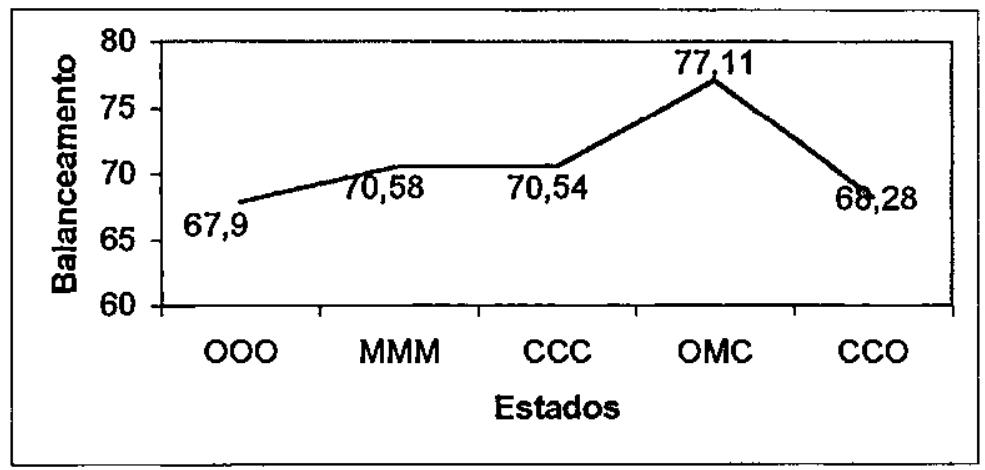

\section{Gráfico 2 - DPWP Original Determinística c/ Plataforma Heterogênea}

O Gráfico 2 mostra que quando plataformas heterogêneas são consideradas, um balanceamento com valores inferiores aos obtidos no Gráfico 1 para os casos (OOO), (MMM) e (CCC) e valores melhores para os demais casos. Isto ocorre porque ao considerar plataformas heterogêneas, apesar da DPWP levar esse fato em consideração, a estratégia de amostragem da carga apenas no início do processo de escalonamento é suficiente para produzir um balanceamento ruim em certos casos, pois de forma análoga ao caso homogêneo, o estado dos processadores (ou máquina) variam imediatamente após o escalonamento dos processos e isto não é considerado na política. Por outro lado, a ponderação da carga eliminou o caso de balanceamento nulo (apesar da situação continuar, potencialmente, possível de ocorrer).

O balanceamento obtido não é ideal, estando longe de $100 \%$, mas é mais realista do que o mostrado no Gráfico 1.

\section{Probabilístico}

Os Gráficos 3 e 4 mostram os valores para o balanceamento de carga realizado pela DPWP: 


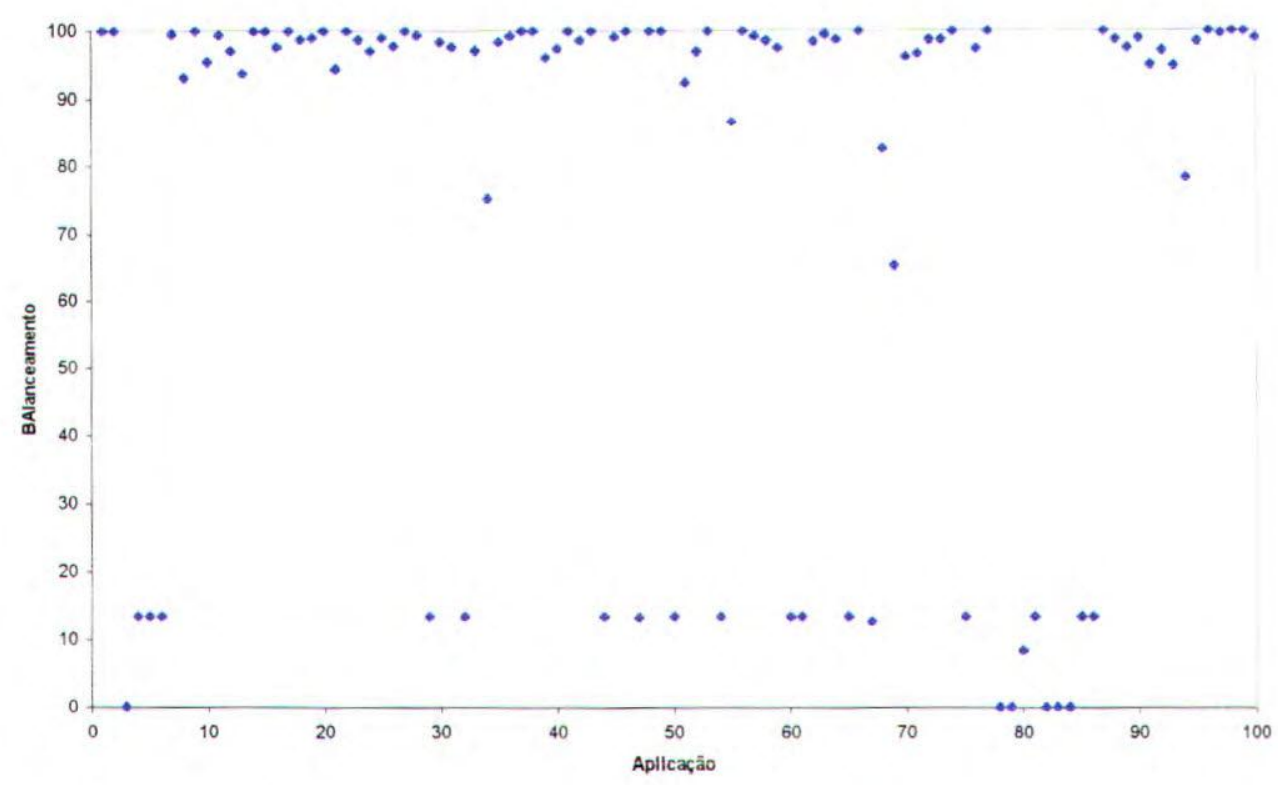

Gráfico 3 - DPWP Original Probabilística c/ Plataforma Homogênea

No Gráfico 3 cada ponto indica o valor do balanceamento observado após uma aplicação ser submetida ao sistema.

Pode-se observar que os resultados observados possuem um comportamento semelhante ao visto no Gráfico 1, onde o balanceamento permanece muito bom para alguns casos e quando há diferença entre o estado das máquinas o balanceamento tende a cair.

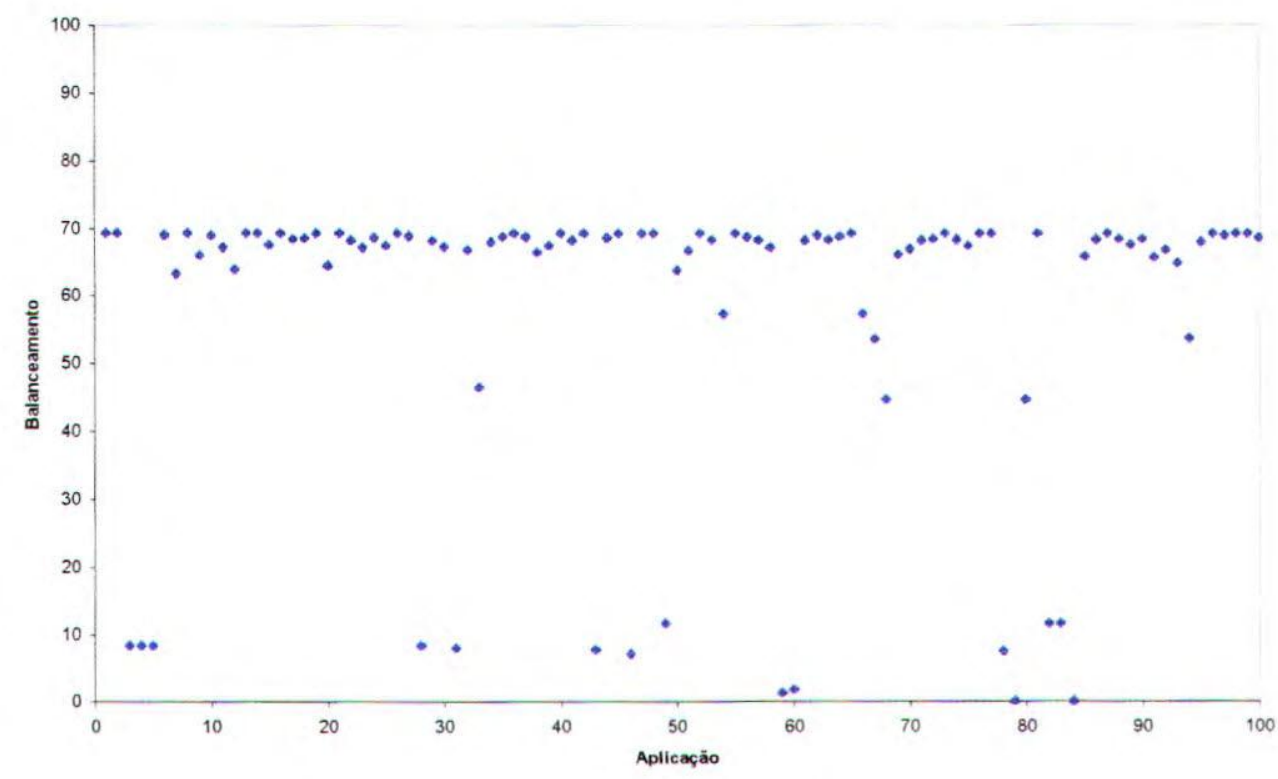

Gráfico 4 - DPWP Original Probabilística c/ Plataforma Heterogênea 
De forma análoga a anterior, quando plataformas heterogêneas são consideradas, o balanceamento permanece regular, mas com algumas quedas, provocadas pelo valor da carga inicial das máquinas.

Observa-se ainda que enquanto no caso de plataformas homogêneas existe uma concentração próxima a $100 \%$ de balanceamento, na plataforma heterogênea esta concentração encontra-se em torno de $70 \%$. Isso mostra a maior dificuldade em obter-se balanceamento de carga em plataformas heterogêneas.

Nos 2 experimentos que geraram os Gráficos 3 e 4, cabem observações semelhantes às efetivadas por os casos dos Gráficos 1 e 2, onde a atuação da DPWP determina situações onde o balanceamento obtido no sistema é pobre.

\section{Estocástico}

Os gráficos de 5 a 14 referem-se a 10 execuções do modelo da DPWP original. As 5 primeiras consideram máquinas homogêneas e as demais, máquinas heterogêneas. Cada uma das cinco execuções considera uma semente diferente para a geração de números aleatórios.

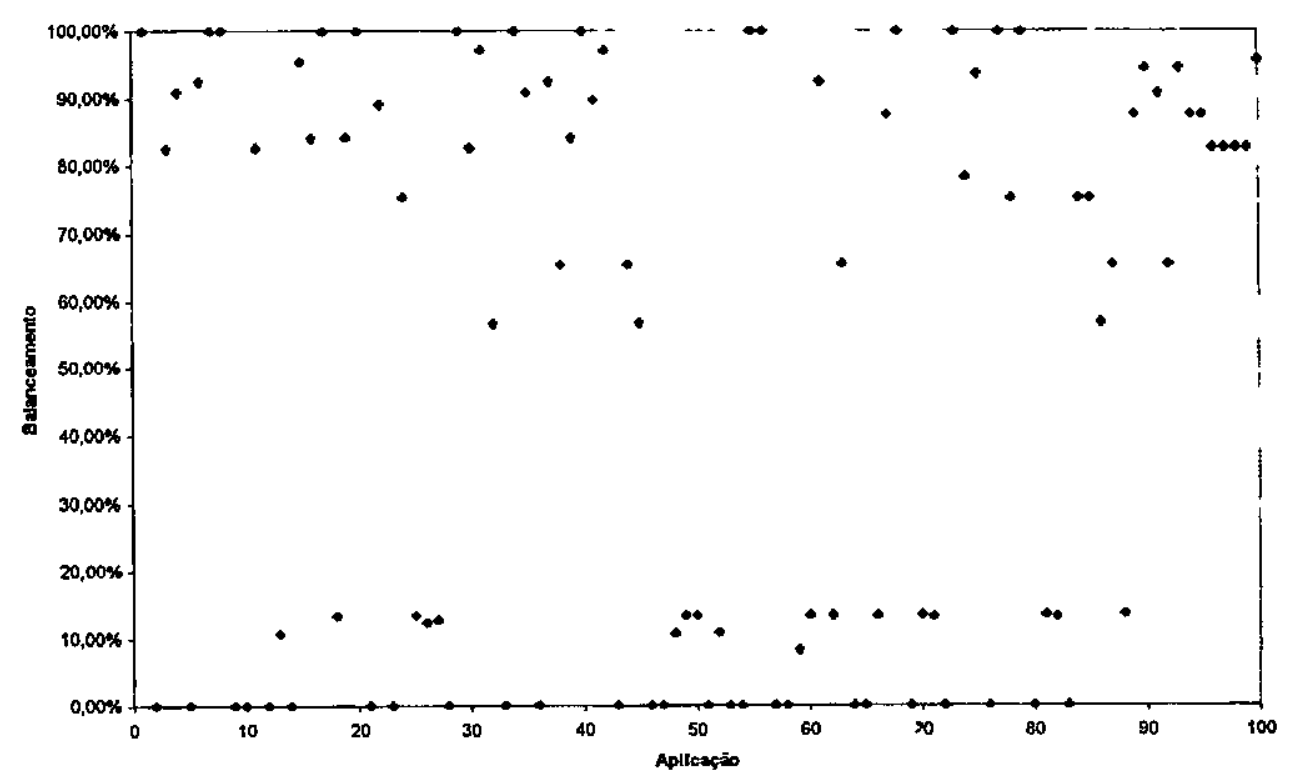

Gráfico 5 -DPWP Original Estocástica c/ Plataforma Homogênea (1) 


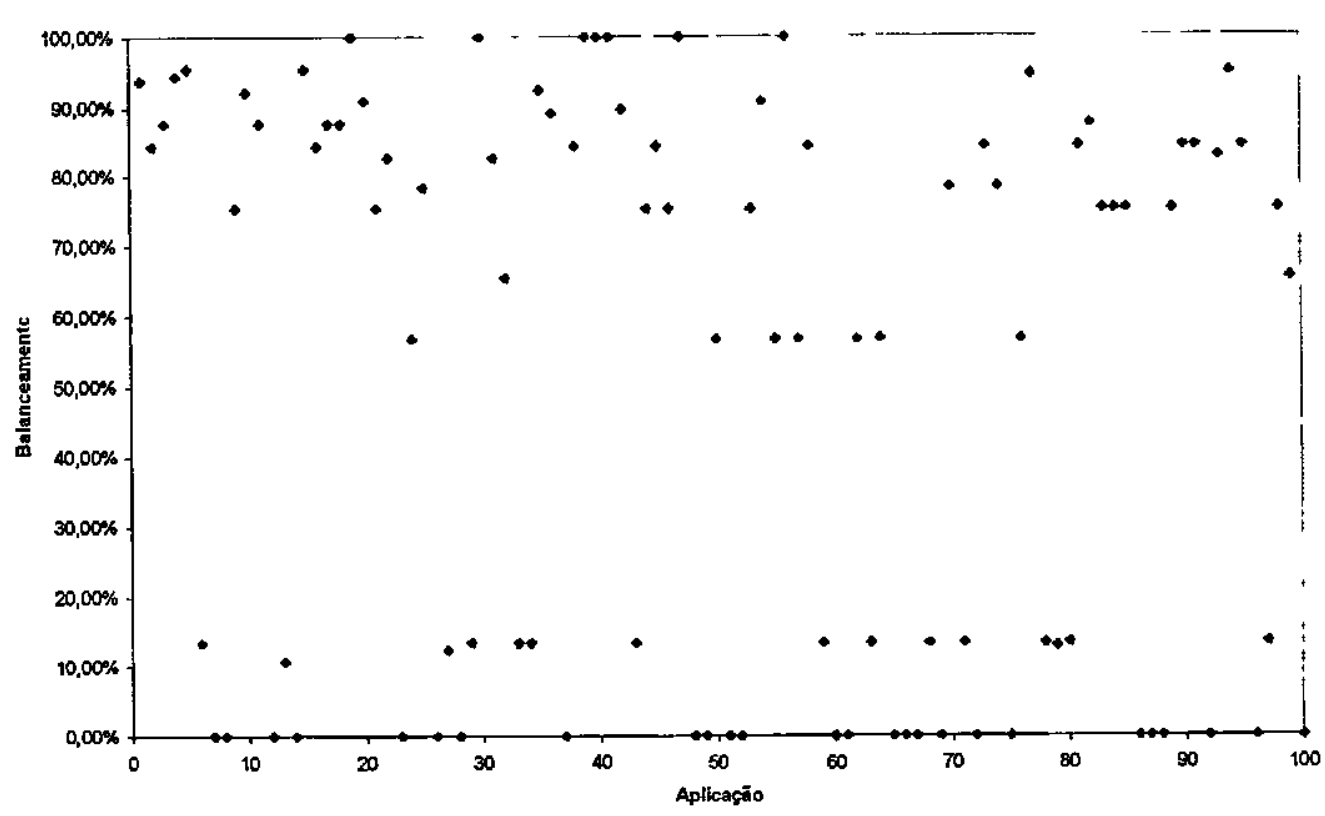

Gráfico 6 -DPWP Original Estocástica c/ Plataforma Homogênea (2)

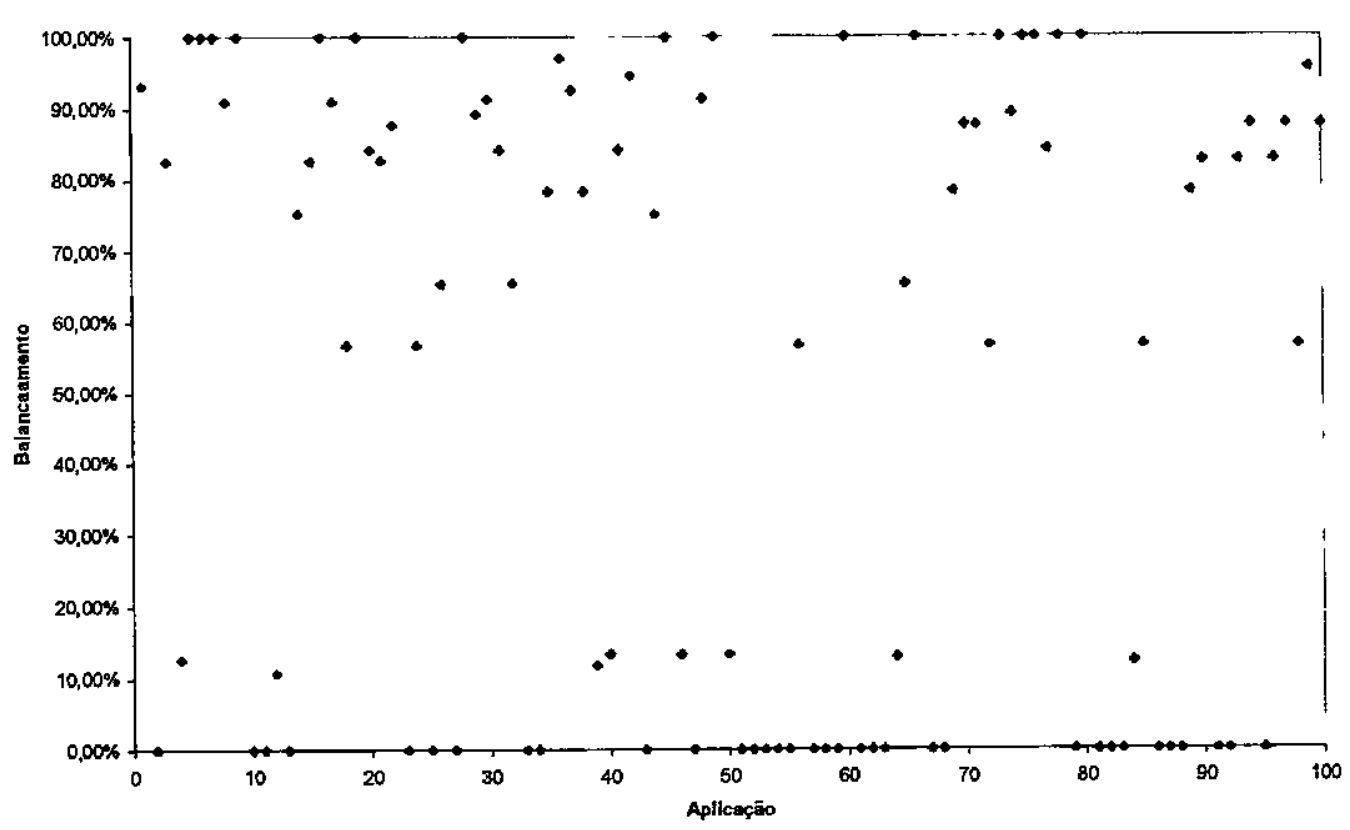

Gráfico 7 -DPWP Original Estocástica c/ Plataforma Homogênea (3) 


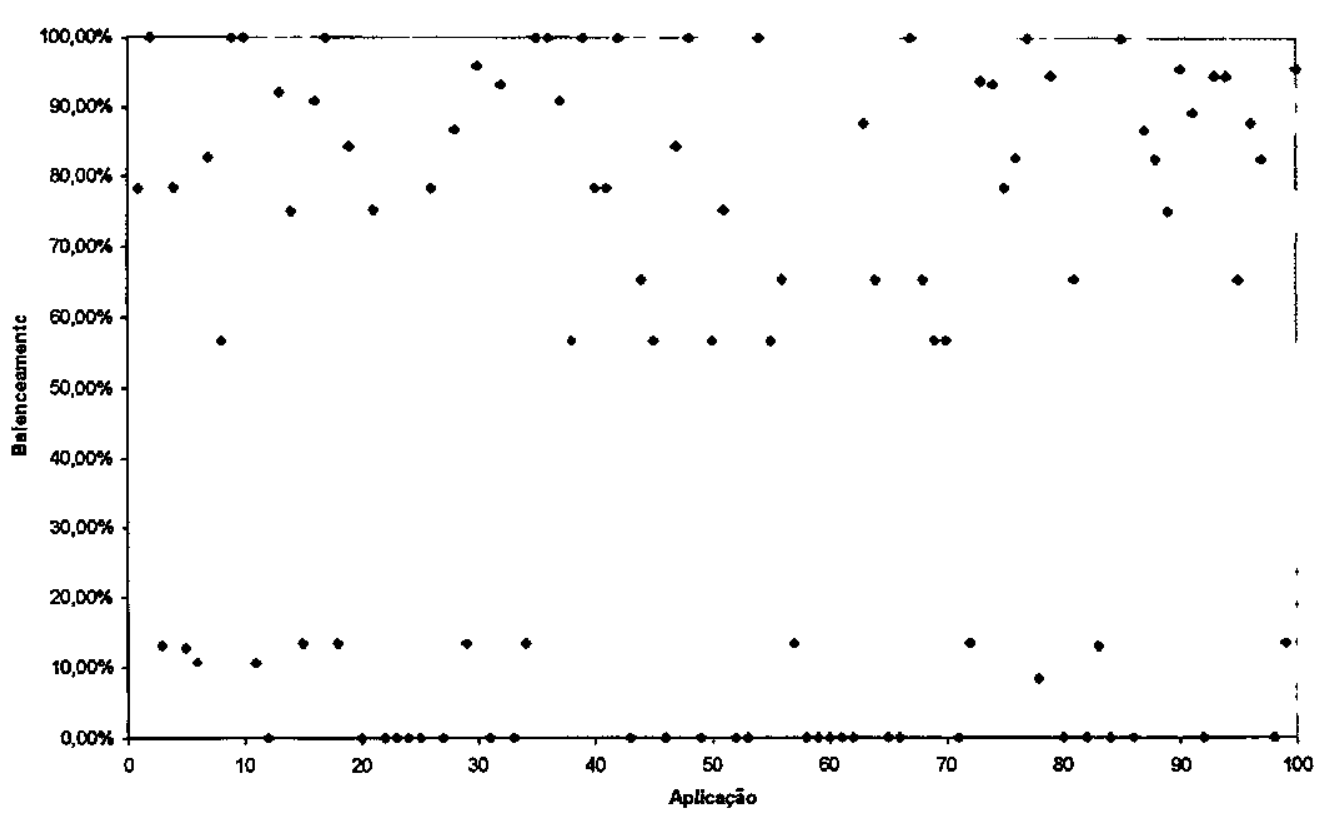

Gráfico 8 -DPWP Original Estocástica c/ Plataforma Homogênea (4)

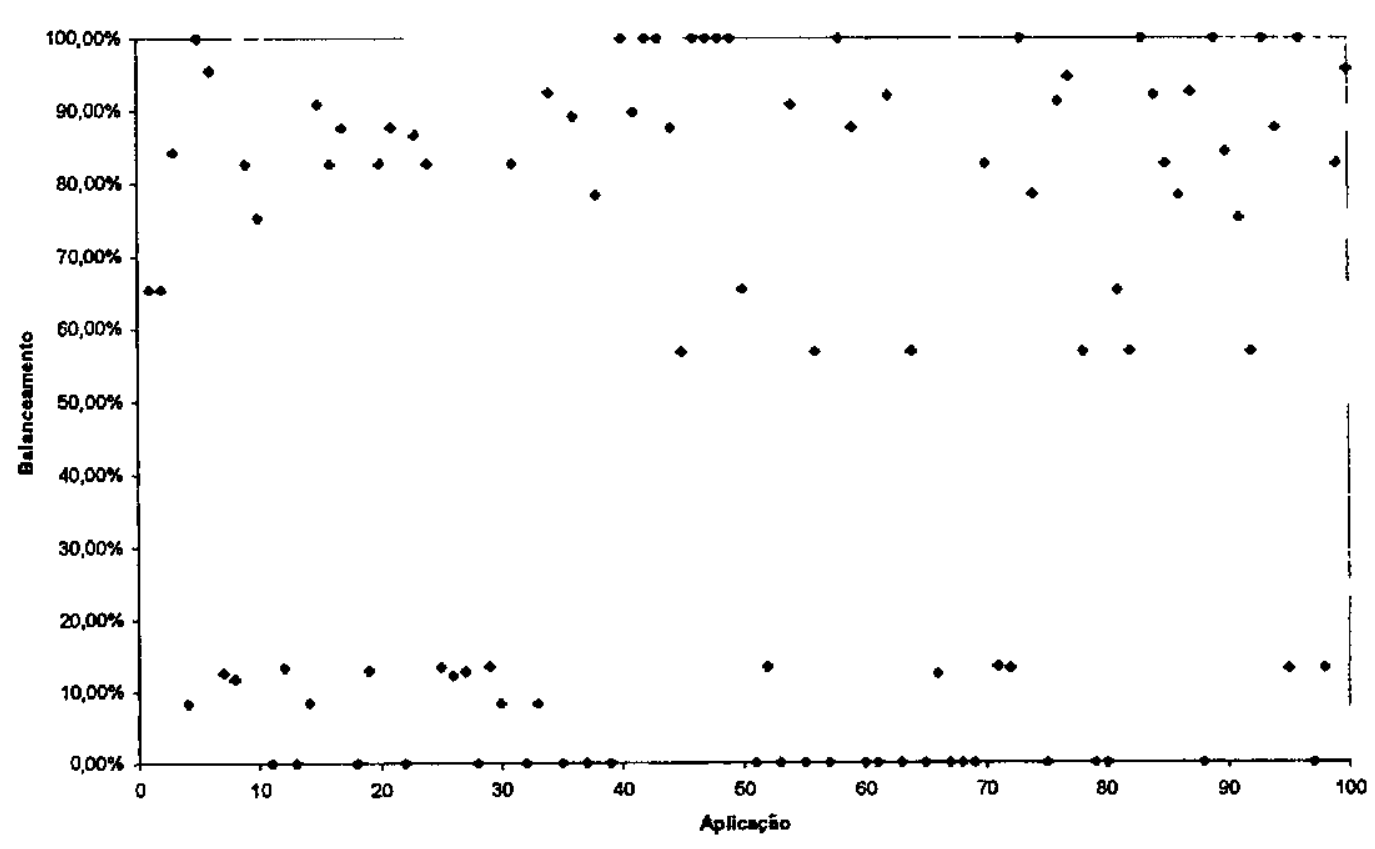

Gráfico 9 -DPWP Original Estocástica c/ Plataforma Homogênea (5)

Através dos Gráficos de 5 a 9, observa-se o comportamento não estável da DPWP em situações de grande variabilidade de carga. Os processos escalonados interferem nas cargas locais de máquina e a DPWP amostra a carga somente no início da alocação, o que faz com que o balanceamento seja bastante variado, tendo valores bons e ruins. 
A Tabela 4 mostra os valores médios de balanceamento obtidos em cada uma das execuções da simulação do modelo, a média geral e o intervalo de confiança de $95 \%$.

Tabela 4 - Intervalo de Confiança p/ DPWP Original c/ Plataforma Homogênea

\begin{tabular}{|c|c|}
\hline Execuções & Balanceamento \\
\hline 1 & $50,82 \%$ \\
\hline 2 & $50,55 \%$ \\
\hline 3 & $50,75 \%$ \\
\hline 4 & $50,85 \%$ \\
\hline 5 & $50,64 \%$ \\
\hline MÉDIA & $50,72 \%$ \\
\hline INTERV. CONF. & $50,72 \% \pm 0,35 \%$ \\
\hline
\end{tabular}

Os gráficos de 10 a 14 são referentes às simulações realizadas considerando máquinas heterogêneas e cinco sementes distintas.

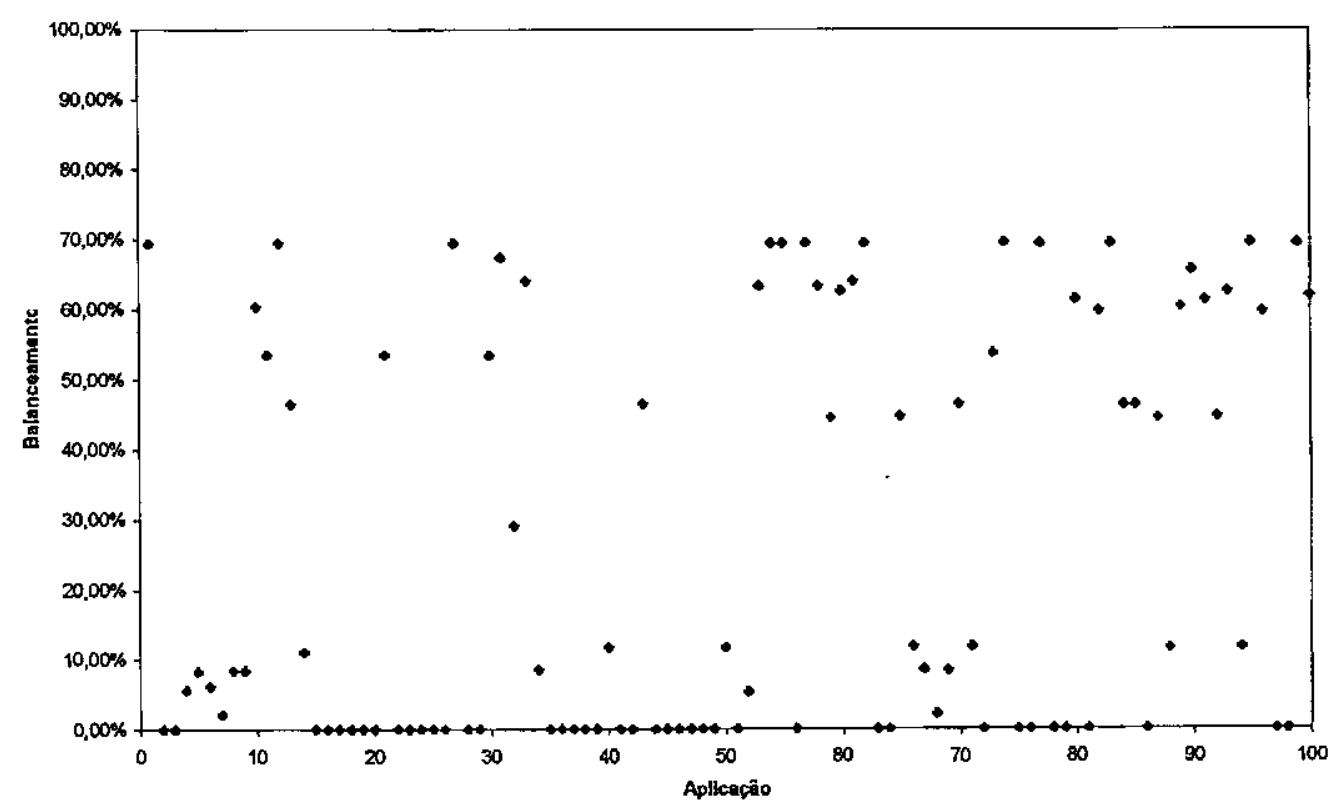

Gráfico 10 -DPWP Original Estocástica c/ Plataforma Heterogênea (1) 


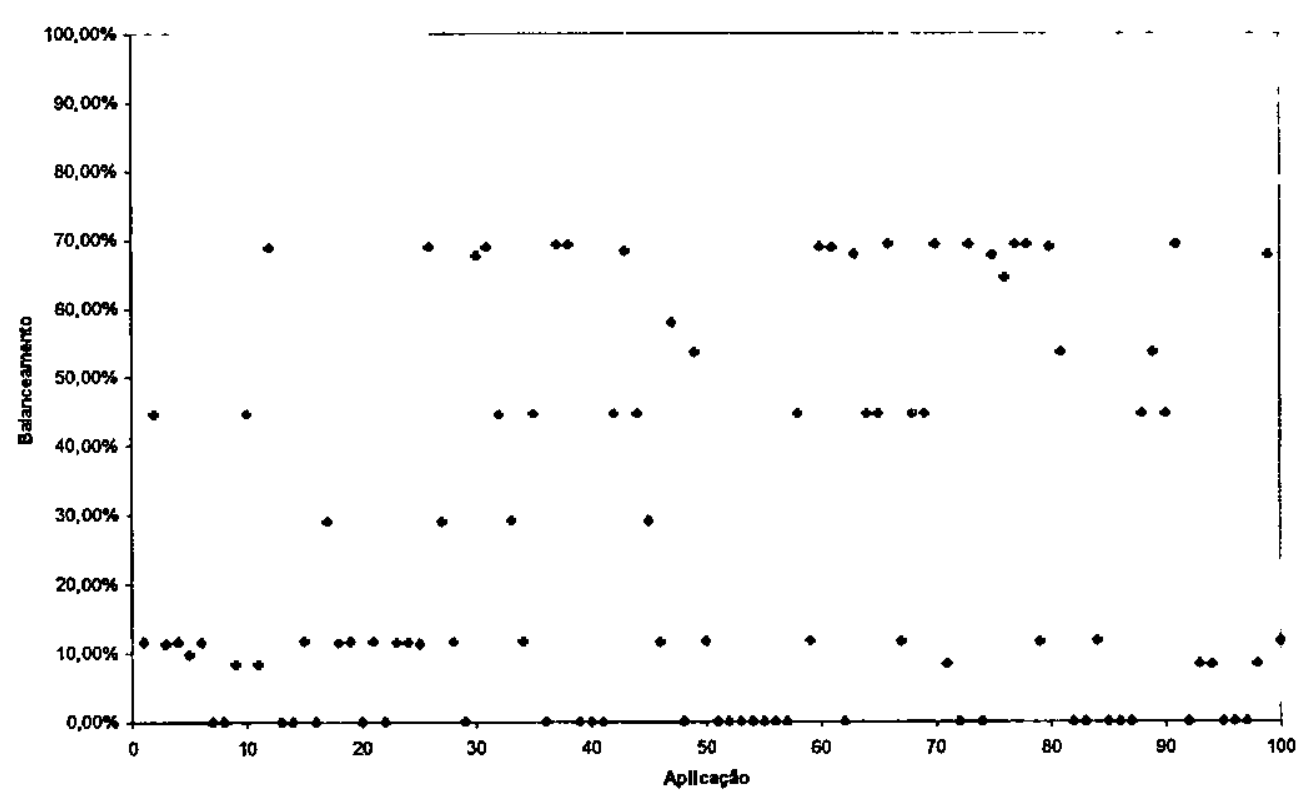

Gráfico 11 - Original Estocástica c/ Plataforma Heterogênea (2)

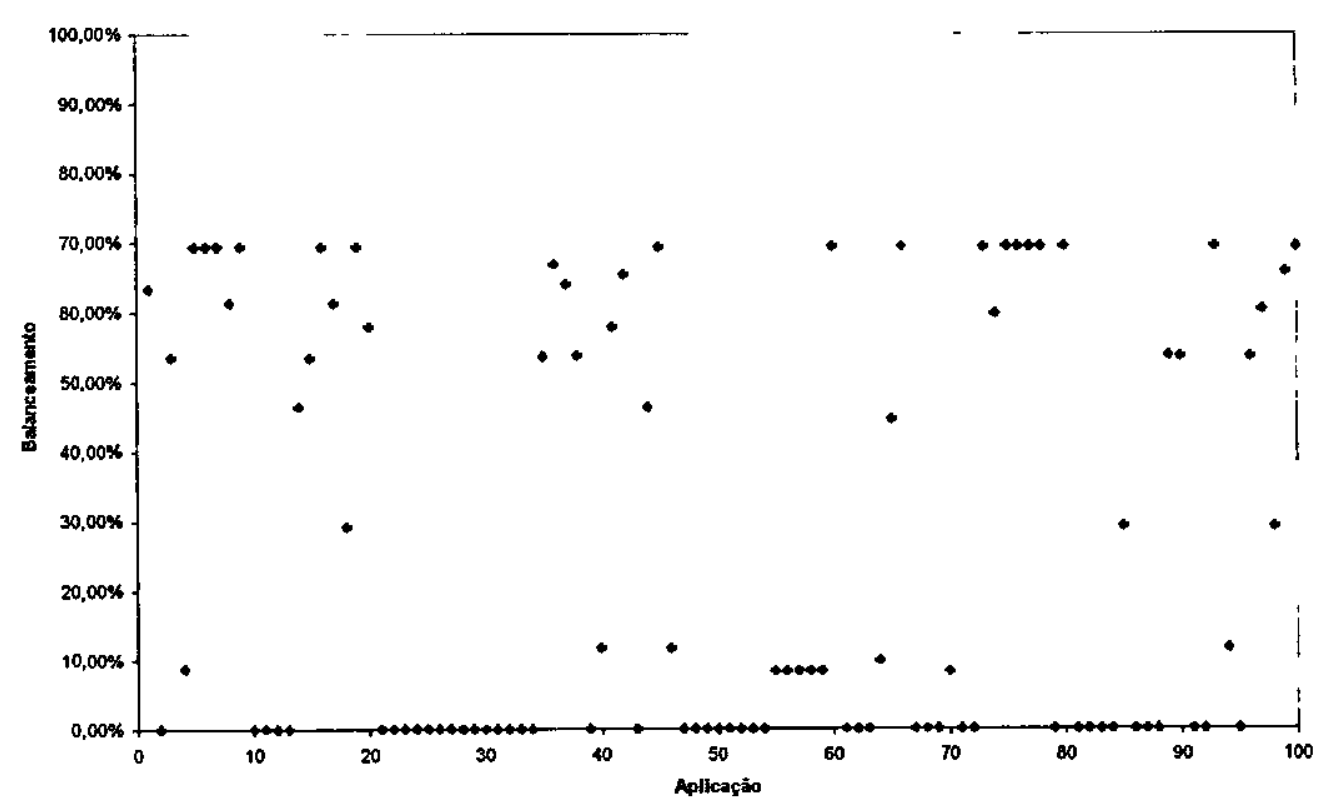

Gráfico 12 - Original Estocástica c/ Plataforma Heterogênea (3) 


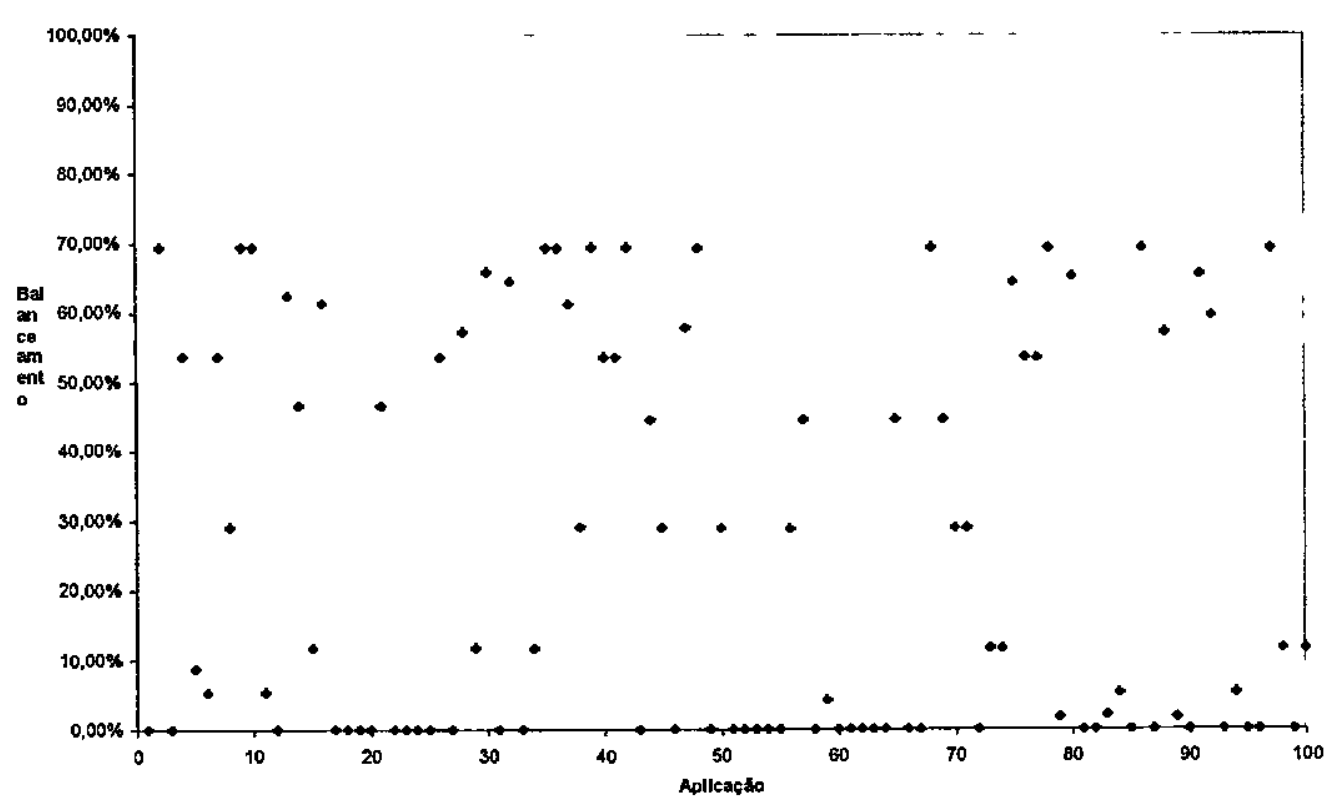

Gráfico 13 - Original Estocástica c/ Plataforma Heterogênea (4)

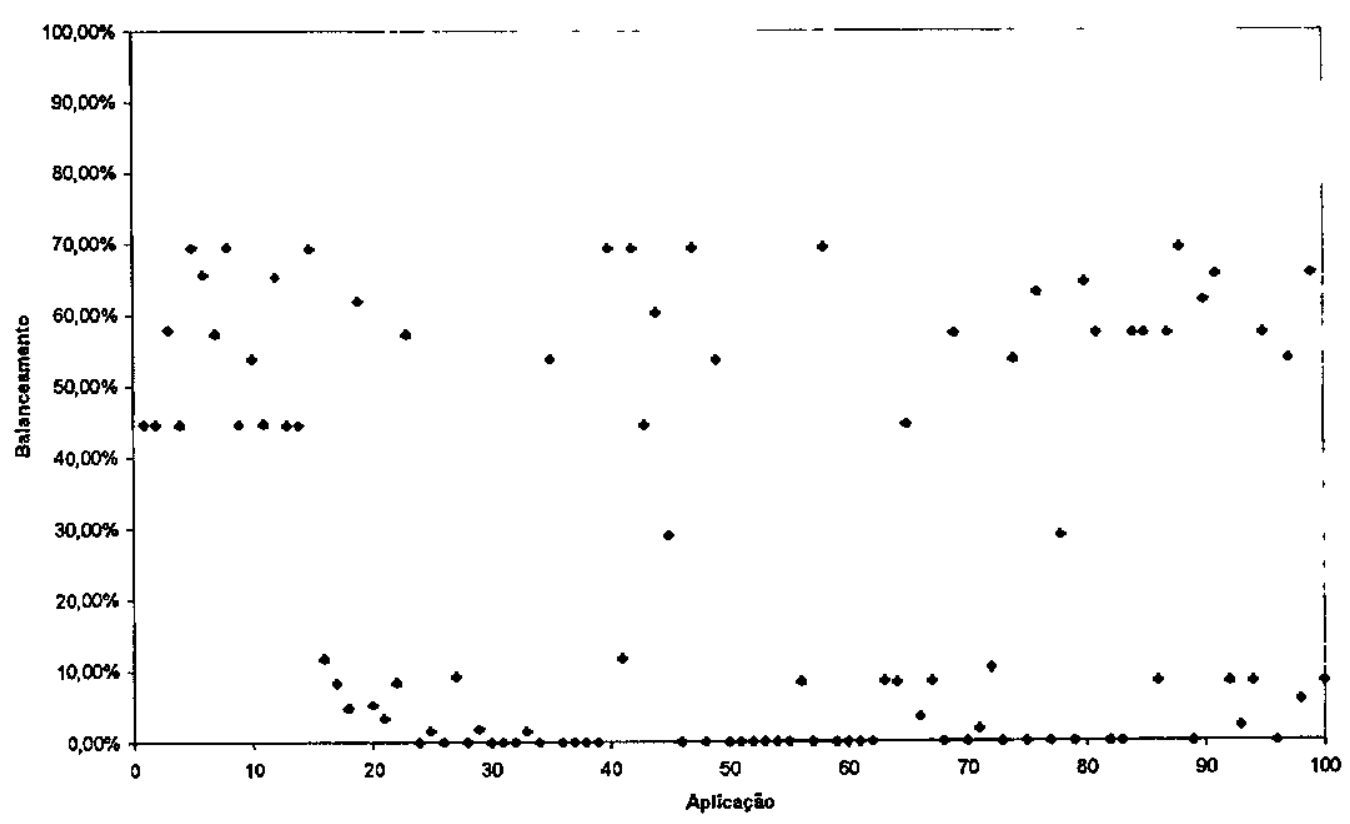

Gráfico 14 - Original Estocástica c/ Plataforma Heterogênea (5)

O mesmo comportamento observado nos gráficos anteriores se repete nos Gráficos de 10 a 14 , com valores médios de balanceamento ainda piores. 
A Tabela 5 apresenta os valores médios dos balanceamentos realizados e o intervalo de confiança.

Tabela 5 - Intervalo de Confiança p/ DPWP Original c/ Plataforma Heterogênea

\begin{tabular}{|c|c|}
\hline Execuções & Balanceamento \\
\hline 1 & $25,76 \%$ \\
\hline 2 & $25,80 \%$ \\
\hline 3 & $25,66 \%$ \\
\hline 4 & $25,47 \%$ \\
\hline 5 & $25,31 \%$ \\
\hline MÉDIA & $25,60 \%$ \\
\hline INTERV. CONF. & $25,60 \% \pm 0,57 \%$ \\
\hline
\end{tabular}

Através do ensaio 1, pode-se observar a utilidade da metodologia para avaliação de políticas de escalonamento de processos proposta neste trabalho. Aplicando-se essa metodologia à DPWP observou-se que essa política não apresenta bons resultados quando a aplicação possui vários processos e o sistema inicial possui uma carga desbalanceada.

O ensaio 2 apresenta uma solução para o problema identificado no ensaio 1. Assim, o ensaio 2 exemplifica mais uma utilização da metodologia proposta. Além de analisar políticas já implementadas (como no caso do ensaio 1) pode-se analisar políticas ou características ainda não implementadas (como no caso do ensaio 2).

\subsection{Ensaio 2}

Para o ensaio 2, é utilizado um modelo da DPWP alterada, onde procura-se resolver o problema do escalonamento que leva em conta apenas a configuração das cargas quando uma aplicação chega ao sistema. Para tanto, o modelo original foi alterado de tal forma a permitir que de $\mathbf{N}$ em $\mathbf{N}$ alocações $(\mathbf{N}=$ no. de processadores), a carga das máquinas seja verificada a fim de que, baseado nessa nova configuração, os processos restantes possam ser alocados de forma mais adequada. É importante observar que alterações na política com o intuito de deixá-la mais eficiente, podem aumentar a sua complexidade e com isso diminuir o desempenho obtido (mas isso não esta sendo aferido nestes ensaios). 
A simulação determinística do modelo já mostra que a alteração proposta consegue melhorar o balanceamento de carga realizado. Quando as máquinas envolvidas são iguais, o balanceamento realizado é melhor, enquanto que com máquinas diferentes, ele sempre tende a ficar inferior. Isso é bastante plausível já que no primeiro caso, são desprezados os problemas de heterogeneidade.

Comparando-se os resultados dos Gráficos 15 e 16 com os da política DPWP original, observa-se uma melhora considerável no balanceamento para plataformas homogêneas e uma pequena melhora para plataformas heterogêneas.

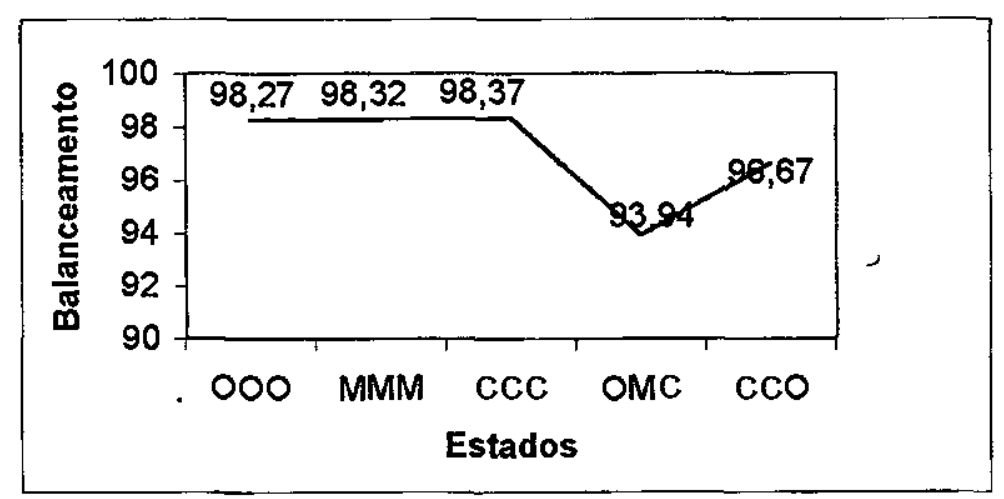

Gráfico 15 - Alteração 1 Determinística c/ Plataforma Homogênea

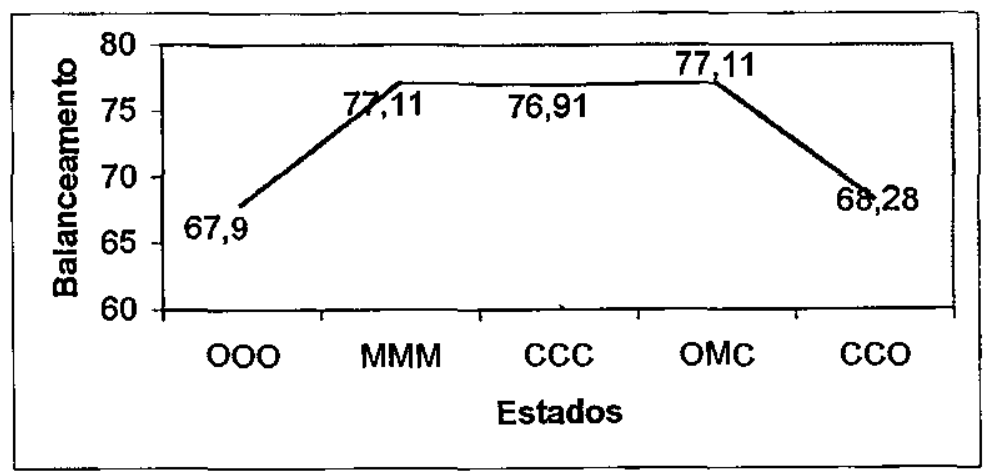

Gráfico 16 - Alteração 1 Deterministica c/ Plataforma Heterogênea

Esses resultados simples, obtidos a partir de alterações também simples, já evidenciam que a utilização do procedimento proposto nesta dissertação para avaliação de políticas é atrativo pois indica um caminho para a obtenção de uma política melhor. 
Probabilístico

Para o caso probabilístico, pode-se perceber que com a alteração, foram cortados os pontos que tendiam a zero e o balanceamento de um modo geral ficou mais uniforme, apesar de ainda se observar um comportamento bastante variável.

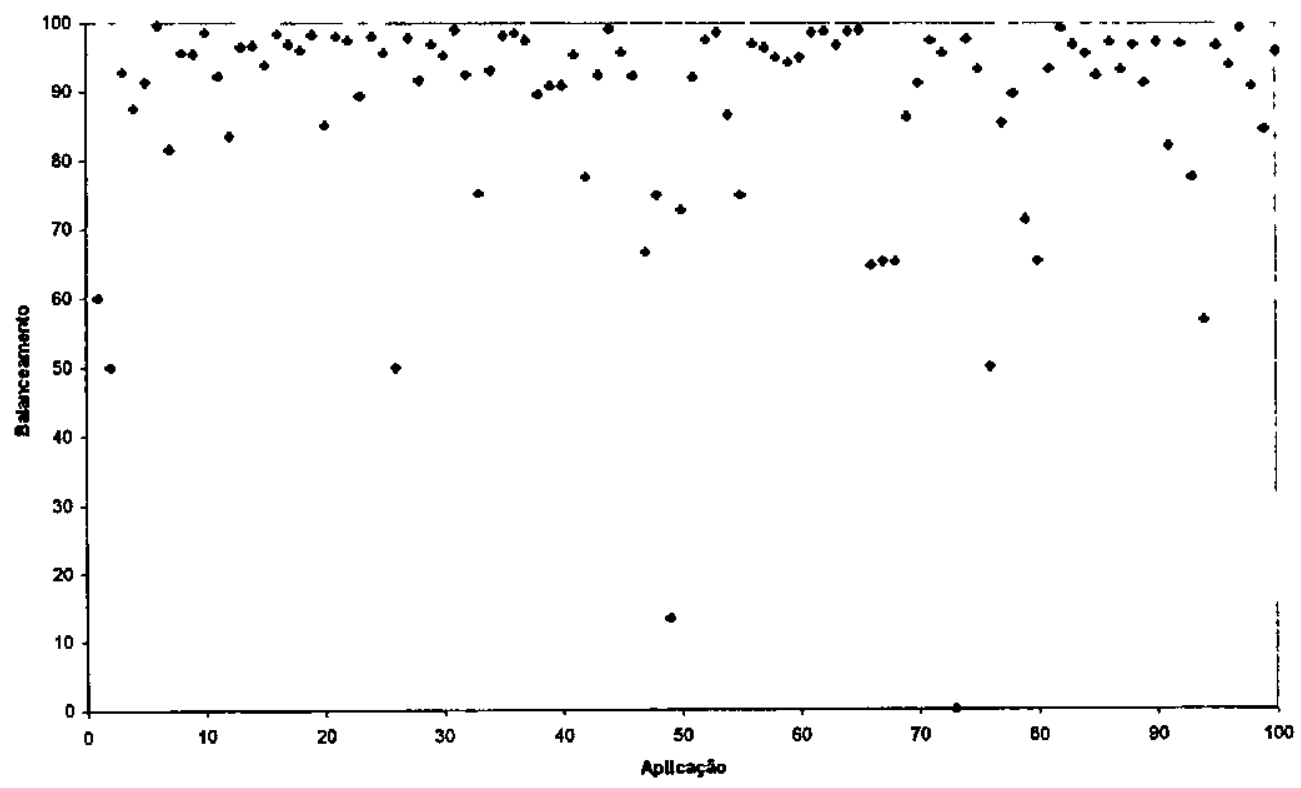

Gráfico 17 - Alteração 1 Probabilística c/ Plataforma Homogênea

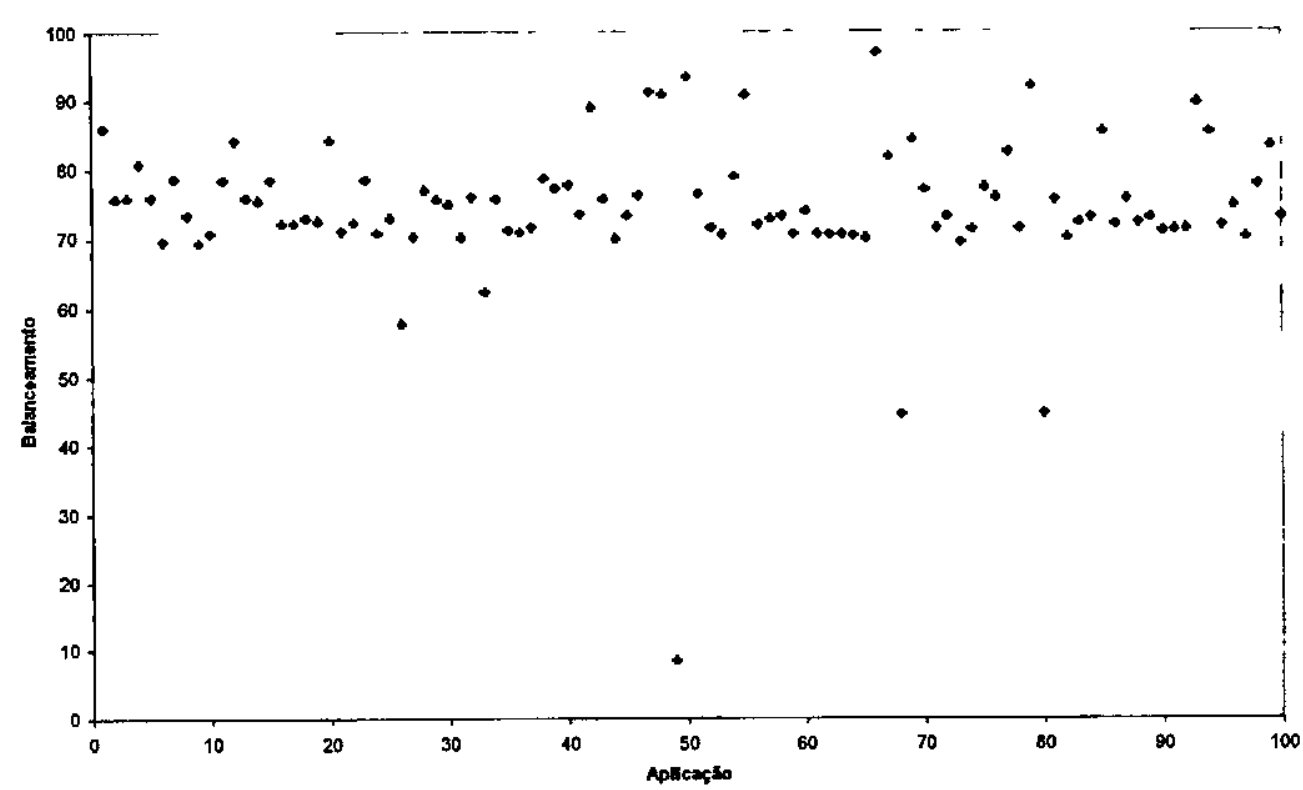

Gráfico 18 - Alteração 1 Probabilística c/ Plataforma Heterogênea 
Particularmente no Gráfico 17, o balanceamento fica ainda melhor do que o obtido no Gráfico 18, porque, como a carga é verificada várias vezes durante o escalonamento, as máquinas com maior potência tendem a receber mais processos, piorando, assim, o balanceamento como um todo.

Estes resultados reforçam a observação apresentada nos casos anteriores (Gráficos 7 e 8) e vêm ao encontro da utilidade da metodologia proposta neste trabalho.

\section{Estocástico}

No caso estocástico, observa-se que os valores de balanceamento tendem a ficar menos esparsos em relação a política original, já que os valores das cargas das máquinas são verificados mais de uma vez durante o escalonamento, fazendo com que a alocação dos processos seja melhorada. Os Gráficos de 19 a 28 foram gerados a partir dos dados obtidos nas simulações.

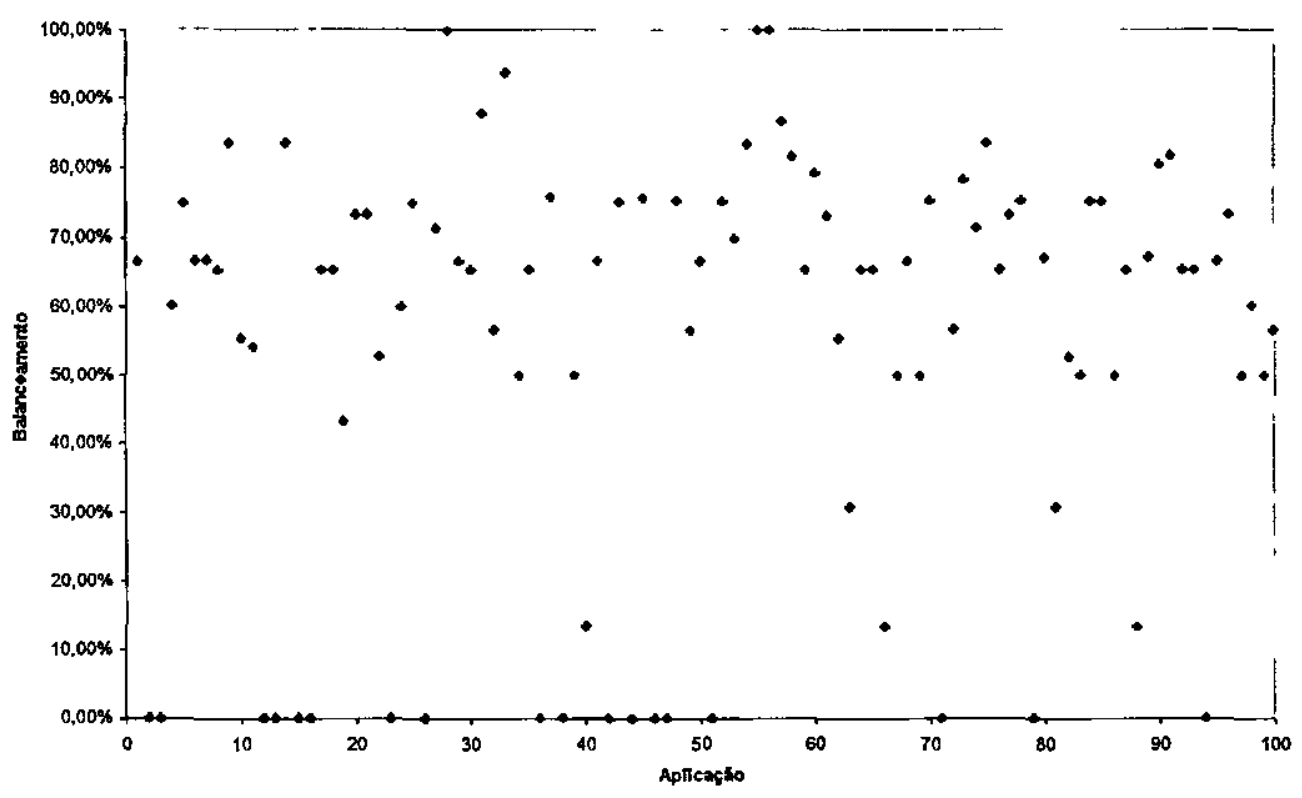

Gráfico 19 - Alteração 1 Estocástica c/ Plataforma Homogênea (1) 


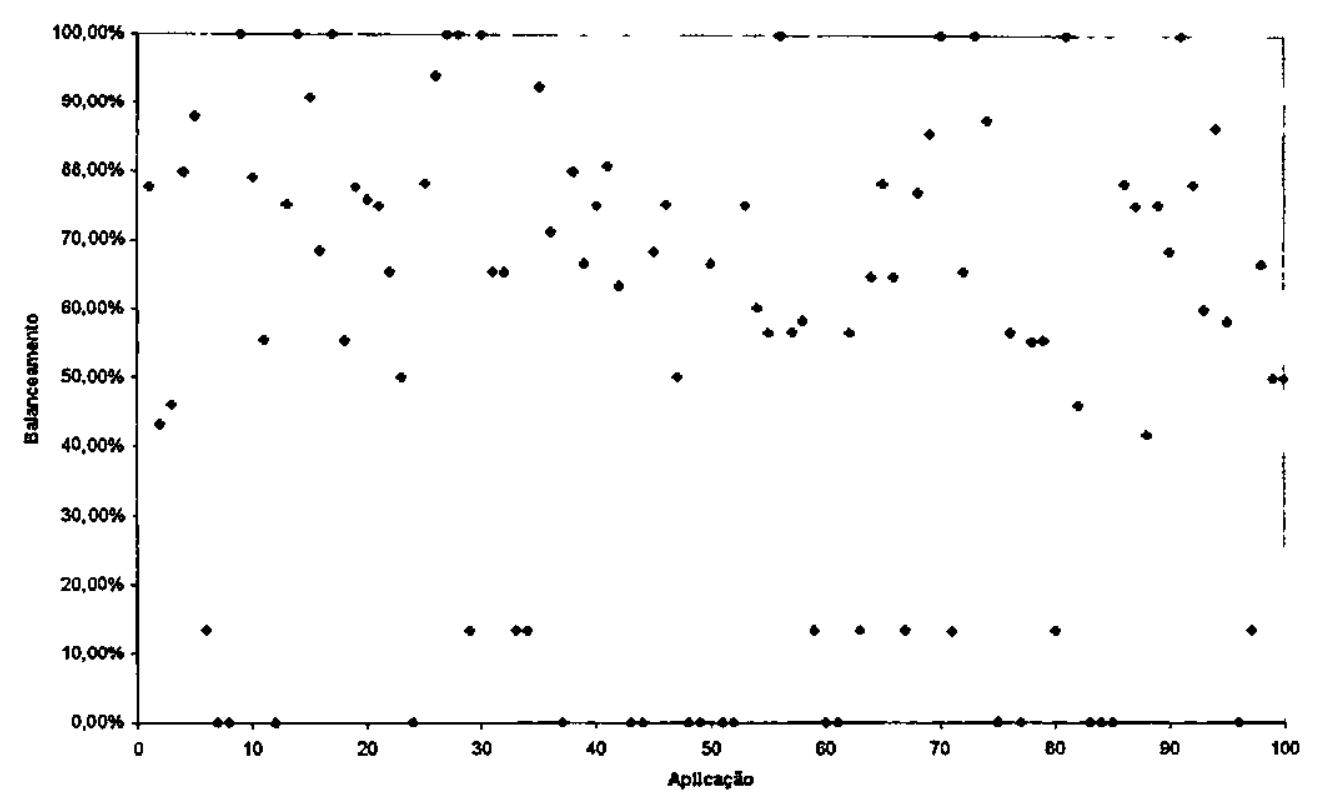

Gráfico 20 - Alteração 1 Estocástica c/ Plataforma Homogênea (2)

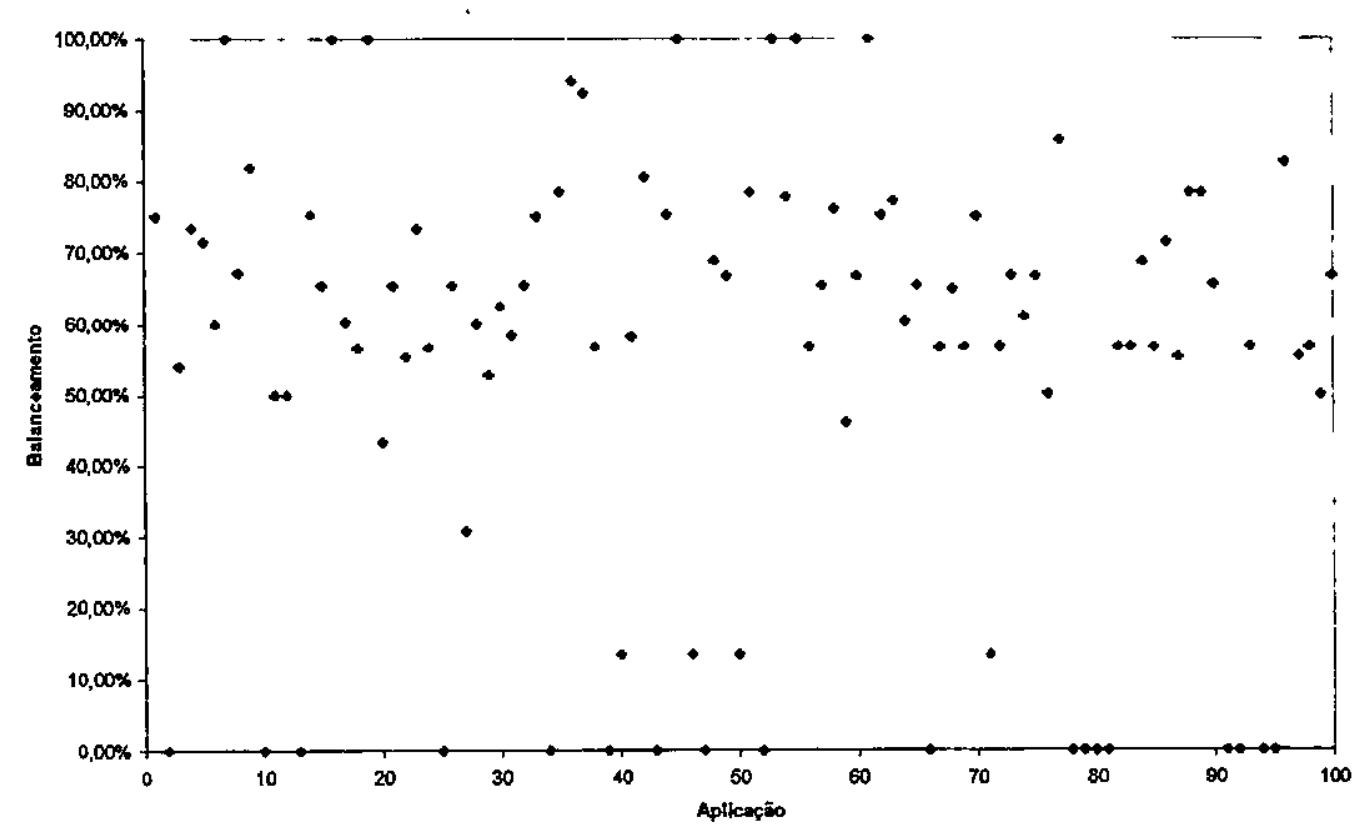

Gráfico 21 - Alteração 1 Estocástica c/ Plataform^ Homogênea (3) 


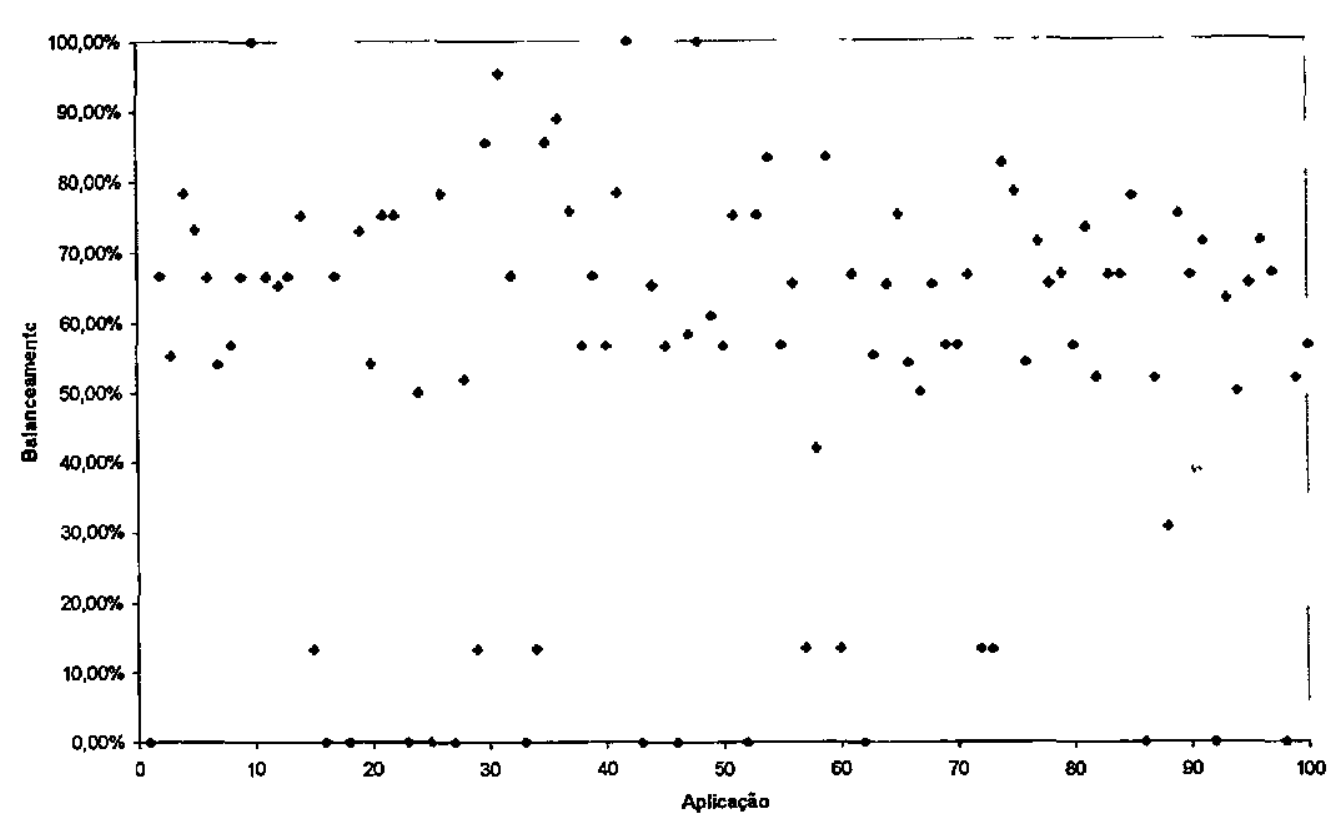

Gráfico 22 - Alteração 1 Estocástica c/ Plataforma Bomogênea (4)

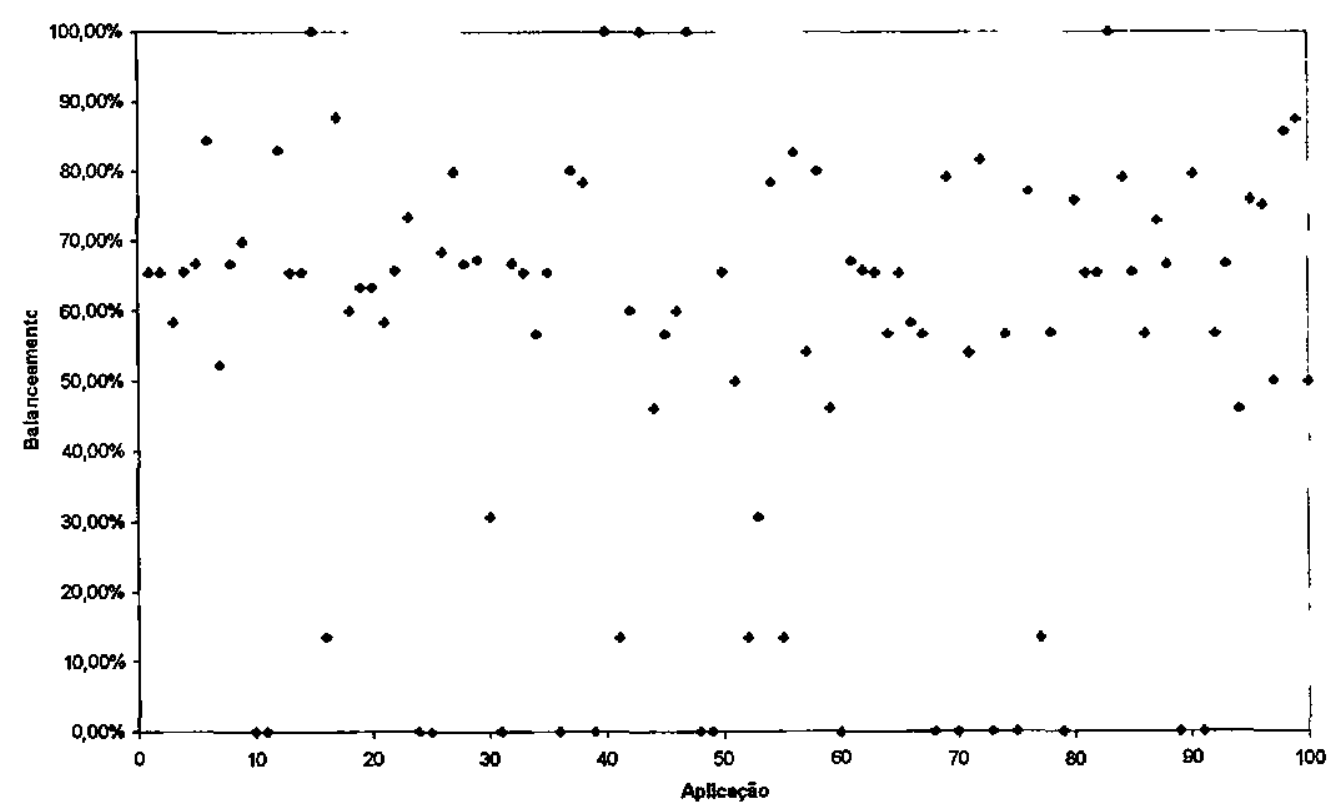

Gráfico 23- Alteração 1 Estocástica c/ Plataforma Homogênea (5)

Em relação as valores obtidos com a DPWP original, esta alteração mostrou que consegue diminuir a dispersão dos dados e o número de valores que tendem a zero, fazendo com que os valores médios de balanceamento ficassem maiores. 
A Tabela 6 mostra os valores médios considerando plataforma homogênea, é apresentada a seguir:

Tabela 6 - Intervalo de Confiança p/ Alteração 1 c/ Plataforma Homogênea

\begin{tabular}{|c|c|}
\hline Execuções & Balanceamento \\
\hline 1 & $53,87 \%$ \\
\hline 2 & $53,21 \%$ \\
\hline 3 & $53,69 \%$ \\
\hline 4 & $53,91 \%$ \\
\hline 5 & $53,43 \%$ \\
\hline MÉDIA & $53,62 \%$ \\
\hline INTERV. CONF. & $53,62 \% \pm 0,83 \%$ \\
\hline
\end{tabular}

Para plataforma heterogênea, têm-se os seguintes gráficos de 24 a 28:

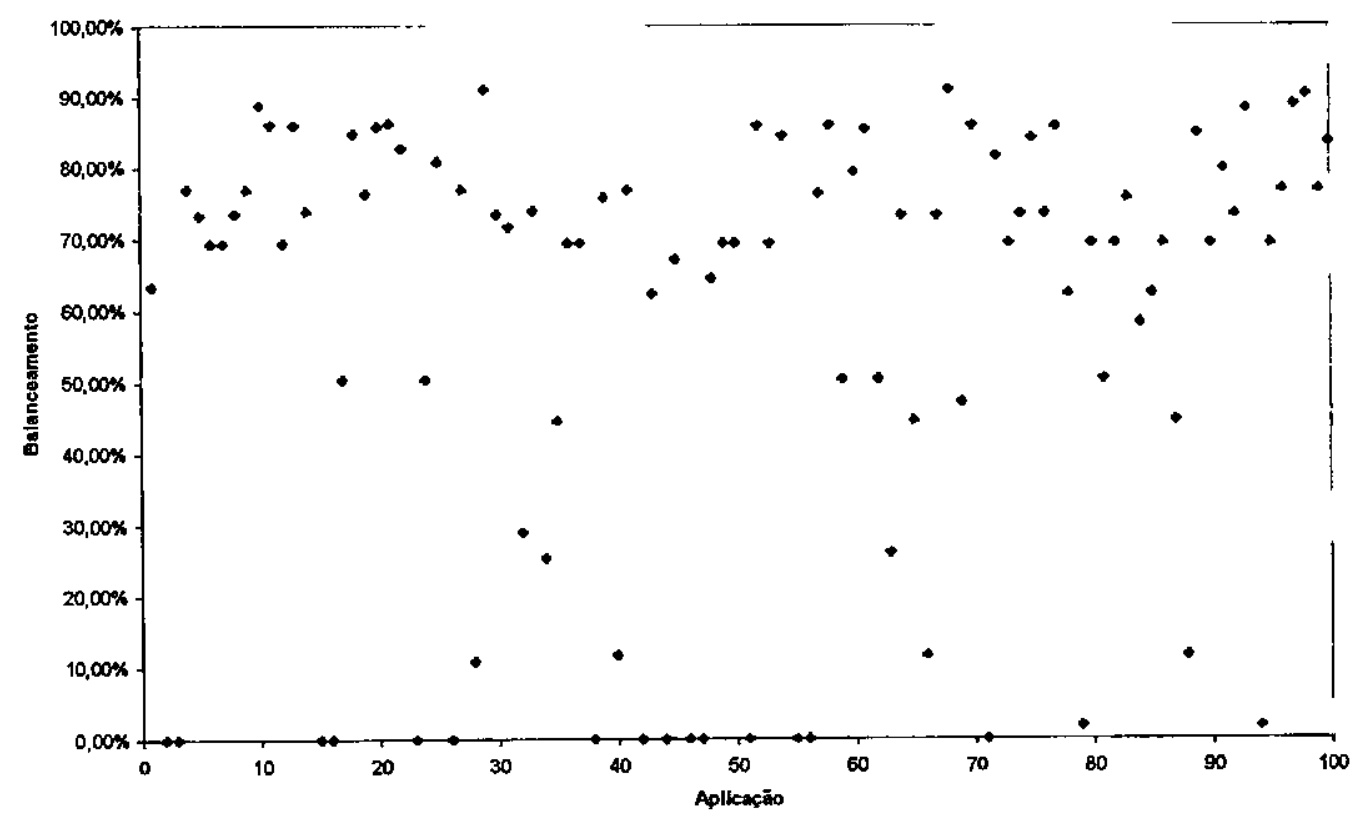

Gráfico 24 - Alteração 1 Estocástica c/ Plataforma Heterogênea (1) 


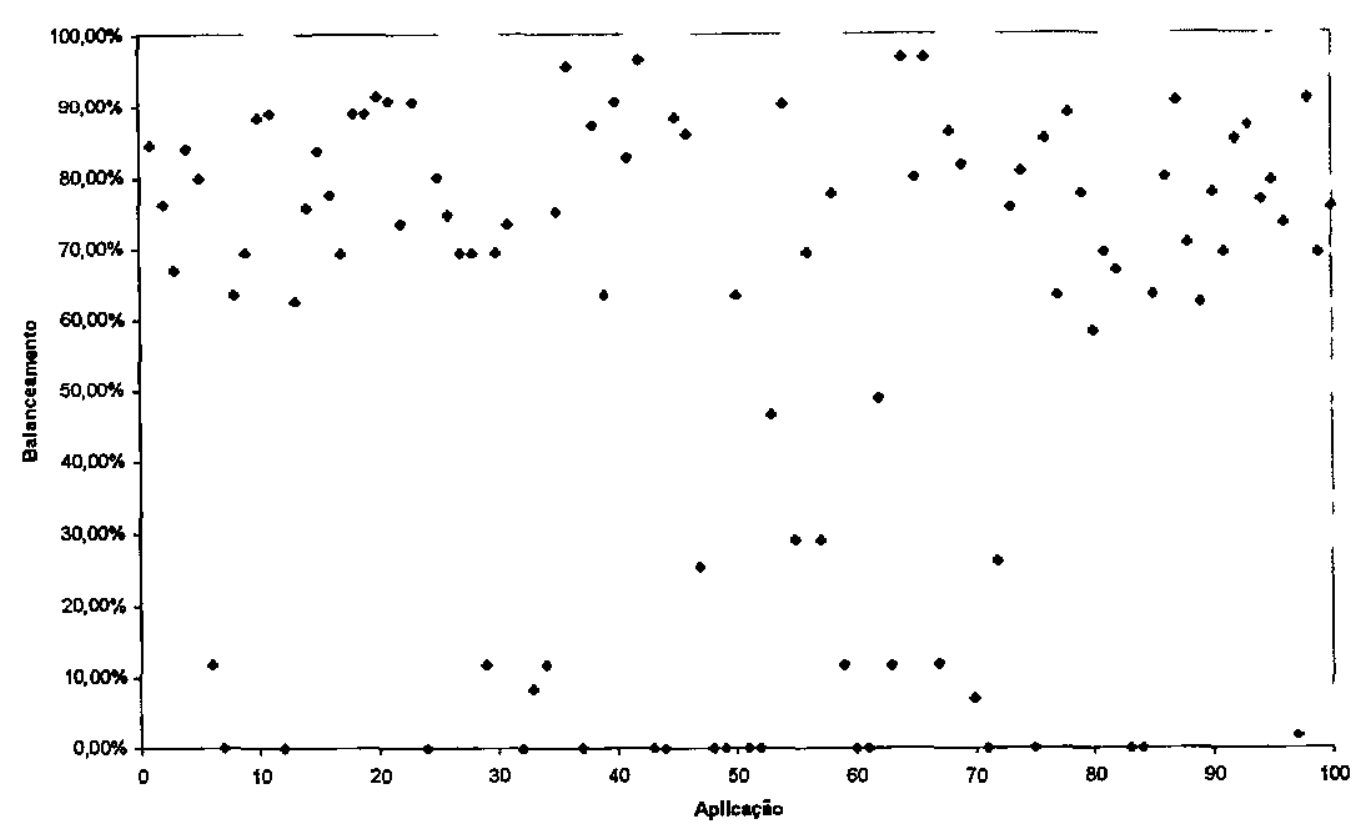

Gráfico 25 - Alteração 1 Estocástica c/ Plataforma Heterogênea (2)

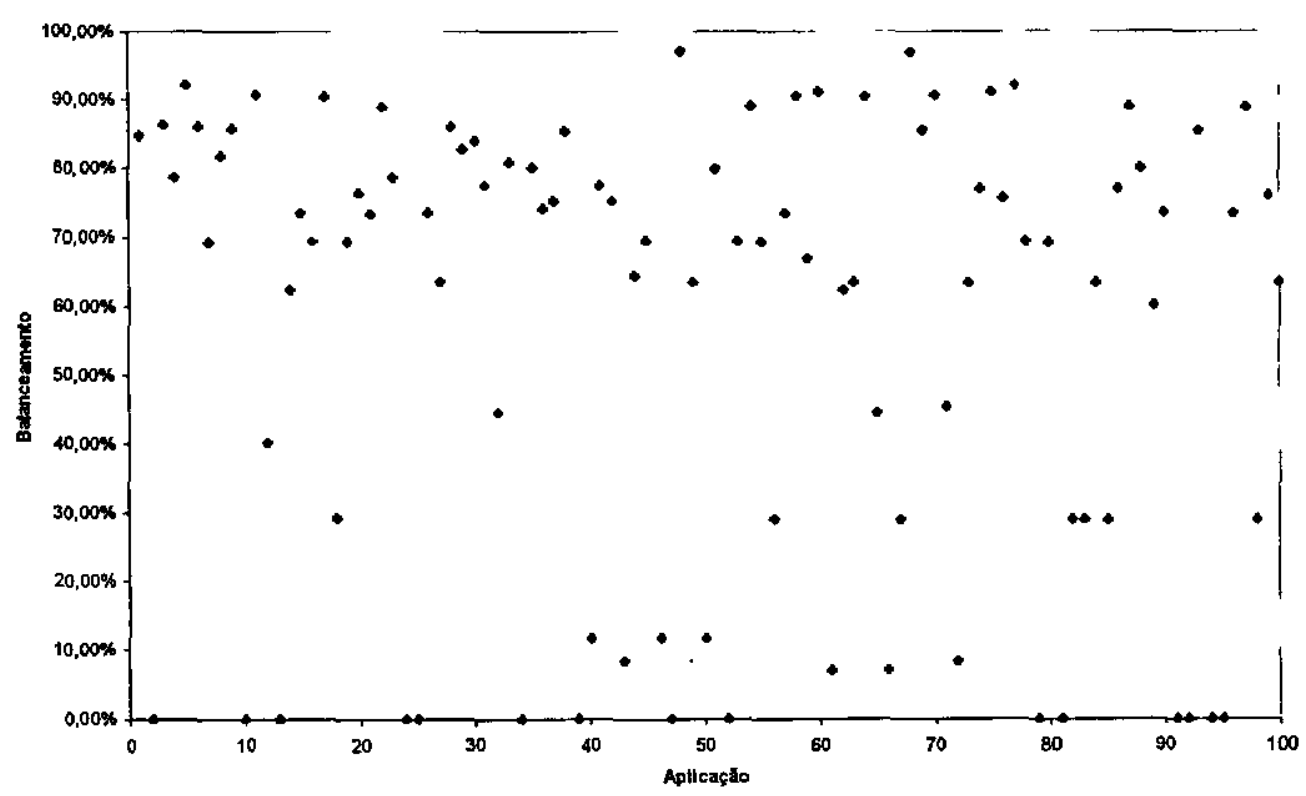

Gráfico 26 - Alteração 1 Estocástica c/ Plataforma Heterogênea (3) 


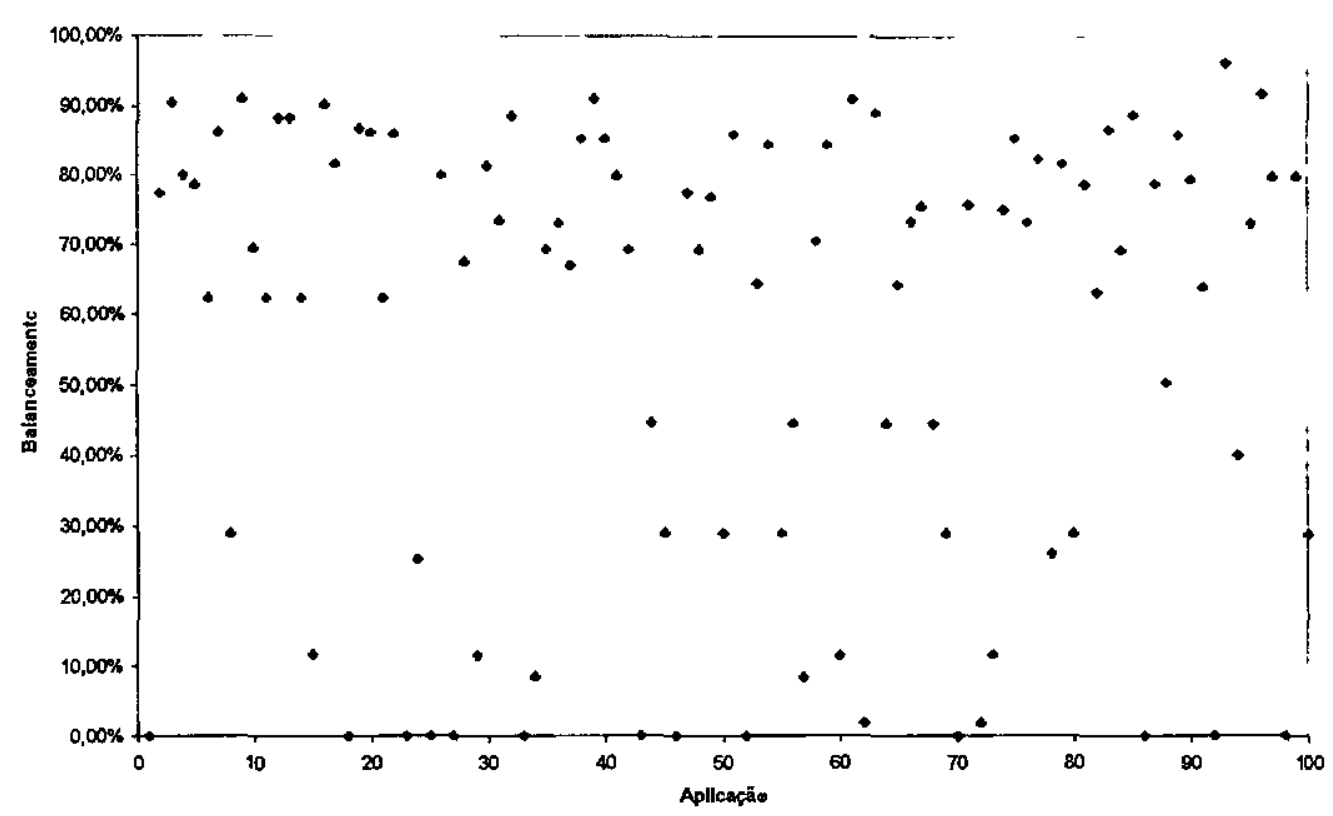

Gráfico 27 - Alteração 1 Estocástica c/ Plataforma Heterogênea (4)

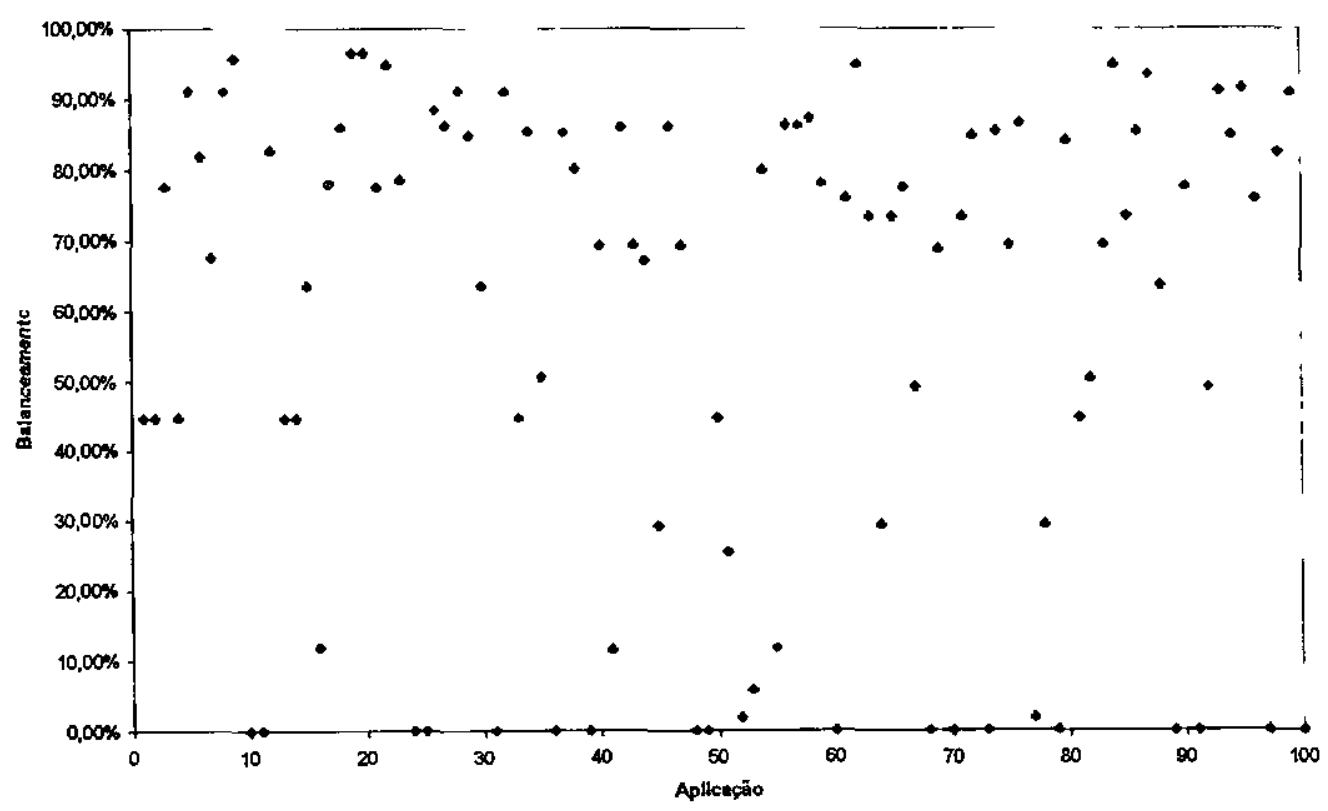

Gráfico 28 - Alteração 1 Estocástica c/ Plataforma Heterogênea (5)

Os resultados obtidos para o balanceamento com a plataforma heterogênea, mostram um fato interessante, os valores médios são maiores do que aqueles verificados considerando as máquinas homogêneas, isso porque, como a amostragem da carga é realizada mais de uma vez 
durante o escalonamento, a máquina mais potente tende a receber mais processos que a menos potentes.

Esses valores médios são mostrados na Tabela 7, juntamente com o intervalo de confiança.

Tabela 7 - Intervalo de Confiança p/ Alteração 1 c/Plataforma Heterogênea

\begin{tabular}{|c|c|}
\hline Execuções & Balanceamento \\
\hline 1 & $56,86 \%$ \\
\hline 2 & $56,52 \%$ \\
\hline 3 & $56,79 \%$ \\
\hline 4 & $56,33 \%$ \\
\hline 5 & $56,13 \%$ \\
\hline MÉDIA & $56,53 \%$ \\
\hline INTERV. CONF. & $56,53 \% \pm 0,85 \%$ \\
\hline
\end{tabular}

Comparando-se os resultados das Tabelas 1 e 2 com os resultados das Tabelas 3 e 4, observa-se um aumento de 50,72\% para $53,62 \%$ de balanceamento para sistemas homogêneos e de $25,60 \%$ para $56,53 \%$ para sistemas heterogêneos. Estes dados demostram a validade da alteração proposta e a importância da metodologia proposta, que possibilita a avaliação da alteração.

\subsection{Ensaio 3}

Com o ensaio 3 é verificado como o balanceamento se comporta se, ao invés dos processos serem todos iguais, eles forem diferentes. A alteração realizada leva em consideração os três tipos de processos discutidos no início deste capítulo (leves, médios e pesados). Ao final do escalonamento, a informação do número de processos leves, médios e.pesados alocados para cada máquina é utilizada para calcular o balanceamento. 


\section{Determinístico}

O teste determinístico mostra que quando são considerados processos diferentes, o balanceamento tende a cair bastante, isto porque, a DPWP original não foi preparada para tratar processos diferentes.

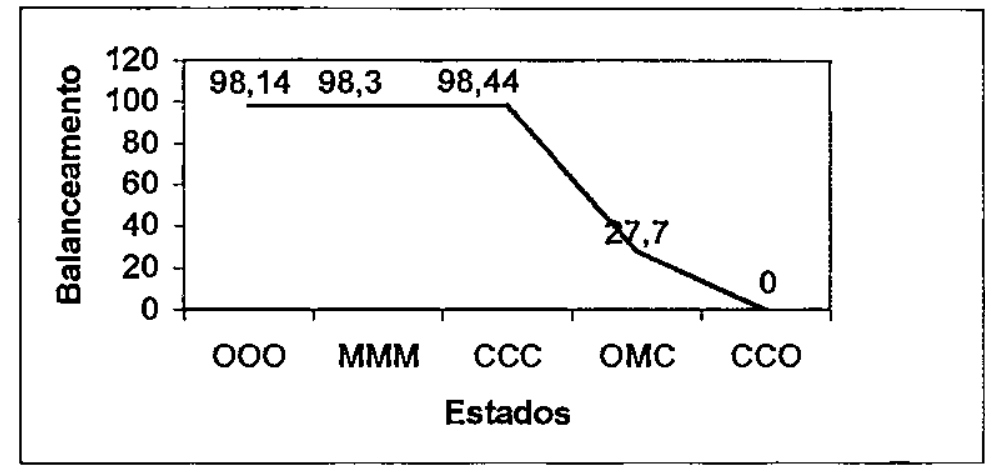

Gráfico 29 - Alteração 2 Determinística c/ Plataforma Homogênea

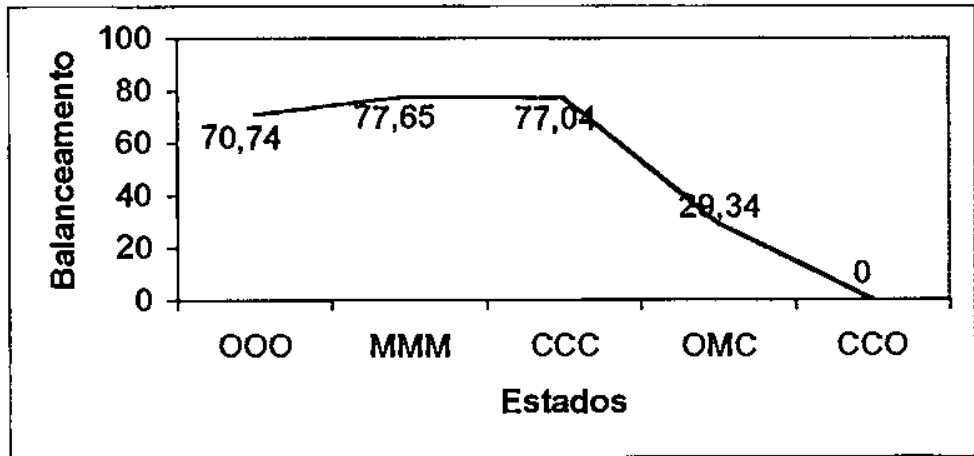

Gráfico 30 - Alteração 2 Determinística c/ Plataforma Heterogênea

Os resultados mostrados nos Gráficos 13 e 14 são semelhantes aos obtidos nos Gráficos 1 e 2, reforçando o comportamento inadequado da DPWP no que se refere à observação do balanceamento produzido no sistema.

Para algumas combinações ou estados, como no exemplo OMC e CCO, observa-se uma piora considerável do sistema para ambos os casos (plataformas homogêneas e heterogêneas). 


\section{Probabilístico}

O teste probabilístico reforça os resultados vistos no caso determinístico, onde o balanceamento fica bastante prejudicado com a adoção de processos de pesos diferentes. No caso do Gráfico 31, o balanceamento ficou disperso, com alguns picos, e o gráfico mostra uma média geral $(31,84 \%)$ do balanceamento bastante baixa.

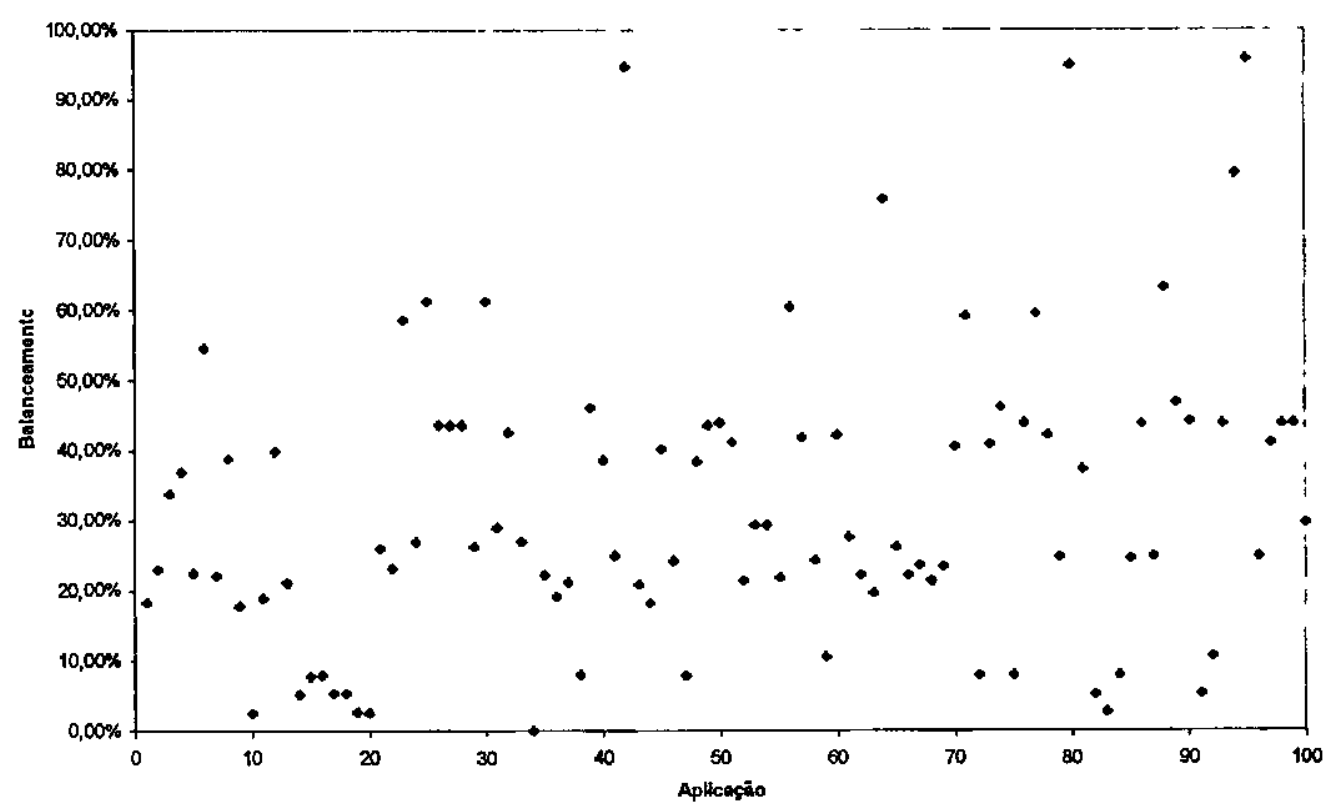

Gráfico 31 - Alteração 2 Probabilística c/ Plataforma Homogênea

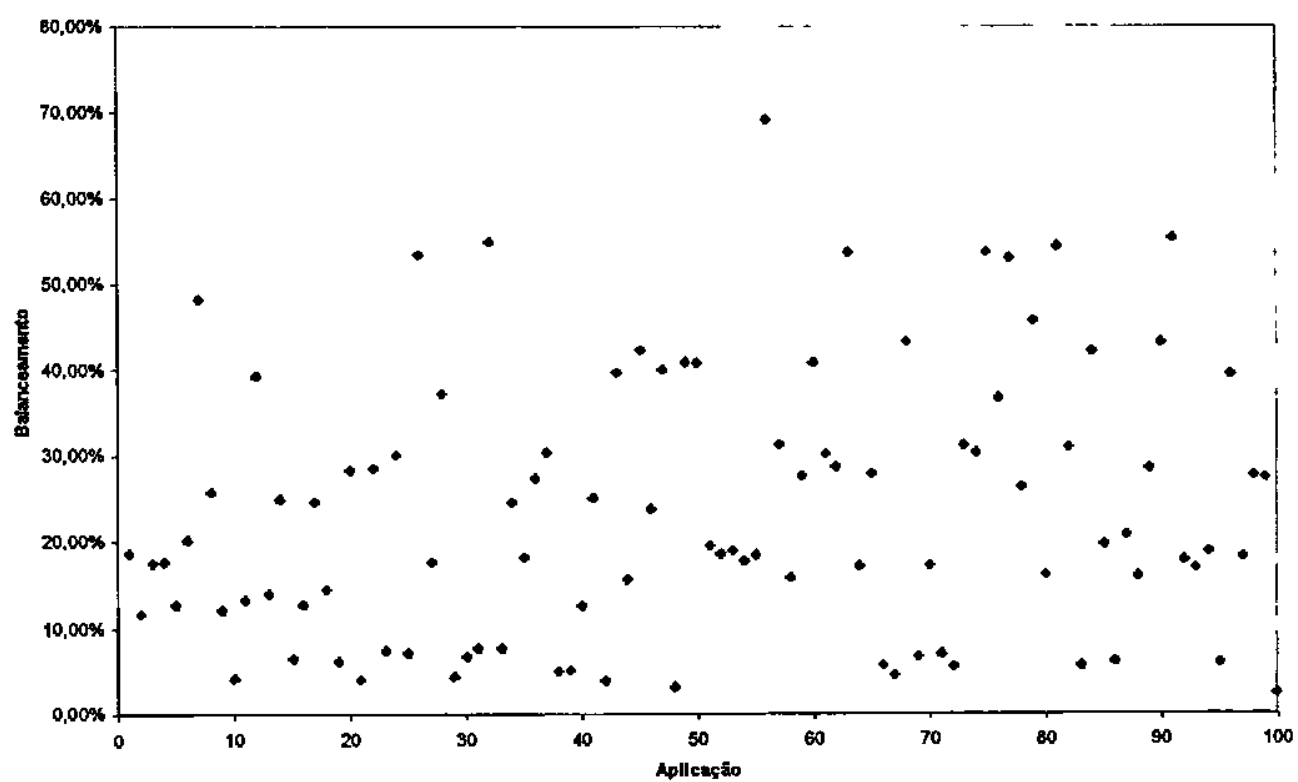

Gráfico 32 - Alteração 2 Probabilistica c/ Plataforma Heterogênea 
Com as máquinas diferentes, o balanceamento ficou menos esparso e com poucos picos (Gráfico 32). O que deve ser observado atentamente neste caso é que, ocasionalmente o sistema pode apresentar um bom balanceamento mas isso é pontual porque a DPWP original não consegue recuperar o balanceamento quando a alocação dos processos se torna equivocada devido ao próprio carregamento produzido pela alocação dos processos. Para esse caso tem-se que o valor médio do balanceamento é de $23,55 \%$, mostrando mais uma vez a maior dificuldade em obter-se bom balanceamento em sistemas heterogêneos.

\section{Estocástico}

Nesta alteração, é sabido que os processos são diferentes, mas a DPWP trata-os como se fossem iguais. A influência dos processos diferentes no balanceamento final, com máquinas homogêneas, é observada nos Gráficos de 33 a 37. Observa-se que os valores tendem a ficar nos 2 extremos, próximos a $100 \%$ e a $0 \%$. Isso ocorre devido aos valores das cargas das máquinas e do número de processos pesados, quanto mais processos pesados, maior a tendência de um balanceamento pobre.

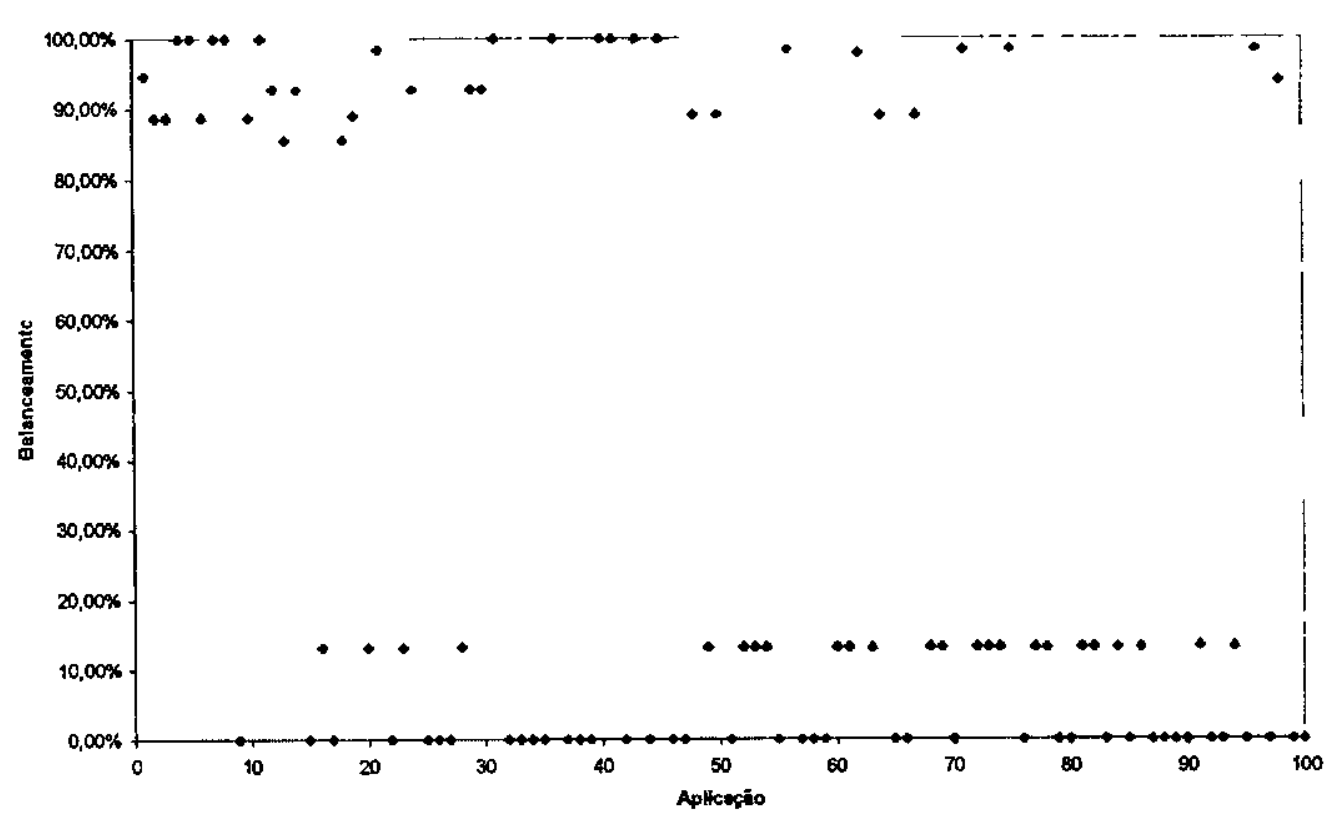

Gráfico 33 - Alteração 2 Estocástica c/ Plataforma Homogênea (1) 


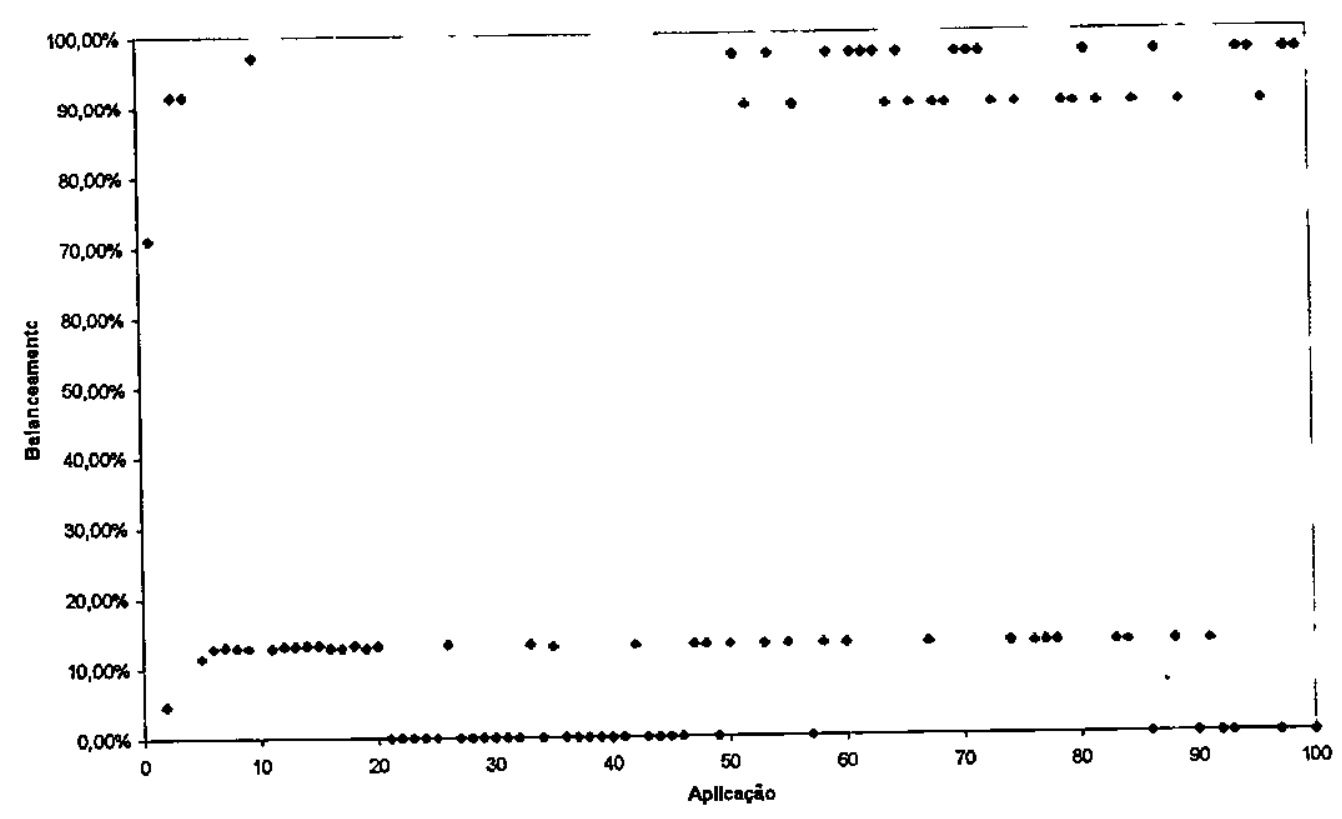

Gráfico 34 - Alteração 2 Estocástica c/ Plataforma Homogênea (2)

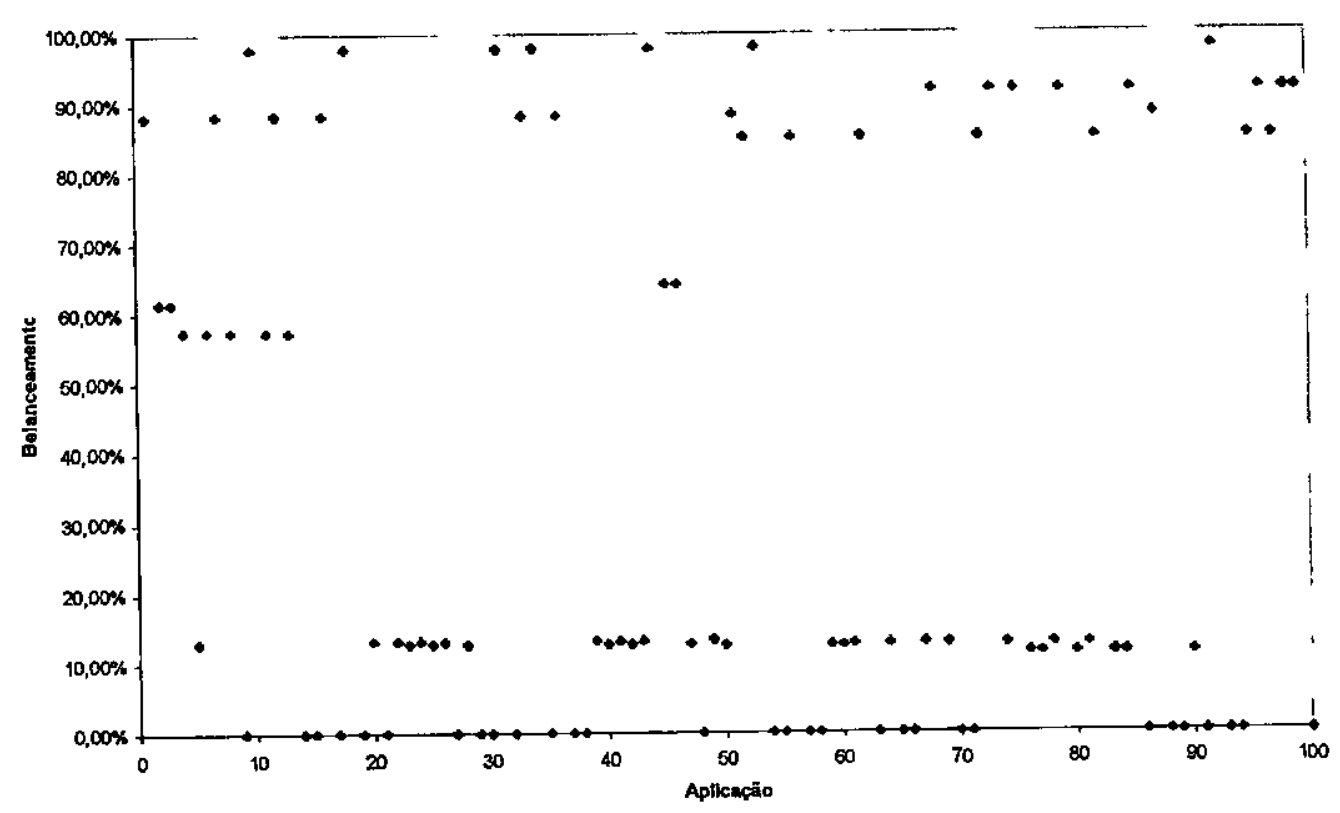

Gráfico 35 - Alteração 2 Estocástica c/ Plataforma Homogênea (3) 


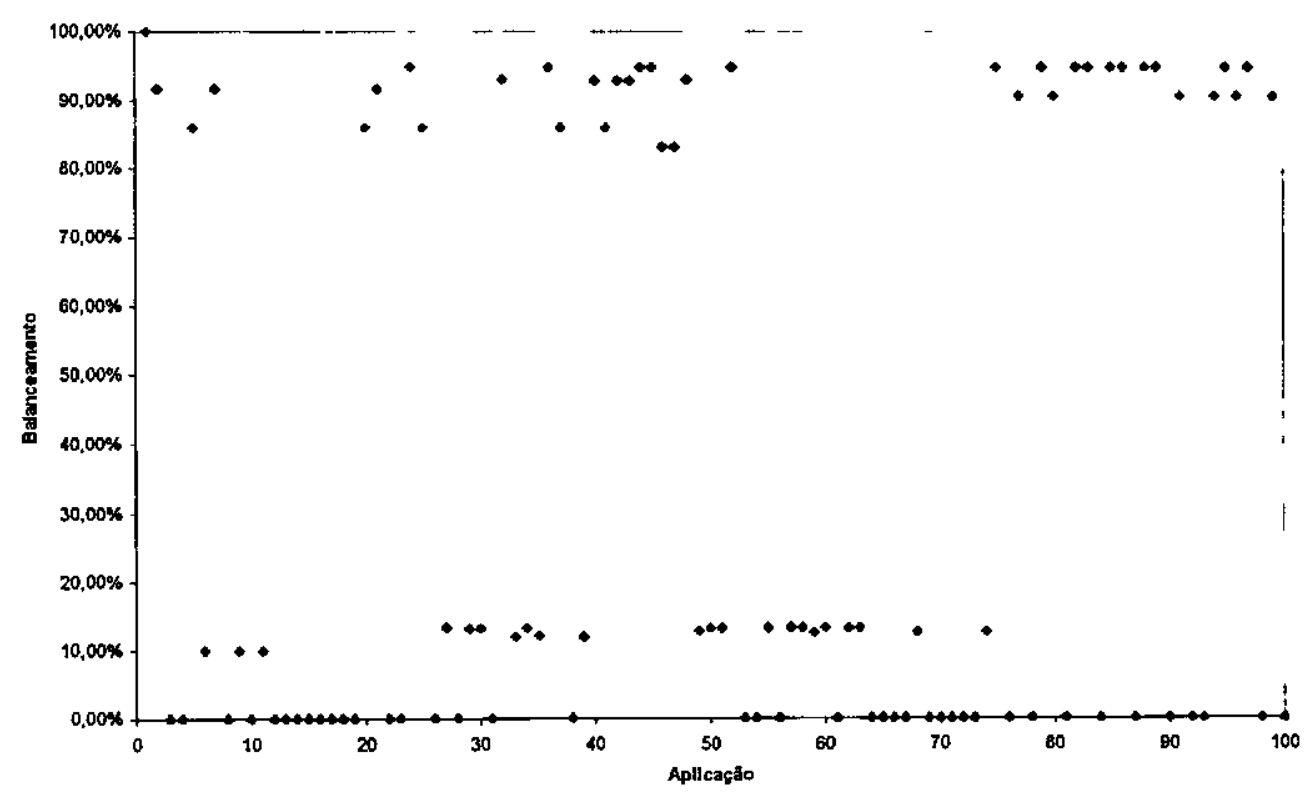

Gráfico 36 - Alteração 2 Estocástica c/ Plataforma Homogênea (4)

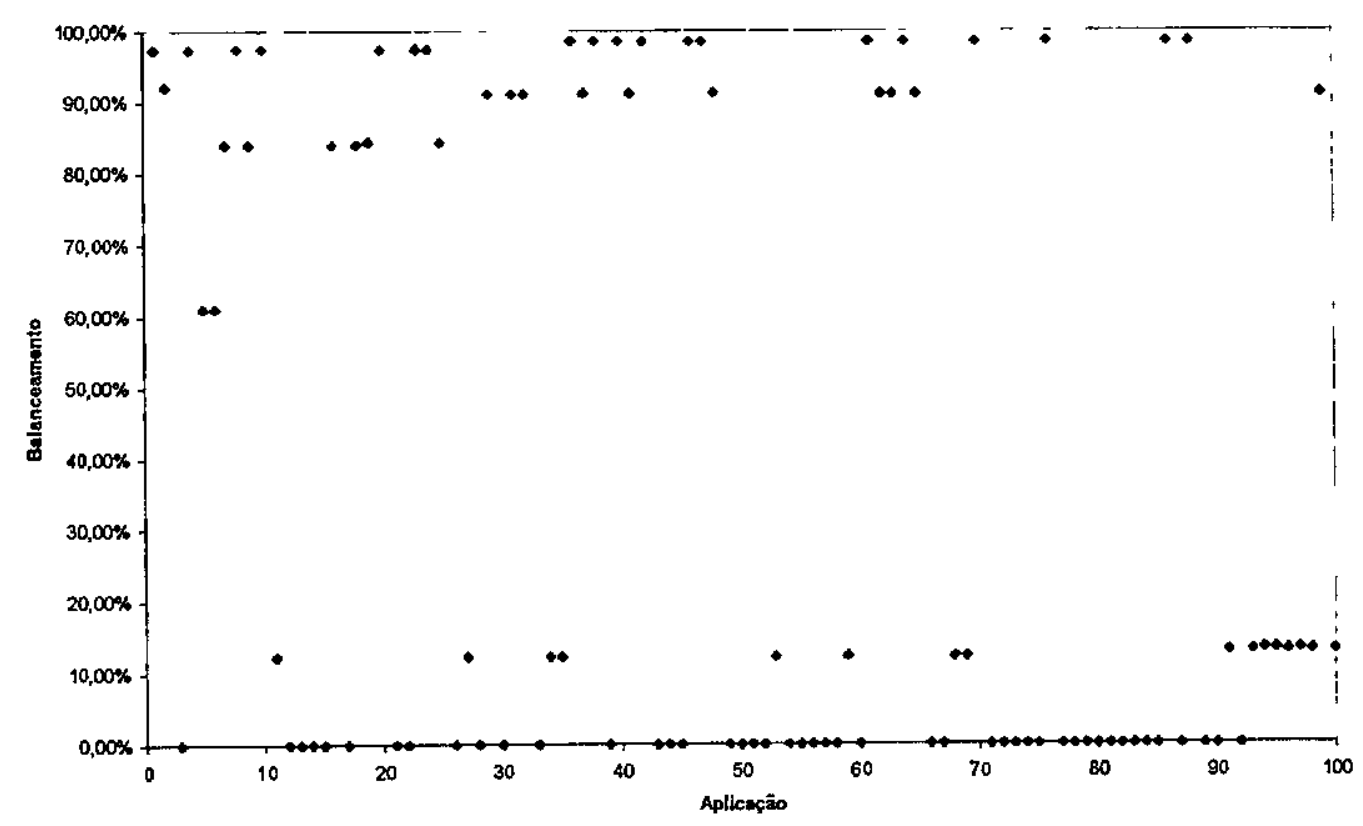

Gráfico 37 - Alteração 2 Estocástica c/ Plataforma Homogênea (5)

A Tabela 8 , apresenta os valores médios para o balanceamento obtido com máquina homogêneas, para cada simulação do modelo, a média geral e o intervalo de confiança. 
Tabela 8 - Intervalo de Confiança p/ Alteração 2 c/ Plataforma Homogênea

\begin{tabular}{|c|c|}
\hline Execuções & Balanceamento \\
\hline 1 & $36,30 \%$ \\
\hline 2 & $36,26 \%$ \\
\hline 3 & $36,54 \%$ \\
\hline 4 & $36,77 \%$ \\
\hline 5 & $36,98 \%$ \\
\hline MÉDIA & $36,57 \%$ \\
\hline INTERV. CONF. & $36,57 \% \pm 0,85 \%$ \\
\hline
\end{tabular}

Para o caso de plataforma heterogênea, os valores também ficaram situados em duas regiões, a diferença é que o valor máximo ficou em torno de $70 \%$, o que confirma o comportamento já observado no ensaio 1 (plataforma heterogênea implica em pior balanceamento).

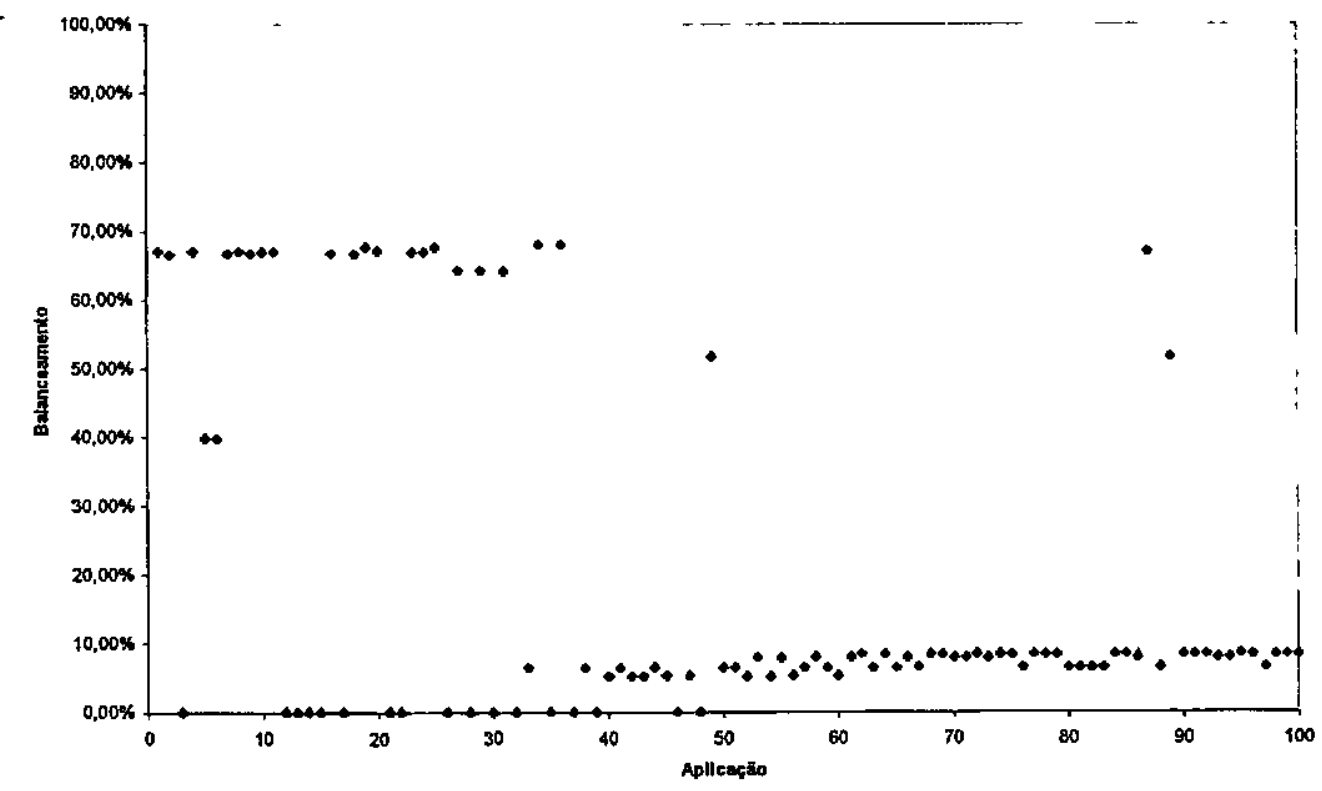

Gráfico 38 - Alteração 2 Estocástica c/ Plataforma Heterogênea (1) 


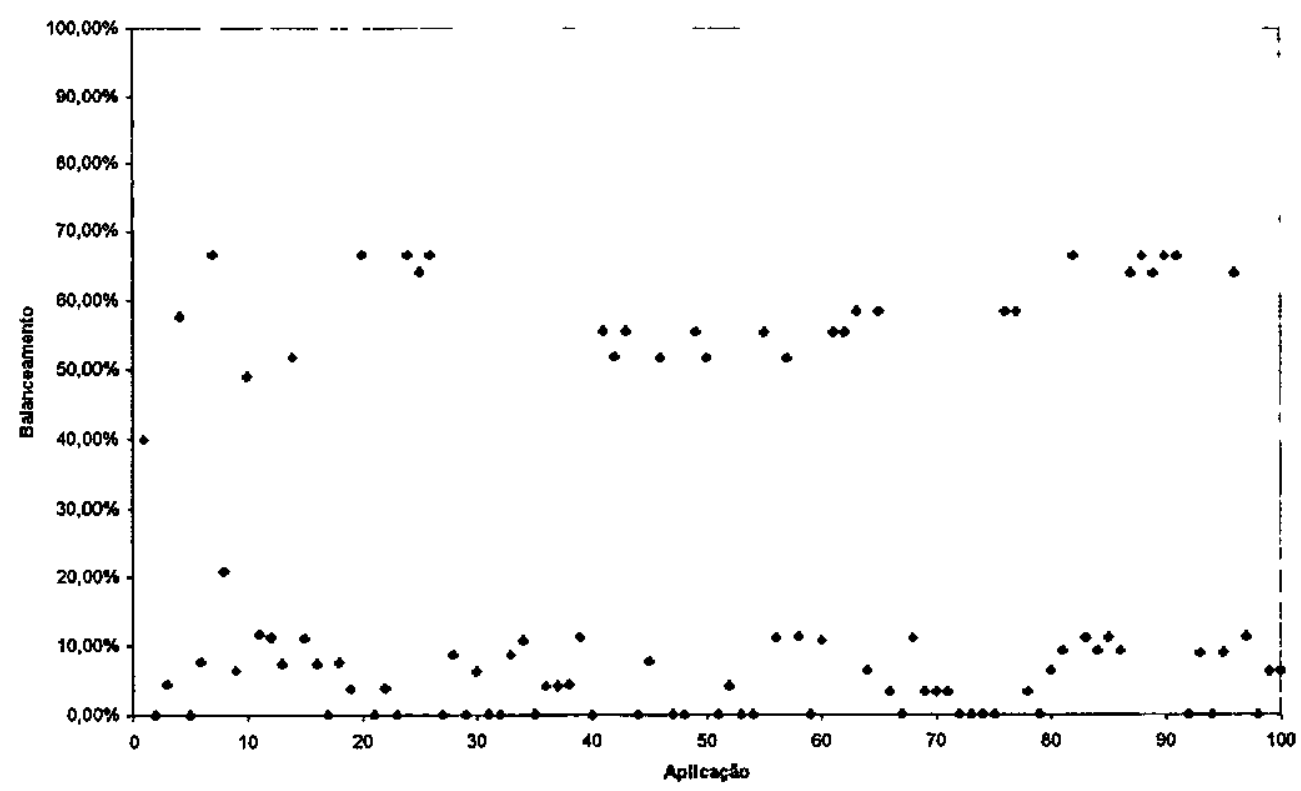

Gráfico 39 - Alteração 2 Estocástica c/ Plataforma Heterogênea (2)

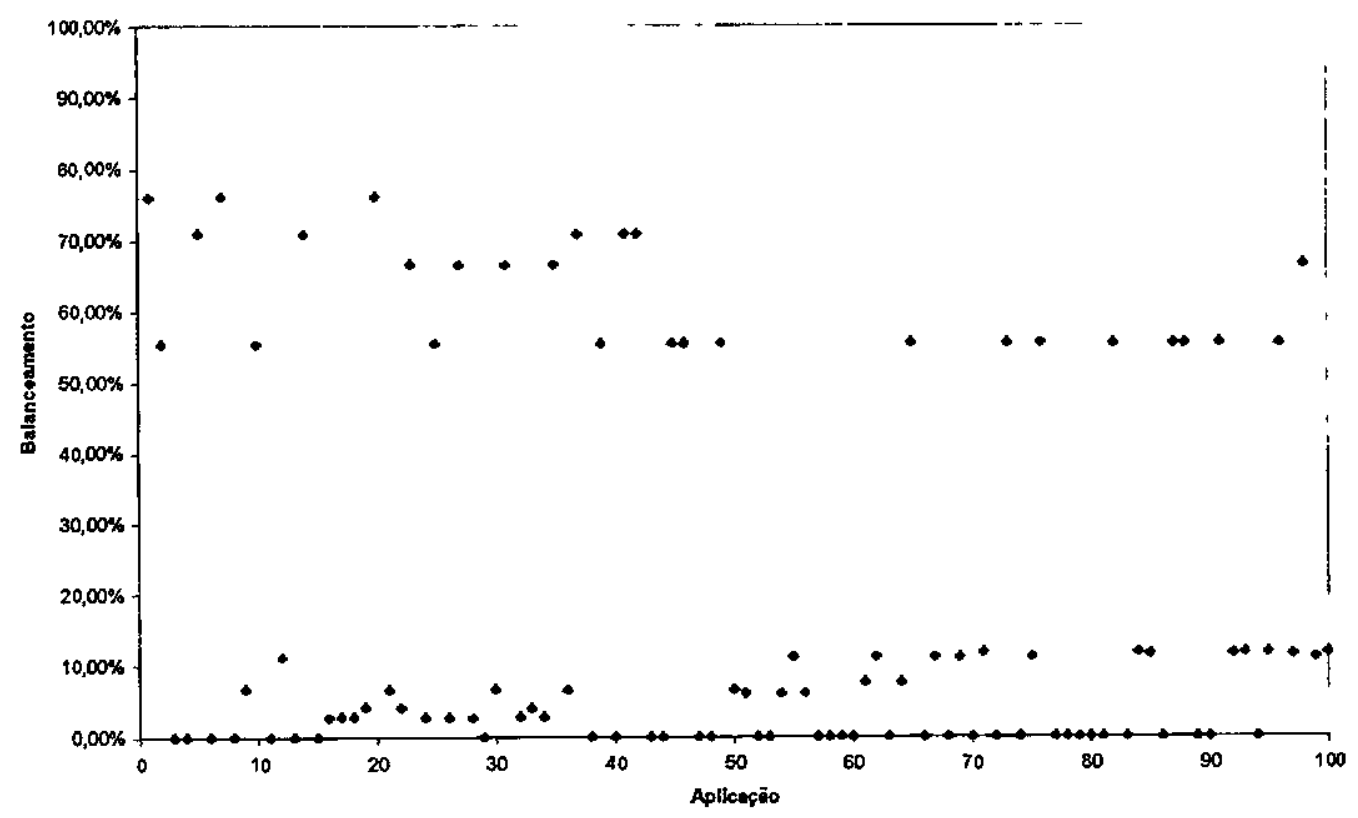

Gráfico 40 - Alteração 2 Estocástica c/ Plataforma Heterogênea (3) 


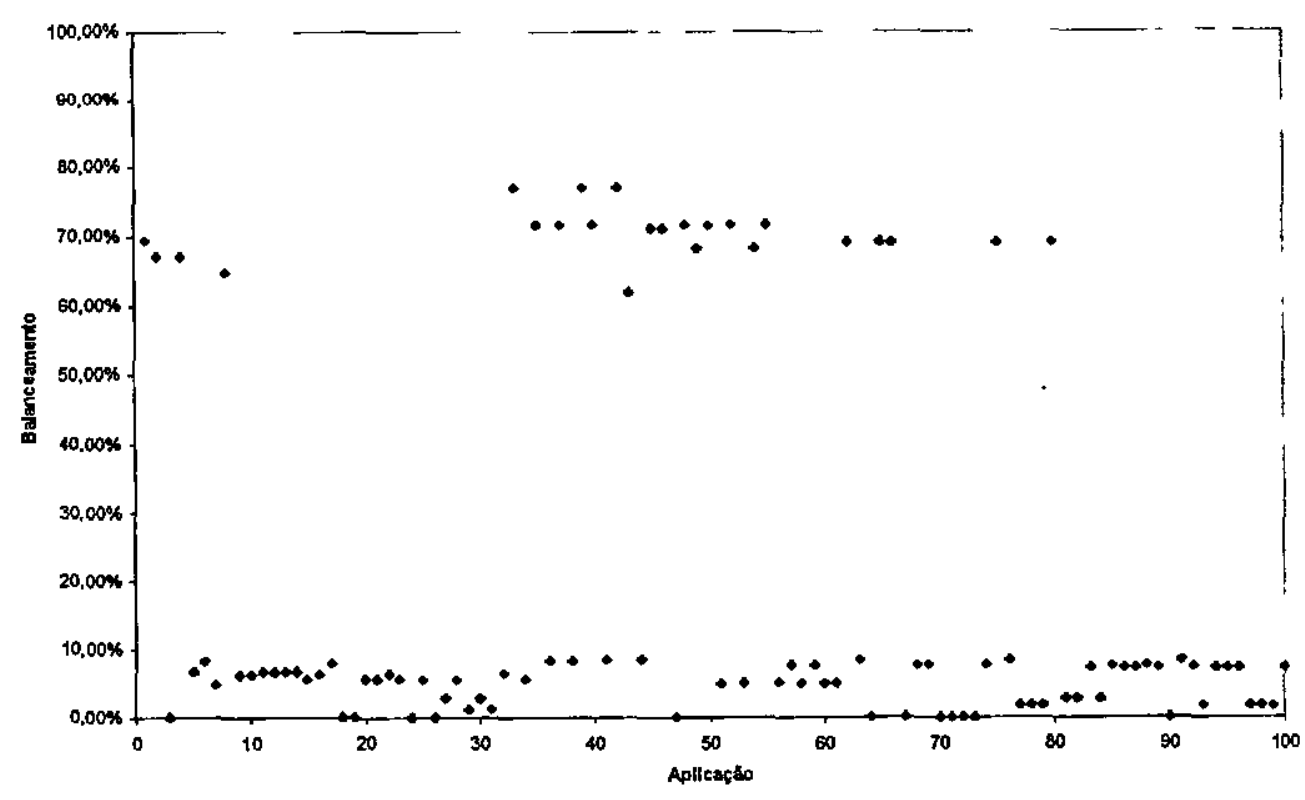

Gráfico 41 - Alteração 2 Estocástica c/ Plataforma Heterogênea (4)

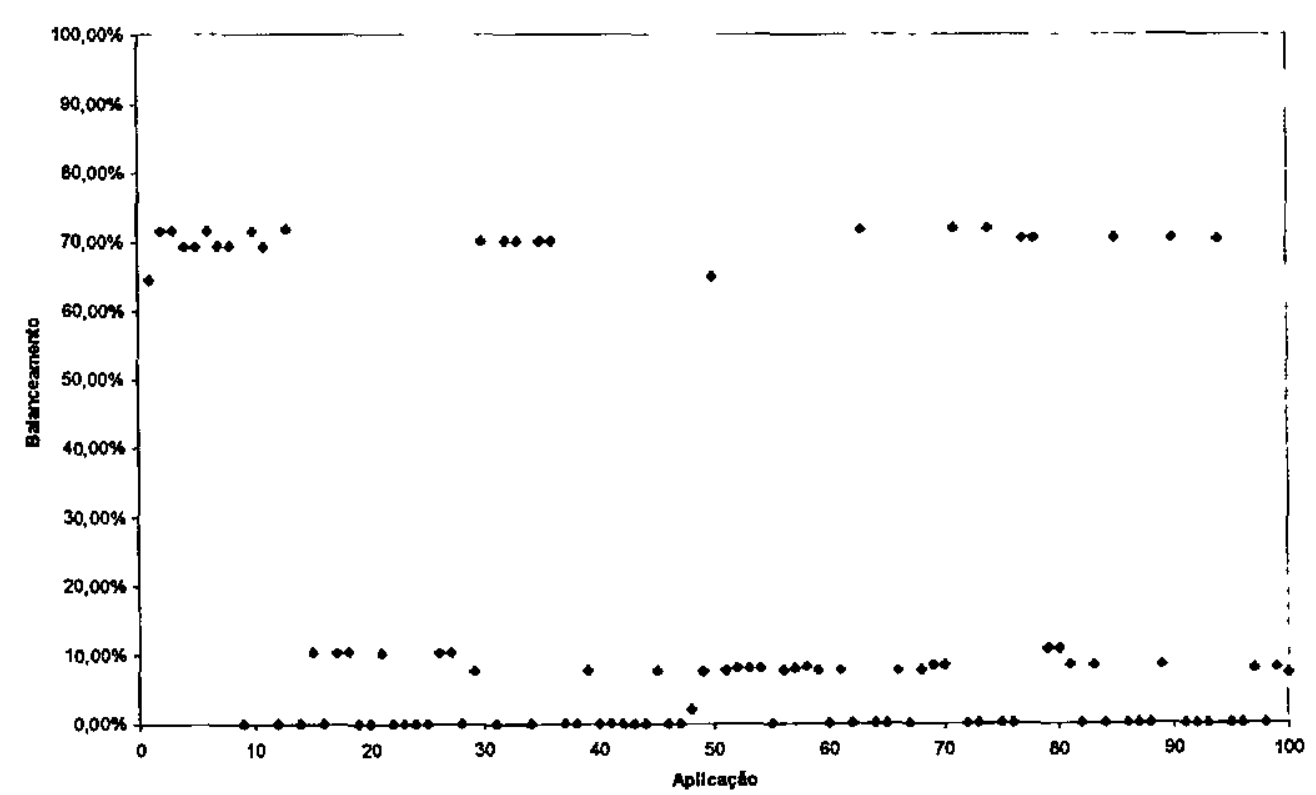

Gráfico 42 - Alteração 2 Estocástica c/ Plataforma Heterogênea (5)

O valores médios de balanceamento, média geral e intervalo de confiança, são apresentados na Tabela 9. 
Tabela 9 - Intervalo de Confiança p/ Alteração 2 c/ Plataforma Heterogênea

\begin{tabular}{|c|c|}
\hline Execuções & Balanceamento \\
\hline 1 & $20,01 \%$ \\
\hline 2 & $20,99 \%$ \\
\hline 3 & $20,21 \%$ \\
\hline 4 & $20,47 \%$ \\
\hline 5 & $20,24 \%$ \\
\hline MÉDIA & $20,38 \%$ \\
\hline INTERV. CONF. & $20,38 \% \pm 1,04 \%$ \\
\hline
\end{tabular}

Comparando-se as Tabelas 8 e 9 com as Tabelas 4 e 5 observa-se um pior balanceamento quando processos com complexidade diferente são considerados. No caso das plataformas homogêneas o balanceamento caiu de $50,72 \%$ para $36,57 \%$ e no caso heterogêneo, de $25,60 \%$ para $20,38 \%$.

\subsection{Considerações Finais}

Este capítulo mostra os resultados obtidos com a avaliação da política DPWP, utilizandose a modelagem proposta neste trabalho o que permitiu a identificação de problemas e proposição de soluções para os mesmos.

Os testes apresentados neste capitulo serviram para comprovar a aplicabilidade e a eficiência do uso da metodologia proposta e que a mesma pode ser aplicadá tanto para políticas existentes (DPWP) como para aquelas que não estão implementadas (alterações na DPWP), o que confirma que os seus objetivos foram alcançados.

Todos os ensaios foram realizados levando em conta a cargas das máquinas, em termos de processamento, isto porque a DPWP é uma política do tipo CPU-Bound, mas como a metodologia é flexível, o estudo pode ser ampliado acrescentando-se características de aplicações I/O-Bound e alterações no modelo para que sejam capazes de tratar esse tipo de aplicação. 
O que deve ser observado atentamente é que, com os ensaios, passo a passo, fica evidente alguns possíveis problemas existentes na política com o resultado obtido com as melhorias propostas.

A observação do impacto das alterações é imediata, o que pode favorecer muito no tempo de desenvolvimento do sistema real, uma vez que a política que será considerada no sistema será aquela que mostrar o comportamento mais adequado nos ensaios.

Em resumo, a metodologia proposta, usando modelagem e simulação traz vantagens e pode ser facilmente utilizada. 


\section{Capítulo 6}

\section{Conclusão}

\subsection{Considerações Iniciais}

Esta dissertação propôs uma metodologia para avaliação de políticas de escalonamento de processos, que não requer que as mesmas estejam implementadas. A metodologia é simples e fácil de ser aplicada, além de ser flexível no que diz respeito à definição de métricas de observação, deixando o usuário livre para escolher aquela que melhor se adequar aos seus objetivos.

O uso da metodologia foi exemplificado através de um ensaio com a DPWP, uma política de escalonamento de processos já implementada. O modelo da DPWP foi feito em redes de Petri estocástica generalizada, por ser esta uma técnica com numerosos recursos. Entretanto, o uso de redes de Petri pode não ser a melhor alternativa quando o modelo é muito grande, visto que a sua visualização e entendimento ficam prejudicados.

O modelo implementado foi validado através de comparações entre a execução da política real e os resultados obtidos a partir da simulação do modelo.

A política foi estudada com base nos resultados obtidos a partir de várias simulações, onde foram realizados ensaios determinísticos (que serviu para reforçar a validação do modelo), probabilísticos e estocásticos.

\subsection{Dificuldades}

As maiores dificuldades enfrentadas na elaboração deste trabalho são relacionadas ao processo de modelagem e simulação do modelo. Redes de Petri foram escolhidas como a técnica a ser utilizada e isso, apesar de todas as vantagens oferecidas pelos inúmeros recursos disponíveis, traz dificuldades no momento em que o modelo cresce e sua complexidade tende a ficar muito grande.

Em trabalhos futuros, outras técnicas podem ser testadas e os problemas encontrados comparados aos encontrados nesta dissertação. 
Com relação à simulação, a escolha do ambiente ALPHA/Sim foi adequada e estratégica, porém o uso de uma versão para Windows NT trouxe alguns problemas sérios, no que se refere ao tempo máximo de simulação. A versão NT do ambiente de simulação apresenta problemas (agora já reconhecidos pelos implementadores) o que limita a amplitude das execuções. A versão UNIX resolve esse problema mas não esteve liberada para este trabalho, uma vez que apenas a NT foi licenciada para o grupo.

Uma outra dificuldade encontrada foi entender bem o processo de avaliação da política, como mapear esse processo nos modelos e como elaborar a estratégia de teste da política. A estratégia utilizada, empregada em cada ensaio, que inclui experimentos determinísticos, probabilísticos e estocásticos, foi um caminho definido que trouxe bons resultados. Outras estratégias podem ser arquitetadas mas não houve disponibilidade de tempo para serem abordadas nesta dissertação.

Por fim, uma terceira categoria de dificuldades diz respeito à bibliografia relacionada a este trabalho. Como o trabalho envolve uma área de múltiplas disciplinas, a bibliografia foi altamente diversificada, envolvendo sistemas distribuídos, escalonamento de processos, modelagem e simulação. No que se refere ao tema da dissertação, a literatura é baseada em estudos específicos, conduzidos de modo personalizado, não havendo, de modo geral, casos mais abrangentes, como o que se pretendeu abordar neste trabalho.

\subsection{Contribuições}

Esta dissertação contribui tanto para a área de escalonamento de processos como para a área de avaliação de desempenho. No que se refere a escalonamento de processos, fica claro pelos ensaios efetuados que a metodologia proposta leva, de modo simples e rápido, à identificação de possíveis problemas existentes na política em estudo. Da mesma maneira, é simples e rápido implementarem-se alterações na política, elaborarem-se novos testes e tiraremse novas conclusões. Isso é, sem dúvida, importante e de certo modo fundamental, quando se busca otimizar as políticas que serão empregadas no escalonamento de processos em ambientes paralelos/distribuídos.

No que se refere à avaliação de desempenho, esta dissertação contribui ao aplicar técnicas de modelagem e simulação como elementos básicos da metodologia proposta. Modelagem e simulação são, indubitavelmente, dois aliados da avaliação de desempenho de sistemas computacionais. Esta dissertação aborda a avaliação de desempenho de políticas de escalonamento de processos com uma visão geral do problema, propondo uma metodologia 
completa. A exemplificação de uso foi particularizada para o caso da DPWP, por ser esta uma política definida e implementada previamente, o que facilitou a demonstração da metodologia.

Além disso, os testes usados para exemplificar o uso da metodologia, levaram a um estudo bastante importante da DPWP, sugerindo soluções para problemas potencialmente existentes.

Em resumo, as principais contribuições identificadas nesta dissertação são:

- Uma metodologia para avaliar o desempenho de políticas de escalonamento de processos, de forma simples e flexível (proposta, implementada e testada);

- Complementação dos testes já realizados com a DPWP, desta vez sobre um outro enfoque, o do balanceamento de carga.

- Identificação de possiveis falhas no projeto da DPWP, sugerindo alterações para corrigi-las.

- Introdução do uso de modelagem e simulação como ferramenta para avaliação de desempenho de políticas de escalonamento de processos.

\subsection{Trabalhos Futuros}

Esta dissertação apenas iniciou o estudo sobre avaliação de políticas de escalonamento de processos. Muitos pontos ficaram em aberto e servirão para gerar futuros trabalhos. Destacamse:

- Transformar a metodologia proposta em uma ferramenta automatizada, tornando a avaliação mais rápida e eficiente;

- Ampliar os testes para outras políticas incluindo outros aspectos além do processamento, por exemplo comunicação;

- Utilizar outras técnicas de modelagem tais como Redes de Fila e Statecharts, comparando os modelos obtidos aos gerados a partir das redes de Petri.

\subsection{Considerações Finais}

A utilização de uma metodologia para auxiliar a tarefa de avaliar políticas de escalonamento de processos é de grande valia no que diz respeito à otimização e racionalização desse processo, já que sugere passos a serem seguidos, procurando fazer com que o usuário não se distancie dos seus objetivos.

A possibilidade das políticas serem avaliadas sem a necessidade de estarem implementadas, facilita em muito a tarefa de construção de novas políticas já que o seu 
comportamento pode ser conhecido antecipadamente, com a identificação e correção de possíveis erros.

Este trabalho mostrou, através dos resultados discutidos no Capítulo 5, que a metodologia proposta é válida, que satisfaz os objetivos a que se propõe, é atrativa, requerendo um esforço computacional compatível com as plataformas de PCs, largamente utilizadas e permite a avaliação simples e objetiva de políticas de escalonamento de processos. 


\section{Referências Bibliográficas}

(ALPHA/Sim, 1995)

(Araújo, 1999)

(Beguelin et al., 1994)

(Casavant \& Kuhl, 1988)

(Chen, 1996)

(Chiola et al., 1993)

(Colouris et al., 1994)

(Eskicioglu, 1989)

(Ferrari \& Ẑhou, 19̄8̄̄)

(Figueiredo, 2000)
ALPHA/SIM, User's Guidè - Vèrsion 1.0, USA, 1995.

ARAÚJJO, A. P. F., "DPWP - Uma Nova Abordagem ao Escalonamento Dinâmico em Computação Paralela Virtual", Iñstituto de Ciências Mâtemáticas e de Computaçăo, Universidade de São Paulo (ICMC/USP), 1999.

BEGUELIN, A., GEIST, A., DONGARRA, J., JIANG, W., MANCHEK, R., SUNDERAM, V., PVM: Parallel Virtual Machine. A User's Guide and Tutorial for Networked Parallel Computing. The MIT Press, 1994.

CASAVANT, T. L., KUHL, J. G., "A Taxonomy of Schèduling in General-Purpose Distributed Computing Systems", IEEE Transactions on Software Engineering, vol. 14, n. 2, Fevereiro, 1988.

CHEN, X., "Process Migration in Distributed System", http://wèb.cs.ualberta.ca/ xinguang/516/paper.html, 1996.

CHIOLA, G., MARSAN M. A., CONTE, G. "Generalized Stochastic Petri Nets: A Definition at the Net Level and Its Implications" IEEE Transactions on Software Engineering, vol. 19, n. 2, 1993.

COLOURIS G., DOLLIMORE, J., KINDBERG, T., Distributed Systems. Concepts and Design, AddisonWesley Publishing Company, $2^{*}$ ed., 1994.

ESKICIOGLU, M. R., Design Issues of Process Migration Facilities in Distributed Systems, IEE Technical Committee on Operating Systems Newsletter, vol. 4, n. 2, 1989.

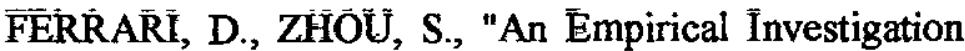
of Load Indices for Load Balancing Applications", Proceedings of Performance'87, 12 $2^{\text {th }}$ Int'l Symposium on Computer Performance Modeling, Measurement and Evaluation, pp. 515-528, 1987.

FIGUEIREDO, T. C., "Interface AMIGO-MPI: Uma Abordagem Flexível e Dinâmica para Escalonamento de Processos", Dissertação de Mestrado, Instituto de 
(Fonlupt et al., 1998)

(Francês, 1998)

(Henderson, 1995)

(Hillis, 1988)

(Hjálmtýsson \& Whitt ,1998)

(Hoover, 1990)

(Jackson \& Humphres, 1997)

(Jain, 1991)

(Kleinrock, 1976)

(Kobayashi, 1978)

(Lawrence et al., 1997)

(Lazowska et al., 1984)

(Litzkow et al., 1997)

(Lüling et al., 1991)
Ciências Matemáticas e de Computação, Universidade de São Paulo (ICMC/USP), 2000.

FONLUPT, C., MARQUET, P., DEKEYSER, J., "Dataparallel load balancing strategies", Parallel Computing, n. 24, 1998.

FRANCÊS, C. R. L., "Stochastic Feature Charts - Uma Extensão Estocástica para os State Charts", Dissertação de Mestrado, Instituto de Ciências Matemáticas e de Computação, Universidade de São Paulo (ICMC/USP), 1998.

HENDERSON, R. L., "Job Scheduling Under the Portable Batch System", IPPS'95 - Workshop on Job Scheduling Strategies for Parallel Processing, Lecture Notes in Computer Science, v. 949, Santa Barbara, USA, abril, 1995.

HILLIS, W. D., The Connection Machine, The MIT Press, Cambridge, MA, 1985; Traduction francaise, Masson, Paris, 1988.

HJÁLMTÝSSON, G., WHITT, W., 'Periodic load balancing”, Queuing Systems, n. 30, 1998.

HOOVER, S. V., Simulation a problem-solving approach, Addison-Wesley Publishing Company, 1990.

JACKSON, D. J., HUMPHRES, C. W., "A Simple yet Effective Load Balancing Extension to the PVM Software System", Parallel Computer, vol. 22, pp. 1647-1660, 1997.

JAIN, Raj, The Art of Computer Systems Performance Analysis. Techniques for Experimental Design, Measurement: Simulation and Modeling, John Wiley \& Sons Inc., 1991.

KLEINROCK, L., Queuing Systems, John Wiley \& Sons Inc., vol. 2, 1976.

KOBAYASHI, H., Modeling and Analysis: An Introduction to System Performance Evaluation Methodology, Addison-Wesley Publishing Company, 1978.

LAWRENCE, J. H., GATTl, B. A., WALTMAN, J. Avaliação de Disciplinas, Cátedra UNESCO de Educação a Distância da UNB, 1997.

LAZOWSKA, E. D., ZAHORJAN, J.; GRAHAM, G. S.; SEVCIK, K. C., Quantitative System Performance: Computer System Analysis Using Queuing Network Models, Prentice-Hall, 1984.

LITZKOW, M., TANNENBAUM, T., BASNEY, J., LIVNY M., "Checkpoint and Migration of UNIX Processes in the Condor Distributed Processing System", Computer Sciences Technical Report \#1346, University of Wisconsin-Madison, abril, 1997.

LÜLING, R., MONIEN, B., RAMME, F., "Load balancing in large networks: A comparative study", Third IEEE Symposium on Parallel and Distributed 
(MacDougall, 1989)

(Maciel et al., 1996)

(Mehra \& Wah, 1993)

(Molloy, 1982)

(Muniz, 1994)

(Murata, 1989)

(Orlandi, 1995)

(Peterson, 1981)

(Powley et al., 1993)

(Prado, 1999)

(Santana \& Zaluska, 1988)

(Santana, 1990)

(Shirazi et al., 1995)

(Shivaratri et al.,1992)

(Silva, 2000)
Processing, Dallas, 1991.

MACDOUGALL, M. H., Simulating Computer Systems. Techniques and Tools, The MT Press, 1989.

MACIEL, P. R. M., LINS, R. D., CUNHA, P. R. F., Introdução às Redes de Petri e Aplicaçóes, $10^{t}$ Escola de Computação, Campinas, Julho, 1996.

MEHRA, P., WAH, B.W., Automated Learning of Load Balancing Strategies for A Distributed Computer System, University of Illinois at Urbana-Champaign, ftp://ftp.ibr.cs.tu-bs.de, 1993.

MOLLOY, M. K., "Performance Evaluation Using Stochastic Petri Nets", IEEE Trans. Comput., vol. C31, n. 9, p. 913-17, 1982.

MUNIZ, F.J., "Parallel Load Balancing on Message Passing Architectures", T'ese de Doutorado, Faculdade de Engenharia, Universidade de Southampton, Março, 1994.

MURATA, T, Petri Nets: Properties Analysis and Applications, Proceedings of the IEEE, vol. 77, n. 4, pp. 541-580, 1989.

ORLANDI, R. C. G. S., "Ferramentas para Análise de Desempenho de Sistemas Computacionais Distribuídos", Instituto de Ciências Matemáticas e de Computação, Universidade de São Paulo (ICMC/USP), 1995.

PETERSON, J. L. Petri Nets. An Introduction. s.l., Prentice Hall Inc., 1981.

POWLEY, C., FERGUSON, C., KORF, R. E., "Depthfirst heuristic search on a SIMD machine", Artificial Intelligence, vol. 60, 1993.

PRADO, D. S., Teoria das Fillas e da Simulação, Editora de Desenvolvimento Gerencial, 1999.

SANTANA, M. J., ZALUSKA, E. J., Load Balancing in a Session-based Distributed File-store Architecture, Software-Practice and Experience, vol. 18(11), pp. 1091-1107, Novembro, 1988.

SANTANA, M. J., "An Advanced Filestore Architecture for a Multiple - Lan Distributed Computing System", PHD Thesis, University of Southampton, 1990.

SHIRAZl, B. A., HURSON, A. R., KAVI, K. M., Scheduling and Load Balancing in Parallel and Distributed Systems, $1^{\mathbf{A}}$ ed., IEEE Computer Society Press, 1995.

SHIVARATRI, N. G., KREUGER, P., SINGHAL, M., "Load Distribution for Locally Distributed Systems", Computer, v. 25, pp. 33-44, Dezembro, 1992.

SILVA, A. R. F., "Modelos de redes de filas para Sistemas Computacionais Distribuídos - Simulação X 
(Snir et al., 1996)

(Soares, 1992)

(Souza, 1996)

(Souza, 2000)

(Souza et al., 2000)
Métodos Analíticos", Dissertação de Mestrado, Instituto de Ciências Matemáticas e de Computação, Universidade de São Paulo (ICMC/USP), 2000.

SNIR, M., OTTO, S., STEVEN, H., WALKER, D., DONGARRA, J. J., MPI: The Complete Reference, The MIT Press, 1996.

SOARES, L. F. G., Modelagem e Simulação Discreta de Sistemas, Editora Campus, 1992.

SOUZA, M. A., "Avaliação das Rotinas de Comunicação Ponto-a-Ponto do MPI", Dissertação de Mestrado, Instituto de Ciências Matemáticas e de Computação, Universidade de São Paulo (ICMC/USP), 1996.

SOUZA, P. S. L.. "AMIGO: Uma Contribuição para a Convergência na Área de Escalonamento de Processos", Tese de Doutorado, Instituto de Física de São Carlos (IFSC/USP), junho, 2000.

SOUZA, P. S. L., SANTANA, M. J., SANTANA, R. H. C., "Escalonamento de Processos: Uma Contribuição para a Convergência da Área", Notas, Instituto de Ciências Matemáticas e de Computação, Universidade de São Paulo (ICMC/USP), 2000.

(Vaughan \& O'Donovan, 1998) VAUGHAN, J. G., O'DONOVAN, M., 'Experimental evaluation of distributed load balancing implementations", Concurrency: Pract. Exper., vol. 10(10), 1998. 


\section{Apêndice A}

\section{Tabelas com os valores de Balanceamento de Carga obtidos nas Simulações}

Este Apêndice contém as tabelas utilizadas nos cálculos dos balanceamentos para os casos probabilísticos e estocásticos. 


\begin{tabular}{|c|c|c|c|c|}
\hline \multicolumn{5}{|c|}{ Execuç̄es p/ Alteragăo 1 porbabilistica Homogếnea } \\
\hline 1 & 2 & 3 & 4 & \\
\hline $60,97 \%$ & $0,00 \%$ & $91,34 \%$ & $87,63 \%$ & $84,39 \%$ \\
\hline $0,00 \%$ & $66,67 \%$ & $34,53 \%$ & $50,00 \%$ & $70,96 \%$ \\
\hline $0,00 \%$ & $66,67 \%$ & $0,00 \%$ & $13,40 \%$ & $65,36 \%$ \\
\hline $73,04 \%$ & $75,26 \%$ & $65,36 \%$ & $8,35 \%$ & $13,40 \%$ \\
\hline $0,00 \%$ & $78,35 \%$ & $64,75 \%$ & $100,00 \%$ & $100,00 \%$ \\
\hline $13,40 \%$ & $0,00 \%$ & $50,00 \%$ & $13,40 \%$ & $54,17 \%$ \\
\hline $0,00 \%$ & $50,00 \%$ & $75,00 \%$ & $13,40 \%$ & $41,92 \%$ \\
\hline $88,82 \%$ & $84,25 \%$ & $0,00 \%$ & $56,70 \%$ & $81,87 \%$ \\
\hline $13,40 \%$ & $81,82 \%$ & $86,68 \%$ & $50,00 \%$ & $71,36 \%$ \\
\hline $13,40 \%$ & $66,67 \%$ & $88,82 \%$ & $0,00 \%$ & $73,04 \%$ \\
\hline $100,00 \%$ & $0,00 \%$ & $82,66 \%$ & $95,65 \%$ & $78,35 \%$ \\
\hline $0,00 \%$ & $75,00 \%$ & $91,34 \%$ & $50,00 \%$ & $60,00 \%$ \\
\hline $88,83 \%$ & $56,70 \%$ & $65,36 \%$ & $71,43 \%$ & $65,36 \%$ \\
\hline $65,36 \%$ & $0,00 \%$ & $41,92 \%$ & $50,00 \%$ & $56,70 \%$ \\
\hline $65,36 \%$ & $66,67 \%$ & $75,88 \%$ & $64,75 \%$ & $66,67 \%$ \\
\hline $75,00 \%$ & $100,00 \%$ & $83,33 \%$ & $50,00 \%$ & $43,23 \%$ \\
\hline $100,00 \%$ & $0,00 \%$ & $0,00 \%$ & $65,36 \%$ & $83,63 \%$ \\
\hline $66,67 \%$ & $0,00 \%$ & $0,00 \%$ & $50,00 \%$ & $71,43 \%$ \\
\hline $13,40 \%$ & $85,66 \%$ & $100,00 \%$ & $54,17 \%$ & $60,00 \%$ \\
\hline $78,35 \%$ & $0,00 \%$ & $77,79 \%$ & $60,00 \%$ & $78,35 \%$ \\
\hline $66,67 \%$ & $78,35 \%$ & $0,00 \%$ & $50,00 \%$ & $65,36 \%$ \\
\hline $75,26 \%$ & $0,00 \%$ & $0,00 \%$ & $71,36 \%$ & $60,00 \%$ \\
\hline $75,88 \%$ & $100,00 \%$ & $87,61 \%$ & $50,00 \%$ & $13,40 \%$ \\
\hline $71,36 \%$ & $41,92 \%$ & $75,26 \%$ & $78,35 \%$ & $85,71 \%$ \\
\hline $67,27 \%$ & $66,67 \%$ & $0,00 \%$ & $30,72 \%$ & $13,40 \%$ \\
\hline $66,67 \%$ & $0,00 \%$ & $92,31 \%$ & $25,82 \%$ & $65,36 \%$ \\
\hline $63,26 \%$ & $54,17 \%$ & $13,40 \%$ & $50,00 \%$ & $75,26 \%$ \\
\hline $0,00 \%$ & $13,40 \%$ & $69,80 \%$ & $0,00 \%$ & $71,43 \%$ \\
\hline $80,00 \%$ & $0,00 \%$ & $80,00 \%$ & $60,00 \%$ & $65,36 \%$ \\
\hline $64,75 \%$ & $50,00 \%$ & $13,40 \%$ & $50,00 \%$ & $66,67 \%$ \\
\hline $30,72 \%$ & $13,40 \%$ & $67,27 \%$ & $75,00 \%$ & $66,67 \%$ \\
\hline $63,26 \%$ & $0,00 \%$ & $0,00 \%$ & $50,00 \%$ & $50,00 \%$ \\
\hline $75,26 \%$ & $13,40 \%$ & $71,36 \%$ & $66,67 \%$ & $94,03 \%$ \\
\hline $87,63 \%$ & $50,00 \%$ & $56,70 \%$ & $0,00 \%$ & $66,67 \%$ \\
\hline $0,00 \%$ & $0,00 \%$ & $75,26 \%$ & $0,00 \%$ & $100,00 \%$ \\
\hline $56,70 \%$ & $66,67 \%$ & $81,82 \%$ & $60,00 \%$ & $75,26 \%$ \\
\hline $43,23 \%$ & $73,35 \%$ & $13,40 \%$ & $50,00 \%$ & $54,17 \%$ \\
\hline $75,26 \%$ & $64,75 \%$ & $65,36 \%$ & $56,70 \%$ & $90,64 \%$ \\
\hline $55,39 \%$ & $0,00 \%$ & $0,00 \%$ & $8,35 \%$ & $56,70 \%$ \\
\hline $73,04 \%$ & $90,00 \%$ & $64,75 \%$ & $0,00 \%$ & $86,14 \%$ \\
\hline $75,00 \%$ & $0,00 \%$ & $79,17 \%$ & $78,35 \%$ & $50,00 \%$ \\
\hline $80,13 \%$ & $85,22 \%$ & $0,00 \%$ & $8,35 \%$ & $0,00 \%$ \\
\hline $100,00 \%$ & $67,27 \%$ & $75,65 \%$ & $13,40 \%$ & $66,67 \%$ \\
\hline $65,36 \%$ & $66,67 \%$ & $0,00 \%$ & $51,96 \%$ & $56,70 \%$ \\
\hline $100,00 \%$ & $73,04 \%$ & $54,17 \%$ & $50,00 \%$ & $75,98 \%$ \\
\hline $50,00 \%$ & $65,36 \%$ & $71,13 \%$ & $78,35 \%$ & $56,70 \%$ \\
\hline $79,17 \%$ & $60,00 \%$ & $78,35 \%$ & $0,00 \%$ & $64,75 \%$ \\
\hline $75,26 \%$ & $78,35 \%$ & $100,00 \%$ & $0,00 \%$ & $89,17 \%$ \\
\hline $0,00 \%$ & $100,00 \%$ & $73,04 \%$ & $89,81 \%$ & $68,78 \%$ \\
\hline $0,00 \%$ & $55,39 \%$ & $60,26 \%$ & $50,00 \%$ & $75,26 \%$ \\
\hline $100,00 \%$ & $41,92 \%$ & $66,67 \%$ & $13,40 \%$ & $87,50 \%$ \\
\hline $75,26 \%$ & $0,00 \%$ & $81,82 \%$ & $50,00 \%$ & $0,00 \%$ \\
\hline $64,75 \%$ & $0,00 \%$ & $90,00 \%$ & $13,40 \%$ & $100,00 \%$ \\
\hline $13,40 \%$ & $87,50 \%$ & $84,25 \%$ & $78,35 \%$ & $89,17 \%$ \\
\hline $78,35 \%$ & $0,00 \%$ & $56,70 \%$ & $0,00 \%$ & $56,70 \%$ \\
\hline $71.43 \%$ & $66,78 \%$ & $0,00 \%$ & $9,86 \%$ & $65,36 \%$ \\
\hline $66,67 \%$ & $92,31 \%$ & $0,00 \%$ & $13,40 \%$ & $87,51 \%$ \\
\hline $0,00 \%$ & $66,67 \%$ & $56,70 \%$ & $50,00 \%$ & $65,36 \%$ \\
\hline $50,51 \%$ & $56,70 \%$ & $100,00 \%$ & $34,53 \%$ & $0,00 \%$ \\
\hline $0,00 \%$ & $73,04 \%$ & $0,00 \%$ & $43,23 \%$ & $100,00 \%$ \\
\hline $0,00 \%$ & $0,00 \%$ & $65,36 \%$ & $50,00 \%$ & $0,00 \%$ \\
\hline $13,40 \%$ & $65,36 \%$ & $100,00 \%$ & $82,37 \%$ & 13,40 \\
\hline $13,40 \%$ & $0,00 \%$ & $65,36 \%$ & $50,00 \%$ & 78,35 \\
\hline $92,49 \%$ & $88,89 \%$ & $100,00 \%$ & $80,00 \%$ & $75,00 \%$ \\
\hline $65,36 \%$ & $0,00 \%$ & $13,40 \%$ & $50,00 \%$ & $65,36 \%$ \\
\hline $88,90 \%$ & $0,00 \%$ & $0,00 \%$ & $8,35 \%$ & $78,35 \%$ \\
\hline $75,02 \%$ & $72,85 \%$ & $66,67 \%$ & $0,00 \%$ & $0,00 \%$ \\
\hline $13,40 \%$ & $50,51 \%$ & $13,40 \%$ & $84,77 \%$ & 100,00 \\
\hline $56,70 \%$ & $65,36 \%$ & $53,34 \%$ & $50,00 \%$ & $56,70 \%$ \\
\hline $0,00 \%$ & $100,00 \%$ & $0,00 \%$ & $13,40 \%$ & $75,26 \%$ \\
\hline $0,00 \%$ & $58,34 \%$ & $75,00 \%$ & $50,00 \%$ & \\
\hline $75,00 \%$ & $84,20 \%$ & $75,26 \%$ & $13,40 \%$ & $65,68 \%$ \\
\hline
\end{tabular}

\begin{tabular}{|c|c|c|c|c|}
\hline \multicolumn{5}{|c|}{ Execuçōes p/ Alteraçä́ 1 porbabilística Heterogênea } \\
\hline 1 & 2 & 3 & 4 & \\
\hline $76,87 \%$ & $1,76 \%$ & $75,94 \%$ & $78,06 \%$ & $81,92 \%$ \\
\hline $0,00 \%$ & $91,06 \%$ & $64,51 \%$ & $8,33 \%$ & $88,67 \%$ \\
\hline $0,00 \%$ & $91,06 \%$ & $0,00 \%$ & $48,97 \%$ & $44,82 \%$ \\
\hline $71,51 \%$ & $86,04 \%$ & $73,42 \%$ & $73,35 \%$ & $11,67 \%$ \\
\hline $0,03 \%$ & $85,38 \%$ & $96,90 \%$ & $92,02 \%$ & $69,38 \%$ \\
\hline $8,33 \%$ & $0,00 \%$ & $75,75 \%$ & $96,90 \%$ & $86,29 \%$ \\
\hline $8,33 \%$ & $69,38 \%$ & $90,77 \%$ & $44,82 \%$ & $70,65 \%$ \\
\hline $74,76 \%$ & $79,40 \%$ & $0,00 \%$ & $86,04 \%$ & $85,98 \%$ \\
\hline $0,00 \%$ & $85,81 \%$ & $79,00 \%$ & $95,70 \%$ & $95,70 \%$ \\
\hline $45,51 \%$ & $63,48 \%$ & $74,76 \%$ & $80,02 \%$ & $86,86 \%$ \\
\hline $4726 \%$ & $1,76 \%$ & $81,70 \%$ & $86,04 \%$ & $80,02 \%$ \\
\hline $10,80 \%$ & $90,77 \%$ & $75,94 \%$ & $90,77 \%$ & $86,04 \%$ \\
\hline $46,51 \%$ & $29,06 \%$ & $44,82 \%$ & $63,48 \%$ & $44,62 \%$ \\
\hline $77,44 \%$ & $0,00 \%$ & $70,66 \%$ & $86,04 \%$ & $29,06 \%$ \\
\hline $44,62 \%$ & $91,05 \%$ & $91,45 \%$ & $29,06 \%$ & $91,06 \%$ \\
\hline $0,00 \%$ & $7,00 \%$ & $84,51 \%$ & $80,02 \%$ & $76,34 \%$ \\
\hline $90,77 \%$ & $0,00 \%$ & $0,00 \%$ & $67,59 \%$ & $84,15 \%$ \\
\hline $69,38 \%$ & $0,00 \%$ & $0,00 \%$ & $80,02 \%$ & $92,02 \%$ \\
\hline $91,05 \%$ & $81,72 \%$ & $69,38 \%$ & $76,88 \%$ & $86,04 \%$ \\
\hline $11,67 \%$ & $0,00 \%$ & $89,71 \%$ & $8,33 \%$ & $80,02 \%$ \\
\hline $80,02 \%$ & $80,02 \%$ & $0,00 \%$ & $80,02 \%$ & $44,82 \%$ \\
\hline $91,06 \%$ & $0,00 \%$ & $7,00 \%$ & $8,33 \%$ & $86,04 \%$ \\
\hline $82,41 \%$ & $6938 \%$ & $80,47 \%$ & $76,34 \%$ & $11,67 \%$ \\
\hline $91,45 \%$ & $70,66 \%$ & $82,41 \%$ & $84,01 \%$ & $82,41 \%$ \\
\hline $95,70 \%$ & $9106 \%$ & $0,00 \%$ & $87,31 \%$ & $1,76 \%$ \\
\hline $84,79 \%$ & $0,00 \%$ & $76,42 \%$ & $82,63 \%$ & $50,47 \%$ \\
\hline $91,06 \%$ & $86,29 \%$ & $11,67 \%$ & $8,33 \%$ & $62,41 \%$ \\
\hline $96,55 \%$ & $1,76 \%$ & $95,54 \%$ & $91,06 \%$ & $92,02 \%$ \\
\hline $69,36 \%$ & $0,00 \%$ & $87,31 \%$ & $75,75 \%$ & $44,62 \%$ \\
\hline $87,31 \%$ & $40,23 \%$ & $11,67 \%$ & $76,88 \%$ & $91,06 \%$ \\
\hline $67,59 \%$ & $8,33 \%$ & $84,79 \%$ & $0,00 \%$ & $91,06 \%$ \\
\hline $44,82 \%$ & $0,00 \%$ & $0,00 \%$ & $0,00 \%$ & $75,75 \%$ \\
\hline $96,55 \%$ & $8,33 \%$ & $95,70 \%$ & $10,80 \%$ & $74,10 \%$ \\
\hline $86,04 \%$ & $57,93 \%$ & $48,97 \%$ & $80,02 \%$ & $91,06 \%$ \\
\hline $78,06 \%$ & $0,00 \%$ & $82,41 \%$ & $76,39 \%$ & $69,38 \%$ \\
\hline $10,80 \%$ & $63,48 \%$ & $77,70 \%$ & $80,02 \%$ & $82,41 \%$ \\
\hline $29,06 \%$ & $78,64 \%$ & $0,00 \%$ & $80,02 \%$ & $86,29 \%$ \\
\hline $76,34 \%$ & $78,64 \%$ & $44,62 \%$ & $90,77 \%$ & $72,81 \%$ \\
\hline $62,41 \%$ & $0,00 \%$ & $0,00 \%$ & $90,77 \%$ & $48,97 \%$ \\
\hline $89,00 \%$ & $78,53 \%$ & $70,66 \%$ & $88,33 \%$ & $74,44 \%$ \\
\hline $71,51 \%$ & $1,76 \%$ & $88,33 \%$ & $76,34 \%$ & $47,26 \%$ \\
\hline $90,77 \%$ & $82,68 \%$ & $0,00 \%$ & $84,08 \%$ & $10,80 \%$ \\
\hline $86,19 \%$ & $84,79 \%$ & $91,61 \%$ & $80,02 \%$ & $91,06 \%$ \\
\hline $69,38 \%$ & $91,06 \%$ & $0,00 \%$ & $1,76 \%$ & $29,06 \%$ \\
\hline $73,42 \%$ & $93,72 \%$ & $73,42 \%$ & $69,38 \%$ & $79,00 \%$ \\
\hline $69,38 \%$ & $44,82 \%$ & $91,06 \%$ & $0,00 \%$ & $85,38 \%$ \\
\hline $69,38 \%$ & $87,31 \%$ & $85,38 \%$ & $69,38 \%$ & $96,90 \%$ \\
\hline $88,33 \%$ & $80,02 \%$ & $69,38 \%$ & $91,06 \%$ & $77,24 \%$ \\
\hline $62,41 \%$ & $69,38 \%$ & $86,66 \%$ & $29,06 \%$ & $81,70 \%$ \\
\hline $8,33 \%$ & $89,00 \%$ & $90,37 \%$ & $0,00 \%$ & $86,04 \%$ \\
\hline $0,00 \%$ & $70,65 \%$ & $84,51 \%$ & $91,06 \%$ & $80,81 \%$ \\
\hline $69,38 \%$ & $0,00 \%$ & $77,70 \%$ & $82,41 \%$ & $0,00 \%$ \\
\hline $86,04 \%$ & $0,00 \%$ & $76,53 \%$ & $82,41 \%$ & $69,38 \%$ \\
\hline $96,90 \%$ & $80,81 \%$ & $79,40 \%$ & $79,40 \%$ & $77,24 \%$ \\
\hline $11,67 \%$ & $0,00 \%$ & $0,03 \%$ & $80,02 \%$ & $29,05 \%$ \\
\hline $80,02 \%$ & $81,70 \%$ & $0,00 \%$ & $50,47 \%$ & $73,42 \%$ \\
\hline $92,02 \%$ & $76,42 \%$ & $0,00 \%$ & $59,06 \%$ & $80,19 \%$ \\
\hline $91,06 \%$ & $91,06 \%$ & $85,38 \%$ & $92,02 \%$ & $73,42 \%$ \\
\hline $0,00 \%$ & $29,06 \%$ & $10,80 \%$ & $80,02 \%$ & $0,00 \%$ \\
\hline $58,21 \%$ & $86,86 \%$ & $0,00 \%$ & $0,00 \%$ & $69,38 \%$ \\
\hline $0,00 \%$ & $0,00 \%$ & $87,31 \%$ & $77,01 \%$ & $0,00 \%$ \\
\hline $0,00 \%$ & $73,42 \%$ & $75,75 \%$ & $85,38 \%$ & $11,67 \%$ \\
\hline $11,67 \%$ & $69,38 \%$ & $73,42 \%$ & $91,45 \%$ & $80,02 \%$ \\
\hline $11,67 \%$ & $79,54 \%$ & $69,38 \%$ & $90,37 \%$ & $90,77 \%$ \\
\hline $76,04 \%$ & $0,00 \%$ & $8,33 \%$ & $11,67 \%$ & $50,47 \%$ \\
\hline $44,82 \%$ & $8,33 \%$ & $8,33 \%$ & $79,40 \%$ & $80,02 \%$ \\
\hline $79,39 \%$ & $80,19 \%$ & $91,06 \%$ & $66,96 \%$ & $0,00 \%$ \\
\hline $84,78 \%$ & $58,21 \%$ & $11,67 \%$ & $83,38 \%$ & $69,38 \%$ \\
\hline $8,33 \%$ & $73,42 \%$ & $77,52 \%$ & $44,82 \%$ & $48,97 \%$ \\
\hline $29,06 \%$ & $69,38 \%$ & $0,00 \%$ & $94,84 \%$ & $62,41 \%$ \\
\hline $0,00 \%$ & $77,52 \%$ & $90,77 \%$ & $69,38 \%$ & $0,00 \%$ \\
\hline $73,42 \%$ & $82,79 \%$ & $82,41 \%$ & $90,77 \%$ & $94,84 \%$ \\
\hline
\end{tabular}




\begin{tabular}{|c|c|c|c|c|}
\hline \multicolumn{5}{|c|}{ Execuçōes P/ Alteraçăo 2 Probabilistica Homogônea } \\
\hline 1 & 2 & 3 & 4 & 5 \\
\hline $8,7 \overline{4} \%$ & $0,00 \%$ & $82,68 \%$ & $0,00 \%$ & $0,00 \%$ \\
\hline $94,75 \%$ & $0,00 \%$ & $11,71 \%$ & $0,00 \%$ & $8,93 \%$ \\
\hline $94,75 \%$ & $55,12 \%$ & $10,49 \%$ & $0,00 \%$ & $8,93 \%$ \\
\hline $94,75 \%$ & $76,35 \%$ & $0,00 \%$ & $0,00 \%$ & $11,46 \%$ \\
\hline $12,98 \%$ & $13,07 \%$ & $74,96 \%$ & $0,00 \%$ & $11,46 \%$ \\
\hline $12,98 \%$ & $13,07 \%$ & $74,96 \%$ & $67,01 \%$ & $84,01 \%$ \\
\hline $12,98 \%$ & $13,07 \%$ & $0,00 \%$ & $0,00 \%$ & $84,01 \%$ \\
\hline $12,98 \%$ & $13,07 \%$ & $0,00 \%$ & $-83,90 \%$ & $84,01 \%$ \\
\hline $0,00 \%$ & $78,82 \%$ & $10,49 \%$ & $0,00 \%$ & $0,00 \%$ \\
\hline $0,00 \%$ & $0,00 \%$ & $12,56 \%$ & $0,00 \%$ & $0,00 \%$ \\
\hline $94,75 \%$ & $0,00 \%$ & $0,00 \%$ & $0,00 \%$ & $0,00 \%$ \\
\hline $94,75 \%$ & $93,30 \%$ & $0,00 \%$ & $0,00 \%$ & $11,71 \%$ \\
\hline $12,98 \%$ & $93,30 \%$ & $0,00 \%$ & $0,00 \%$ & $0,00 \%$ \\
\hline $12,98 \%$ & $0,00 \%$ & $0,00 \%$ & $12,89 \%$ & $0,00 \%$ \\
\hline $12,98 \%$ & $13,13 \%$ & $0,00 \%$ & $12,89 \%$ & $0,00 \%$ \\
\hline $12,98 \%$ & $13,13 \%$ & $0,00 \%$ & $13,40 \%$ & $0,00 \%$ \\
\hline $0,00 \%$ & $0,00 \%$ & $0,00 \%$ & $13,40 \%$ & $13,25 \%$ \\
\hline $0,00 \%$ & $0,00 \%$ & $0,00 \%$ & $13,40 \%$ & $13,25 \%$ \\
\hline $0,00 \%$ & $0,00 \%$ & $0,00 \%$ & $0,00 \%$ & $13,25 \%$ \\
\hline $0,00 \%$ & $0,00 \%$ & $12,79 \%$ & $0,00 \%$ & $0,00 \%$ \\
\hline $12,98 \%$ & $0,00 \%$ & $12,79 \%$ & $13,40 \%$ & $91,08 \%$ \\
\hline $12,98 \%$ & $0,00 \%$ & $12,79 \%$ & $90,36 \%$ & $0,00 \%$ \\
\hline $94,75 \%$ & $13,13 \%$ & $94,60 \%$ & $90,36 \%$ & $0,00 \%$ \\
\hline $94,75 \%$ & $13,13 \%$ & $13,40 \%$ & $13,40 \%$ & $0,00 \%$ \\
\hline $95,42 \%$ & $93,30 \%$ & $13,35 \%$ & $13,40 \%$ & $91,08 \%$ \\
\hline $13,37 \%$ & $93,30 \%$ & $98,01 \%$ & $13,40 \%$ & $0,00 \%$ \\
\hline $0,00 \%$ & $93,30 \%$ & $98,01 \%$ & $13,40 \%$ & $13,00 \%$ \\
\hline $0,00 \%$ & $30 \%$ & $01 \%$ & $13,40 \%$ & $13,00 \%$ \\
\hline $0,00 \%$ & $13,13 \%$ & $13,35 \%$ & $13,40 \%$ & $91,08 \%$ \\
\hline $95,42 \%$ & $93,30 \%$ & $13,35 \%$ & $13,40 \%$ & $91,08 \%$ \\
\hline $13,37 \%$ & $13,13 \%$ & $13,35 \%$ & $13,40 \%$ & $91,08 \%$ \\
\hline $95,42 \%$ & $13,13 \%$ & $0,00 \%$ & $13,40 \%$ & $91,08 \%$ \\
\hline $95,42 \%$ & $13,13 \%$ & $13,35 \%$ & $0,00 \%$ & $13,00 \%$ \\
\hline $0,00 \%$ & $0,00 \%$ & $0,00 \%$ & $0,00 \%$ & $0,00 \%$ \\
\hline $0,00 \%$ & $13,13 \%$ & $98,01 \%$ & $0,00 \%$ & $0,00 \%$ \\
\hline $95,42 \%$ & $0,00 \%$ & $0,00 \%$ & $0,00 \%$ & $0,00 \%$ \\
\hline $0,00 \%$ & $93,30 \%$ & $0,00 \%$ & $0,00 \%$ & $13,00 \%$ \\
\hline $13,37 \%$ & $0,00 \%$ & $0,00 \%$ & $13,35 \%$ & $13,00 \%$ \\
\hline $13,37 \%$ & $93,30 \%$ & $98,01 \%$ & $13,35 \%$ & $13,00 \%$ \\
\hline $95,42 \%$ & $0,00 \%$ & $98,01 \%$ & $0,00 \%$ & $0,00 \%$ \\
\hline $13,38 \%$ & $0,00 \%$ & $98,01 \%$ & $13,35 \%$ & $0,00 \%$ \\
\hline $95,93 \%$ & $93,30 \%$ & $98,01 \%$ & $95,12 \%$ & $91,08 \%$ \\
\hline $13,38 \%$ & $0,00 \%$ & $0,00 \%$ & $0,00 \%$ & $91,08 \%$ \\
\hline $0,00 \%$ & $0,00 \%$ & $0,00 \%$ & $0,00 \%$ & $91,08 \%$ \\
\hline $0,00 \%$ & $93,30 \%$ & $0,00 \%$ & $95,12 \%$ & $13,00 \%$ \\
\hline $0,00 \%$ & $13,07 \%$ & $0,00 \%$ & $95,12 \%$ & $13,00 \%$ \\
\hline $13,38 \%$ & $13,07 \%$ & $13,35 \%$ &, $00 \%$ & $0,00 \%$ \\
\hline $0,00 \%$ & $93,30 \%$ & $98,01 \%$ & $0,00 \%$ & \\
\hline $13,38 \%$ & $93,30 \%$ & $98,01 \%$ & $0,00 \%$ & $13,00 \%$ \\
\hline $13,38 \%$ & $93,30 \%$ & $100,00 \%$ & $0,00 \%$ & $13,00 \%$ \\
\hline $0,00 \%$ & $93,30 \%$ & $100,00 \%$ & $0,00 \%$ & $13,00 \%$ \\
\hline $0,00 \%$ & $93,30 \%$ & $13,40 \%$ & $0,00 \%$ & $0,00 \%$ \\
\hline $13,38 \%$ & $93,30 \%$ & $13,40 \%$ & $13,35 \%$ & $13,00 \%$ \\
\hline $13,38 \%$ & $93,30 \%$ & $13,40 \%$ & $13,35 \%$ & $13,00 \%$ \\
\hline $95,93 \%$ & $0,00 \%$ & $13,40 \%$ & $0,00 \%$ & $0,00 \%$ \\
\hline $95,93 \%$ & $93,30 \%$ & $100,00 \%$ & $0,00 \%$ & $13,00 \%$ \\
\hline $95,93 \%$ & $0,00 \%$ & $100,00 \%$ & $13,25 \%$ & $0,00 \%$ \\
\hline $0,00 \%$ & $13,13 \%$ & $13,40 \%$ & $0,00 \%$ & $95,15 \%$ \\
\hline $13,38 \%$ & $13,13 \%$ & $13,40 \%$ & $0,00 \%$ & $13,00 \%$ \\
\hline $0,00 \%$ & $93,30 \%$ & $13,40 \%$ & $13,25 \%$ & $91,08 \%$ \\
\hline $13,38 \%$ & $13,13 \%$ & $0,00 \%$ & $98,01 \%$ & $13,00 \%$ \\
\hline $0,00 \%$ & $13,13 \%$ & $0,00 \%$ & $98,01 \%$ & $0,00 \%$ \\
\hline $0,00 \%$ & $0,00 \%$ & $0,00 \%$ & $98,01 \%$ & $0,00 \%$ \\
\hline $95,93 \%$ & $0,00 \%$ & $94,07 \%$ & $98,01 \%$ & $91,08 \%$ \\
\hline $0,00 \%$ & $13,13 \%$ & $13,40 \%$ & $13,25 \%$ & $91,08 \%$ \\
\hline $0.00 \%$ & $13,13 \%$ & $0,00 \%$ & $98,01 \%$ & $0,00 \%$ \\
\hline $0,00 \%$ & $13,13 \%$ & $13,40 \%$ & $0,00 \%$ & $91,08 \%$ \\
\hline $13,38 \%$ & $93,30 \%$ & $0,00 \%$ & $0,00 \%$ & $0,00 \%$ \\
\hline $13,38 \%$ & $0,00 \%$ & $0,00 \%$ & $13,25 \%$ & $91,08 \%$ \\
\hline $13,38 \%$ & $0,00 \%$ & $0,00 \%$ & $98,01 \%$ & $91,08 \%$ \\
\hline $13,38 \%$ & $93,30 \%$ & $0,00 \%$ & $98,01 \%$ & $91,08 \%$ \\
\hline $13,38 \%$ & $13,13 \%$ & $0,00 \%$ & $13,25 \%$ & $0,00 \%$ \\
\hline
\end{tabular}

\begin{tabular}{|c|c|c|c|c|}
\hline \multicolumn{5}{|c|}{ Execucöes P/ Alteractao 2 Probabilistica Hoterogonea } \\
\hline 1 & 2 & 3 & 4 & 5 \\
\hline $8,33 \%$ & $7,62 \%$ & $2,78 \%$ & $8,35 \%$ & $66,14 \%$ \\
\hline $8,33 \%$ & $0,00 \%$ & $2,78 \%$ & $6,58 \%$ & $40,77 \%$ \\
\hline $9,66 \%$ & $4,31 \%$ & $7,24 \%$ & $0,00 \%$ & $66,14 \%$ \\
\hline $9,66 \%$ & $6.37 \%$ & $68,58 \%$ & $4,11 \%$ & $0,00 \%$ \\
\hline $6,38 \%$ & $0,00 \%$ & $7,24 \%$ & $7,24 \%$ & $42,72 \%$ \\
\hline $8,33 \%$ & $20,67 \%$ & $26.51 \%$ & $4,11 \%$ & $40,77 \%$ \\
\hline $76,13 \%$ & $65,55 \%$ & $26,51 \%$ & $5,83 \%$ & $66,14 \%$ \\
\hline $5,55 \%$ & $20,67 \%$ & $59,43 \%$ & $0,00 \%$ & $42,72 \%$ \\
\hline $9,66 \%$ & $6.37 \%$ & $0,00 \%$ & $4,11 \%$ & $40,77 \%$ \\
\hline $5,55 \%$ & $6,37 \%$ & $0,00 \%$ & $4,11 \%$ & $5,05 \%$ \\
\hline $9,66 \%$ & $49,09 \%$ & $0,00 \%$ & $6,19 \%$ & $1,76 \%$ \\
\hline $67,82 \%$ & $66,55 \%$ & $0,00 \%$ & $63,10 \%$ & $5,05 \%$ \\
\hline $58,77 \%$ & $7,19 \%$ & $0.00 \%$ & $4,28 \%$ & $0,00 \%$ \\
\hline $6,88 \%$ & $51,80 \%$ & $59,43 \%$ & $6.19 \%$ & $0,00 \%$ \\
\hline $8,33 \%$ & $11,22 \%$ & $2,78 \%$ & $10,44 \%$ & $0,00 \%$ \\
\hline & $6,37 \%$ & & $50,98 \%$ & $0,00 \%$ \\
\hline $6,46 \%$ & $3,77 \%$ & $47,63 \%$ & $63,10 \%$ & $1,76 \%$ \\
\hline $0,00 \%$ & $7,62 \%$ & $0,00 \%$ & $63,10 \%$ & $1,76 \%$ \\
\hline $6,33 \%$ & $3,77 \%$ & $0,00 \%$ & $10,44 \%$ & $6,33 \%$ \\
\hline $0,00 \%$ & $66,55 \%$ & $2,78 \%$ & $61,82 \%$ & $10,02 \%$ \\
\hline $4,35 \%$ & $7,62 \%$ & $0,00 \%$ & $6,88 \%$ & $76 \%$ \\
\hline $61,47 \%$ & $64,11 \%$ & $0,00 \%$ & $6,88 \%$ & $10,02 \%$ \\
\hline $8,33 \%$ & $7,62 \%$ & $6,95 \%$ & $6,19 \%$ & $8,33 \%$ \\
\hline $68,35 \%$ & $66,55 \%$ & $0,00 \%$ & $6,88 \%$ & $8,33 \%$ \\
\hline $5,02 \%$ & $7,62 \%$ & $6,29 \%$ & $6,88 \%$ & $10,02 \%$ \\
\hline $68,35 \%$ & $66,55 \%$ & $62.26 \%$ & $61,82 \%$ & $8,37 \%$ \\
\hline $4,35 \%$ & $6,24 \%$ & $0,00 \%$ & $4,28 \%$ & $73,49 \%$ \\
\hline $4,35 \%$ & $8,49 \%$ & $68,58 \%$ & $61,82 \%$ & $42,72 \%$ \\
\hline $5,55 \%$ & $0,00 \%$ & $10,10 \%$ & $6,46 \%$ & $0,00 \%$ \\
\hline $0,00 \%$ & $6,24 \%$ & $9 ; 49 \%$ & $6,19 \%$ & $11.67 \%$ \\
\hline $5,55 \%$ & $8,49 \%$ & $56 \%$ & $5,54 \%$ & $8,33 \%$ \\
\hline $4,35 \%$ & $66,55 \%$ & $65,58 \%$ & $68,70 \%$ & $66,74 \%$ \\
\hline $5,55 \%$ & $8,59 \%$ & $-9,49 \%$ & $3,46 \%$ & \\
\hline $5,55 \%$ & $6,37 \%$ & $68,58 \%$ & $0,00 \%$ & $-42,72 \%$ \\
\hline $5,55 \%$ & $66,55 \%$ & $0,00 \%$ & $10,44 \%$ & $8,37 \%$ \\
\hline $6,88 \%$ & $.51,80 \%$ & $68,58 \%$ & $9,50 \%$ & $0,00 \%$ \\
\hline $6,88 \%$ & $7,62 \%$ & $6,29 \%$ & $57,58 \%$ & $73,49 \%$ \\
\hline $4,35 \%$ & $4,31 \%$ & $2,78 \%$ & $5,54 \%$ & $8,37 \%$ \\
\hline $4,81 \%$ & $11,22 \%$ & $=.0,00 \%$ & $9,50 \%$ & $0,00 \%$ \\
\hline $5,60 \%$ & $0,00 \%$ & & $57,58 \%$ & $0,00 \%$ \\
\hline $0,00 \%$ & $55,51 \%$ & $59,43 \%$ & $5,39 \%$ & $5,22 \%$ \\
\hline $0,00 \%$ & $\therefore 0,00 \%$ & $0,00 \%$ & $10,85 \%$ & $-8,33 \%$ \\
\hline $0,00 \%$ & $55.51 \%$ & $59,43 \%$ &, $44 \%$ & $.73,49 \%$ \\
\hline $5,55 \%$ & $=0,00 \%$ & & & $8 \%$ \\
\hline $5,60 \%$ & $7,62 \%$ & $59,43 \%$ & $51 \%$ & $73,49 \%$ \\
\hline $0,00 \%$ & $51,80 \%$ & $0,00 \%$ & $31 \%$ & $0,00 \%$ \\
\hline $6,88 \%$ & $51,80 \%$ & $.0,00 \%$ & $65,51 \%$ & $75,92 \%$ \\
\hline $0,00 \%$ & $0,00 \%$ & & $.4,28 \%$ & $11,67 \%$ \\
\hline $76,13 \%$ & $55,51 \%$ & $7,40 \%$ & $65,51 \%$ & $0,00 \%$ \\
\hline $5,55 \%$ & $0,00 \%$ & $59,43 \%$ & $65 ; 55 \%$ & $73,49 \%$ \\
\hline & $0,00 \%$ & $6,29 \%$ & $8,33 \%$ & $75,92 \%$ \\
\hline $0,00 \%$ & $4,11 \%$ & $7,40 \%$ & $5,49 \%$ & $75,92 \%$ \\
\hline $6,88 \%$ & $1,17 \%$ & $6,29 \%$ & $68 ; 70 \%$ & $11,67 \%$ \\
\hline $6,98 \%$ & $6,37 \%$ & $0,00 \%$ & $.9,50 \%$ & $66,14 \%$ \\
\hline $6,98 \%$ & $0,00 \%$ & $58 \%$ & $8,33 \%$ & $8,33 \%$ \\
\hline $65,35 \%$ & $66,55 \%$ & $68,58 \%$ & $68,70 \%$ & $73,49 \%$ \\
\hline $5,55 \%$ & $6,37 \%$ & $2,78 \%$ & $65,51 \%$ & $75,92 \%$ \\
\hline $0,00 \%$ & $1122 \%$ & $0,00 \%$ & $1,94 \%$ & $66,14 \%$ \\
\hline $68,35 \%$ & $0,00 \%$ & $59,43 \%$ & $1,94 \%$ & $8,33 \%$ \\
\hline $68,35 \%$ & $55,51 \%$ & $9,49 \%$ & $4,62 \%$ & $66,14 \%$ \\
\hline $6,98 \%$ & $6,95 \%$ & $60,56 \%$ & $68,70 \%$ & $7,66 \%$ \\
\hline $6,88 \%$ & $55,51 \%$ & $60,58 \%$ & $4,62 \%$ & $7,68 \%$ \\
\hline $76,13 \%$ & $58,56 \%$ & $60,56 \%$ & $65,55 \%$ & $7,68 \%$ \\
\hline $62,76 \%$ & $6,24 \%$ & $6,29 \%$ & & $8,33 \%$ \\
\hline $62,78 \%$ & $58,56 \%$ & $5,55 \%$ & $4 ; 62 \%$ & $7,68 \%$ \\
\hline $5,55 \%$ & $3,28 \%$ & $5,55 \%$ & $6,19 \%$ & $7,68 \%$ \\
\hline $6,98 \%$ & $0,00 \%$ & $6,29 \%$ & $1,94 \%$ & $7,68 \%$ \\
\hline $63,35 \%$ & $64,14 \%$ & $6,29 \%$ & $69,38 \%$ & $8,33 \%$ \\
\hline $6,98 \%$ & $3,28 \%$ & $7,40 \%$ & $8,24 \%$ & $7,66 \%$ \\
\hline $5,55 \%$ & $53,56 \%$ & $5,55 \%$ & $8,24 \%$ & $8,33 \%$ \\
\hline $5,55 \%$ & $6,37 \%$ & $6,29 \%$ & $8,24 \%$ & $6,33 \%$ \\
\hline $8,17 \%$ & $0,00 \%$ & $5,55 \%$ & $5,49 \%$ & $8,33 \%$ \\
\hline
\end{tabular}




\begin{tabular}{|c|c|c|c|c|}
\hline \multicolumn{5}{|c|}{ Exocucöes D/DPWP original Estochstica Homogêne } \\
\hline 1 & 2 & 3 & $\begin{array}{r}4 \\
\end{array}$ & \\
\hline $100,00 \%$ & $93,81 \%$ & $93,07 \%$ & $78,35 \%$ & $65,36 \%$ \\
\hline $0,00 \%$ & $84,25 \%$ & $0,00 \%$ & $100,00 \%$ & $65,36 \%$ \\
\hline $82,68 \%$ & $87,63 \%$ & $82,68 \%$ & $13,04 \%$ & $84,25 \%$ \\
\hline $90,88 \%$ & $94,41 \%$ & $12,63 \%$ & $78,35 \%$ & $8,35 \%$ \\
\hline $0,00 \%$ & $95,44 \%$ & $100,00 \%$ & $12,63 \%$ & $100,00 \%$ \\
\hline$\overline{92,47 \%}$ & $13,40 \%$ & $100,00 \%$ & $10,79 \%$ & $95,67 \%$ \\
\hline $100,00 \%$ & $0,00 \%$ & $100,00 \%$ & $82,63 \%$ & $12,63 \%$ \\
\hline $100,00 \%$ & $0,00 \%$ & $90,88 \%$ & $56,70 \%$ & $11,81 \%$ \\
\hline $0,00 \%$ & $75,26 \%$ & $100,00 \%$ & $100,00 \%$ & $82,68 \%$ \\
\hline $0,00 \%$ & $92,13 \%$ & $0,00 \%$ & $100,00 \%$ & $75,26 \%$ \\
\hline $82,68 \%$ & $87,63 \%$ & $0,00 \%$ & $10,79 \%$ & $0,00 \%$ \\
\hline $0,00 \%$ & $0,00 \%$ & $10,79 \%$ & $0,00 \%$ & $13,30 \%$ \\
\hline $10,79 \%$ & $10,79 \%$ & $0,00 \%$ & $92,13 \%$ & $0,00 \%$ \\
\hline $0,00 \%$ & $0,00 \%$ & $75,26 \%$ & $75,26 \%$ & $8,35 \%$ \\
\hline $95,44 \%$ & $95,44 \%$ & $82,68 \%$ & $13,40 \%$ & $90,88 \%$ \\
\hline $84,25 \%$ & $84,25 \%$ & $100,00 \%$ & $90,88 \%$ & $82,68 \%$ \\
\hline $100,00 \%$ & $87,63 \%$ & $90,88 \%$ & $100,00 \%$ & $87,63 \%$ \\
\hline $13,40 \%$ & $87,63 \%$ & $56,70 \%$ & $13,40 \%$ & $0,00 \%$ \\
\hline $84,25 \%$ & $100,00 \%$ & $100,00 \%$ & $84,25 \%$ & $12,95 \%$ \\
\hline $100,00 \%$ & $90,88 \%$ & $84,25 \%$ & $0,00 \%$ & $82, \overline{63 \%}$ \\
\hline $0,00 \%$ & $75,26 \%$ & $82,68 \%$ & $75,26 \%$ & $87,63 \%$ \\
\hline $89,17 \%$ & $\overline{82}, 68 \%$ & $87,63 \%$ & $0,00 \%$ & $0,00 \%$ \\
\hline $0,00 \%$ & $0,00 \%$ & $0,00 \%$ & $0,00 \%$ & $8 \overline{6}, 68 \%$ \\
\hline $75,26 \%$ & $56,70 \%$ & $56,70 \%$ & $0,00 \%$ & $82,68 \%$ \\
\hline $13,40 \%$ & $78,35 \%$ & $0,00 \%$ & $0,00 \%$ & $13,40 \%$ \\
\hline $12,33 \%$ & $0,00 \%$ & $65,36 \%$ & $78,35 \%$ & $12,33 \%$ \\
\hline $12,82 \%$ & $12,33 \%$ & $0,00 \%$ & $0,00 \%$ & $12,82 \%$ \\
\hline $0,00 \%$ & $0,00 \%$ & $100,00 \%$ & $86,68 \%$ & $0,00 \%$ \\
\hline $100,00 \%$ & $13,40 \%$ & $89,17 \%$ & $13,40 \%$ & $13,40 \%$ \\
\hline $82,68 \%$ & $100,00 \%$ & $91,34 \%$ & $95,97 \%$ & $8,35 \%$ \\
\hline $97,21 \%$ & $82,68 \%$ & $84,25 \%$ & $0,00 \%$ & $82,68 \%$ \\
\hline $56,70 \%$ & $\overline{65,36 \%}$ & $65,36 \%$ & $93,34 \%$ & $00 \%$ \\
\hline $0,00 \%$ & $13,40 \%$ & $0,00 \%$ & $0,00 \%$ & $8,35 \%$ \\
\hline $100,00 \%$ & $13,40 \%$ & $0,00 \%$ & $13,40 \%$ & $92,47 \%$ \\
\hline $90,88 \%$ & $92,47 \%$ & $78,35 \%$ & $100,00 \%$ & $0,00 \%$ \\
\hline $0,00 \%$ & $89,17 \%$ & $97,01 \%$ & $100,00 \%$ & $8 \overline{9}, 17 \%$ \\
\hline $92,47 \%$ & $0,00 \%$ & $92,47 \%$ & $90,88 \%$ & $0,00 \%$ \\
\hline $65,36 \%$ & $84,25 \%$ & $78,35 \%$ & $56,70 \%$ & $78,35 \%$ \\
\hline $84,25 \%$ & $100,00 \%$ & $11,81 \%$ & $100,00 \%$ & $0,00 \%$ \\
\hline $100,00 \%$ & $100,00 \%$ & $13,40 \%$ & $78,35 \%$ & $100,00 \%$ \\
\hline $89,81 \%$ & $100,00 \%$ & $84,25 \%$ & $78,35 \%$ & $89,81 \%$ \\
\hline $97,01 \%$ & $89,81 \%$ & $94,59 \%$ & $100,00 \%$ & $100,00 \%$ \\
\hline $0,00 \%$ & $13,40 \%$ & $0,00 \%$ & $0,00 \%$ & $100,00 \%$ \\
\hline $65,36 \%$ & $75,26 \%$ & $75,26 \%$ & $65,36 \%$ & $87,63 \%$ \\
\hline $56,70 \%$ & $84,25 \%$ & $100,00 \%$ & $56,70 \%$ & $56,70 \%$ \\
\hline $0,00 \%$ & $75,26 \%$ & $13,40 \%$ & $0,00 \%$ & $100,00 \%$ \\
\hline $0,00 \%$ & $100,00 \%$ & $0,00 \%$ & $84,25 \%$ & $100,00 \%$ \\
\hline $10,79 \%$ & $0,00 \%$ & $91,34 \%$ & $100,00 \%$ & $100,00 \%$ \\
\hline $13,40 \%$ & $0,00 \%$ & $100,00 \%$ & $0,00 \%$ & $100,00 \%$ \\
\hline $13,40 \%$ & $56,70 \%$ & $13,40 \%$ & $56,70 \%$ & $65,36 \%$ \\
\hline $0,00 \%$ & $0,00 \%$ & $0,00 \%$ & $75,26 \%$ & $0,00 \%$ \\
\hline $10,79 \%$ & $0,00 \%$ & $0,00 \%$ & $0,00 \%$ & $13,40 \%$ \\
\hline $0,00 \%$ & $75,26 \%$ & $0,00 \%$ & $0,00 \%$ & $0,00 \%$ \\
\hline $0,00 \%$ & $90,88 \%$ & $0,00 \%$ & $100,00 \%$ & $90,88 \%$ \\
\hline $100,00 \%$ & $56,70 \%$ & $0,00 \%$ & $56,70 \%$ & $0,00 \%$ \\
\hline $100,00 \%$ & $100,00 \%$ & $56,70 \%$ & $65,36 \%$ & $56,70 \%$ \\
\hline $0,00 \%$ & $56,70 \%$ & $0,00 \%$ & $13,40 \%$ & $0,00 \%$ \\
\hline $0,00 \%$ & $84,25 \%$ & $0,00 \%$ & $0,00 \%$ & $100,00 \%$ \\
\hline $8,35 \%$ & $13,40 \%$ & $0,00 \%$ & $0,00 \%$ & $87,63 \%$ \\
\hline $13,40 \%$ & $0,00 \%$ & $100,00 \%$ & $0,00 \%$ & $0,00 \%$ \\
\hline $92,47 \%$ & $0,00 \%$ & $0,00 \%$ & $0,00 \%$ & $0,00 \%$ \\
\hline $13,36 \%$ & $58,70 \%$ & $0,00 \%$ & $0,00 \%$ & $92,13 \%$ \\
\hline $65,36 \%$ & $13,40 \%$ & $0,00 \%$ & $87,63 \%$ & $0,00 \%$ \\
\hline $0,00 \%$ & $5 \overline{8}, 7 \overline{0} \%$ & $13,04 \%$ & $65,36 \%$ & $56,70 \%$ \\
\hline $0,00 \%$ & $0,00 \%$ & $65,36 \%$ & $0,00 \%$ & $0,00 \%$ \\
\hline$\overline{13,40 \%}$ & $\overline{0,00 \%}$ & $100,00 \%$ & $0,00 \%$ & $12,33 \%$ \\
\hline $87,63 \%$ & $0,00 \%$ & $0,00 \%$ & $100,00 \%$ & $0,00 \%$ \\
\hline $100,00 \%$ & $13,40 \%$ & $0,00 \%$ & $65,36 \%$ & $0,00 \%$ \\
\hline $0,00 \%$ & $0,00 \%$ & $78,35 \%$ & $56,70 \%$ & $0,00 \%$ \\
\hline $13,40 \%$ & $78,35 \%$ & $87,63 \%$ & $56,70 \%$ & $82,68 \%$ \\
\hline $13,19 \%$ & $13,40 \%$ & $87,63 \%$ & $0,00 \%$ & $13,40 \%$ \\
\hline $0,00 \%$ & $0,00 \%$ & $56,70 \%$ & $13,40 \%$ & $13,19 \%$ \\
\hline
\end{tabular}

\begin{tabular}{|c|c|c|c|c|}
\hline \multicolumn{5}{|c|}{ Execucōes p/ DPWP original Estocástica Heterogône: } \\
\hline 1 & 2 & 3 & 4 & $\mathbf{5}$ \\
\hline $69,38 \%$ & $11,67 \%$ & $63,26 \%$ & $0,00 \%$ & $44,62 \%$ \\
\hline $0,00 \%$ & $44,62 \%$ & $0,00 \%$ & $69,38 \%$ & $44,62 \%$ \\
\hline $0,00 \%$ & $11,39 \%$ & $53,56 \%$ & $0,00 \%$ & $57,90 \%$ \\
\hline $5,60 \%$ & $11,67 \%$ & $8,77 \%$ & $53,68 \%$ & $44,62 \%$ \\
\hline $8,33 \%$ & $9,82 \%$ & $69,38 \%$ & $8,77 \%$ & $69,38 \%$ \\
\hline $6,11 \%$ & $11,67 \%$ & $69,38 \%$ & $5,35 \%$ & $65,61 \%$ \\
\hline $2,07 \%$ & $0,00 \%$ & $69,38 \%$ & $53,56 \%$ & $57,33 \%$ \\
\hline $8,33 \%$ & $0,00 \%$ & $61,25 \%$ & $29,06 \%$ & $69,38 \%$ \\
\hline $8,33 \%$ & $8,33 \%$ & $69,38 \%$ & $69,38 \%$ & $44,62 \%$ \\
\hline $60,34 \%$ & $44,62 \%$ & $0,00 \%$ & $69,38 \%$ & $53,68 \%$ \\
\hline $53,56 \%$ & $8,33 \%$ & $0,00 \%$ & $5,35 \%$ & $44,62 \%$ \\
\hline $69,38 \%$ & $68,73 \%$ & $0,00 \%$ & $0,00 \%$ & $65,29 \%$ \\
\hline $46,51 \%$ & $0,00 \%$ & $0,00 \%$ & $62,40 \%$ & $44,62 \%$ \\
\hline $11,16 \%$ & $0,00 \%$ & $46.51 \%$ & $46,51 \%$ & $44,62 \%$ \\
\hline $0,00 \%$ & $11,67 \%$ & $53,56 \%$ & $11,67 \%$ & $69,38 \%$ \\
\hline $0,00 \%$ & $0,00 \%$ & $69,38 \%$ & $61,25 \%$ & $11,67 \%$ \\
\hline $0,00 \%$ & $29,06 \%$ & $61,25 \%$ & $0,00 \%$ & $8,33 \%$ \\
\hline $0,00 \%$ & $11, \overline{48 \%}$ & $29,06 \%$ & $0,00 \%$ & $4,80 \%$ \\
\hline $0,00 \%$ & $11,67 \%$ & $69,38 \%$ & $0,00 \%$ & $61,92 \%$ \\
\hline $0,00 \%$ & $0,00 \%$ & $57,90 \%$ & $0,00 \%$ & $5,25 \%$ \\
\hline $53,56 \%$ & $11,67 \%$ & $0,00 \%$ & $46,51 \%$ & $3,35 \%$ \\
\hline $0,00 \%$ & $0,00 \%$ & $0,00 \%$ & $0,00 \%$ & $8,33 \%$ \\
\hline $0,00 \%$ & $11,67 \%$ & $0,00 \%$ & $0,00 \%$ & $57,33 \%$ \\
\hline $0,00 \%$ & $11,67 \%$ & $0,00 \%$ & $0,00 \%$ & $0,00 \%$ \\
\hline $0,00 \%$ & $11,23 \%$ & $0,00 \%$ & $0,00 \%$ & $1,76 \%$ \\
\hline $0,00 \%$ & $69,05 \%$ & $0,00 \%$ & $53,68 \%$ & $0,00 \%$ \\
\hline $69,38 \%$ & $29,06 \%$ & $0,00 \%$ & $0,00 \%$ & $9,23 \%$ \\
\hline $0,00 \%$ & $11,67 \%$ & $0,00 \%$ & $57,33 \%$ & $0,00 \%$ \\
\hline $0,00 \%$ & $0,00 \%$ & $0,00 \%$ & $11,67 \%$ & $1,76 \%$ \\
\hline $53,56 \%$ & $67,66 \%$ & $0,00 \%$ & $65,88 \%$ & $0,00 \%$ \\
\hline $67,33 \%$ & $69,00 \%$ & $0,00 \%$ & $0,00 \%$ & $0,00 \%$ \\
\hline $29,06 \%$ & $44,62 \%$ & $0,00 \%$ & $64,49 \%$ & $0,00 \%$ \\
\hline $63,94 \%$ & $29,06 \%$ & $0,00 \%$ & $0,00 \%$ & $1,73 \%$ \\
\hline $8,33 \%$ & $11,67 \%$ & $0,00 \%$ & $11,67 \%$ & $0,00 \%$ \\
\hline $0,00 \%$ & $44,62 \%$ & $53,63 \%$ & $69,38 \%$ & $53,68 \%$ \\
\hline $0,00 \%$ & $0,00 \%$ & $66,80 \%$ & $69,38 \%$ & $0,00 \%$ \\
\hline $0,00 \%$ & $69,38 \%$ & $63,86 \%$ & $61,25 \%$ & $0,00 \%$ \\
\hline $0,00 \%$ & $69,38 \%$ & $53,63 \%$ & $29,06 \%$ & $0,00 \%$ \\
\hline $0,00 \%$ & $0,00 \%$ & $0,00 \%$ & $69,38 \%$ & $0,00 \%$ \\
\hline $11,67 \%$ & $0,00 \%$ & $11,67 \%$ & $53,68 \%$ & $69,38 \%$ \\
\hline $0,00 \%$ & $0,00 \%$ & $57,90 \%$ & $53,68 \%$ & $11,67 \%$ \\
\hline $0,00 \%$ & $44,62 \%$ & $65,41 \%$ & $69,38 \%$ & $69,38 \%$ \\
\hline $46,51 \%$ & $68,36 \%$ & $0,00 \%$ & $0,00 \%$ & $44,62 \%$ \\
\hline $0,00 \%$ & $44,82 \%$ & $46,51 \%$ & $44,82 \%$ & $60,34 \%$ \\
\hline $0,00 \%$ & $29,06 \%$ & $69,38 \%$ & $29,06 \%$ & $29,06 \%$ \\
\hline $0,00 \%$ & $11,67 \%$ & $11,67 \%$ & $0,00 \%$ & $0,00 \%$ \\
\hline $0,00 \%$ & $57,90 \%$ & $0,00 \%$ & $57,90 \%$ & $69,38 \%$ \\
\hline $0,00 \%$ & $0,00 \%$ & $0,00 \%$ & $69,38 \%$ & $0,00 \%$ \\
\hline $0,00 \%$ & $53,68 \%$ & $0,00 \%$ & $0,00 \%$ & $53,68 \%$ \\
\hline $11,67 \%$ & $11,67 \%$ & $0,00 \%$ & $29,06 \%$ & $0,00 \%$ \\
\hline $0,00 \%$ & $0,00 \%$ & $0,00 \%$ & $0,00 \%$ & $0,00 \%$ \\
\hline $5,35 \%$ & $0,00 \%$ & $0,00 \%$ & $0,00 \%$ & $0,00 \%$ \\
\hline $63,26 \%$ & $0,00 \%$ & $0,00 \%$ & $0,00 \%$ & $0,00 \%$ \\
\hline $69,38 \%$ & $0,00 \%$ & $0,00 \%$ & $0,00 \%$ & $0,00 \%$ \\
\hline $69,38 \%$ & $0,00 \%$ & $8,33 \%$ & $0,00 \%$ & $0,00 \%$ \\
\hline $0,00 \%$ & $0,00 \%$ & $8,33 \%$ & $29,06 \%$ & $8,33 \%$ \\
\hline $69,38 \%$ & $0,00 \%$ & $8,33 \%$ & $44,62 \%$ & $0,00 \%$ \\
\hline $63,26 \%$ & $44,62 \%$ & $8,33 \%$ & $0,00 \%$ & $69,38 \%$ \\
\hline $44,62 \%$ & $11,67 \%$ & $8,33 \%$ & $4,20 \%$ & $0,00 \%$ \\
\hline $62,40 \%$ & $69,02 \%$ & $69,38 \%$ & $0,00 \%$ & $0,00 \%$ \\
\hline $63,86 \%$ & $68,84 \%$ & $0,00 \%$ & $0,00 \%$ & $0,00 \%$ \\
\hline $69,38 \%$ & $0,00 \%$ & $0,00 \%$ & $0,00 \%$ & $0,00 \%$ \\
\hline $0,00 \%$ & $67,90 \%$ & $0,00 \%$ & $0,00 \%$ & $8,33 \%$ \\
\hline $0,00 \%$ & $44,62 \%$ & $9,82 \%$ & $0,00 \%$ & $8,33 \%$ \\
\hline $44,62 \%$ & $44,62 \%$ & $44,62 \%$ & $44,62 \%$ & $44,62 \%$ \\
\hline $11,67 \%$ & $69,38 \%$ & $69,38 \%$ & $0,00 \%$ & $3,35 \%$ \\
\hline $8,33 \%$ & $11,67 \overline{\%}$ & $0,00 \%$ & $0,00 \%$ & $8,33 \%$ \\
\hline $2,07 \%$ & $44,62 \%$ & $0,00 \%$ & $69,38 \%$ & $0,00 \%$ \\
\hline $8,33 \%$ & $44,62 \%$ & $\overline{0}, 00 \%$ & $44,62 \%$ & $57,33 \%$ \\
\hline $46,51 \%$ & $69,38 \%$ & $8,33 \%$ & $29,06 \%$ & $0,00 \%$ \\
\hline $11,67 \%$ & $8,33 \%$ & $0,00 \%$ & $29,06 \%$ & $1,76 \%$ \\
\hline $0,00 \%$ & $0,00 \%$ & $0,00 \%$ & $0,00 \%$ & $10,32 \%$ \\
\hline
\end{tabular}




\begin{tabular}{|c|c|c|c|c|}
\hline \multicolumn{5}{|c|}{ Execucóbes p/Atteração 1 Estocástlea Hornogênes } \\
\hline \multicolumn{5}{|c|}{ Execucóes p/ Afteracáo 1 Estocástlea Homogênef } \\
\hline \multicolumn{5}{|c|}{ 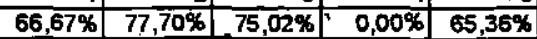 } \\
\hline \multicolumn{5}{|c|}{\begin{tabular}{|l|l|l|l|l|}
$0,00 \%$ & $43,23 \%$ & $0.00 \%$ & $66,67 \%$ & $65,36 \%$ \\
\end{tabular}} \\
\hline \multicolumn{5}{|l|}{$0,00 \%$} \\
\hline $60, \overline{26 \%}$ & $79,85 \%$ & $73,35 \%$ & $78,35 \%$ & $65,36 \%$ \\
\hline \multicolumn{5}{|l|}{$75,00 \%$} \\
\hline \multicolumn{5}{|l|}{$66,67 \%$} \\
\hline $66,67 \%$ & $0,00 \%$ & $100,00 \%$ & $54,17 \%$ & $51,96 \%$ \\
\hline $65,36 \%$ & $0,00 \%$ & $67,13 \%$ & $56,70 \%$ & $66,67 \%$ \\
\hline $83,63 \%$ & $100,00 \%$ & $81,82 \%$ & $66,67 \%$ & $69,80 \%$ \\
\hline $55,39 \%$ & $79,17 \%$ & $0,00 \%$ & $100,00 \%$ & $0,00 \%$ \\
\hline $54,17 \%$ & $55,39 \%$ & $50,00 \%$ & $66,67 \%$ & $0,00 \%$ \\
\hline $0,00 \%$ & $0,00 \%$ & $50,00 \%$ & $65,36 \%$ & $83,12 \%$ \\
\hline $0,00 \%$ & $75,26 \%$ & $0,00 \%$ & $66,67 \%$ & $65,36 \%$ \\
\hline $83,63 \%$ & $100,00 \%$ & $75,26 \%$ & $75,26 \%$ & $65,36 \%$ \\
\hline $0,00 \%$ & $90,88 \%$ & $65,36 \%$ & $13,40 \%$ & $100,00 \%$ \\
\hline $0,00 \%$ & $68,51 \%$ & $100,00 \%$ & $0,00 \%$ & $13,40 \%$ \\
\hline $65,36 \%$ & $100,00 \%$ & $60,26 \%$ & $66,67 \%$ & $87,63 \%$ \\
\hline $65,36 \%$ & $55,39 \%$ & $56,70 \%$ & $0,00 \%$ & $60,00 \%$ \\
\hline $43,23 \%$ & $77,78 \%$ & $100,00 \%$ & $73,04 \%$ & $63,26 \%$ \\
\hline $73,35 \%$ & $75,88 \%$ & $43,23 \%$ & $54,17 \%$ & $63,26 \%$ \\
\hline $73,35 \%$ & $75,00 \%$ & $65,36 \%$ & $75,26 \%$ & $58,34 \%$ \\
\hline $52,81 \%$ & $65,36 \%$ & $55,39 \%$ & $75,26 \%$ & $65,68 \%$ \\
\hline $0,00 \%$ & $50,00 \%$ & $73,35 \%$ & $0,00 \%$ & $73,35 \%$ \\
\hline $60,00 \%$ & $0,00 \%$ & $56,70 \%$ & $50,00 \%$ & $0,00 \%$ \\
\hline $75,00 \%$ & $78,35 \%$ & $0,00 \%$ & $0,00 \%$ & $0,00 \%$ \\
\hline $0,00 \%$ & $94,05 \%$ & $65,36 \%$ & $78,35 \%$ & $68,51 \%$ \\
\hline $71,43 \%$ & $100,00 \%$ & $30,72 \%$ & $0,00 \%$ & $80,00 \%$ \\
\hline $100,00 \%$ & $100,00 \%$ & $60,00 \%$ & $51,96 \%$ & $66,67 \%$ \\
\hline $66,67 \%$ & $13,40 \%$ & $52,81 \%$ & $13,40 \%$ & $67,27 \%$ \\
\hline $65,36 \%$ & $100,00 \%$ & $62,25 \%$ & $85,48 \%$ & $30,72 \%$ \\
\hline $87,82 \%$ & $65,36 \%$ & $58,34 \%$ & $95,45 \%$ & $0,00 \%$ \\
\hline $56,70 \%$ & $65,36 \%$ & $65,36 \%$ & $66,67 \%$ & $65,67 \%$ \\
\hline $93,81 \%$ & $13,40 \%$ & $75,00 \%$ & $0,00 \%$ & $65,36 \%$ \\
\hline $50,00 \%$ & $13,40 \%$ & $0,00 \%$ & $13,40 \%$ & $56,70 \%$ \\
\hline $65,36 \%$ & $92,47 \%$ & $78,35 \%$ & $85,48 \%$ & $65,36 \%$ \\
\hline $0,00 \%$ & $71,36 \%$ & $94,03 \%$ & $88,89 \%$ & $0,00 \%$ \\
\hline $75,88 \%$ & $0,00 \%$ & $92,47 \%$ & $75,88 \%$ & $80,08 \%$ \\
\hline $0,00 \%$ & $80,00 \%$ & $56,70 \%$ & $56,70 \%$ & $78,35 \%$ \\
\hline $50,00 \%$ & $66,67 \%$ & $0,00 \%$ & $66,67 \%$ & $0,00 \%$ \\
\hline $13,40 \%$ & $75,00 \%$ & $13,40 \%$ & $56,70 \%$ & $100,00 \%$ \\
\hline $66,67 \%$ & $80,75 \%$ & $58,34 \%$ & $78,35 \%$ & $13,40 \%$ \\
\hline $0,00 \%$ & $63,26 \%$ & $80,48 \%$ & $100,00 \%$ & $60,00 \%$ \\
\hline $75,26 \%$ & $0,00 \%$ & $0,00 \%$ & $0,00 \%$ & $100,00 \%$ \\
\hline $0,00 \%$ & $0,00 \%$ & $75,26 \%$ & $65,36 \%$ & $48,07 \%$ \\
\hline $75,88 \%$ & $68,51 \%$ & $100,00 \%$ & $56,70 \%$ & $56,70 \%$ \\
\hline $0,00 \%$ & $75,26 \%$ & $13,40 \%$ & $0,00 \%$ & $60,00 \%$ \\
\hline $0,00 \%$ & $50,00 \%$ & $0,00 \%$ & $58,34 \%$ & $100,00 \%$ \\
\hline $75,26 \%$ & $0,00 \%$ & $68,78 \%$ & $100,00 \%$ & $0,00 \%$ \\
\hline $56,70 \%$ & $0,00 \%$ & $66,67 \%$ & $60,97 \%$ & $0,00 \%$ \\
\hline $66,67 \%$ & $66,67 \%$ & $13,40 \%$ & $56,70 \%$ & $65,36 \%$ \\
\hline $0,00 \%$ & $0,00 \%$ & $78,35 \%$ & $75,26 \%$ & $50,00 \%$ \\
\hline $75,26 \%$ & $0,00 \%$ & $0,00 \%$ & $0,00 \%$ & $13,40 \%$ \\
\hline $69.80 \%$ & $75,26 \%$ & $100,00 \%$ & $75,26 \%$ & $30.72 \%$ \\
\hline $83,33 \%$ & $60,26 \%$ & $77,78 \%$ & $83,33 \%$ & $78,35 \%$ \\
\hline $100,00 \%$ & $56,70 \%$ & $100,00 \%$ & $56,70 \%$ & $13,40 \%$ \\
\hline $100,00 \%$ & $100,00 \%$ & $56,70 \%$ & $65,36 \%$ & $82,68 \%$ \\
\hline $8666 \%$ & $56,70 \%$ & $65,36 \%$ & $13,40 \%$ & $5417 \%$ \\
\hline $81,67 \%$ & $56,34 \%$ & $75,98 \%$ & $41,92 \%$ & $80,00 \%$ \\
\hline $65,36 \%$ & $13,40 \%$ & $46,07 \%$ & $83,33 \%$ & $46,07 \%$ \\
\hline $79,17 \%$ & $0.00 \%$ & $66,67 \%$ & $13,40 \%$ & $0,00 \%$ \\
\hline $73,35 \%$ & $0,00 \%$ & $100,00 \%$ & $66,67 \%$ & $67,13 \%$ \\
\hline $55,39 \%$ & $56,70 \%$ & $75,26 \%$ & $0,00 \%$ & $65,68 \%$ \\
\hline $30,72 \%$ & $13,40 \%$ & $77,09 \%$ & $55,39 \%$ & $65,36 \%$ \\
\hline $65,36 \%$ & $64,75 \%$ & $60,26 \%$ & $65,36 \%$ & $56,70 \%$ \\
\hline $65,36 \%$ & $78,35 \%$ & $65,36 \%$ & $75,26 \%$ & $65,36 \%$ \\
\hline $13,40 \%$ & $64,75 \%$ & $0,00 \%$ & $54,17 \%$ & $58,34 \%$ \\
\hline $50,00 \%$ & $13,40 \%$ & $56,70 \%$ & $50,00 \%$ & $56,70 \%$ \\
\hline $66,67 \%$ & $77,09 \%$ & $64,75 \%$ & $65,36 \%$ & $0,00 \%$ \\
\hline $50,00 \%$ & $85,68 \%$ & $56,70 \%$ & $56,70 \%$ & $79,17 \%$ \\
\hline $7 \overline{5,26 \%}$ & $100,00 \%$ & $75,00 \%$ & $56,70 \%$ & $0,00 \%$ \\
\hline $0,00 \%$ & $13,40 \%$ & $13,40 \%$ & $66,67 \%$ & $54,17 \%$ \\
\hline $56,70 \%$ & $65,36 \%$ & $56,70 \%$ & $13,40 \%$ & $81,67 \%$ \\
\hline
\end{tabular}

\begin{tabular}{|c|c|c|c|c|}
\hline \multicolumn{5}{|c|}{ Execuçóes p/Alteracáso 1 Estochstica Heterogene } \\
\hline 1 & 2 & 3 & 4 & 5 \\
\hline $63,48 \%$ & $84,63 \%$ & $84,78 \%$ & $0,00 \%$ & $44,62 \%$ \\
\hline $0,00 \%$ & $76,34 \%$ & $0,00 \%$ & $77,34 \%$ & $44,62 \%$ \\
\hline $0,00 \%$ & $66,96 \%$ & $86,29 \%$ & $90,37 \%$ & $77,52 \%$ \\
\hline $76,88 \%$ & $84,09 \%$ & $78,64 \%$ & $80,02 \%$ & $44,62 \%$ \\
\hline $73,42 \%$ & $79,96 \%$ & $92,02 \%$ & $78,64 \%$ & $91,06 \%$ \\
\hline $69,38 \%$ & $11,67 \%$ & $86,04 \%$ & $62,41 \%$ & $81,92 \%$ \\
\hline $69,38 \%$ & $0,00 \%$ & $69,38 \%$ & $86,29 \%$ & $67,59 \%$ \\
\hline $73, \overline{42} \%$ & $63,48 \%$ & $81,80 \%$ & $29,06 \%$ & $91,06 \%$ \\
\hline $76,08 \%$ & $69,38 \%$ & $85,81 \%$ & $91,06 \%$ & $95,54 \%$ \\
\hline $69,00 \%$ & $88,33 \%$ & $0,00 \%$ & $69,38 \%$ & $0,00 \%$ \\
\hline $86,29 \%$ & $89,00 \%$ & $90,77 \%$ & $62,41 \%$ & $0,00 \%$ \\
\hline $69,38 \%$ & $0,00 \%$ & $40,23 \%$ & $88,38 \%$ & $82,64 \%$ \\
\hline $86,04 \%$ & $62,41 \%$ & $0,00 \%$ & $88,33 \%$ & $44,62 \%$ \\
\hline $73,89 \%$ & $75,75 \%$ & $62,41 \%$ & $62,41 \%$ & $44,62 \%$ \\
\hline $0,00 \%$ & $83,71 \%$ & $73,42 \%$ & $11,67 \%$ & $63,48 \%$ \\
\hline $0,00 \%$ & $77,52 \%$ & $69,38 \%$ & $90,37 \%$ & $11,67 \%$ \\
\hline $50,47 \%$ & $69,38 \%$ & $90,37 \%$ & $81,70 \%$ & $78,06 \%$ \\
\hline $84,79 \%$ & $89,00 \%$ & $29,06 \%$ & $0,00 \%$ & $86,04 \%$ \\
\hline $76,34 \%$ & $89,00 \%$ & $69,38 \%$ & $86,86 \%$ & $96,55 \%$ \\
\hline $85,81 \%$ & $91,45 \%$ & $76,34 \%$ & $86,29 \%$ & $96,55 \%$ \\
\hline $86,29 \%$ & $90,77 \%$ & $73,42 \%$ & $62,41 \%$ & $77,52 \%$ \\
\hline $82,75 \%$ & $73,42 \%$ & $89,00 \%$ & $86,04 \%$ & $94,84 \%$ \\
\hline $0,00 \%$ & $90,77 \%$ & $78,64 \%$ & $0,00 \%$ & $78,64 \%$ \\
\hline $50,47 \%$ & $0,00 \%$ & $0,03 \%$ & $25,36 \%$ & $0,00 \%$ \\
\hline $80,81 \%$ & $80,02 \%$ & $0,00 \%$ & $0,00 \%$ & $0,00 \%$ \\
\hline $0,00 \%$ & $74,76 \%$ & $73,42 \%$ & $80,02 \%$ & $88,27 \%$ \\
\hline $76,88 \%$ & $69,38 \%$ & $63,56 \%$ & $0,00 \%$ & $86,04 \%$ \\
\hline $10,80 \%$ & $69,38 \%$ & $86,04 \%$ & $67,59 \%$ & $91,06 \%$ \\
\hline $91,06 \%$ & $11,67 \%$ & $82,75 \%$ & $11,67 \%$ & $84,79 \%$ \\
\hline $73,42 \%$ & $69,38 \%$ & $83,79 \%$ & $81,24 \%$ & $63,56 \%$ \\
\hline $71,67 \%$ & $73,42 \%$ & $77,52 \%$ & $73,53 \%$ & $0,00 \%$ \\
\hline $29,06 \%$ & $0,00 \%$ & $44,62 \%$ & $88,67 \%$ & $91,06 \%$ \\
\hline $73,90 \%$ & $8,33 \%$ & $80,81 \%$ & $0,00 \%$ & $44,62 \%$ \\
\hline $25,36 \%$ & $11,67 \%$ & $0,00 \%$ & $8,33 \%$ & $85,38 \%$ \\
\hline $44,62 \%$ & $75,20 \%$ & $80,02 \%$ & $69,38 \%$ & $50,47 \%$ \\
\hline $69,38 \%$ & $95,70 \%$ & $74,10 \%$ & $73,08 \%$ & $: 0,00 \%$ \\
\hline $69,38 \%$ & $0,00 \%$ & $75,20 \%$ & $67,07 \%$ & $85,30 \%$ \\
\hline $0,00 \%$ & $87,31 \%$ & $85,38 \%$ & $85,38 \%$ & $80,02 \%$ \\
\hline $75,75 \%$ & $63,48 \%$ & $0,00 \%$ & $91,06 \%$ & $0,00 \%$ \\
\hline $11,67 \%$ & $90,77 \%$ & $11,67 \%$ & $85,38 \%$ & $69,38 \%$ \\
\hline $76,08 \%$ & $82,93 \%$ & $77,52 \%$ & $80,02 \%$ & $11,67 \%$ \\
\hline $0,00 \%$ & $96,55 \%$ & $75,23 \%$ & $69,38 \%$ & $86,04 \%$ \\
\hline $62,41 \%$ & $0,00 \%$ & $8,33 \%$ & $0,00 \%$ & $69,38 \%$ \\
\hline $0,00 \%$ & $0,00 \%$ & $64,51 \%$ & $44,62 \%$ & $66,96 \%$ \\
\hline $67,07 \%$ & $88,27 \%$ & $69,38 \%$ & $29,06 \%$ & $29,06 \%$ \\
\hline $0,00 \%$ & $86,04 \%$ & $11,67 \%$ & $0,00 \%$ & $86,04 \%$ \\
\hline $0,00 \%$ & $25,36 \%$ & $0,00 \%$ & $77,52 \%$ & $69,38 \%$ \\
\hline $64,51 \%$ & $0,00 \%$ & $97,02 \%$ & $69,38 \%$ & $0,00 \%$ \\
\hline $69,38 \%$ & $0,00 \%$ & $63,48 \%$ & $76,87 \%$ & $0,00 \%$ \\
\hline $69,38 \%$ & $63,48 \%$ & $11,67 \%$ & $29,06 \%$ & $44,62 \%$ \\
\hline $0,00 \%$ & $0,00 \%$ & $80,02 \%$ & $86,04 \%$ & $25,36 \%$ \\
\hline $86,04 \%$ & $0,00 \%$ & $0,00 \%$ & $0,00 \%$ & $1,76 \%$ \\
\hline $69,38 \%$ & $46,51 \%$ & $69,38 \%$ & $84,51 \%$ & $5,72 \%$ \\
\hline $64,51 \%$ & $.90,37 \%$ & $89,00 \%$ & $84,51 \%$ & $80,02 \%$ \\
\hline $0,00 \%$ & $29,06 \%$ & $69,38 \%$ & $29,06 \%$ & $11,67 \%$ \\
\hline $0,00 \%$ & $69,38 \%$ & $29,06 \%$ & $44,62 \%$ & $86,29 \%$ \\
\hline $76,42 \%$ & $29,06 \%$ & $73,42 \%$ & $8,33 \%$ & $86,29 \%$ \\
\hline $85,98 \%$ & $77,52 \%$ & $90,60 \%$ & $70,66 \%$ & $87,31 \%$ \\
\hline $50,47 \%$ & $11,67 \%$ & $66,96 \%$ & $84,51 \%$ & $78,06 \%$ \\
\hline $79,40 \%$ & $0,00 \%$ & $91,06 \%$ & $11,67 \%$ & $0,00 \%$ \\
\hline $85,30 \%$ & $0.00 \%$ & $7,00 \%$ & $91,06 \%$ & $76,02 \%$ \\
\hline $50,47 \%$ & $48,97 \%$ & $62,41 \%$ & $1,76 \%$ & $94,84 \%$ \\
\hline $26,19 \%$ & $91,67 \%$ & $63,48 \%$ & $89,00 \%$ & $73,42 \%$ \\
\hline $73,42 \%$ & $96,90 \%$ & $90,37 \%$ & $44,62 \%$ & $29,06 \%$ \\
\hline $44,62 \%$ & $80,02 \%$ & $44,62 \%$ & $64.51 \%$ & $73,42 \%$ \\
\hline $11,67 \%$ & $96,90 \%$ & $7,00 \%$ & $73,42 \%$ & $77,52 \%$ \\
\hline $73,42 \%$ & $11,67 \%$ & $29,06 \%$ & $75,75 \%$ & $48,97 \%$ \\
\hline $91,06 \%$ & $86,48 \%$ & $96,90 \%$ & $44,62 \%$ & $0,00 \%$ \\
\hline $47,26 \%$ & $81,72 \%$ & $85,38 \%$ & $29,06 \%$ & $68,77 \%$ \\
\hline $86,04 \%$ & $7,00 \%$ & $90,77 \%$ & $0,03 \%$ & $0.00 \%$ \\
\hline $0,00 \%$ & $0,00 \%$ & $45,51 \%$ & $75,75 \%$ & $73,42 \%$ \\
\hline $81,70 \%$ & $26,19 \%$ & $8,33 \%$ & $1,76 \%$ & $84,78 \%$ \\
\hline
\end{tabular}




\begin{tabular}{|c|c|c|c|c|}
\hline \multicolumn{5}{|c|}{ xecuçōes p/ Alteração 2 Estocástica Homogêne } \\
\hline 1 & 2 & 3 & 4 & 5 \\
\hline $92,01 \%$ & $80,73 \%$ & $91,36 \%$ & $80,73 \%$ & $91,36 \%$ \\
\hline $92,01 \%$ & $80,73 \%$ & $91,36 \%$ & $80,73 \%$ & $91,36 \%$ \\
\hline $92,01 \%$ & $80,73 \%$ & $91,36 \%$ & $80,73 \%$ & $91,36 \%$ \\
\hline $92,01 \%$ & $80,73 \%$ & $91,36 \%$ & $80,73 \%$ & $91,36 \%$ \\
\hline $92,01 \%$ & $80,73 \%$ & $91,36 \%$ & $80,73 \%$ & $91,36 \%$ \\
\hline $92,01 \%$ & $80,73 \%$ & $91,36 \%$ & $80,73 \%$ & $91,36 \%$ \\
\hline $92,01 \%$ & $80,73 \%$ & $91,36 \%$ & $80,73 \%$ & $91,36 \%$ \\
\hline $92,01 \%$ & $80,73 \%$ & $91,36 \%$ & $80,73 \%$ & $91,36 \%$ \\
\hline $92,01 \%$ & $80,73 \%$ & $91,36 \%$ & $80,73 \%$ & $91,36 \%$ \\
\hline $92,01 \%$ & $80,73 \%$ & $91,36 \%$ & $80,73 \%$ & $91,36 \%$ \\
\hline $92,01 \%$ & $80,73 \%$ & $95,16 \%$ & $80,73 \%$ & $91,36 \%$ \\
\hline $92,01 \%$ & $95,07 \%$ & $95,16 \%$ & $95,07 \%$ & $91,36 \%$ \\
\hline $92,01 \%$ & $95,07 \%$ & $95,16 \%$ & $95,07 \%$ & $91,36 \%$ \\
\hline $92,01 \%$ & $95,07 \%$ & $95,16 \%$ & $95,07 \%$ & $91,36 \%$ \\
\hline $92,01 \%$ & $100,00 \%$ & $95,16 \%$ & $100,00 \%$ & $91,36 \%$ \\
\hline $92,01 \%$ & $100,00 \%$ & $95,16 \%$ & $100,00 \%$ & $91,36 \%$ \\
\hline $92,01 \%$ & $100,00 \%$ & $95,16 \%$ & $100,00 \%$ & $91,36 \%$ \\
\hline $92,01 \%$ & $100,00 \%$ & $95,16 \%$ & $100,00 \%$ & $1,36 \%$ \\
\hline $92,01 \%$ & $100,00 \%$ & $95,16 \%$ & $100,00 \%$ & $1,36 \%$ \\
\hline $92,01 \%$ & $100,00 \%$ & $95,16 \%$ & $100,00 \%$ & $91,36 \%$ \\
\hline $92,01 \%$ & $100,00 \%$ & $95,16 \%$ & $100,00 \%$ & $91,36 \%$ \\
\hline $92,01 \%$ & $100,00 \%$ & $95,16 \%$ & $100,00 \%$ & $1,36 \%$ \\
\hline $92,01 \%$ & $100,00 \%$ & $95,16 \%$ & $100,00 \%$ & $91,36 \%$ \\
\hline $92,01 \%$ & $100,00 \%$ & $95,16 \%$ & $100,00 \%$ & $91,36 \%$ \\
\hline $92,01 \%$ & $100,00 \%$ & $95,16 \%$ & $100,00 \%$ & $1,36 \%$ \\
\hline $92,01 \%$ & $100,00 \%$ & $95,16 \%$ & $00 \%$ & $36 \%$ \\
\hline $92,01 \%$ & $100,00 \%$ & $95,16 \%$ & $100,00 \%$ & $94,91 \%$ \\
\hline $92,01 \%$ & $100,00 \%$ & $95,16 \%$ & $100,00 \%$ & $94,91 \%$ \\
\hline $92,01 \%$ & $100,00 \%$ & $95,16 \%$ & $100,00 \%$ & $91 \%$ \\
\hline $92,01 \%$ & $100,00 \%$ & $95,16 \%$ & $100,00 \%$ & $91 \%$ \\
\hline $92,01 \%$ & $100,00 \%$ & $95,16 \%$ & $100,00 \%$ & $94,91 \%$ \\
\hline $92,01 \%$ & $100,00 \%$ & $95,16 \%$ & $100,00 \%$ & $94,91 \%$ \\
\hline $92,01 \%$ & $100,00 \%$ & $95,16 \%$ & $100,00 \%$ & $91 \%$ \\
\hline $92,01 \%$ & $100,00 \%$ & $95,16 \%$ & $100,00 \%$ & $94,91 \%$ \\
\hline $92,01 \%$ & $100,00 \%$ & $95,16 \%$ & $100,00 \%$ & $94,91 \%$ \\
\hline $92,01 \%$ & $100,00 \%$ & $95,16 \%$ & $100,00 \%$ & $94,91 \%$ \\
\hline $92,01 \%$ & $100,00 \%$ & $95,16 \%$ & $100,00 \%$ & $94,91 \%$ \\
\hline $92,01 \%$ & $100,00 \%$ & $95,16 \%$ & $100,00 \%$ & $94,91 \%$ \\
\hline $92,01 \%$ & $100,00 \%$ & $95,16 \%$ & $100,00 \%$ & $94,91 \%$ \\
\hline $95,16 \%$ & $100,00 \%$ & $95,16 \%$ & $100,00 \%$ & $94,91 \%$ \\
\hline $95,16 \%$ & $100,00 \%$ & $95,16 \%$ & $100,00 \%$ & $94,91 \%$ \\
\hline $95,16 \%$ & $100,00 \%$ & $95,16 \%$ & $100,00 \%$ & $94,91 \%$ \\
\hline $95,16 \%$ & $100,00 \%$ & $95,16 \%$ & $100,00 \%$ & $94,91 \%$ \\
\hline $95,16 \%$ & $100,00 \%$ & $95,16 \%$ & $100,00 \%$ & $94,91 \%$ \\
\hline $95,16 \%$ & $100,00 \%$ & $95,16 \%$ & $100,00 \%$ & \\
\hline $95,16 \%$ & $100,00 \%$ & $95,16 \%$ & $100,00 \%$ & $94,91 \%$ \\
\hline $95,16 \%$ & $100,00 \%$ & $95,16 \%$ & $100,00 \%$ & $94,91 \%$ \\
\hline $95,16 \%$ & $100,00 \%$ & $95,16 \%$ & $100,00 \%$ & $94,91 \%$ \\
\hline $95,16 \%$ & $100,00 \%$ & $95,16 \%$ & $100,00 \%$ & \\
\hline $95,16 \%$ & $100,00 \%$ & $95,16 \%$ & $100,00 \%$ & $94,91 \%$ \\
\hline $95,16 \%$ & $100,00 \%$ & $95,16 \%$ & $100,00 \%$ & $94,91 \%$ \\
\hline $95,16 \%$ & $100,00 \%$ & $95,16 \%$ & $100,00 \%$ & $96,49 \%$ \\
\hline $95,16 \%$ & $100,00 \%$ & $95,16 \%$ & $100,00 \%$ & $96,49 \%$ \\
\hline $95,16 \%$ & $100,00 \%$ & $95,16 \%$ & $100,00 \%$ & $96,49 \%$ \\
\hline $95,16 \%$ & $100,00 \%$ & $95,16 \%$ & $100,00 \%$ & $96,49 \%$ \\
\hline $95,16 \%$ & $100,00 \%$ & $95,16 \%$ & $100,00 \%$ & $96,49 \%$ \\
\hline $95,16 \%$ & $100,00 \%$ & $95,16 \%$ & $100,00 \%$ & $96,49 \%$ \\
\hline $95,16 \%$ & $100,00 \%$ & $95,16 \%$ & $100,00 \%$ & $96,49 \%$ \\
\hline $95,16 \%$ & $100,00 \%$ & $95,16 \%$ & $100,00 \%$ & $96,49 \%$ \\
\hline $95,16 \%$ & $100,00 \%$ & $95,16 \%$ & $100,00 \%$ & $96,49 \%$ \\
\hline $95,16 \%$ & $93,09 \%$ & $95,16 \%$ & $93,09 \%$ & $96,49 \%$ \\
\hline $95,16 \%$ & $93,09 \%$ & $95,16 \%$ & $93,09 \%$ & $96,49 \%$ \\
\hline $95,16 \%$ & $93,09 \%$ & $95,16 \%$ & $93,09 \%$ & $96,49 \%$ \\
\hline $95,16 \%$ & $93,09 \%$ & $95,16 \%$ & $93,09 \%$ & $96,49 \%$ \\
\hline $95,16 \%$ & $93,09 \%$ & $95,16 \%$ & $93,09 \%$ & $96,49 \%$ \\
\hline $95,16 \%$ & $93,09 \%$ & $95,16 \%$ & $93,09 \%$ & $96,49 \%$ \\
\hline $95,16 \%$ & $93,09 \%$ & $95,16 \%$ & $93,09 \%$ & $96,49 \%$ \\
\hline $95,16 \%$ & $80,73 \%$ & $95,16 \%$ & $80,73 \%$ & $96,49 \%$ \\
\hline $95,16 \%$ & $80,73 \%$ & $95,16 \%$ & $80,73 \%$ & $96,49 \%$ \\
\hline $95,16 \%$ & $80,73 \%$ & $95,16 \%$ & $80,73 \%$ & $96,49 \%$ \\
\hline $95,16 \%$ & $80,73 \%$ & $95,16 \%$ & $80,73 \%$ & $96,49 \%$ \\
\hline $95,16 \%$ & $80,73 \%$ & $95,16 \%$ & $80,73 \%$ & $96,49 \%$ \\
\hline
\end{tabular}

\begin{tabular}{|c|c|c|c|c|}
\hline \multicolumn{5}{|c|}{ Execuçōes p/ Alteração 2 Estocástica Heterogênea } \\
\hline 1 & 21 & 3 & 41 & \\
\hline $60,54 \%$ & $71,79 \%$ & $59,93 \%$ & $59,93 \%$ & $73,12 \%$ \\
\hline $60,54 \%$ & $71,79 \%$ & & & \\
\hline & $71,79 \%$ & & & \\
\hline $60,54 \%$ & $62,75 \%$ & $59,93 \%$ & $59,93 \%$ & \\
\hline $62,75 \%$ & $62,75 \%$ & $59,93 \%$ & $59,93 \%$ & $73,12 \%$ \\
\hline & $62,75 \%$ & $59,93 \%$ & $59,93 \%$ & $73,12 \%$ \\
\hline $62,75 \%$ & $62,75 \%$ & $59,93 \%$ & $59,93 \%$ & \\
\hline $62,75 \%$ & $62,75 \%$ & $62,75 \%$ & & \\
\hline & $62,75 \%$ & $2,75 \%$ & $59,93 \%$ & $62,75 \%$ \\
\hline & $62,75 \%$ & $2,75 \%$ & & \\
\hline $62,75 \%$ & $62,75 \%$ & $62,75 \%$ & $59,93 \%$ & $75 \%$ \\
\hline $62,75 \%$ & $62,75 \%$ & $62,75 \%$ & & \\
\hline & $62,75 \%$ & & & \\
\hline & $5 \%$ & $5 \%$ & & \\
\hline & & & $75 \%$ & \\
\hline $62,75 \%$ & & & & \\
\hline & & & & \\
\hline & & & & \\
\hline & & & & \\
\hline & & & & \\
\hline & & & & \\
\hline & & & & \\
\hline & & & & \\
\hline & & & & \\
\hline & & & & \\
\hline & & & & \\
\hline & & & & \\
\hline & & & & \\
\hline & & & & \\
\hline & & & & \\
\hline & & & & \\
\hline & & & & \\
\hline & & & & \\
\hline & & & & \\
\hline & & & & \\
\hline & & & & \\
\hline & & & & \\
\hline & & & & \\
\hline & & & & \\
\hline & & & & \\
\hline & & & & \\
\hline & & & $3 \%$ & \\
\hline & & & & \\
\hline & & & & \\
\hline & & & & \\
\hline & & & & \\
\hline & & & & \\
\hline & & & & \\
\hline & & & & \\
\hline & & & & \\
\hline & & & & \\
\hline & & & & \\
\hline & & & & \\
\hline & & & & \\
\hline & & & & \\
\hline & & & & \\
\hline & & & & \\
\hline & & & & \\
\hline & & & $38 \%$ & \\
\hline & & & & \\
\hline & & & & \\
\hline & & & & \\
\hline & & & & \\
\hline $69,38 \%$ & & $69,38 \%$ & $72,03 \%$ & \\
\hline & & & & \\
\hline & & & & \\
\hline $69,38 \%$ & $68,21 \%$ & $69,38 \%$ & $72,03 \%$ & $67,43 \%$ \\
\hline & $68,21 \%$ & $69,38 \%$ & & \\
\hline $69,38 \%$ & $68,21 \%$ & $69,38 \%$ & $69,38 \%$ & \\
\hline $69,38 \%$ & & $69,38 \%$ & $69,38 \%$ & $67,43 \%$ \\
\hline & $68,21 \%$ & $69,38 \%$ & $69,38 \%$ & \\
\hline $69,38 \%$ & $68,21 \%$ & $72,03 \%$ & $69,38 \%$ & $67,43 \%$ \\
\hline
\end{tabular}

